JIMMY MAURICIO VALENCIA RIVAS

AVALIAÇÃO QUASI-ESTÁTICA DA MECÂNICA RESPIRATÓRIA EM ROEDORES UTILIZANDO INSUFLADOR PULMONAR

São Paulo

2013 
JIMMY MAURICIO VALENCIA RIVAS

\title{
AVALIAÇÃO QUASI-ESTÁTICA DA MECÂNICA RESPIRATÓRIA EM ROEDORES UTILIZANDO INSUFLADOR PULMONAR
}

\author{
Dissertação apresentada à Escola \\ Politécnica da Universidade de São Paulo \\ para obtenção de título de Mestre em \\ Ciências
}

São Paulo 
JIMMY MAURICIO VALENCIA RIVAS

\title{
AVALIAÇÃO QUASI-ESTÁTICA DA MECÂNICA RESPIRATÓRIA EM ROEDORES UTILIZANDO INSUFLADOR PULMONAR
}

\author{
Dissertação apresentada à Escola \\ Politécnica da Universidade de São Paulo \\ para obtenção de título de Mestre em \\ Ciências
}

Área de concentração:

Sistemas Eletrônicos

Opção:

Engenharia Biomédica

Orientador:

Prof. Dr. Henrique Takachi Moriya

São Paulo 
Este exemplar foi revisado e alterado em relação à versão original, sob responsabilidade única do autor e com a anuência de seu orientador.

São Paulo, 29 de janeiro de 2013.

Assinatura do autor

Assinatura do orientador

FICHA CATALOGRÁFICA

Valencia Rivas, Jimmy Mauricio

Avaliação quasi-estática da mecânica respiratória em roedores utilizando insuflador pulmonar / J.M. Valencia Rivas. -ed.rev. -- São Paulo, 2013.

$129 \mathrm{p}$.

Dissertação (Mestrado) - Escola Politécnica da Universidade de São Paulo. Departamento de Engenharia de Telecomunicações e Controle.

1. Sistema respiratório 2. Modelos matemáticos 3. Bioengenharia 4. Biomecânica 5. Roedores I. Universidade de São Paulo. Escola Politécnica. Departamento de Engenharia de Telecomunicações e Controle II. t. 
DEDICATÓRIA

Aos meus pais, pelo amor, pelo carinho, pela compreensão e pelo exemplo de vida. 


\section{AGRADECIMENTOS}

A Deus, por todas as oportunidades.

Ao professor doutor Henrique Takachi Moriya, pela excelente orientação e pelo constante estímulo transmitido durante todo o trabalho.

A meus pais, Judith e Hernando, por sua fé, seu apoio, sua compreensão,sua ajuda e, em especial, por todo carinho ao longo deste percurso.

A meus irmãos, Mario e Alex, por me acompanharem à distância.

Ao professor doutor Adriano Mesquita Alencar, pela co-orientação e pelo apoio.

À doutora Marjorie Fregonesi Rodrigues da Silva, por sua ajuda e sua participação nas experimentações de laboratório.

A todos que colaboraram, direta ou indiretamente, na execução deste trabalho. 
"Straight ahead of him, nobody can go very far..."

(Antoine Saint-Exupéry) 


\section{RESUMO}

A avaliação da mecânica respiratória (AMR) busca descrever o comportamento mecânico do sistema respiratório, para melhor entender a sua fisiologia e a sua patofisiologia. O método quasi-estático é caracterizado pela AMR em condições nas quais a aceleração dos tecidos pode ser considerada desprezível. Esta dissertação de mestrado teve como objetivo avaliar a mecânica respiratória pelo método quasiestático em roedores, utilizando um insuflador pulmonar para pequenos roedores (IPPR)construído no Laboratório de Engenharia Biomédica (LEB) da Escola Politécnica da Universidade de São Paulo (EPUSP). Uma extensa revisão da literatura sobre fisiologia e técnicas de AMR em humanos e roedores é apresentada. Uma documentação bastante detalhada sobre a implementação e o funcionamento do IPPR é fornecida, com o intuito de permitir que o dispositivo seja reproduzido. Testes de bancada foram executados, para avaliar o funcionamento do IPPR, e um protocolo experimental com modelo animal de doença, em ratos Wistar envenenados por Paraquat, foi realizado. Os resultados dos testes de bancada mostraram que o equipamento ainda carece de alguns ajustes, pois apresenta erros na indicação de volume, da ordem de $5 \%$, mas que podem ser compensados na análise dos dados experimentais obtidos. No futuro, pretende-se sanar essa imprecisão, tornando o IPPR independente de um microcomputador com sistema operacional multitarefa. Os resultados da aplicação do modelo matemático exponencial, nos dados obtidos de curvas pressão-volume no protocolo experimental, trouxeram informações que estão de acordo com as características observadas no modelo animal de envenenamento por Paraquat.

Palavras-chave: Sistema respiratório. Modelos matemáticos. Bioengenharia. Biomecânica. Roedores. 


\begin{abstract}
The assessment of respiratory mechanics (AMR) aims to describe the mechanical behavior of the respiratory system in order to better understand its physiology and pathophysiology. The quasi-static method is characterized by the AMR under conditions where the tissue's acceleration can be considered negligible. The purpose of this master degree dissertation was to assess the respiratory mechanics by quasistatic method in rats using a lung insufflator for small rodents (IPPR) implemented in the Biomedical Engineering Laboratory (LEB) of Escola Politécnica of University of São Paulo (EPUSP). Abroad literature review on AMR techniques and on physiology in humans and rodents was presented. A fairly detailed documentation of the assembly and the operation of the IPPR was provided in order to allow the device to be reproduced. Bench tests were conducted to evaluate the behavior of the IPPR, and an animal disease model by Paraquat poisoning protocol was performed in Wistar rats. The bench tests results showed that the equipment still needs some tweaking, because it presents errors in volume indication of the order of $5 \%$, but these errors can be compensated in the analysis of the experimental data. In the future, there is an intention to correct this inaccuracy turning the IPPR independent of a multitask microcomputer operating system. The results of the mathematical exponential modeling applied on the pressure-volume curves in the experimental protocol are in good agreement with the characteristics observed on Paraquat poisoning animal model.
\end{abstract}

Keywords: Respiratory system. Mathematical models. Bioengineering. Biomechanics. Rodents. 


\section{LISTA DE FIGURAS}

Figura 2.1 - Sistema respiratório humano (modificada de BATES, 2009). 6

Figura 2.2 - Esquema idealizado das vias aéreas humanas (modificado de WEST, 2000a).

Figura 2.3 - Estrutura fisiológica da zona respiratória (modificado de TORTORA, 2000).

Figura 2.4 - Esquema do sistema pulmonar coberto pela pleura (modificado de TORTORA, 2000).

Figura 2.5 - Variação das pressões pleural, alveolar e transpulmonar na inspiração e na expiração (modificado de GUYTON, 1992).

Figura 2.6 - Estruturas envolvidas na inspiração e na expiração (modificado de TORTORA, 2000). 10

Figura 2.7 - Volumes pulmonares (modificado de TORTORA, 2000). 11

Figura 2.8 - Medição da curva P-V de um pulmão isolado (modificado de WEST, 2002b). 12

Figura 2.9 - Esquema do SR em ratos adultos (Fisher-344) (modificada de SCHULZ; MUHLE, 2000)

Figura 2.10 - Imagem de um rato Wistar durante experimento com o IPPR. Pulmões expostos ao se abrir a parede torácica. 16

Figura 2.11 - À esquerda do gráfico encontra-se uma curva P-V de expiração típica. Do lado direito apresenta-se um exame de espirometria típico, com subdivisões do volume pulmonar relacionadas à cada seção da curva P-V (modificado de D'ANGELO; MILIC-EMILI, 2005). 19

Figura 2.12 - Ajuste da curva descrita pela equação 2.9 à curva $P-V$ experimental do sujeito EC do grupo analisado por Salazar e Knowles (1964). Cl é a capacidade inspiratória, Max. $\mathrm{P}$ é a máxima pressão e $\ln$ é o logaritmo neperiano (modificada de SALAZAR; KNOWLES, 1964). .24

Figura 2.13 - Curva do gradiente de pressão intrapleural vertical versus profundidade da câmara fluidizada (Modificada de GLAISTER et al., 1973). 
Figura 2.14 - Curva P-V de pulmão canino isolado. A linha contínua corresponde aos dados experimentais e a linha tracejada à curva ajustada pela equação exponencial (modificada de GLAISTER et al., 1973).

Figura 2.15 - Curva P-V experimental ajustadas à função exponencial a partir da CPT até o limite inferior do volume de 40,50, 60 e 70\% de CPT (modificada de COLEBATCH; NG; NIKOV, 1979)

Figura 2.16 - Curvas teóricas obtidas variando $V_{o}$ e $K$ '. Relação P-V simulada pela equação sigmoidal equação 2.14 para diferentes valores dos parâmetros. Todas as curvas passam por PRFE (modificada de PAIVA et al. 1975) 29

Figura 2.17 - Curva quasi-estática P-V no intervalo de inspiração, dados medidos em paciente com síndrome da angústia respiratória aguda(SARA) e ajustados à equação2.16(modificado de VENEGAS; HARRIS; SIMON, 1998). 30

Figura 2.18 - Curva P-V respiratória representada pela equação2.17. PIM é o ponto de insuflação médio, PII é o ponto de inflexão inferior e PIS é o ponto de inflexão superior (modificada de DO AMARAL et al., 2011).

Figura 2.19 - Curva PV quasi-estática. As retas A, B e C ajudam a identificar os pontos de inflexão inferior e superior. PII é o ponto de inflexão inferior e PIS é o ponto de inflexão superior (modificada de HAAS, 2000)....33 Figura 2.20 - Exemplo de uma curva P-V em uma manobra de insuflação. Os pulmões são insuflados assegurando que o volume inicial dentro deles seja zero (atelectasiados). O quadro ilustra uma magnificação da região com muita elasticidade negativa local, a linha vermelha destaca um choque de avalanche (modificado de ALENCAR et al., 2002) 34

Figura 2.21 - Representação esquemática do sistema usado para a obtenção de curvas P-V em pulmões isolados (modificado de SILVA; ZIN; SALDIVA, 1998). 36

Figura 3.1 - Diagrama de blocos do IPPR. 39

Figura 3.2 - Fotografia do insuflador pulmonar para pequenos roedores sem o microcomputador: a) Módulo mecânico; b) Módulo de potência; c) 
Módulo de alimentação; d) Módulo de transdução de pressão; e) Módulo de controle e aquisição de sinais.

Figura 3.3 - Diagrama de blocos explicativo do protocolo experimental para testes de bancada.

Figura 3.4 - Equipamentos usados para avaliação de volume e velocidade do IPPR, com exceção do microcomputador (f).

Figura 3.5 - Esquema geométrico da seringa do IPPR. Linhas da cor preta desenham a geometria do êmbolo da seringa. Linhas da cor laranja desenham a geometria do tambor da seringa.

Figura 3.6 - Esquema ilustrativo da montagem realizada para avaliação de deslocamento e velocidade do IPPR.

Figura 3.7 - Esquema explicativo da montagem para avaliação de pressão do IPPR.

a) Multímetro digital, b) Módulo de transdução de pressão conectado ao transdutor de pressão (c), d) Seringa auxiliar, e) Manômetro de coluna de água auxiliar

Figura 3.9 - Fotografia de um animal CTR preparado e acoplado ao IPPR. 52

Figura 3.10 - Diagrama de blocos dos processos de preparação do IPPR .53

Figura 3.11 - Fotografia do IPPR em funcionamento. .54

Figura 3.12 - Janela para a configuração do módulo de potência .55

Figura 3.13 - Imagem do arquivo de configuração do IPPR .56

Figura 3.14 - Janela para o ajuste da posição do êmbolo da seringa 56

Figura 3.15 - Janela para a calibração do módulo de transdução de pressão .57

Figura 3.16 - Fotografia do módulo de transdução de pressão acoplado ao manômetro auxiliar, necessários para a calibração de pressão do IPPR. .58

Figura 3.17 - Janela virtual para a configuração de execução do experimento com o IPPR 59

Figura 3.18 - Diagrama explicativo da chave de fechamento de três vias e suas ligações. a) Seringa, b) Chave de fechamento de três vias, c) Transdutor de pressão, d) Cânula. 60

Figura 3.19 - Figura da AMR de roedor utilizando o IPPR .60

Figura 3.20 - Curva P-V de um animal do grupo CTR utilizando o IPPR. .62 
Figura 3.21 - Diagrama de blocos dos processos realizados para a análise de dados obtidos pelo IPPR.

Figura 4.1 - Diagrama de blocos do módulo mecânico .65

Figura 4.2 - Fotografia do módulo mecânico do insuflador pulmonar para pequenos roedores .66

Figura 4.3 - Diagrama esquemático das ligações das bobinas.

Figura 4.4 - Esquema da secção transversal de um motor de passo unipolar de 30 graus por passo (AN907, Microchip, EUA).

Figura 4.5 - Diagrama de blocos do módulo mecânico, com ênfase nas interações do motor de passo. .68

Figura 4.6 - Desenho do mecanismo de fixação do motor na base de acrílico. 68

Figura 4.7 - Motor de passo fixado na base de acrílico e na placa metálica de fixação.

Figura 4.8 - Dimensões da placa de fixação do motor na base de acrílico. (a) Comprimento e largura. (b) Posicionamento dos orifícios correspondentes aos parafusos M5 de fixação. 69

Figura 4.9 - Diagrama de blocos do módulo mecânico, com ênfase nas interações do acoplamento.

Figura 4.10 - Dimensões do acoplamento. (a) Vista frontal da peça. (b) Vista lateral da peça. .71

Figura 4.11 - Desenho do acoplamento ainda não colocado na posição final no insuflador mecânico .71

Figura 4.12 - Acoplamento no insuflador para pulmões de pequenos roedores.......72

Figura 4.13 - Diagrama de blocos do módulo mecânico, com ênfase nas interações do fuso cilíndrico de esferas. 72

Figura 4.14 - Desenho da castanha de fuso cilíndrico de esferas (HIWIN Technologies Corp.) 73

Figura 4.15 - Desenho de configuração da união entre a castanha do fuso cilíndrico e o carrinho de fixação do êmbolo.

Figura 4.16 - Fuso de esferas do insuflador conectado, à esquerda, ao acoplamento e apoiado, à direita, no suporte de acrílico. Observa-se também o carrinho de fixação do êmbolo da seringa. 
Figura 4.17 - Diagrama de blocos do módulo mecânico, com ênfase nas interações do carrinho de fixação do êmbolo.

Figura 4.18 - Desenho 3D do carrinho com os acoplamentos. O Acoplamento 1 é composto pela porca da castanha do fuso de esferas e por dois parafusos M5 e a placa de acrílico. O Acoplamento 2 é composto por quatro parafusos M5.O Acoplamento 3 é composto por uma peça acrílica para fixação do extremo do êmbolo. .76

Figura 4.19 - Desenho do acoplamento entre o êmbolo da seringa e o carrinho de fixação (Acoplamento 3). .76

Figura 4.20 - Dimensões do Acoplamento 3. (a) Vista superior. (b) Vista lateral. ....77 Figura 4.21 - Dimensões do carrinho de fixação do êmbolo. (a) Vista lateral direita. (b) Vista posterior. (c) Vista inferior 77

Figura 4.22 - Carrinho de fixação do êmbolo. (a) Vista em perspectiva da lateral direita e frontal. (b) Vista frontal. (c) Vista posterior/inferior .78

Figura 4.23 - Carrinho de fixação do êmbolo. (a) Vista lateral-posterior. (b) Vista lateral-frontal .78

Figura 4.24 - Diagrama de blocos do módulo mecânico, com ênfase nas interações da guia linear e do trilho 79

Figura 4.25 - Corte da guia linear para verificar conexão com o trilho. Figura editada de HIWIN Technologies Corp., Taiwan .79

Figura 4.26 - Dimensões da guia linear e do trilho. (a) Dimensões do trilho. (b) Dimensões da guia linear - vista superior. (c) Dimensões da guia linear - vista posterior .80

Figura 4.27 - Desenho 3D da guia linear e do trilho. .80

Figura 4.28 - Diagrama de blocos do módulo mecânico, com ênfase nas interações do suporte de acrílico

Figura 4.29 - Desenho espacial do suporte de acrílico. (a) Base do insuflador mecânico. (b) Suporte do motor. (c) Suporte de fixação da seringa a peça à esquerda também serve de mancal para o fuso cilíndrico de esferas.

Figura 4.30 - Dimensões da base do insuflador mecânico. (a) Orifícios com rosca e espessura do acrílico. (b) Posições dos orifícios de fixação. .82 
Figura 4.31 - Dimensões dos suportes do motor. (a) Dimensões gerais laterais do suporte. (b) Vista posterior do suporte

Figura 4.32 - Dimensões das duas peças de suporte para a seringa, sendo que uma das peças apresenta um orifício de $14 \mathrm{~mm}$ de diâmetro e a outra não. (a) Vista frontal. (b) Vista lateral. .83

Figura 4.33 - Desenho espacial do acoplamento metálico para ajuste de seringa...83 Figura 4.34 - Dimensões da placa metálica de acoplamento com a seringa. (a) Vista frontal da peça. (b) Vista lateral

Figura 4.35 - Fotografia da peça metálica de fixação de seringa no suporte de acrílico.

Figura 4.36 - Suportes em acrílico. (a) Suporte do motor. (b) Duas peças para suporte da seringa a peça mais à esquerda também serve de mancal para o fuso de esferas. (c) Base de acrílico do insuflador. 84

Figura 4.37 - Diagrama de blocos do módulo mecânico, com ênfase nas interações da seringa .85

Figura 4.38 - Fotografia da seringa de $50 \mathrm{~mL}$ utilizada. .85

Figura 4.39 - Diagrama de blocos do insuflador de pulmões, com ênfase nas interações do módulo de potência. .86

Figura 4.40 - Circuito do módulo de potência. .87

Figura 4.41 - Diagrama lógico do controle do motor de passos .87

Figura 4.42 - Simulação dos estados das fases do motor em modo passo completo, com frequência de passos de $80 \mathrm{~Hz}$. (A) Estados de ativação das bobinas do motor de passo quando a direção está em estado desativado. (B) Estados de ativação das bobinas do motor de passos quando a direção está em estado ativado. .89

Figura 4.43 - Desenho esquemático da ligação do módulo de potência 89

Figura 4.44 - Diagrama de blocos, com ênfase nas interações do módulo de alimentação .90

Figura 4.45 - Circuito do módulo de alimentação ……….....................................90

Figura 4.46 - Fotografia do módulo de alimentação ............................................

Figura 4.47 - Diagrama de blocos, com ênfase nas interações do módulo de transdução de pressão ..............................................................92

Figura 4.48 - Transdutor de pressão utilizado (Fujikura, Japão). 92 
Figura 4.49 - Esquema interno do transdutor de pressão (fornecido pelo fabricante). Os números circulados indicam os pinos no circuito integrado (Fujikura, Japão) .93

Figura 4.50 - Esquema do transdutor e ligações com o conector DB-9 fêmea ........93

Figura 4.51 - Fotografia final do transdutor conectado ao cabo. ...........................94

Figura 4.52 - Fonte de corrente que alimenta o transdutor de pressão.....................95

Figura 4.53 - Ganho da amplificação em função do valor do potenciômetro .............96

Figura 4.54 - Circuito responsável pela amplificação e pelo acréscimo de valor DC (off-set) ao sinal analógico

Figura 4.55 - Esquema do filtro passa-baixas com frequência de corte de $50 \mathrm{~Hz}$...97 Figura 4.56 - Diagrama de blocos do insuflador, com ênfase nas interações do módulo de controle e aquisição de sinais. 98

Figura 4.57 - Módulo de controle e aquisição de sinais 99

Figura 4.58 - Desenho esquemático das ligações do conversor AD/DA com o módulo de transdução de pressão e com o módulo de potência junto com o motor de passo 101

Figura 4.59 - Diagrama de blocos do insuflador,com ênfase nas interações do microcomputador 102

Figura 4.60 - Fluxograma do programa de controle do insuflador pulmonar para pequenos roedores 103

Figura 4.61 - Comportamento do erro sistemático do volume medido a diferentes volumes e velocidades programados no IPPR. 108

Figura 4.62 - Comportamento do erro sistemático do intervalo de tempo medido a diferentes volumes e velocidades programados no IPPR. 108

Figura 4.63 - Comportamento do erro sistemático da velocidade medida a diferentes volumes e velocidades programados no IPPR. 109

Figura 4.64 - llustração da linearidade $\operatorname{Lin}(\%)$ dos transdutores $S n 1$ e $S n 2$ ao variar $G$. Valores apresentados (média \pm desvio-padrão)\%. 111

Figura 4.65 - As retas tracejadas representam o comportamento linear dos transdutores $\mathrm{Sn} 1$ e $\mathrm{Sn} 2$

Figura 4.66 - Curvas P-V dos animais do grupo CTR. 113

Figura 4.67 - Curvas $P-V$ dos animais do grupo $P R Q$. 114 
Figura 4.68 - Ajuste exponencial, CTR (quadrado) e PRQ (estrela). $V_{C T R}, V_{P R Q}$ são as equações resultantes do ajuste matemático exponencial dos

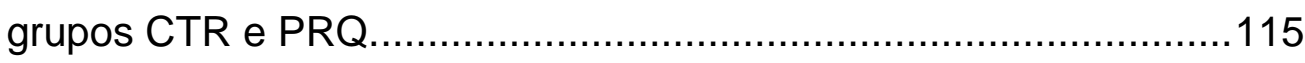




\section{LISTA DE TABELAS}

Tabela 2.1- Resumo das características fisiológicas pulmonares em ratos Wistar. Animais anestesiados e com a caixa torácica fechada (modificado de SCHULZ; MUHLE, 2000). 16

Tabela 4.1 - Características principais do motor de passos (57BYGH207, Circuit Specialists, EUA) 66

Tabela 4.2- Especificações do fuso cilíndrico de esferas (todos os valores estão em milímetros) 73

Tabela 4.3- Simulação de 8 passos com troca de direção no quinto passo. .88

Tabela 4.4 - Características do sistema de aquisição de dados multifunção (USB 6008, National Instruments, EUA)

Tabela 4.5 - Conexões do sistema de aquisição de dados multifunção com módulo de potência 100

Tabela 4.6 - Resultados da avaliação com velocidade determinada para $0,01 \mathrm{~mL} / \mathrm{s}$ 105

Tabela 4.7 - Resultados da avaliação com velocidade determinada para $0,055 \mathrm{~mL} / \mathrm{s}$ 105

Tabela 4.8 - Resultados da avaliação com velocidade determinada para $0,1 \mathrm{~mL} / \mathrm{s}$ 106

Tabela 4.9 - Resultados da avaliação com velocidade determinada para $0,55 \mathrm{~mL} / \mathrm{s}$ 106

Tabela 4.10 - Resultados da avaliação com velocidade determinada para $1 \mathrm{~mL} / \mathrm{s} .107$

Tabela 4.11 - Dados referentes às manobras de insuflação para avaliação de volume e velocidade do IPPR 109

Tabela 4.12 - Dados referentes às incursões de pressão para avaliação de pressão 110

Tabela 4.13 - Dados referentes aos índices envolvidos na avaliação de pressão do IPPR 110

Tabela 4.14 - Dados dos índices de sensibilidade, regressão linear e Res. MTP dos transdutores utilizados 
Tabela 4.15 - Dados referentes às incursões de avaliação de pressão do módulo de transdução de pressão 112

Tabela 4.16 - Massa em gramas dos animais CTR e PRQ .................................113

Tabela 4.17 - Dados do coeficiente de correlação $R^{2}$ para cada intervalo. ..............114

Tabela 4.18-Parâmetros do ajuste exponencial para o intervalo de dados escolhido 


\section{LISTA DE ABREVIATURAS}

$\begin{array}{ll}\text { AMR } & \text { Avaliação da Mecânica Respiratória } \\ \text { bmp } & \text { bitmap } \\ \text { BNC } & \text { Conector para cabos coaxiais (do inglês Bayonet Neil Concelman) } \\ \text { CAPPesq } & \text { Comissão para Análises de Projetos de Pesquisa } \\ \text { CPT } & \text { Capacidade Pulmonar Total } \\ \text { CRF } & \text { Capacidade Residual Funcional } \\ \text { CTR } & \text { Grupo Controle } \\ \text { CV } & \text { Capacidade Vital } \\ \text { DB-9 } & \text { Conector tipo D de 9 pinos } \\ \text { DPOC } & \text { Doença Pulmonar Obstrutiva Crônica } \\ \text { EPUSP } & \text { Escola Politécnica da Universidade de São Paulo } \\ \text { EUA } & \text { Estados Unidos da América } \\ \text { FMUSP } & \text { Faculdade de Medicina da Universidade de São Paulo } \\ \text { htmI } & \text { HyperText Markup Language } \\ \text { IPPR } & \text { Insuflador Pulmonar paraPequenos Roedores } \\ \text { LEB } & \text { Laboratório de Engenharia Biomédica } \\ \text { LMA } & \text { Algoritmo interativo de optimização Levenberg-Marquardt } \\ \text { LPIV } & \text { Lesão Pulmonar Induzida por Ventilador } \\ \text { LVGEAS } & \text { Large-Volume Gas-Exchanging Airspaces } \\ \text { PAMC } & \text { Ponto de Aumento Máximo da Complacência } \\ \text { Pamc } & \text { Pressão no ponto de aumento máximo de complacência } \\ \text { PEEP } & \text { Pressão Positiva no Final da Expiração } \\ \text { PF } & \text { Ponto Fixo } \\ \text { PII } & \text { Ponto de inflexão inferior } \\ \text { PIS } & \text { Ponto de inflexão superior } \\ \text { Pqmc } & \text { Pressão no ponto de queda máximo de complacência } \\ \text { PQMC } & \text { Ponto de Queda Máxima de Complacência } \\ \text { PRFE } & \text { Posição de Repouso ao Final da Expiração } \\ \text { PRQ } & \text { Grupo Paraquat } \\ \text { PV } & \text { Ponto variável } \\ \end{array}$




$\begin{array}{ll}\text { S/V } & \text { Surface-to-Volume } \\ \text { SDRA } & \text { Síndrome de Desconforto Respiratório Agudo } \\ \text { SPF } & \text { Specific Pathogen Free } \\ \text { SR } & \text { Sistema Respiratório } \\ \text { USB } & \text { Universal Serial Bus } \\ \text { USP } & \text { Universidade de São Paulo } \\ \text { VC } & \text { Volume Corrente } \\ \text { VR } & \text { Volume Residual } \\ \text { VRE } & \text { Volume Residual Expiratório } \\ \text { VRI } & \text { Volume Residual Inspiratório }\end{array}$




\section{LISTA DE SÍMBOLOS}

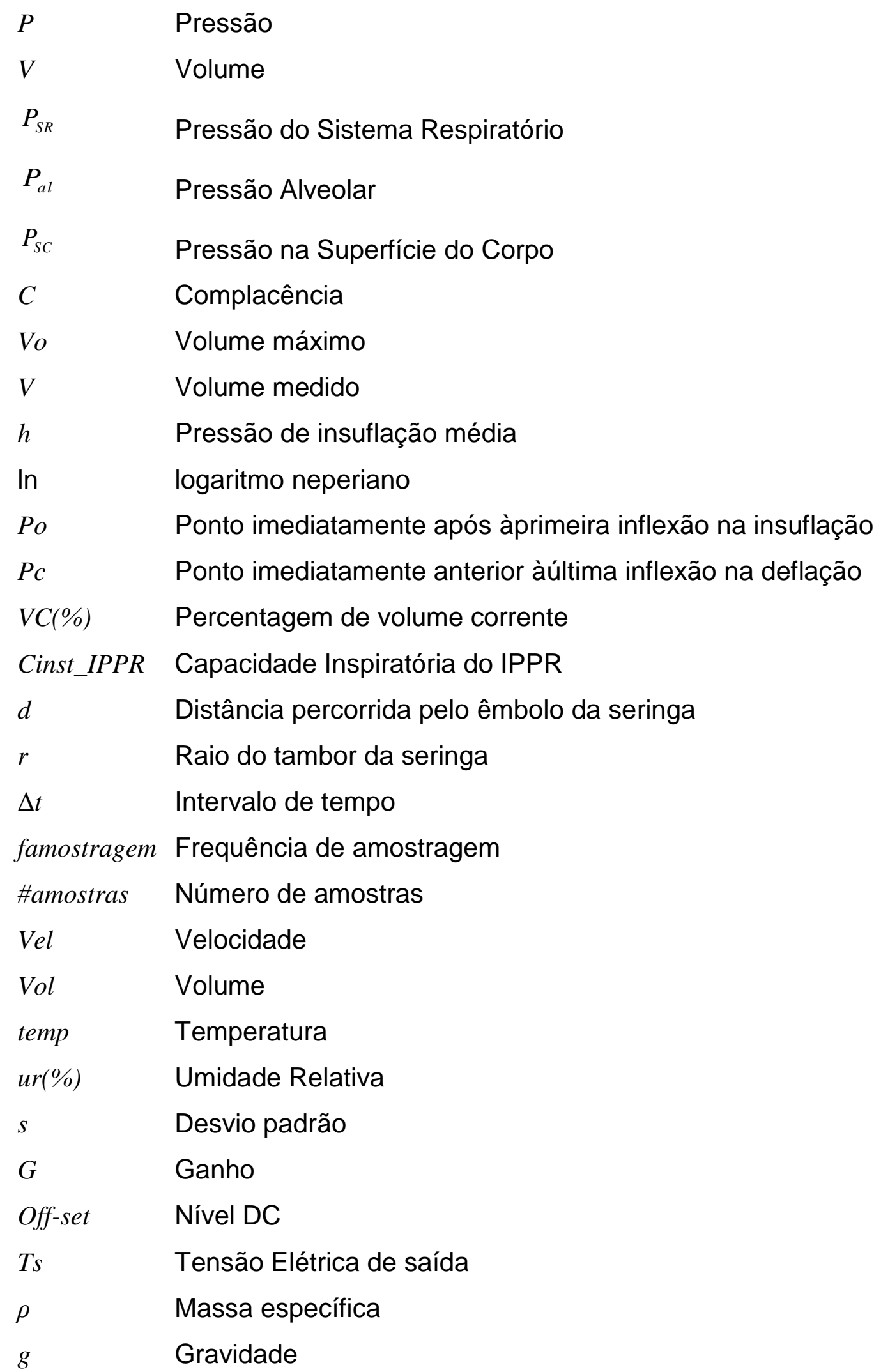




\begin{tabular}{|c|c|}
\hline Snl & Transdutor de pressão 1 \\
\hline $\operatorname{Sn} 2$ & Transdutor de pressão 2 \\
\hline Gmín & Ganho mínimo \\
\hline Gmáx & Ganho máximo \\
\hline$R^{2}$ & Coeficiente de correlação de Pearson \\
\hline Lin\% & Porcentagem de linearidade \\
\hline Difmáx & Diferença máxima \\
\hline FEs & Fundo de escala de saída \\
\hline$S$ & Sensibilidade \\
\hline$\Delta T s$ & $\begin{array}{l}\text { Razão de variação de tensão elétrica de saída do módulo de } \\
\text { transdução de pressão }\end{array}$ \\
\hline$\Delta P$ & $\begin{array}{l}\text { Razão de variação de pressão na entrada do módulo de transdução de } \\
\text { pressão }\end{array}$ \\
\hline$V_{\text {faixa.entrada }}$ & Valor da amplitude da faixa nominal de entrada \\
\hline N.bits & Número de bits \\
\hline$R_{A D}$ & Resolução do conversor analógico digital \\
\hline Res_Pr & Resolução de medição de pressão do IPPR \\
\hline$F E_{E}$ & Fundo de escala de entrada \\
\hline CPT_apróx & Capacidade pulmonar aproximada \\
\hline$T e$ & Tensão elétrica de entrada \\
\hline$N$ & Número de medidas \\
\hline
\end{tabular}




\section{SUMÁRIO}

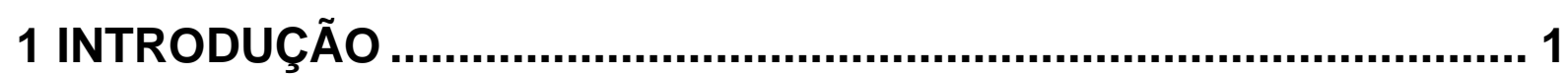

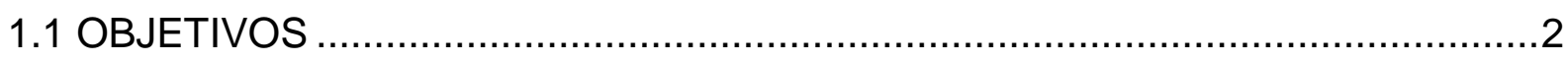

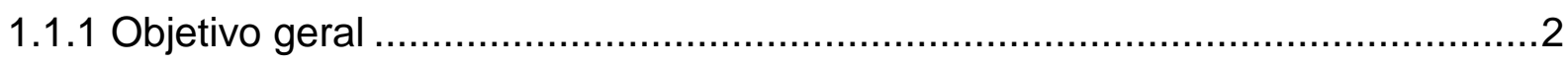

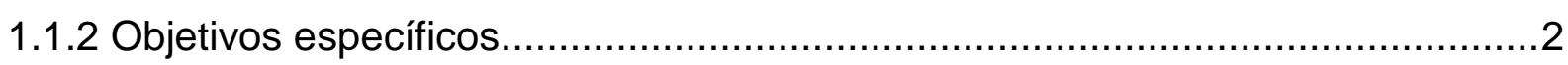

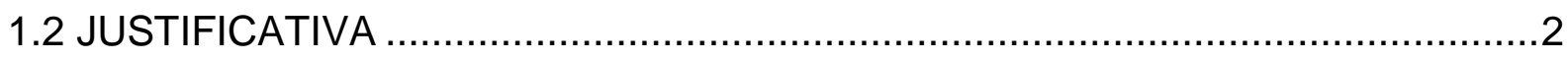

1.3 ORGANIZAÇÃO DA DISSERTAÇÃO .........................................................

2 REVISÃO DA LITERATURA...................................................... 5

2.1 ANATOMIA E FISIOLOGIA RESPIRATÓRIA EM HUMANOS ...........................5

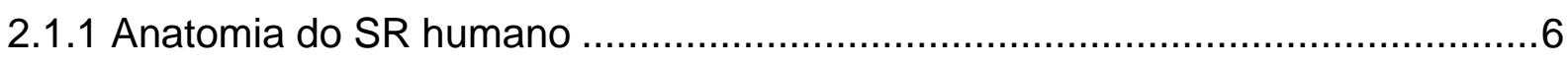

2.1.2 Mecânica da ventilação pulmonar .....................................................8

2.1.3 Volumes e capacidades pulmonares.................................................... 11

2.1.4 Forças elásticas ........................................................................... 12

2.2 ANATOMIA E FISIOLOGIA RESPIRATÓRIA EM RATOS WISTAR ..................14

2.3 AMR PELO MÉTODO QUASI-ESTÁTICO .............................................. 17

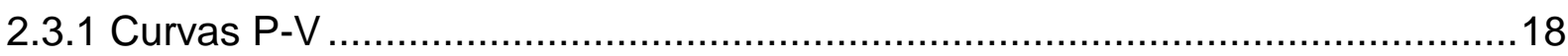

2.3.2 Modelagem matemática das curvas $\mathrm{P}-\mathrm{V}$ quasi-estáticas .............................20

2.3.3 Ajuste matemático exponencial ........................................................ 21

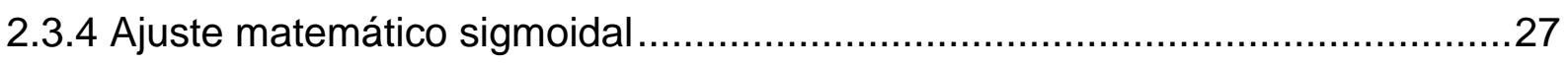

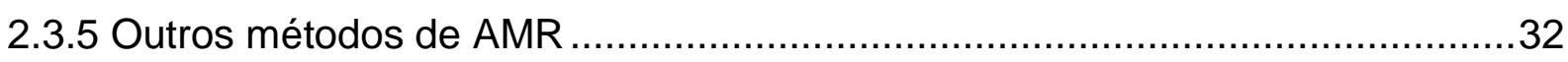

2.4 TÉCNICAS EMPREGADAS PARA A AVALIAÇÃO QUASI-ESTÁTICA DE

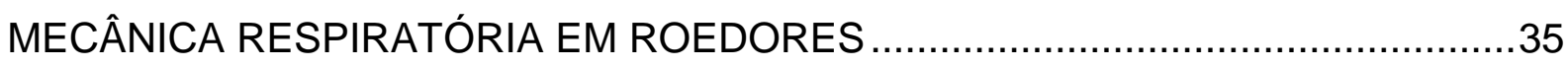

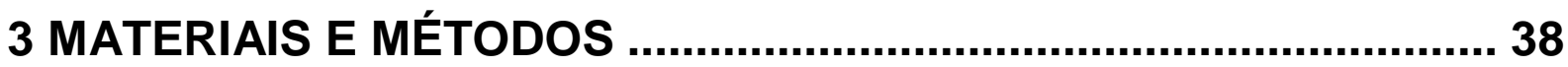

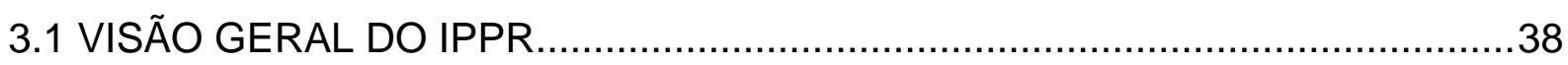

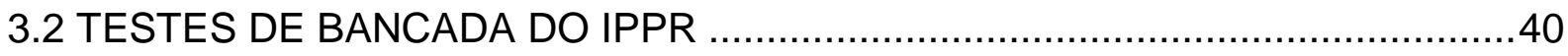

3.2.1 Avaliação de volume e velocidade do IPPR .............................................41

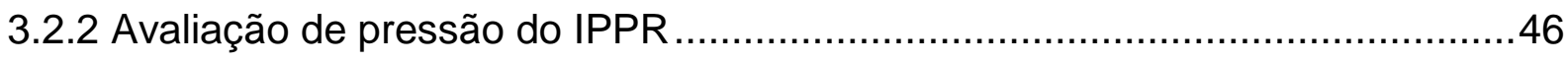

3.3 AMR DE MODELO ANIMAL DE DOENÇA PELO MÉTODO QUASI-ESTÁTICO

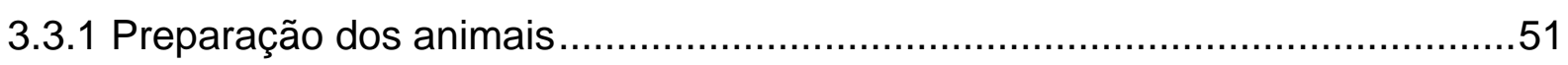

3.3.2 Protocolo experimental utilizando o IPPR ..........................................52 


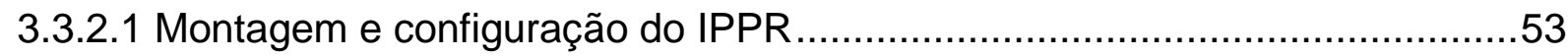

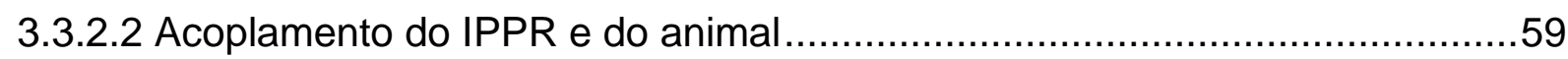

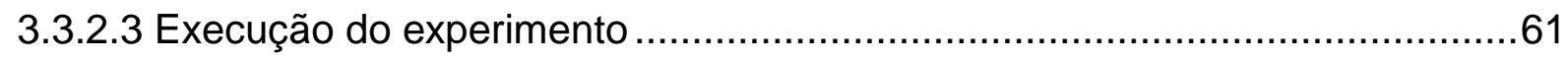

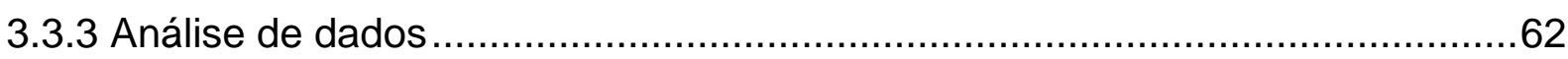

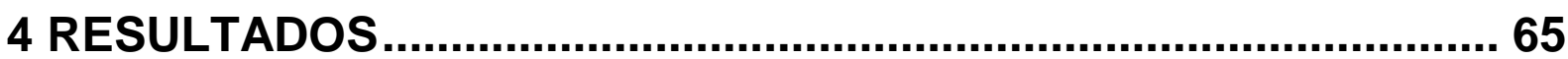

4.1 INSUFLADOR PULMONAR PARA PEQUENOS ROEDORES (IPPR) ...............65

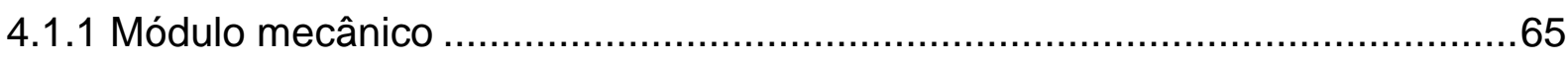

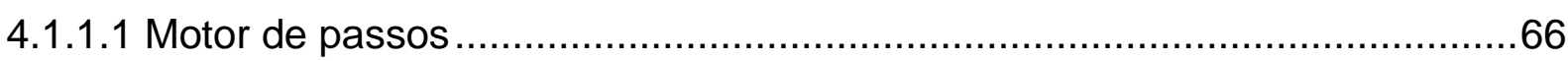

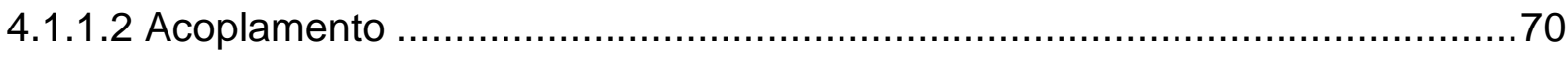

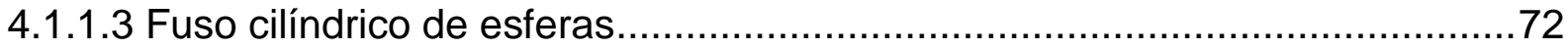

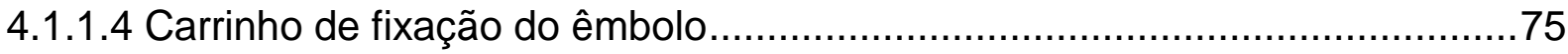

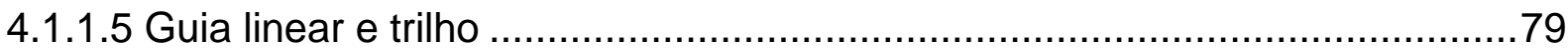

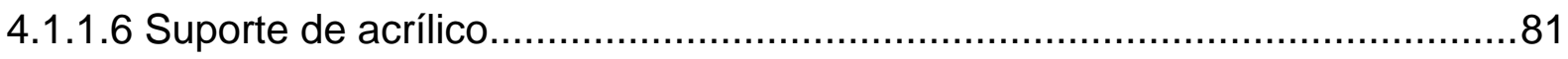

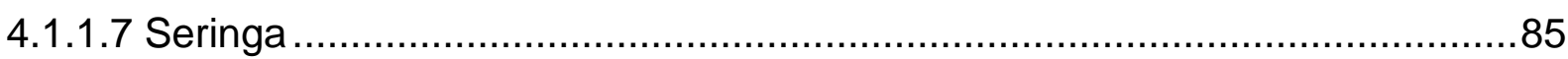

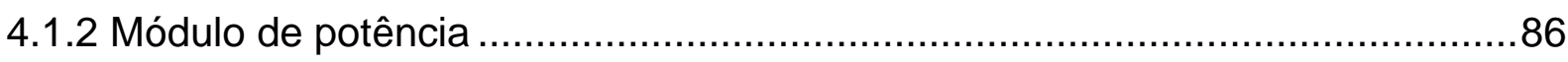

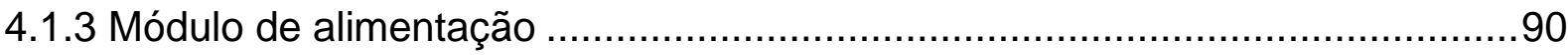

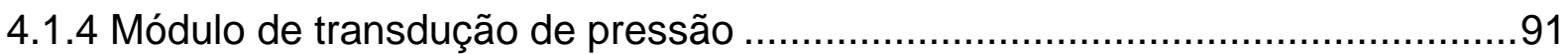

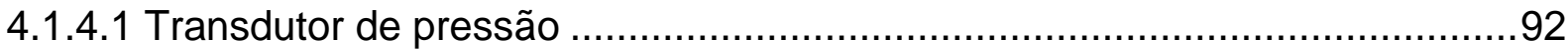

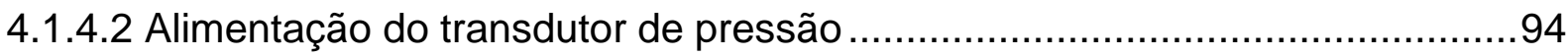

4.1.4.3 Amplificação e ajuste de nível DC do sinal analógico ................................95

4.1.4.4 Filtragem pré-digitalização ...............................................................97

4.1.5 Módulo de controle e aquisição de sinais ....................................................

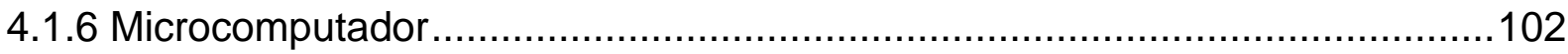

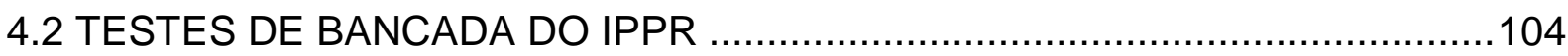

4.2.1 Avaliação de volume e velocidade do IPPR ............................................104

4.2.2 Avaliação de pressão do IPPR .............................................................110

4.3 AMR DE MODELO ANIMAL DE DOENÇA PELO MÉTODO QUASI-ESTÁTICO

5 DISCUSSÃO

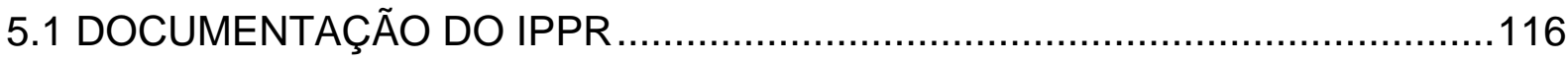

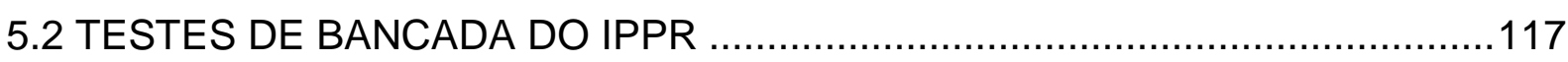

5.2.1 AVALIAÇÃO DE VOLUME E VELOCIDADE DO IPPR ...............................117

5.2.2 AVALIAÇÃO DE PRESSÃO DO IPPR …....................................................119 
5.3 AMR DE MODELO ANIMAL DE DOENÇA PELO MÉTODO QUASI-ESTÁTICO 120

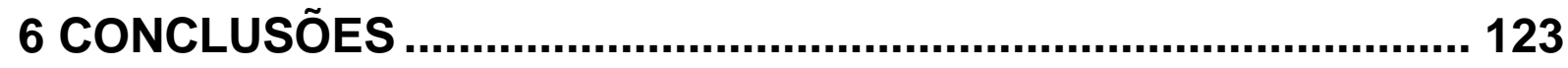

REFERÊNCIAS................................................................................ 125 


\section{INTRODUÇÃO}

A avaliação da mecânica respiratória (AMR) é uma área da medicina que busca descrever o comportamento mecânico das estruturas envolvidas na respiração. Atualmente, esta ciência, de suma importância para a saúde humana, é estudada por profissionais de diversas áreas, como médicos, engenheiros, físicos, além de outros profissionais da área a saúde, que contribuem com sua evolução (BATES, 2009).

O comportamento mecânico do sistema respiratório (SR) é avaliado, de forma geral, através da análise das grandezas físicas, pressão $(P)$ e volume (V), envolvidas na respiração. As variáveis $P$ e $V$ são tipicamente representadas, de forma gráfica, em curvas que demonstram o comportamento viscoelástico doSR.

A AMR é uma área na qual engenheiros biomédicos aplicam conhecimentos multidisciplinares, dentre eles: anatomia, fisiologia, instrumentação biomédica, modelagem matemática e processamento de sinais. Tudo isto, para favorecer a compreensão da fisiologia respiratória e do mecanismo de doenças ligadas à mecânica respiratória, sugerindo aprimoramentos de métodos esoluções práticas.

A pesquisa, apresentada nesta dissertação de mestrado, ilustra os esforços de pesquisa em Engenharia Biomédica realizados no Laboratório de Engenharia Biomédica (LEB) da Escola Politécnica da Universidade de São Paulo (EPUSP), aprimorados com o projeto, a implementação e a documentação de um equipamento para AMR em pequenos animais, em conjunto com as técnicas de medição e modelagem matemática aplicadas em curvas pressão-volume (P-V) do SR de ratos.

O equipamento, nomeado como Insuflador Pulmonar de Pequenos Roedores (IPPR), desenvolvido no LEB, foi projetado com o propósito de insuflar pulmões de roedores,à velocidade lenta e controlada, para medir pequenas variações de pressão.

A análise de resultados obtidos da AMR pelo método quasi-estático em roedores, com ajuda de modelos matemáticos, é uma forma de compreender os efeitos de agentes externos, como, por exemplo, o pesticida Paraquat, no comportamento do sistema respiratório de roedores, e iniciar a avaliação de possíveis soluções em doenças respiratórias humanas. 


\subsection{OBJETIVOS}

\subsubsection{Objetivo geral}

Avaliar a mecânica respiratória em roedores, através da análise de curvas P$V$ adquiridas pelo método quasi-estático,utilizando o equipamento IPPR.

\subsubsection{Objetivos específicos}

- Documentar o IPPR

- Avaliar o funcionamento do IPPR para obtenção de dados experimentais; úteis para AMR em pequenos roedores

- Aplicar modelos matemáticos de curvas P-V em roedores com lesão pulmonar induzida por envenenamento com Paraquat

\subsection{JUSTIFICATIVA}

A AMR busca descrever a relação das variáveis físicas, $\mathrm{P}$ e V, medidas de forma criteriosa e em pontos específicos do sistema respiratório, de maneira que seja possível caracterizar o funcionamento mecânico da respiração.

As insuficiências ou falências respiratórias em humanos são causadas por diversos fatores e, em particular, destacam-se aqueles nos quais as propriedades mecânicas respiratórias se encontram comprometidas (BATES, 2009).

As propriedades mecânicas do SR caracterizam a relação existente entre as pressões exercidas pelos músculos, pelo fluxo nas vias aéreas e pelos volumes pulmonares existentes na respiração. Pressões que não superem a tendência do tecido pulmonar e da caixa torácica, ao colapso, podem dificultar a entrada de ar nos pulmões e, em consequência, diminuir a livre troca gasosa necessária para oxigenar 
o sangue e liberar o gás carbônico residual do metabolismo (BATES, 2009; WEST, 2002b).

As variações da mecânica do SR são tipicamente perceptíveis em pacientes afetados; portanto, elas também são mensuráveis usando equipamentos adequados. De fato, profissionais da saúde regularmente avaliam a mecânica respiratória, para diagnosticar doenças, fazendo uso de instrumentos adequados (BATES, 2009). Estes dispositivos têm permitido aos investigadores adquirir dados precisos e fortemente relacionados com as funções pulmonares, permitindo a evolução de métodos cada vez mais sofisticados de aquisição e análises de dados (BATES, 2009).

Um dos métodos que evoluíram para AMR é o quasi-estático baseado nas análises de curvas $\mathrm{P}-\mathrm{V}$ adquiridas à velocidade lenta de insuflação/desinsuflação (HAAS, 2000).

Este tipo de metodologia surgiu como uma possível solução para determinar os parâmetros corretos na terapia respiratória por ventilação mecânica, tratamento usado para substituir a ventilação normal em pacientes incapazes de manter o ciclo respiratório e ao qual se atribui, também, a origem de lesões pulmonares e possíveis danos em outros órgãos do sistema (HAAS, 2000).

Para obter curvas P-V condizentes com os processos da respiração, é necessário, além do desenvolvimento de equipamentos precisos, o aperfeiçoamento de técnicas de medição que permitam a confiabilidade dos resultados, agregando valor aos estudos de mecânica respiratória e, consequentemente, à área de Engenharia Biomédica.

Dessa forma, a construção de um equipamento de investigação e o aperfeiçoamento de técnicas de AMR são de suma importância. Tanto como gerador de novas oportunidades de pesquisa, em temas como complacência e elastância pulmonar, recrutamento alveolar e modelo animal de doença (BLANCHARD, 2005), como também permitindo a implementação de um equipamento réplica (ou com melhorias), possibilitando o conhecimento e o treinamento científico para formação de mão de obra especializada.

Optou-se, neste projeto, pela aplicação do IPPR e de técnicas de AMR pelo método quasi-estático em um modelo animal de envenenamento por Paraquat, um produto químico para controle de ervas daninhas utilizado no Brasil e que afeta diretamente o sistema respiratório. Este modelo já foi bastante estudado (SILVA; 
ZIN; SALDIVA, 1998; SILVA; SALDIVA, 1998) pela equipe de pesquisadores do Laboratório de Investigação Médica $n^{0} 5$ (LIM 05 - Laboratório de Poluição Atmosférica Experimental), da Faculdade de Medicina da Universidade de São Paulo (FMUSP), com o qual o LEB mantém uma cooperação em pesquisa. Assim sendo, tratou-se do modelo animal de doença mais acessível para comparar os resultados obtidos com a AMR pelo método quasi-estático com outros resultados de importância fisiológica.

\subsection{ORGANIZAÇÃO DA DISSERTAÇÃO}

Esta dissertação apresenta, primeiramente, no Capítulo 2, uma revisão da literatura sobre fisiologia e técnicas de AMR em humanos e em roedores.

No Capítulo 3, é apresentada uma visão geral do IPPR. Também neste capítulo, são apresentados os materiais e os métodos que testam o funcionamento do equipamento, baseados em técnicas de metrologia e estatística, efetuadas no LEB-EPUSP. Descrevem-se, ainda, os protocolos experimentais realizados para AMR na Faculdade de Medicina da Universidade de São Paulo (FMUSP), fazendo uso de experimentos com modelo animal e modelagem matemática de curvas P-V.

No Capítulo 4, é apresentada uma documentação técnica do IPPR, fazendo uso de ferramentas gráficas e simulações eletrônicas. Além disso, são apresentados os resultados dos testes de funcionamento do IPPR e da AMR, ao se comparar o comportamento da mecânica respiratória entre ratos normais e aqueles com lesão pulmonar induzida pelo herbicida Paraquat.

As discussões referentes a todos os resultados obtidos nessa pesquisa são apresentadas no Capítulo 5.

Finalmente, no Capítulo 6, são apresentadas as conclusões do trabalho. 


\section{REVISÃO DA LITERATURA}

O presente capítulo tem por objetivo apresentar alguns dos conceitos teóricos fundamentais para realizar a AMR pelo método quasi-estático em pequenos roedores, utilizando o IPPR descrito neste documento.

Deste modo, foi realizada uma revisão focada nos seguintes tópicos:

a) Anatomia e fisiologia respiratória em humanos

b) Anatomia e fisiologia respiratória em roedores

c) AMR pelo método quasi-estático

d) Técnicas empregadas para a avaliação quasi-estática da mecânica respiratória em roedores

Estes temas, de importância na ventilação mecânica do SR, serão descritos do ponto de vista quantitativo, com base nas grandezas físicas necessárias para a compreensão do funcionamento do IPPR.

\subsection{ANATOMIA E FISIOLOGIA RESPIRATÓRIA EM HUMANOS}

Dentro do processo homeostático do corpo humano, no qual são mantidas as células devidamente oxigenadas e limpas do acúmulo de resíduos produzidos nos processos metabólicos, o sistema cardiovascular, em conjunto com o aparelho respiratório, cumpre uma função vital: realizam o intercâmbio de gases da atmosfera à corrente sanguínea (respiração externa) e transportam gases entre os pulmões e as células dos tecidos (respiração interna) (TORTORA, 2000).

Ao definir a respiração externa, podemos afirmar que todas as estruturas fisiológicas envolvidas têm como objetivo primordial permitir o intercâmbio gasoso por difusão simples, propagando o oxigênio da atmosfera aos capilares e o dióxido de carbono dos capilares para a atmosfera. Considera-se que existam aproximadamente 300 milhões de alvéolos destinados aos processos de difusão através da membrana do tecido alveolar (WEST, 2002a). 


\subsubsection{Anatomia do SR humano}

O SR humano é constituído por diversos órgãos, como se observa na Figura 2.1, e cada um pode ser classificado de acordo com a sua estrutura ou a sua função (TORTORA, 2000).

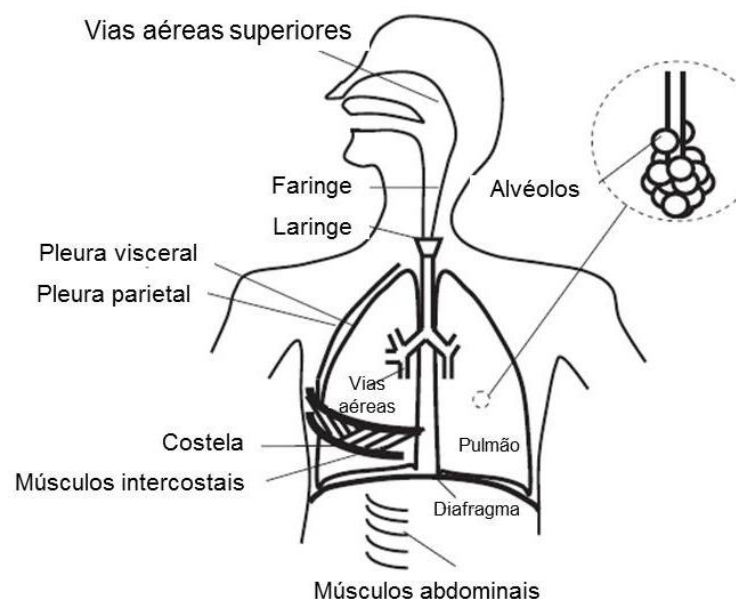

Figura 2.1 - Sistema respiratório humano (modificada de BATES, 2009).

De acordo com a estrutura, o SR se divide em duas partes:

a) Vias aéreas superiores, que abrangem: o nariz, a faringe e as estruturas que os acompanham

b) Vias aéreas inferiores, que incluem: laringe, traqueia, brônquios e pulmões

Do ponto de vista funcional, este sistema também se divide em duas partes:

a) A zona de condução, que compreende um conjunto de cavidades e dutos conectados entre si, fora e dentro dos pulmões (nariz, faringe, laringe, traqueia, brônquios, bronquíolos e bronquíolos terminais), os quais filtram, aquecem, umectam e conduzem o ar até os pulmões

b) A zona respiratória, formada pelos tecidos pulmonares nos quais ocorre o intercâmbio gasoso, ou seja, bronquíolos respiratórios, dutos e sacos 
alveolares, assim como alvéolos. Estes últimos representam o principal local de intercâmbio gasoso entre o meio externo e o plasma sanguíneo

Segundo Guyton (1992), existem diferentes classificações funcionais do SR: ventilação pulmonar, difusão, transporte e controle da ventilação pulmonar. Adicionalmente, West (2002a) classifica os pulmões como elemento metabolizador, filtro e reservatório de plasma sanguíneo e, ainda, explica que as vias aéreas humanas dividem-se em duas regiões idealizadas, chamadas de zona de condução e zona de transição e respiratória, como se mostra na Figura 2.2.

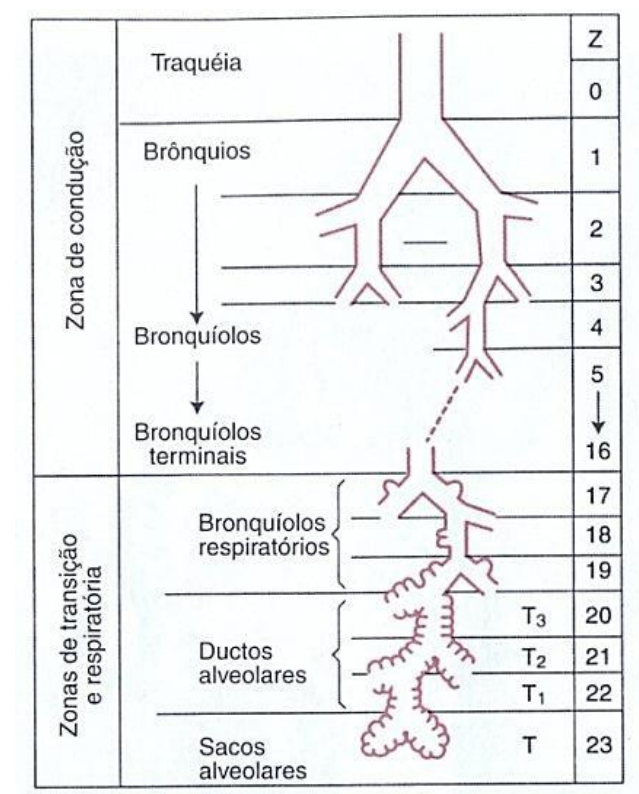

Figura 2.2 - Esquema idealizado das vias aéreas humanas (modificado de WEST, 2000a).

As estruturas e órgãos do SR, em sua maioria, estão constituídos por material viscoelástico, que permitem a entrada e a saída dos gases da respiração. Este material encontra-se majoritariamente concentrado na zona respiratória, devido à existência do tecido conjuntivo elástico formando uma estrutura complexa, unindo, nos alvéolos, a rede de capilares e células importantes no funcionamento normal da troca gasosa (PALLADINO; DAVIS, 2005), como se observa na Figura 2.3. 


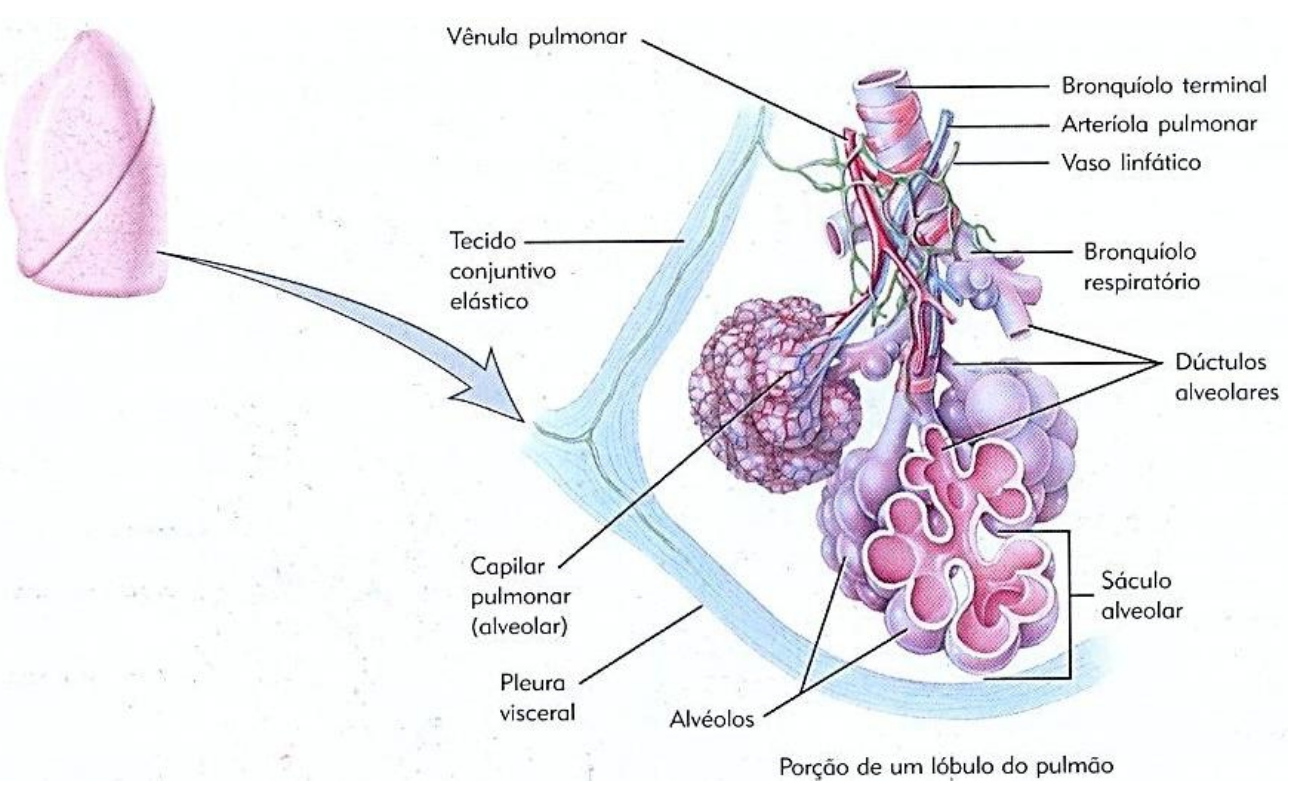

Figura 2.3 - Estrutura fisiológica da zona respiratória (modificado de TORTORA, 2000).

Além disso, para gerar a entrada e a saída de gases de forma natural, o aparelho respiratório conta com músculos como o diafragma, os intercostais externos, os retos abdominais, os intercostais internos, entre outros. Existe também a cavidade pleural separada por duas membranas, chamadas de membrana pleural visceral e membrana pleural parietal. Estas membranas estão encarregadas de manter as pressões dentro do aparelho respiratório e de permitir movimentos pulmonares elásticos e lubrificados (GUYTON, 1992). Estas estruturas envolvidas na mecânica respiratória são descritas com maior profundidade nas seções seguintes.

\subsubsection{Mecânica da ventilação pulmonar}

O fluxo de gases a partir do pulmão e em direção a ele é gerado, do ponto de vista mecânico, por diferenças de pressões. Para isso, o SR mantém os pulmões em níveis de pressão adequados para o transporte de gases dentro de uma cavidade hermética chamada de cavidade pleural. Esta espécie de envelope pulmonar permite que os pulmões literalmente flutuem na caixa torácica graças ao líquido pleural em seu interior, que lubrifica e reduz o atrito dos movimentos pulmonares (GUYTON, 1992), como se observa na Figura 2.4. 


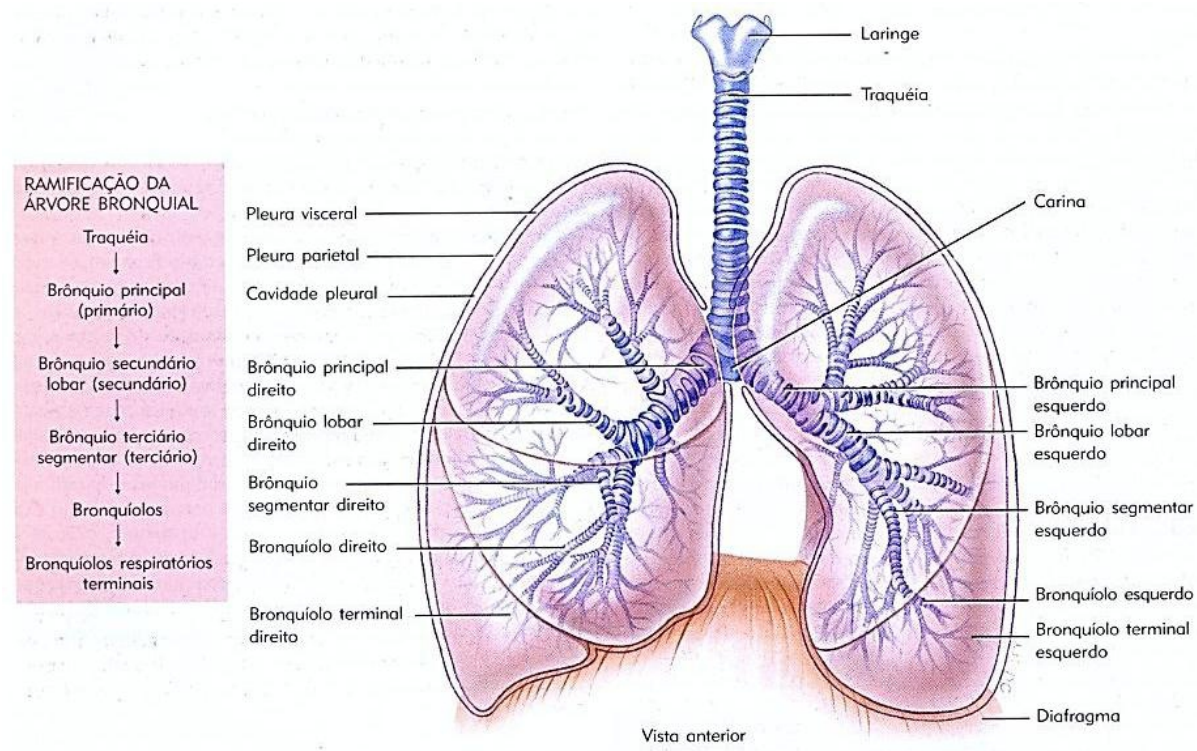

Figura 2.4 - Esquema do sistema pulmonar coberto pela pleura (modificado de TORTORA, 2000).

Ademais, esta cavidade mantém um nível constante de sucção ou pressão negativa (GUYTON, 1992). Na posição de repouso, esta pressão é de aproximadamente $-5 \mathrm{cmH}_{2} \mathrm{O}$; na inspiração, é ainda mais negativa, de até $-8 \mathrm{cmH}_{2} \mathrm{O}$ e, na expiração, retorna aos seus valores normais (WEST, 2002b), como se observa na Figura 2.5 .

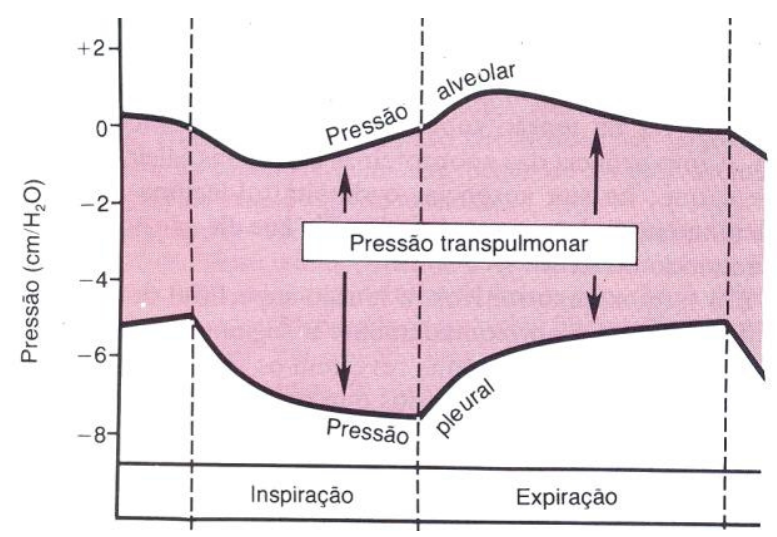

Figura 2.5 - Variação das pressões pleural, alveolar e transpulmonar na inspiração e na expiração (modificado de GUYTON, 1992).

O aparelho respiratório possui dois ciclos de ventilação pulmonar, baseados fisicamente em dois movimentos fisiológicos fundamentais: inspiração e expiração.

- $\quad$ Durante a inspiração, a zona respiratória aumenta sua área superficial para difundir o ar da atmosfera, em altas concentrações de oxigênio, 
para os capilares pulmonares, como resultado do acionamento dos músculos adequados, como o diafragma localizado no tórax. Desta forma, é gerado um fluxo de gás em direção ao interior alveolar pela diferença de pressões (WEST, 2002a)

- A expiração é o processo no qual o dióxido de carbono $\left(\mathrm{CO}_{2}\right)$, produto da metabolização celular, é expulso dos capilares pulmonares para a atmosfera. Diferentemente da inspiração, a expiração é um processo de relaxamento muscular, isso significa que o gás, em sua maioria, é expulso pela retração elástica de tecidos pulmonares, como diafragma, parede torácica e as estruturas abdominais, gerando um fluxo em direção ao exterior alveolar como resultado da diferença de pressões (WEST, 2002a).

Estes dois processos são realizados por estruturas especializadas e podem ser observados na Figura 2.6.

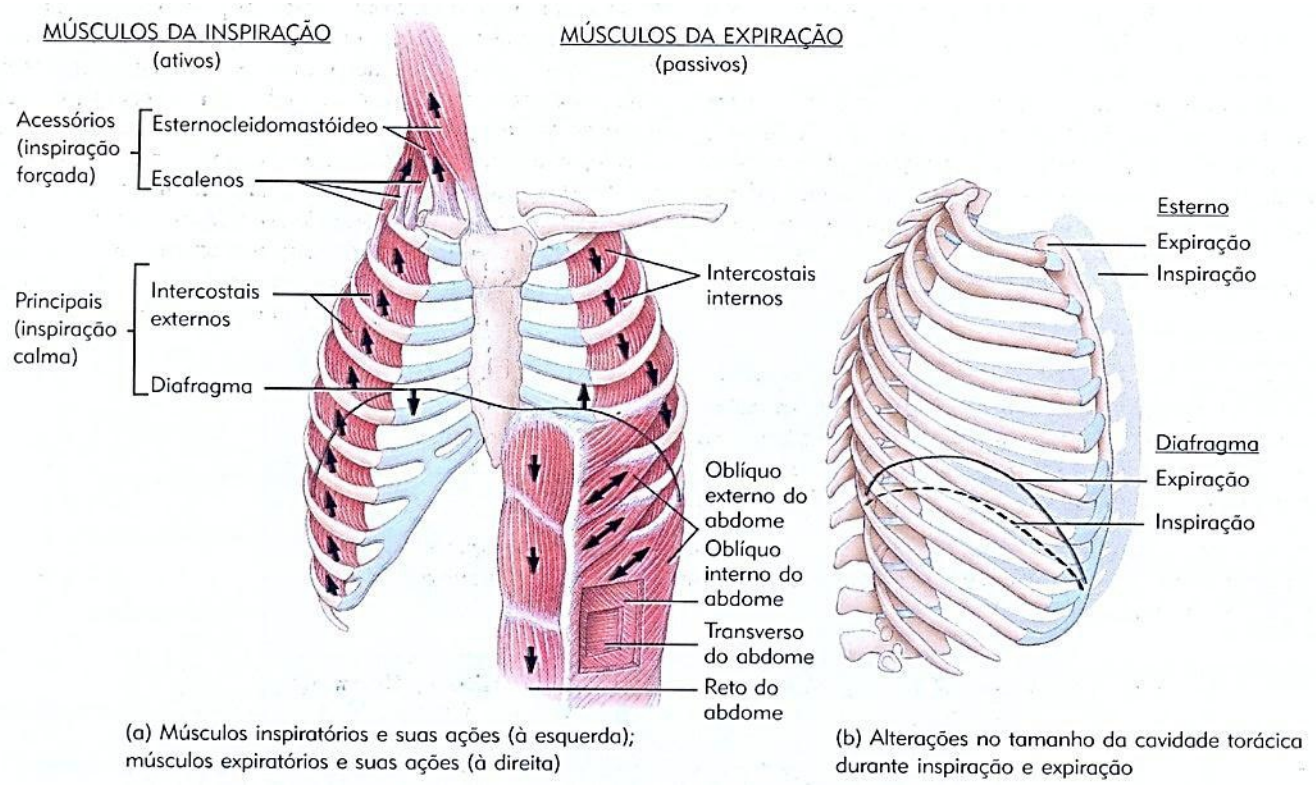

Figura 2.6 - Estruturas envolvidas na inspiração e na expiração (modificado de TORTORA, 2000).

Durante a inspiração e a expiração, o principal músculo de acionamento é o diafragma. O diafragma é uma fina folha de músculo em formato de cálice inserido nas costelas inferiores e é controlado pelo nervo frênico a partir dos segmentos cervicais 3, 4 e 5 (WEST, 2002b). Na inspiração, o diafragma, em conjunto com os músculos intercostais externos, aumenta o volume da caixa torácica, descendo 0 
diafragma e subindo as costelas pela ação dos músculos, o que gera a pressão negativa em relação ao meio ambiente. $\mathrm{Na}$ expiração, o diafragma volta à sua posição natural (sobe) junto com os músculos intercostais internos, diminuindo o volume interno da caixa torácica e gerando pressão positiva em relação ao ambiente. Na figura anterior, observam-se também outras estruturas da respiração, estas estruturas são acionadas somente quando é necessária a ativação adicional; por exemplo, durante o exercício físico, para aumentar o volume de ar inspirado e, portanto, o expirado.

\subsubsection{Volumes e capacidades pulmonares}

É importante destacar que o ciclo respiratório é analisado, com frequência, utilizando-se um espirômetro, que mede o volume de gás por unidade de tempo. As quantidades de gás inspirado/expirado e as variações de volume e do intervalo de tempo do ciclo respiratório são determinantes nos processos de diagnóstico clínico (WEST, 2002c).

$\mathrm{Na}$ Figura 2.7, são observados alguns dos valores medidos por um espirômetro típico.

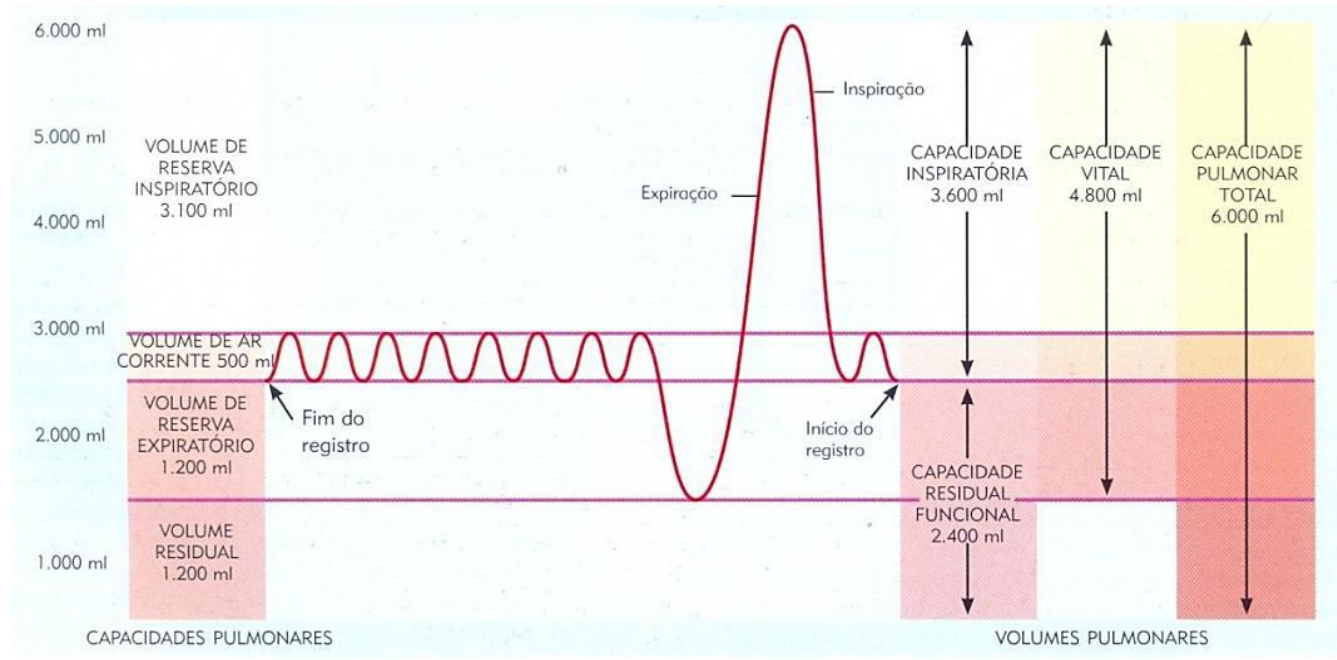

Figura 2.7 - Volumes pulmonares (modificado de TORTORA, 2000).

O volume corrente (VC) é a quantidade de gás inspirado e expirado em um ciclo respiratório normal. Os volumes de reserva inspiratório (VRI) e expiratório 
(VRE) são as quantidades máximas possíveis em uma inspiração e em uma expiração, respectivamente. O volume total entre uma expiração máxima e uma inspiração máxima é chamado de capacidade vital (CV). O volume residual (VR) é a quantidade de gás que permanece no pulmão; este volume não pode ser medido por espirometria normal e,somado ao VRE, define a capacidade residual funcional (CRF). Por último, a Capacidade Pulmonar Total (CPT) é o volume total que cabe no SR e é o resultado de adicionar ao VR a CV (WEST, 2002d).

\subsubsection{Forças elásticas}

Como foi mostrado na seção 2.1.1, os pulmões estão conformados parcialmente por material viscoelástico;isto significa que o tecido pulmonar é capaz de recobrar seu formato e dimensões originais ao acabar o esforço que havia determinado sua deformação (VAN VLACK, 1970; PALLADINO; DAVIS, 2005).

Uma das formas mais simples de demonstrar o comportamento viscoelástico dos pulmões é mostrada na Figura 2.8.
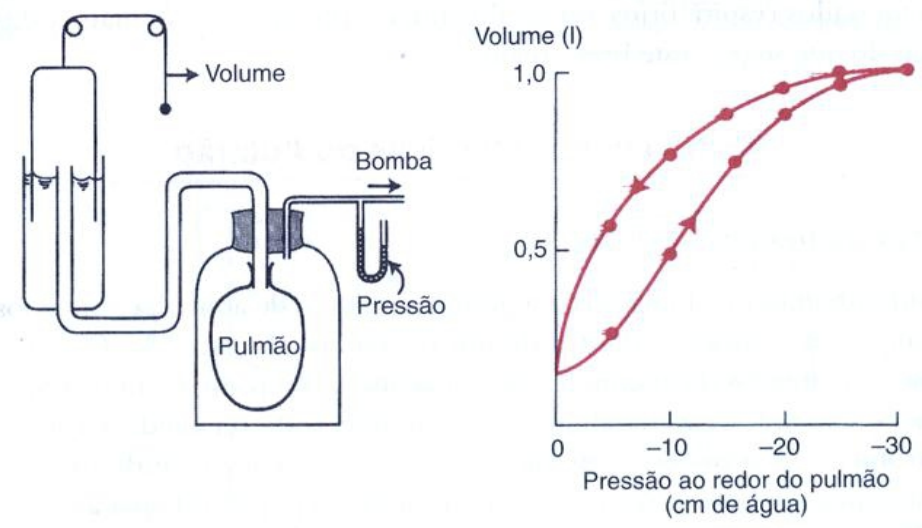

Figura 2.8 - Medição da curva P-V de um pulmão isolado (modificado de WEST, 2002b).

Esta figura mostra um equipamento simples para observar o comportamento $\mathrm{P}-\mathrm{V}$ de pulmões isolados de roedores em um recipiente hermético. O sistema mede, com o auxílio de um espirômetro, o volume de ar dentro do pulmão ao se variar, aos poucos, a pressão dentro do recipiente com uma bomba, gerando uma curva $P-V$ do pulmão. A pressão gerada pela bomba no entorno do pulmão permite sua expansão 
ou sua distensão, simulando a variação do volume da caixa torácica. O espaço existente entre o pulmão e a parede do frasco é similar ao espaço intrapleural.

$\mathrm{Na}$ experimentação da Figura 2.8, a pressão zero no eixo horizontal refere-se à diferença nula em pressão entre o lado de dentro e o de fora do pulmão. Portanto, a pressão no interior das vias aéreas e dos alvéolos do pulmão é igual à pressão atmosférica. Esta pressão é conhecida também como pressão transpulmonar e é numericamente igual à pressão ao redor do pulmão, quando a pressão alveolar é a atmosférica (WEST, 2002b).

$\mathrm{Na}$ curva P-V, presente do lado direito da Figura 2.8, pode ser observado o comportamento do pulmão durante a insuflação e a desinsuflação, conhecido como histerese. Esta histerese evidencia o comportamento viscoelástico do tecido pulmonar, ao mostrar que os pulmões se comportam de maneira diferente na insuflação e na desinsuflação.

A partir da análise $\mathrm{P}-\mathrm{V}$, define-se a variável complacência, como observado na equação 2.1 .

$$
C=\frac{\Delta V}{\Delta P}
$$

Esta variável define a facilidade com que as vias aéreas e a zona respiratória permitem a ocupação de gás em seu interior e está associada ao nível de rigidez do tecido pulmonar. Em unidades físicas, é a relação entre a variação do volume por unidade de variação da pressão $\left[\mathrm{mL} / \mathrm{cmH}_{2} \mathrm{O}\right]$. Um pulmão com complacência baixa é chamado de mais rígido.

A variável antagônica da complacência pulmonar, segundo as propriedades mecânicas dos materiais, é a elastância. Esta propriedade mecânica está associada à habilidade dos materiais de resistir a forças mecânicas (VAN VLACK, 1970). A elastância é o quociente entre a tensão aplicada e a deformação viscoelástica resultante, estando relacionada com a rigidez do material (VAN VLACK, 1970). Neste caso, em especial, a elastância está definida pela equação 2.2.

$$
E=\frac{\Delta P}{\Delta V}
$$

Onde $\Delta P$ é a diferença depressão aplicada e $\Delta V$ a diferença de deformação elástica. 
Estas grandezas físicas, da mesma maneira que os volumes e as capacidades pulmonares, estabelecem parâmetros que ajudam na compreensão do comportamento mecânico do SR e,como consequência, são índices importantes no diagnóstico clínico de pulmões normais ou com deficiências.

O comportamento viscoelástico dos tecidos pulmonares depende fortemente da composição do líquido que recobre a zona respiratória, denominado surfactante pulmonar. O surfactante pulmonar é uma substância tenso ativa produzida por células especializadas dos alvéolos e bronquíolos terminais. Esta substância diminui o trabalho necessário em um ciclo respiratório, ao facilitar a abertura dos alvéolos cuja tendência é a colapsar (GUYTON, 1992).

\subsection{ANATOMIA E FISIOLOGIA RESPIRATÓRIA EM RATOS WISTAR}

Rato de laboratório é o nome comum para qualquer membro da grande família dos roedores usada para investigações biomédicas. Este mamífero é um dos mais usados como animal de experimentação, devido ao fato de que, como modelo, oferece a melhor caracterização funcional (HEDRICH, 2000).

Este mamífero serve como organismo modelo para a análise de importante número de tratamentos biomédicos. Também oferece vantagens únicas como modelo para doenças humanas. O tamanho do rato de laboratório, em relação a outras espécies, faz deste mamífero ideal para certas manipulações fisiológicas. Este também é amplamente usado em investigações clínicas e toxicológicas. Recentemente, esta espécie tem proporcionado ferramentas genéticas e genômicas adicionais para o estudo de doenças humanas. Estas informações e a multiplicidade de linhagens disponíveis definem o rato de laboratório como uma ferramenta indispensável para as pesquisas biomédicas (HEDRICH, 2000).

As linhagens Wistar e Sprague Dawley são as colônias de ratos de laboratório mais usadas em experimentos; suas características genéticas similares e genótipo bem identificado fazem deste animal o ideal para experimentos.

Neste estudo, foi utilizada a linhagem Wistar procedente do biotério da FMUSP, linhagem original do Instituto Wistar na Filadélfia, Pensilvânia (EUA), desde 
1920. Linhagem tipicamente usada em experimentos com animais em estudos primários de toxicologia (KING, 1918 apud HEDRICH, 2000).

De acordo com as características anatômicas e fisiológicas, o SR em roedores divide-se em duas regiões: os dutos ou as vias aéreas não respiratórias, que distribuem o ar inalado (nariz, faringe, laringe, traqueia, brônquios e bronquíolos não alveolares); e as vias aéreas de troca gasosa (brônquios respiratórios, dutos alveolares e sacos de ar alveolares). A Figura 2.9 mostra uma representação esquemática do SR de ratos.

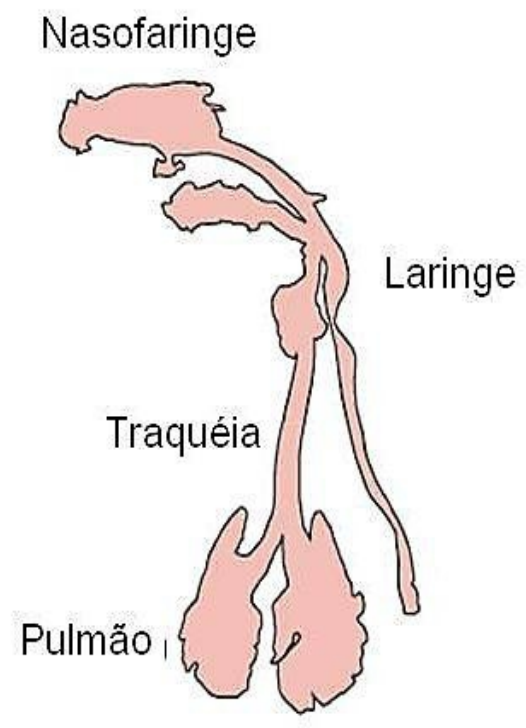

Figura 2.9 - Esquema do SR em ratos adultos (Fisher-344) (modificada de SCHULZ; MUHLE, 2000).

Nesta pesquisa, foi avaliada a mecânica respiratória de ratos Wistar em posição supina, com os pulmões expostos, da região da traqueia até os alvéolos terminais. Na Figura 2.10, mostram-se as estruturas anatômicas de um animal Wistar insuflado pelo IPPR. 


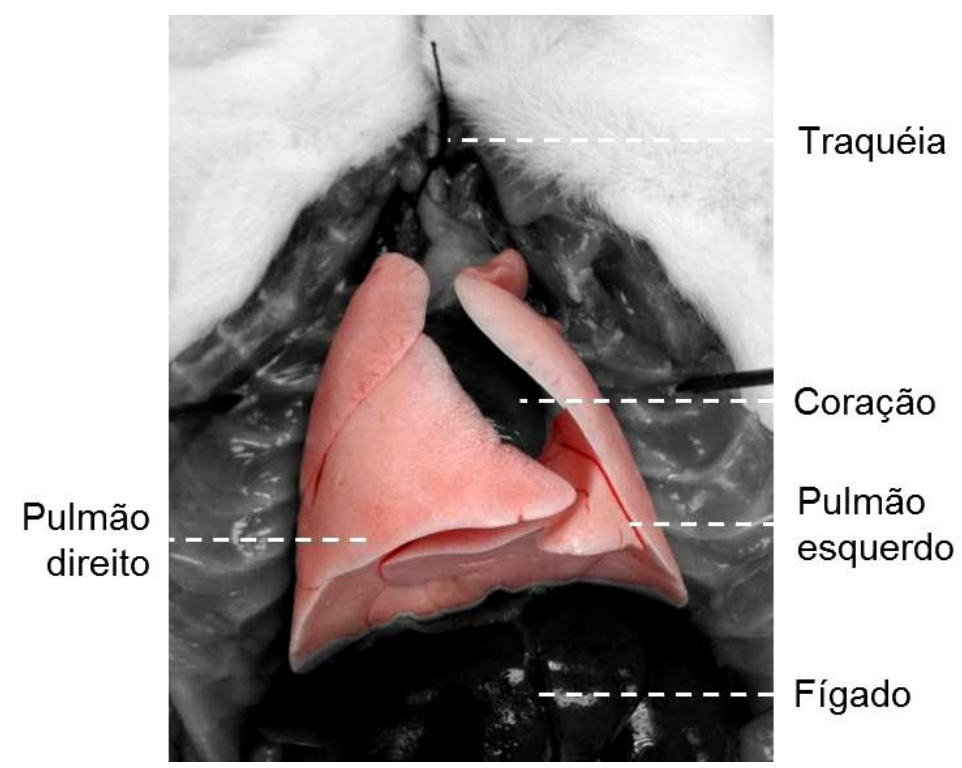

Figura 2.10 - Imagem de um rato Wistar durante experimento com o IPPR. Pulmões expostos ao se abrir a parede torácica.

É importante destacar que a parede torácica em roedores afeta, de forma considerável, as medidas relacionadas à AMR (HIRAl et al., 1999). Segundo Hirai et al. (1999), a parede torácica em ratos de laboratório contribui significativamente com as propriedades resistivas e elásticas do $\mathrm{SR}$, devido à dependência com o volume pulmonar. Em estudos com camundongos de uma linhagem de tamanho menor que os ratos Wistar, os trabalhos de Tomioka, Bates e Irvin (2003) e de Allen et al. (2002) mostraram que aproximadamente $30 \%$ das propriedades resistivas e elásticas do SR podem ser resultado da ação da caixa torácica.

Exemplos de volumes e capacidades pulmonares da linhagem Wistar, utilizada para experimentos com IPPR, são apresentados na Tabela 2.1.

Tabela 2.1- Resumo das características fisiológicas pulmonares em ratos Wistar. Animais anestesiados e com a caixa torácica fechada (modificado de SCHULZ; MUHLE, 2000)

\begin{tabular}{lcc}
\hline \multicolumn{1}{c}{ Parâmetro } & Média & Intervalo \\
\hline massa $(\mathrm{g})$ & 299 & $220-300$ \\
CPT $(\mathrm{mL})$ & 11 & $8,2-12,2$ \\
CPT/PC $(\mathrm{mL} / \mathrm{kg})$ & 42 & $36-54$ \\
$\mathrm{CV}(\mathrm{mL})$ & 9,5 & $5,5-11,0$ \\
$\mathrm{CRF}(\mathrm{mL})$ & 3 & $2,1-4,6$ \\
$\mathrm{VC}(\mathrm{mL})$ & 1,6 & $1,1-2,5$ \\
\hline
\end{tabular}


As magnitudes das capacidades pulmonares dependem das propriedades dos pulmões, dos tecidos da parede torácica, da pressão pulmonar e do gradiente de pressão vertical entre vias aéreas e espaço pleural. A CPT é usualmente determinada quando a pressão transpulmonar em animais anestesiados está entre 25 e $30 \mathrm{cmH}_{2} \mathrm{O}$. O VR em animais anestesiados usualmente escolhe-se quando a pressão transpulmonar é de $-10 \mathrm{cmH}_{2} \mathrm{O}$ (SCHULZ; MUHLE, 2000).

Segundo Sahebjami e Vassallo (1979), a relação entre a CPT e a massa de um animal anestesiado pode ser calculada substituindo-se a massa em gramas na equação 2.3.

$$
C P T=\text { massa } \cdot 0,0368+4,573 \pm 1,67
$$

Existem diversos estudos que caracterizam os volumes de capacidade pulmonar em animais. Estes estudos entregam resultados importantes para entender, analogamente, a fisiologia humana (SAHEBJAMI; VASSALLO, 1979). Desta forma, podem ser comparadas as condições do tecido pulmonar de roedores com as dos humanos.

\subsection{AMR PELO MÉTODO QUASI-ESTÁTICO}

A AMR tem por objetivo estimar experimentalmente os processos mecânicos exercidos pelo SR. Estes processos são caracterizados na aquisição e na análise de variáveis mecânicas, como pressão e volume, envolvidas na respiração em condições normais ou de doença (BATES, 2009).

Tipicamente, a variável controlada que gera a perturbação do SR é o volume, enquanto a variável medida em resposta a esta perturbação é a pressão transpulmonar. Desta forma, são obtidas as curvas P-V que, através da análise e do processamento de dados, podem caracterizar o comportamento viscoelástico do sistema (BATES, 2009). 


\subsubsection{Curvas P-V}

As curvas P-V são uma representação gráfica do comportamento viscoelástico dos pulmões e, na atualidade, são destacadas na AMR. Esta avaliação pode ser utilizada para determinar os parâmetros de ventilação mecânica do SR em pacientes normais ou com insuficiências respiratórias (HAAS, 2000).

Um dos procedimentos típicos usados na terapia respiratória em pacientes com insuficiências respiratória (poliomielite, asma, pneumonia, tuberculose, entre outras) é a ventilação mecânica por pressão positiva (PEREZ; DE LA PARRA; POLLO, 2004).

Hoje em dia, a ventilação mecânica, além de ser usada como procedimento de emergência para doentes críticos, é também empregada frequentemente para superar crises respiratórias. Em síntese, as terapias respiratórias, com ajuda de processos técnicos de medição, como são as curvas $\mathrm{P}-\mathrm{V}$, reúnem esforços para caracterizar deficiências respiratórias complexas (WEST; 2002b).

O comportamento viscoelástico dos pulmões pode ser caracterizado pelas curvas P-V de duas formas: dinâmica e quasi-estática. As curvas $\mathrm{P}-\mathrm{V}$, pelo método dinâmico, determinam o comportamento do SR quando o fluxo respiratório varia com o tempo. Ao contrário, o método quasi-estático estipula a pressão sob condições de fluxo inspiratório próximo a zero, evitando a aceleração dos tecidos (BATES; 2009).

As curvas $\mathrm{P}-\mathrm{V}$ quasi-estáticas consideram, para a análise matemática, que a pressão medida do SR depende unicamente do volume fornecido ao sistema; ademais, não consideram condições morfológicas diferenciadas de cada indivíduo (vias aéreas e pulmões), como volume prévio, aceleração dos tecidos e envelhecimento do sistema, que afetam os valores de pressão medidos (D’ANGELO; MILIC-EMILI, 2005).

O método clássico de construir uma curva quasi-estática P-V utiliza uma seringa com calibração para insuflar ou desinsuflar pulmões, com volume variável entre 50 e100 mL, enquanto se mede a pressão em condições de fluxo zero, depois de alguns segundos de espera, a cada aumento de volume. Antes de qualquer volume ser injetado, os pulmões podem ser desinflados totalmente para que o gás aprisionado não influencie nas medições mecânicas. Geralmente, o paciente é 
paralisado por um agente paralisador, evitando movimentos pulmonares involuntários (HAAS, 2000).

Outra técnica, utilizada por pesquisadores, envolve a medição de pressão transpulmonar quasi-estática durante uma pausa de 3 segundos à final da expiração (medir O PEEP intrínseco), e no final da inspiração, enquanto é variado aleatoriamente o volume corrente. O paciente é ventilado com VC normal entre as medições. Alguns pesquisadores utilizam softwares especializados e ventiladores modificados para programar as condições de ventilação necessárias para conduzir estes testes de respiração, enquanto outros realizam as mudanças manualmente (HAAS, 2000).

Um exemplo didático de curva PV em humanos encontra-se na Figura 2.11.

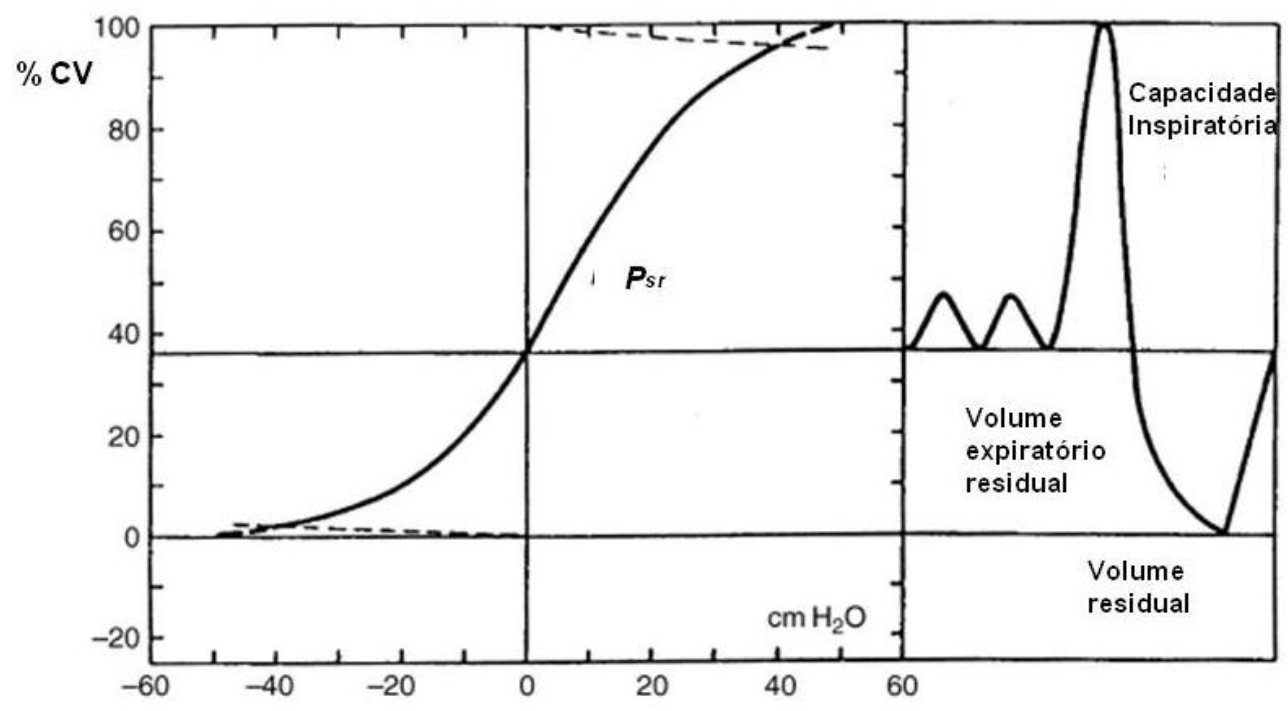

Figura 2.11 - À esquerda do gráfico encontra-se uma curva P-V de expiração típica. Do lado direito apresenta-se um exame de espirometria típico, com subdivisões do volume pulmonar relacionadas à cada seção da curva P-V (modificado de D'ANGELO; MILIC-EMILI, 2005).

A pressão desenvolvida pelo $\mathrm{SR}\left(P_{S R}\right)$ é o produto das forças exercidas pelos elementos elásticos, sendo igual à diferença entre a pressão alveolar $\left(P_{a l}\right)$ e a pressão na superfície do corpo $\left(P_{S C}\right) . A P_{S R}$ indica a pressão que os músculos respiratórios devem exercer para manter o volume pulmonar com as vias aéreas abertas (D'ANGELO; MILIC-EMILI, 2005). 
O processo de medição de curvas $\mathrm{P}-\mathrm{V}$ apresenta vários problemas técnicos, como, por exemplo, a obtenção do relaxamento voluntário dos músculos respiratórios (D'ANGELO; MILIC-EMILI, 2005). Por conta desta limitação, as curvas $\mathrm{P}-\mathrm{V}$ oferecem melhores resultados em sujeitos paralisados; segundo D'Angelo e Milic-Emili (2005), os resultados obtidos em sujeitos paralisados concedem maior precisão para sua posterior análise.

Como consequência destas limitações, recorre-se a espécies menores, similares anatomicamente à humana, para a realização de experimentos. Nestas espécies, tipicamente primatas, caninos e roedores, são adquiridas curvas P-V no intervalo completo de capacidade pulmonar total (CPT). Estas curvas P-V demonstram o comportamento viscoelástico do tecido pulmonar em condições similares às humanas, ajudando a compreender as limitações fisiológicas pulmonares importantes para o benefício humano (GLAISTER et al., 1973; MORSTATTER et al., 1976).

A análise inicial da curva P-V mostra um comportamento linear, no intervalo médio do volume insuflado, e curvilíneo abaixo dos $15 \%$ e acima dos $85 \%$ do volume da CV (D'ANGELO; MILIC-EMILI, 2005). Esta análise simples já é um diferenciador para definir certo comportamento viscoelástico dos tecidos do SR; porém, não descreve o fenômeno com maior solidez. Como consequência, para estimar este processo fisiológico, têm sido propostos diferentes modelos matemáticos das curvas $\mathrm{P}-\mathrm{V}$, alguns deles são explicados na seção seguinte.

\subsubsection{Modelagem matemática das curvas P-V quasi-estáticas}

Para realizar a AMR, é necessário utilizar modelos matemáticos construídos sistematicamente, para quantificar com maior objetividade o fenômeno (BATES, 2009).Estes modelos matemáticos são um conjunto de equações e servem como evidência precisa de como possivelmente funciona a mecânica dos pulmões, sendo usados, também, para explorar as consequências do suposto comportamento (BATES, 2009).

Deste modo, a modelagem matemática deve ser útil e bastante relacionada à fisiologia para facilitar a compreensão do comportamento mecânico pulmonar. Um 
dos primeiros e mais usados modelos matemáticos para a AMR foi desenvolvido a partir da análise por complacência das curvas $\mathrm{P}-\mathrm{V}$ quasi-estáticas.

A complacência, como definimos na equação 2.1, é considerada como o valor da inclinação da curva P-V. A complacência pulmonar quasi-estática mostra que, no começo da inspiração, a pressão aumenta rapidamente, enquanto pequenos volumes de ar entram nos pulmões (complacência baixa). No intervalo de tempo em que há aumento contínuo de volume, novas unidades alveolares são recrutadas, facilitando a entrada de ar (complacência maior) (HAAS, 2000). Depois de recrutadas as unidades alveolares, a relação $\mathrm{P}-\mathrm{V}$ entra em estado linear. Por último, a pressão aumenta rapidamente em relação ao volume, indicando o limite de insuflação pulmonar máximo, sugerindo hiperdistensão pulmonar e complacência próxima de zero (HAAS, 2000).

A variação da complacência comprova, segundo Glaister et. al (1973), que as propriedades elásticas intrínsecas dos pulmões não são isotrópicas, o que sugere a ventilação pulmonar desigual, que depende de estruturas adicionais.

A análise por complacência é de grande importância na atualidade; porém, este estudo possui limitações quando comparadas as forças viscoelásticas envolvidas na respiração pulmonar de indivíduos diferentes. Algumas destas limitações são o resultado de variações fisiológicas, como $\mathrm{CV}, \mathrm{CRF}, \mathrm{CPT}$, que dependem do tamanho dos pulmões (SALAZAR; KNOWLES, 1964).

Para evitar estas limitações, foi necessário utilizar ajustes matemáticos que avaliam o comportamento viscoelástico do pulmão sem a influência direta do seu tamanho (SALAZAR; KNOWLES, 1964).

\subsubsection{Ajuste matemático exponencial}

O comportamento elástico dos pulmões pode ajustar-se matematicamente a uma função exponencial (SALAZAR; KNOWLES, 1964; GLAISTER et al., 1973; COLEBATCH; NG; NIKOV, 1979).

Esta análise matemática especificou, como hipótese inicial, que a complacência dos pulmões segue comportamento definido pela equação 2.4(SALAZAR; KNOWLES, 1964). 


$$
C=\frac{d V}{d P}=K \cdot\left(V_{0}-V\right)
$$

onde $V_{0}$ é o volume máximo nos pulmões quando a complacência tende a zero (pressão tende a infinito), $V$ é o volume atual medido, $d V / d P$ é a derivada parcial do volume em relação à pressão medida e $K$ é uma constante proporcional associada ao fenômeno.

Uma vez definida esta hipótese geradora e adicionando-se alguns passos matemáticos utilizando integração, é obtida uma expressão exponencial definida pela equação 2.5 .

$$
V=V_{0} \cdot\left(1-e^{-K \cdot P}\right)
$$

A utilização do modelo matemático exponencial, definido pela equação acima, ajusta os dados experimentais $\mathrm{P}-\mathrm{V}$, medidos pelo método quasi-estático de pulmões, a uma curva exponencial, modelando o comportamento elástico pulmonar com uma precisão maior que 95\% (SALAZAR; KNOWLES, 1964; GLAISTER et al., 1973; COLEBATCH; NG; NIKOV, 1979).

O modelo exponencial tem sido utilizado para ajustar curvas $\mathrm{P}-\mathrm{V}$ medidas por diferentes protocolos experimentais quasi-estáticos, com o intuito de caracterizar, através de constantes matemáticas, as capacidades pulmonares e a elasticidade do tecido pulmonar. Entre os mais importantes estão os protocolos realizados por Salazar e Knowles (1964), Glaister et al. (1973) e Colebatch, Ng e Nikov (1979).

Salazar e Knowles (1964) utilizaram o modelo matemático exponencial para ajustar as curvas P-V quasi-estáticas em sujeitos adultos saudáveis. O ajuste foi realizado para o intervalo superior da CV, mais especificamente entre a Posição de Repouso no Fim da Expiração (PRFE ${ }^{1}$ ) e a CPT. Adicionalmente, Salazar e Knowles (1964) mostraram um índice de pressão média $(h)$ independente do tamanho do pulmão e das capacidades pulmonares residuais e vitais, resolvendo a equação 2.6.

\footnotetext{
${ }^{1}$ PRFE é termo outorgado, em humanos, ao momento, no fim de uma expiração normal,no qual não existe fluxo de ar.
} 


$$
V=V_{0} \cdot\left(1-e^{\frac{-P \cdot \ln 2}{h}}\right)
$$

onde $h$ é a pressão média de insuflação, $P$ é a pressão medida, ln é o logaritmo neperiano.

A expressão da equação 2.6 é o resultado de substituir na equação $2.5 V$ por $V_{0} / 2$.

O procedimento, para ajustar os dados experimentais na equação 2.6, é realizado ao encontrar as constantes $h$ e $V_{0}$. Salazar e Knowles (1964) deduziram as equações 2.7 e 2.8 para solucionar as constantes de ajuste.

$$
\begin{gathered}
h=\frac{P^{\prime} \cdot \ln 2}{\ln \left[V\left(P^{\prime}\right)\right]-\ln \left[V\left(2 P^{\prime}\right)-V\left(P^{\prime}\right)\right]} \\
V_{0}=\frac{V\left(P^{\prime}\right)}{1-e^{\frac{-P^{\prime} \cdot \ln 2}{h}}}
\end{gathered}
$$

onde $P^{\prime}$ e $2 P^{\prime}$ são pressões medidas em 20 sujeitos, no ponto mais próximo à primeira inflexão e à capacidade inspiratória máxima, respectivamente, das curvas P-V quasi-estáticas. $V\left(P^{\prime}\right)$ e $V\left(2 P^{\prime}\right)$ são os volumes das pressões $P^{\prime}$ e $2 P^{\prime}$.

Um exemplo dos valores de ajuste exponencial aos dados experimentais para um dos sujeitos analisados encontra-se na equação 2.9 .

$$
V=3,46 \cdot\left(1-e^{\frac{-P \cdot \ln 2}{6,81}}\right)
$$

Os valores da pressão média $h$ e $V_{0}$ são aproximadamente $6,81 \mathrm{cmH}_{2} \mathrm{O}$ e 3,46 l. A Figura 2.12 mostra os dados encontrados matematicamente e a curva experimental medida. 


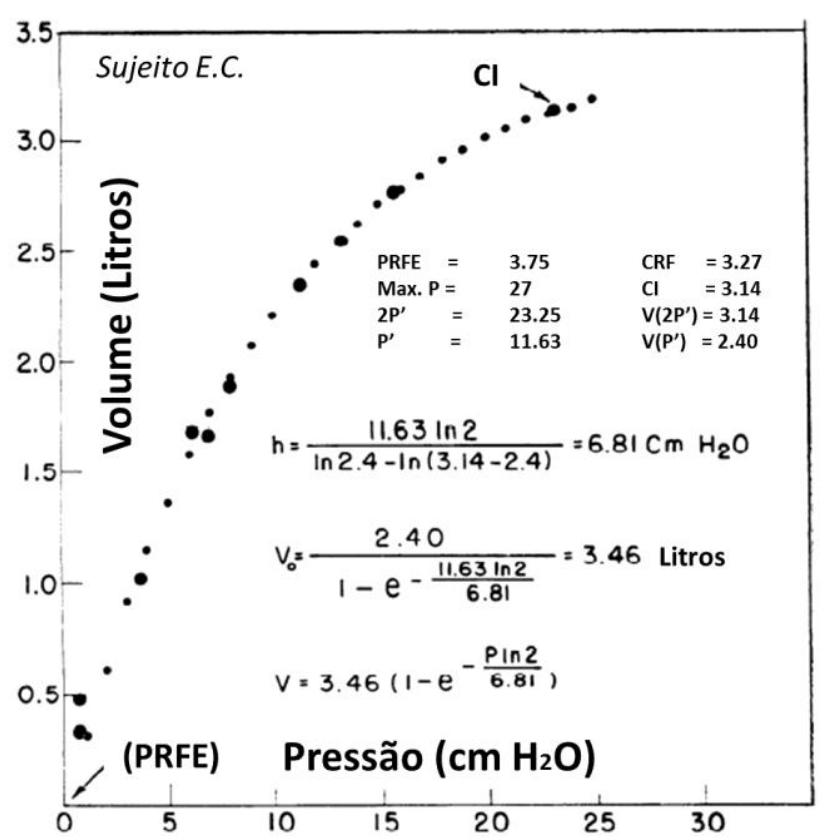

Figura 2.12 - Ajuste da curva descrita pela equação 2.9 à curva $P-V$ experimental do sujeito EC do grupo analisado por Salazar e Knowles (1964). Cl é a capacidade inspiratória, Max. P é a máxima pressão e ln é o logaritmo neperiano (modificada de SALAZAR; KNOWLES, 1964).

De forma diferente, o trabalho de Glaister et al. (1973) ajustou exponencialmente os dados $\mathrm{P}-\mathrm{V}$ quasi-estáticos de pulmões isolados de animais (caninos e primatas). As curvas $\mathrm{P}-\mathrm{V}$ quasi-estáticas medidas dos pulmões isolados foram realizadas durante um fluxo constante lento, evitando a aceleração dos tecidos.

Glaister et al. (1973), com o intuito de simular as condições pulmonares humanas, isolaram os pulmões de animais dentro de uma câmara fluidizada de densidade baixa, simulando o gradiente vertical hidrostático de pressão exercido pela cavidade pleural.

Como foi comentado na seção 2.1.2, a cavidade pleural recobre os pulmões e mantém níveis de pressão adequados para permitir o transporte de gases. Glaister et al. (1973) geraram um gradiente de pressão vertical controlado similar ao da cavidade pleural. Este gradiente hidrostático de pressão depende da altura na qual é colocado o pulmão, como se observa na Figura 2.13. 


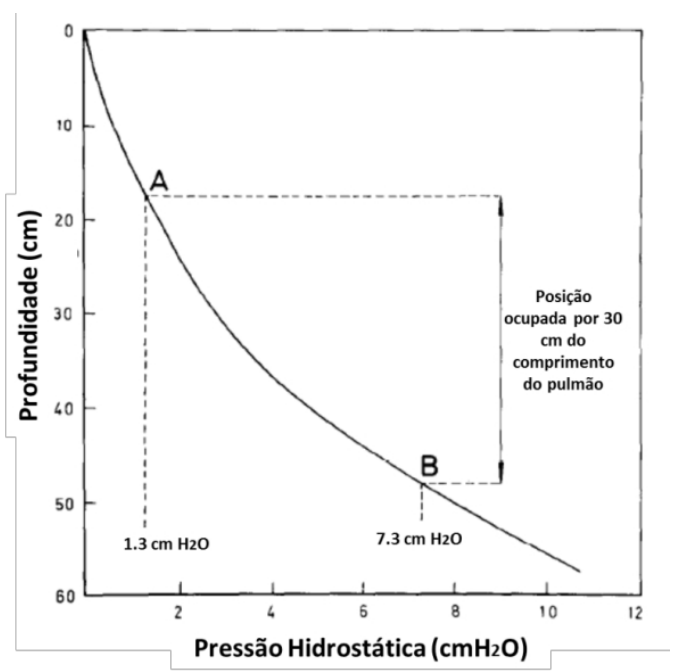

Figura 2.13 - Curva do gradiente de pressão intrapleural vertical versus profundidade da câmara fluidizada (Modificada de GLAISTER et al., 1973).

Com ajuda do gradiente de pressão vertical imposto aos pulmões isolados, Glaister et al. (1973) realizaram manobras de ventilação quasi-estáticas em todo o intervalo da CPT, resultando nas curvas P-V da forma apresentada na Figura 2.14.

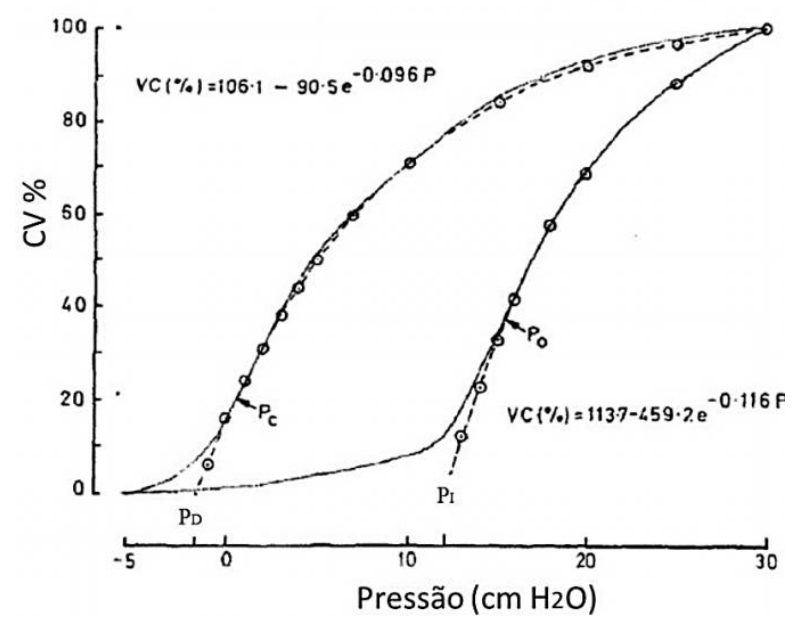

Figura 2.14 - Curva P-V de pulmão canino isolado. A linha contínua corresponde aos dados experimentais e a linha tracejada à curva ajustada pela equação exponencial (modificada de GLAISTER et al., 1973).

Estas curvas quasi-estáticas foram ajustadas a uma função exponencial similar à apresentada por Salazar e Knowles (1964), no intervalo compreendido entre $\mathrm{P}_{\mathrm{O}}$ e CPT, na insuflação, e entre $\mathrm{P}_{\mathrm{C}}$ e CPT, na desinsuflação. $\mathrm{P}_{O}$ e $\mathrm{P}_{\mathrm{C}}$, respectivamente, são o ponto imediatamente após a primeira inflexão, na insuflação, e o ponto imediatamente anterior à última inflexão ao desinflar os pulmões. Esta equação exponencial mostra-se na equação 2.10 . 


$$
V C(\%)=a-b \cdot e^{-c \cdot P}
$$

onde $V C(\%)$ é o volume corrente em percentagem, enquanto $a, b$ e $c$ são constantes. Estas constantes são estimadas pela aplicação de métodos de mínimos quadrados. Na Figura 2.14, podemos observar os valores de ajuste da equação exponencial do intervalo superior na inspiração e na expiração.

Estas constantes, segundo Glaister et al. (1973), foram ajustadas por implementação de um algoritmo de mínimos quadrados, de forma que puderam ser calculadas e substituídas na equação exponencial de ajuste.

Colebatch, $\mathrm{Ng}$ e Nikov (1979) complementaram o trabalho de seus antecessores, realizando um ajuste exponencial nas curvas medidas pelo método quasi-estático de 43 adultos. Os limites do ajuste da curva P-V experimental, diferentes dos propostos por Salazar e Knowles (1964), são valores proporcionais à CPT e maiores à CRF. O limite inferior, para estimar os dados experimentais, foi escolhido entre $50 \%$ e $58 \%$ da CPT, enquanto o limite superior sempre foi $100 \%$ da CPT.

O método por mínimos quadrados usado por Colebatch, $\mathrm{Ng}$ e Nikov (1979) ajustou os dados experimentais das curvas $\mathrm{P}-\mathrm{V}$, encontrando as constantes $A, B$ e $K$ da equação 2.11 .

$$
V=A-B \cdot e^{-K \cdot P}
$$

onde $A$ é teoricamente $o$ valor do volume máximo. $B$ é a diminuição do volume inferior a $A$ até que a pressão nos pulmões seja zero. A constante $K$ refere-se à forma da inclinação da curva P-V.

Foi comprovado que a função exponencial é ajustada com maior precisão, com a curva experimental quasi-estática P-V, quando o limite inferior do ajuste for maior que 50\% de CPT (COLEBATCH; NG; NIKOV, 1979). Na Figura 2.15, mostram-se, com linhas contínuas, as curvas de estimação da função exponencial e, com linhas tracejadas, a curva P-V quasi-estática medida em um sujeito. 


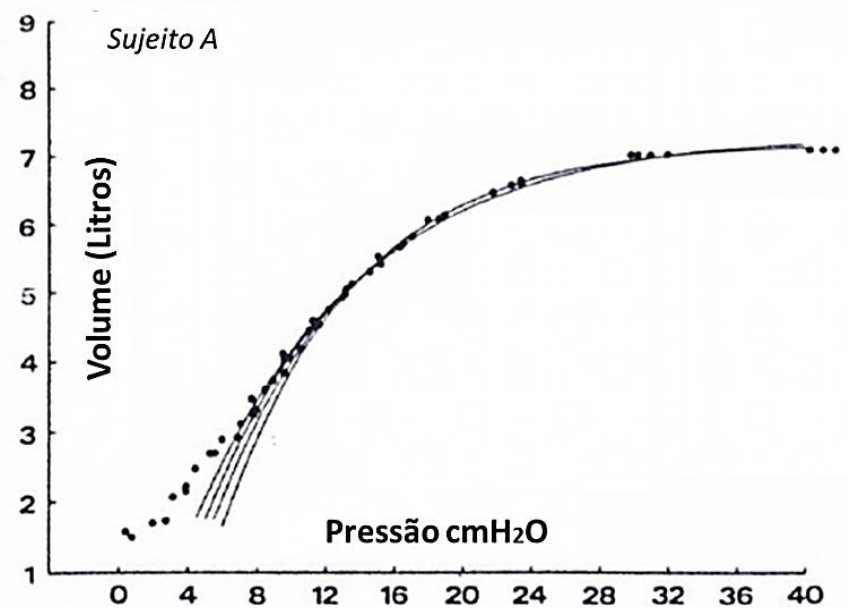

Figura 2.15 - Curva P-V experimental ajustadas à função exponencial a partir da CPT até o limite inferior do volume de 40,50, 60 e $70 \%$ de CPT (modificada de COLEBATCH; NG; NIKOV, 1979)

Colebatch, Nge e Nikov (1979), com ajuda da análise exponencial de Salazar e Knowles (1964) e Glaister et al. (1973), comprovaram que os dados fisiológicos, como CPT e VR, ajustados pela equação exponencial de Salazar e Knowles (1964), apresentam valores altos, pelo grande erro vinculado ao cálculo manual de $V\left(P^{\prime}\right)$ e $V\left(2 P^{\prime}\right)$.

Adicionalmente, Colebatch, $\mathrm{Ng}$ e Nikov (1979) esclarecem que uma análise por complacência das curvas P-V é variável, com as capacidades pulmonares de cada indivíduo, impossibilitando um índice geral para deduzir o estado viscoelástico dos tecidos pulmonares. No entanto, propuseram um intervalo de análise, no qual se considera que as condições fisiológicas podem ser comparadas entre diferentes indivíduos. Este intervalo é definido entre $50 \%$ e $60 \%$, da CPT, e100\% de CPT.

\subsubsection{Ajuste matemático sigmoidal}

O modelo matemático sigmoidal, diferentemente do modelo exponencial, está baseado matematicamente na análise da complacência específica (PAIVA et al., 1975; VENEGAS; HARRIS; SIMON, 1998; DO AMARAL et al., 2011), definida pela equação 2.12. 


$$
\frac{d V}{V \cdot d P}=K^{\prime} \cdot \frac{\left(V_{0}^{\prime}-V\right)}{V_{0}^{\prime}}
$$

onde $V_{0}^{\prime}$ é o volume máximo quando a pressão medida tende a infinito. $V$ é o volume pulmonar atual medido, $K^{\prime}$ é uma constante proporcional e $d V / d P$ é a derivada parcial do volume em relação à pressão medida.

A equação 2.12, proposta por Paiva et al. (1975), é a hipótese geradora de diferentes análises sigmoidais das curvas P-V quasi-estáticas. Paiva et al. (1975), Venegas, Harris e Simon (1998) e Do Amaral et al. (2011) usaram esta equação para ajustar os dados experimentais de curvas $\mathrm{P}-\mathrm{V}$ quasi-estáticas medidas em sujeitos saudáveis, sujeitos com deficiências respiratórias e em pulmões de animais.

Paiva et al. (1975) sugeriram, a partir da hipótese matemática e de alguns processos de integração, que a equação 2.12 define-se como a equação 2.13.

$$
V=\frac{V_{0}^{\prime}}{1+\left(C_{1} \cdot V_{0}^{\prime}\right) \cdot e^{-K^{\prime} \cdot P}}
$$

onde $C_{1}$ é a constante de integração;esta constante é calculada impondo como ponto obrigatório de passagem das curvas $\mathrm{P}-\mathrm{V}$ quasi-estáticas por $\left(P_{1}, V_{1}\right) . P_{1}$ é a pressão no PRFE e $V_{1}$ é o volume de CRF. Substituindo estes valores, é obtida a equação 2.14 (PAIVA et al., 1975).

$$
V=\frac{V_{0}^{\prime} \cdot C R F}{C R F+\left(V_{0}^{\prime}-C R F\right) \cdot e^{-K^{\prime} \cdot(P-P R F E)}}
$$

Paiva et al. (1975) ajustaram os dados experimentais P-V quasi-estáticos de vinte sujeitos à equação 2.14 sigmoidal, minimizando o critério quadrático da equação 2.15 .

$$
f=\sum_{i=1}^{N}\left[V_{E X P}(i)-V_{T E O}(i)\right]^{2}
$$


onde $N$ é o número de pontos experimentais, $V_{E X P}(i)$ é o volume experimental no momento de pressão transpulmonar $i . V_{T E O}(i)$ é o valor de volume dado pela equação 2.14 .

$\mathrm{Na}$ figura seguinte, podemos observar diferentes curvas teóricas de ajuste sigmoidal, como proposto por Paiva et al. (1975).

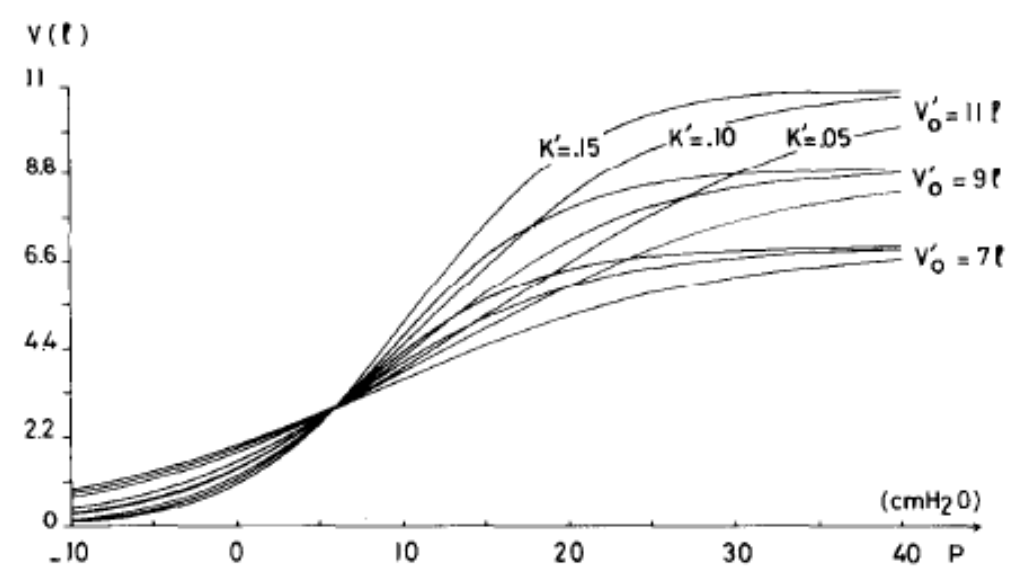

Figura 2.16 - Curvas teóricas obtidas variando $V_{o}$ e $K$ '. Relação P-V simulada pela equação sigmoidal equação 2.14 para diferentes valores dos parâmetros. Todas as curvas passam por PRFE (modificada de PAIVA et al. 1975).

Os dados obtidos pelo método sigmoidal mostram que as curvas P-V experimentais podem ser bem ajustadas por um modelo matemático sigmoidal, especialmente nas curvas de expiração. No entanto, a adequação para ajuste de valores inferiores ao da CRF dificulta a avaliação. Neste ajuste, a análise foi limitada para volumes maiores que $50 \%$ da CPT, pela pouca confiabilidade do método quasiestático e por limitações de medição de dados P-V inferiores da CRF (PAIVA et al., 1975).

Além do ajuste sigmoidal de Paiva et al. (1975), existe o ajuste proposto por Venegas, Harris e Simon (1998). Este modelo ajustou as curvas quasi-estáticas de pulmões de caninos, com caixa torácica intacta e exposta, e de sujeitos com Síndrome de Desconforto Respiratório Agudo (SDRA) à equação sigmoidal equação 2.16, no intervalo de insuflação e desinsuflação (inspiração, expiração). Esta equação descreve, através de suas constantes matemáticas, o comportamento existente nas curvas quasi-estáticas $\mathrm{P}-\mathrm{V}$ experimentais. 


$$
V=a+\left[\frac{b}{1+e^{\frac{-(P-c)}{d}}}\right]
$$

Onde $a, b, c$ e $d$ são constantes. Estas constantes são localizadas no modelo sigmoidal segundo a Figura 2.17. $a$ corresponde ao volume assintótico menor, $b$ é a diferença entre os volumes assintóticos máximo e mínimo, $c$ é a pressão no instante de complacência maior e $d$ é proporcional ao intervalo de pressão no qual ocorre a maior mudança no volume.

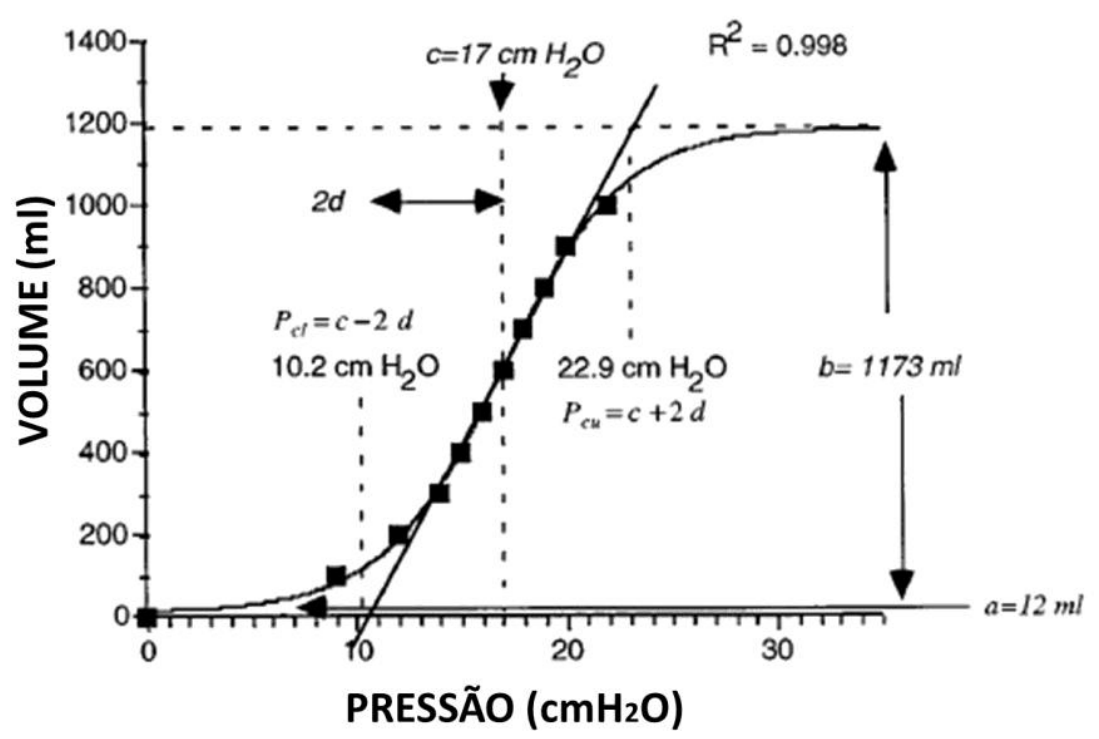

Figura 2.17 - Curva quasi-estática P-V no intervalo de inspiração, dados medidos em paciente com síndrome da angústia respiratória aguda(SARA) e ajustados à equação2.16(modificado de VENEGAS; HARRIS; SIMON, 1998).

Este ajuste sigmoidal comprovou que o modelo pode diferenciar, através de suas constantes, pulmões doentes de pulmões normais. Esta diferenciação observou-se obtendo valores mais altos da constante $c$,em pulmões de animais expostos à lesão induzida por ventilação e a sujeitos com SDRA,sugerindo aumento nas forças elásticas de retração pulmonar (VENEGAS; HARRIS; SIMON, 1998).

Adicionalmente, Do Amaral et al. (2011) formularam uma nova interpretação do modelo sigmoidal. Nesta análise, Do Amaral et al. (2011), com o intuito de descrever os parâmetros que evitam lesões pulmonares em pacientes sob tratamento respiratório por ventilação mecânica, formularam dois novos parâmetros 
que ajudam a definir a mecânica respiratória em pulmões normais e com deficiências. Estes parâmetros são conhecidos como Ponto de Aumento Máximo de Complacência (PAMC) e Ponto de Queda Máxima de Complacência (PQMC).

Estes índices são calculados realizando análise matemática da equação sigmoidal, equação 2.17 .

$$
V-V_{\min }=\frac{V_{\max }-V_{\min }}{1+e^{\frac{-\left(P-P_{i, d}\right)}{k_{i . d}}}}
$$

os subíndices $i$ e $d$ identificam os parâmetros de insuflação e desinsuflação. Os parâmetros $V_{\max }$ e $V_{\min }$ são o volume máximo e mínimo registrados pelas curvas $\mathrm{P}-\mathrm{V}$ e fazem alusão às constantes $a$ e $b$ da eq.(2.16). $P_{i, d}$ e $k_{i, d}$ são constantes que definem o comportamento da curva P-V e são similares às constantes $c$ e $d$ da equação 2.16.

A equação 2.17 pode reproduzir, com alta precisão, as curvas $\mathrm{P}-\mathrm{V}$, ajustando corretamente as constantes matemáticas. Os parâmetros PAMC e PQMC, propostos por Do Amaral et al. (2011), podem ser calculados com precisão, aplicando-se na equação 2.17 a condição da equação 2.18 .

$$
\frac{\partial^{2} C}{\partial P^{2}}=0
$$

onde esta expressão é a segunda derivada parcial da complacência com respeito à pressão medida, igualada a zero. Da equação 2.18 são concluídas as equações 2.19 e 2.20 .

$$
\begin{aligned}
& P_{a m c}=P_{i, d}-\alpha \cdot k_{i, d} \\
& P_{q m c}=P_{i, d}+\alpha \cdot k_{i, d}
\end{aligned}
$$

onde $P_{a m c}$ e $P_{q m c}$ são, respectivamente, as pressões em PAMC e PQMC. A constante $\alpha$ é aproximadamente 1,317. Estes parâmetros observam-se na curva P-V sigmoidal da Figura 2.18. 


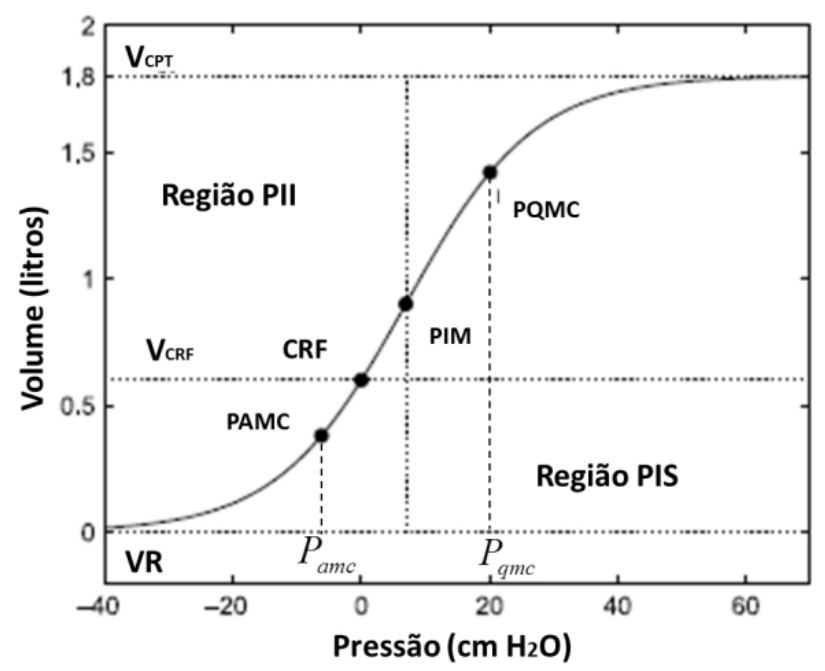

Figura 2.18 - Curva P-V respiratória representada pela equação2.17. PIM é o ponto de insuflação médio, PII é o ponto de inflexão inferior e PIS é o ponto de inflexão superior (modificada de DO AMARAL et al., 2011).

Do Amaral et al. (2011) concluíram, a partir dos índices PAMC e PQMC, que as curvas P-V quasi-estáticas dependem fortemente da velocidade de recrutamento e podem concluir resultados objetivos para a análise do comportamento da MR em pacientes normais ou com deficiências, aplicável a pacientes em tratamento respiratório por ventilação mecânica.

\subsubsection{Outros métodos de AMR}

Haas (2000) quantificou as curvas PV com o objetivo de evitar uma lesão pulmonar induzida por ventilação (LPIV). Esta lesão, de importante reconhecimento na atualidade, é causada por processos vinculados à configuração incorreta dos parâmetros de ventilação mecânica. Parâmetros, como o VC e a Pressão Positiva ao Final da Expiração $\left(\right.$ PEEP$\left.^{2}\right)$, sendo incorretamente calculados, podem levar à geração de altos níveis de pressão dentro do SR e a consequente hiperdistensão do tecido elástico dos pulmões. Adicionalmente, podem causar o rompimento das paredes alveolares, ao reventilarem unidades alveolares colapsadas no fim da expiração. 
Como solução a esta lesão progressiva, Haas (2000) quantificou as curvas PV, modelando três retas, como é mostrado na Figura 2.19, com o propósito de identificar os valores críticos de complacência associados às limitações fisiológicas do SR.

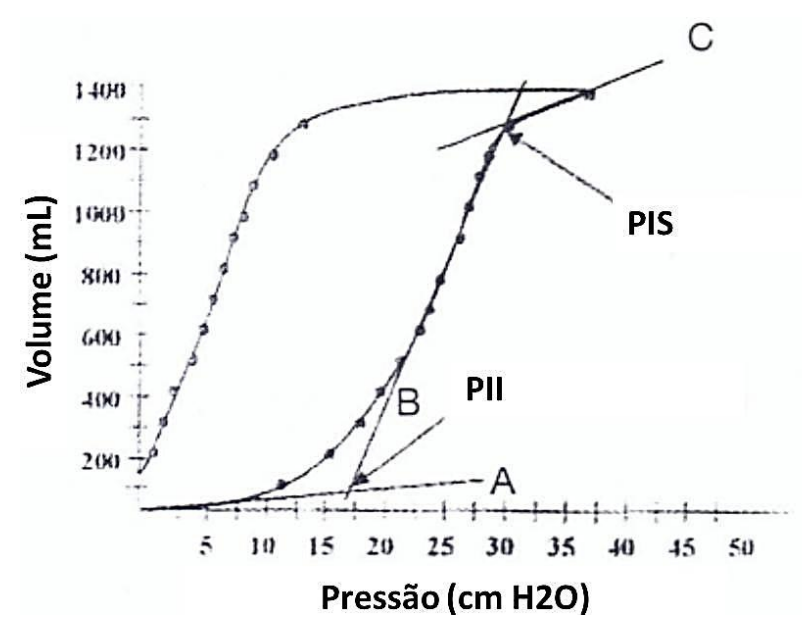

Figura 2.19 - Curva PV quasi-estática. As retas A, B e C ajudam a identificar os pontos de inflexão inferior e superior. Pll é o ponto de inflexão inferior e PIS é o ponto de inflexão superior (modificada de HAAS, 2000).

As variações da curva sigmoidal, segundo Haas (2000), podem ser ajustadas a três retas, cada uma delas representando o maior número de pontos tangenciais dos momentos fisiológicos da curva $\mathrm{P}-\mathrm{V}$, começo de insuflação, região de deformação elástica e excesso de distensão pulmonar. A intersecção destas retas define o fim do recrutamento de novas unidades alveolares, ou o Ponto de Inflexão Inferior (PII), e o começo da região de excesso de distensão pulmonar,ou o Ponto de Inflexão Superior (PIS).

Os índices PII e PIS, encontrados pela modelagem proposta por Haas (2000), delimitam os valores de VC e PRFE adequados para pacientes em terapia respiratória por ventilação mecânica, evitando lesões pulmonares.

Por outro lado, Alencar et al. (2002) introduziram uma nova forma de AMR, descrevendo o comportamento de insuflação pulmonar através de um modelo matemático dinâmico baseado em choques de avalanche. Os choques de avalanche são associados a variações negativas de pressão que geram instabilidade alveolar e elasticidade negativa. Este comportamento, demonstrado em pulmões isolados de ratos, descreve a abertura de regiões fechadas de troca gasosa como um processo 
que ocorre lentamente, abrindo vias aéreas, completamente, quando é superada uma pressão resistiva inicial, até se equilibrar a pressão nesta via aérea, alternando entre elasticidade positiva e negativa. Como mostrado na Figura 2.20.

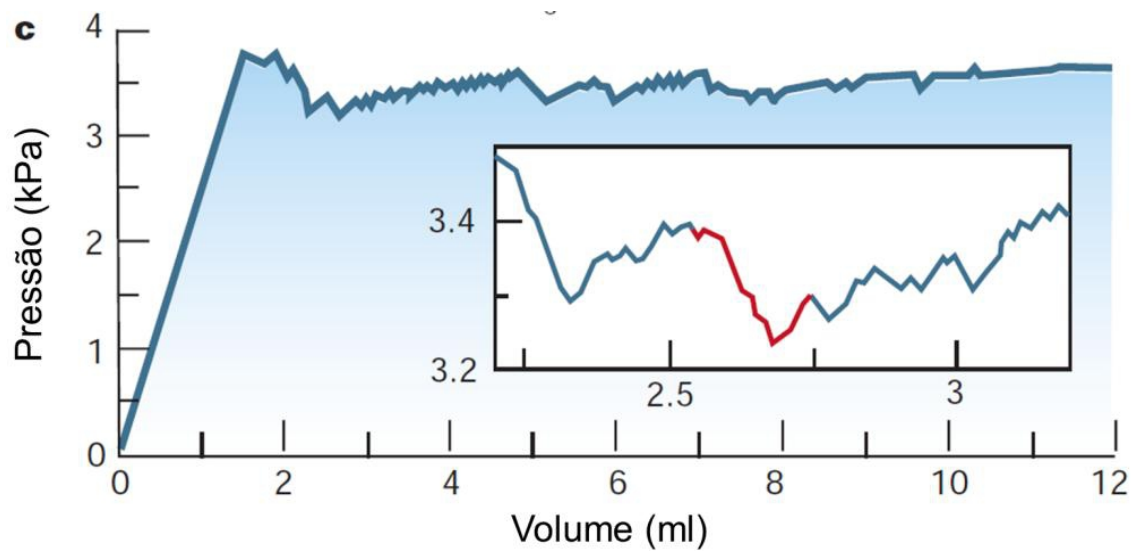

Figura 2.20 - Exemplo de uma curva P-V em uma manobra de insuflação. Os pulmões são insuflados assegurando que o volume inicial dentro deles seja zero (atelectasiados). O quadro ilustra uma magnificação da região com muita elasticidade negativa local, a linha vermelha destaca um choque de avalanche (modificado de ALENCAR et al., 2002)

Concluindo, Alencar et al. (2002) usaram uma nova discussão sobre a instabilidade de pressão nos pulmões. A instabilidade de pressão é atribuída a combinações das propriedades estáticas do líquido alveolar e da não uniformidade do tecido pulmonar. O entendimento desta instabilidade pode ser crucial no tratamento de doenças respiratórias, como asma e lesões pulmonares agudas.

$\mathrm{Na}$ última década, adicionalmente ao ajuste matemático das curvas PV quasiestáticas e dinâmicas, as tecnologias em tratamento de imagens têm experimentado grande progresso, em benefício da fisiologia pulmonar e da patologia pulmonar (HUO; FU, 2012).

Neste sentido, Huo e Fu (2012) apresentam um resumo dos diferentes avanços na modelagem teórica do SR. Estes modelos teóricos envolvem: modelagens macroscópicas, complexidade do $\mathrm{SR}$, intercâmbio gasoso e relação coração-pulmão.

$\mathrm{Na}$ atualidade,os avanços recentes, segundo Huo e Fu (2012), indicam várias tendências na MR, como: 
- Maior precisão na avaliação das funções respiratórias

- Inclusão dos parâmetros que caracterizam as doenças e as microestruturas, nos complexos modelos respiratórios

- Medição e prognóstico das propriedades de intercâmbio de gases dos alvéolos pulmonares

- Estabelecimento da interação conjuntado SR com outros sistemas fisiológicos, especialmente o sistema circulatório e o sistema nervoso

Estas tendências de modelagem pulmonar ajudam a entender a patologia de algumas doenças respiratórias, como SDRA e Doença Pulmonar Obstrutiva Crônica (DPOC). Além disto, fornecem o suporte teórico para o projeto de novos aparelhos médicos, como é o caso dos ventiladores respiratórios mais modernos.

\subsection{TÉCNICAS EMPREGADAS PARA A AVALIAÇÃO QUASI-ESTÁTICA DE MECÂNICA RESPIRATÓRIA EM ROEDORES}

Silva, Zin e Saldiva (1998) avaliaram a MR através da quantificação das diferenças estruturais entre pulmões de ratos normais e pulmões com deficiências respiratórias, induzidas por envenenamento com Paraquat. O Paraquat é um potente herbicida do grupo dos bipiridílicos (1.1' dimetil-4.4' bipiridilo dicloro) e é utilizado na agricultura; em países em desenvolvimento, incluindo o Brasil, é um produto de ampla distribuição e baixo custo. Tem sido comprovado que a inalação ou a ingestão deste produto afeta a saúde em praticamente todos os níveis, mas, de forma especial, causa o comprometimento pulmonar, responsável por grande parte dos casos de falecimento. Esta instabilidade alveolar é atribuída à destruição das células produtoras de surfactante pulmonar (pneumócitos tipo II) existentes na interface arlíquido (PALOMAR 1993 apud RIVERO et al., 2001).

As diferenças estruturais comprovadas entre pulmões normais e doentes foram quantificadas através da definição de dois índices, são eles: 
- LVGEAS, índice que relaciona grandes quantidades de ar em espaços de troca gasosa

- S/V que relaciona o volume e a superfície alveolar; este índice estima a forma do parênquima de troca gasosa

Estes índices foram estimados em pulmões isolados de ratos Wistar no-SPF (do inglês no specific pathogen free), utilizando um sistema simples para a obtenção de curvas $\mathrm{P}-\mathrm{V}$ pelo método quasi-estático e um microscópio de alta definição. $\mathrm{O}$ sistema para a obtenção de curvas P-V é mostrado na Figura 2.21.

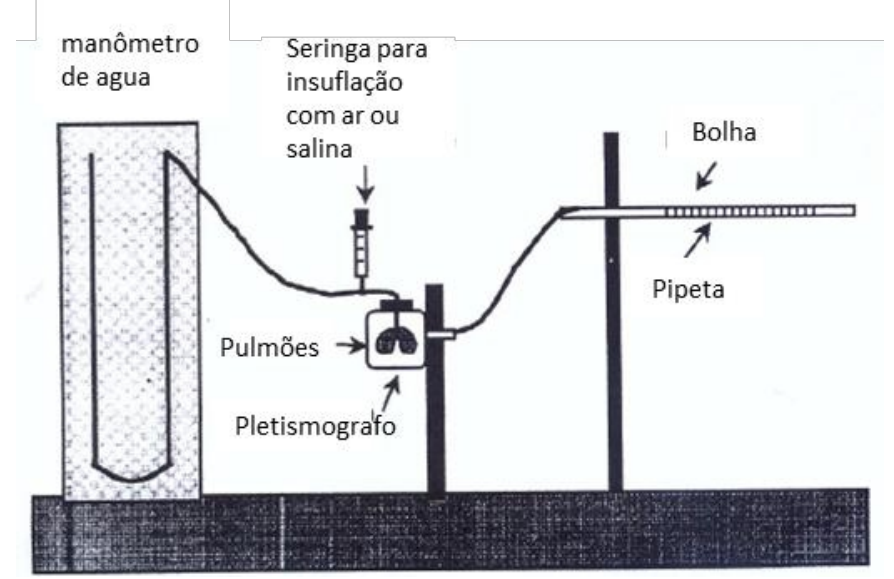

Figura 2.21 - Representação esquemática do sistema usado para a obtenção de curvas P-V em pulmões isolados (modificado de SILVA; ZIN; SALDIVA, 1998).

Neste sistema, foram insuflados e desinsuflados pulmões normais e doentes, medindo o volume pulmonar em três níveis de pressão diferentes: 5,15, e $25 \mathrm{cmH}_{2} \mathrm{O}$. A insuflação e a desinsuflação foram realizadas manualmente, a velocidades muito lentas, até se atingir a pressão desejada; depois de cada aumento foi aguardado um intervalo de tempo curto para medir os valores de volumes de forma mais precisa.

Depois de medido o volume em cada pressão, os pulmões foram submersos em nitrogênio líquido e fixados em solução Carnoy's (Etanol: Clorofórmio: Ácido acético, 60:30:10 em volume) a $-70^{\circ} \mathrm{C}$, para preservar o tecido intacto. As amostras dos tecidos pulmonares foram seccionadas por tamanho de aproximadamente $5 \mu \mathrm{m}$. Com estas secções, foi realizada a avaliação morfológica, através dos índices LVGEAS e S/V, utilizando um microscópio. 
Os resultados obtidos mostraram que, a pressões menores de $25 \mathrm{cmH}_{2} \mathrm{O}$, na insuflação e na desinsuflação, a porcentagem de LVGEAS é maior nos animais com Paraquat; isto quer dizer que existe maior número de regiões fechadas com ar no seu interior, onde a ventilação é nula. Este comportamento diminui para pressões próximas a $25 \mathrm{cmH}_{2} \mathrm{O}$.

Por outro lado, os pulmões normais (controle) possuem, em pressões próximas a $25 \mathrm{cmH}_{2} \mathrm{O}$, na insuflação, maior porcentagem de $\mathrm{S} / \mathrm{V}$, o que sugere que os pulmões normais têm maior superfície de troca gasosa para um dado volume; esta diferença diminui quando os pulmões são desinsuflados.

Estas diferenças morfológicas demonstraram que, a pressões menores de $25 \mathrm{cmH}_{2} \mathrm{O}$, os animais sob o efeito do Paraquat apresentam menor superfície de troca gasosa e maior instabilidade alveolar, sugerindo maior esforço respiratório para abrir novas unidades alveolares. Estas diferenças diminuem quando os pulmões são submetidos a pressões próximas a $25 \mathrm{cmH}_{2} \mathrm{O}$.

Adicionalmente, o trabalho de Silva, Zin e Saldiva (1998) demonstra que as estruturas morfológicas dos pulmões podem ser preservadas mantendo-se a PEEP adequada em pacientes ventilados, evitando o colapso alveolar.

Além da AMR em pequenos roedores, proposta por Silva, Zin e Saldiva (1998), existem diferentes estudos como os propostos por Schuessler e Bates (1995) e Volgyesi et al. (2000), pesquisas que realizaram a AMR de forma dinâmica, diferentementedo IPPR documentado nesta pesquisa,no qual a velocidade de insuflação pode ser indefinidamente lenta. 


\section{MATERIAIS E MÉTODOS}

Neste capítulo, será abordada a metodologia utilizada nesta pesquisa para avaliar a mecânica respiratória de roedores. Em linhas gerais, este capítulo está dividido em três partes:
a) Visão geral do IPPR
b) Testes de bancada do IPPR
c) AMR de modelo animal de doença pelo método quasi-estático

A visão geral do IPPR descreve as características técnicas do equipamento utilizado; a documentação mais detalhada do sistema será apresentada no Capítulo 4. Em seguida, serão apresentados os protocolos de avaliação dos dados de pressão e volume adquiridos pelo IPPR, através da realização de testes de bancada. Por último, descreve-se a metodologia utilizada para a AMR pelo método quasiestático em roedores envenenados por Paraquat.

\subsection{VISÃO GERAL DO IPPR}

O IPPR desenvolvido foi projetado para avaliar a mecânica respiratória pelo método quasi-estático em roedores. Este método relaciona a pressão gerada pelos órgãos do SR, quando este sistema é submetido a incrementos conhecidos de volume durante a insuflação, em velocidade bastante lenta.

Esta relação é representada tipicamente na forma de curvas P-V. As curvas $\mathrm{P}-\mathrm{V}$ devem ser adquiridas e apresentadas de forma simples, para que qualquer pesquisador consiga obter informação suficiente para determinar o comportamento do SR em condições quasi-estáticas.

Este dispositivo possui um módulo mecânico e quatro outros elétricos, que são módulos controlados por um software implementado em um microcomputador comum utilizando uma plataforma de instrumentação virtual (LabVIEW 8.5, National Instruments, EUA). 
A metodologia de funcionamento do IPPR consiste em aumentar o volume pulmonar enquanto se mede simultaneamente a pressão transpulmonar do SR. A pressão é medida através de um módulo de transdução de pressão baseado em um transdutor de pressão gauge (FPM-07PG, Fujikura, Japão). O volume é insuflado nos pulmões, movendo-se linearmente o êmbolo de uma seringa $(50 \mathrm{cc}$, Omega, Brasil), de forma que o ar contido no tambor da seringa seja injetado no interior das vias aéreas e dos pulmões. Este movimento linear é obtido transformando-se o movimento rotacional de um motor de passos (57BYGH207, Circuit Specialists, EUA) usando acoplamentos mecânicos.

$\mathrm{Na}$ plataforma de instrumentação virtual foi implementado um software no qual são configurados os parâmetros para manobras de AMR pelo método quasiestático. A Figura 3.1 apresenta em diagrama de blocos a visão geral do IPPR.

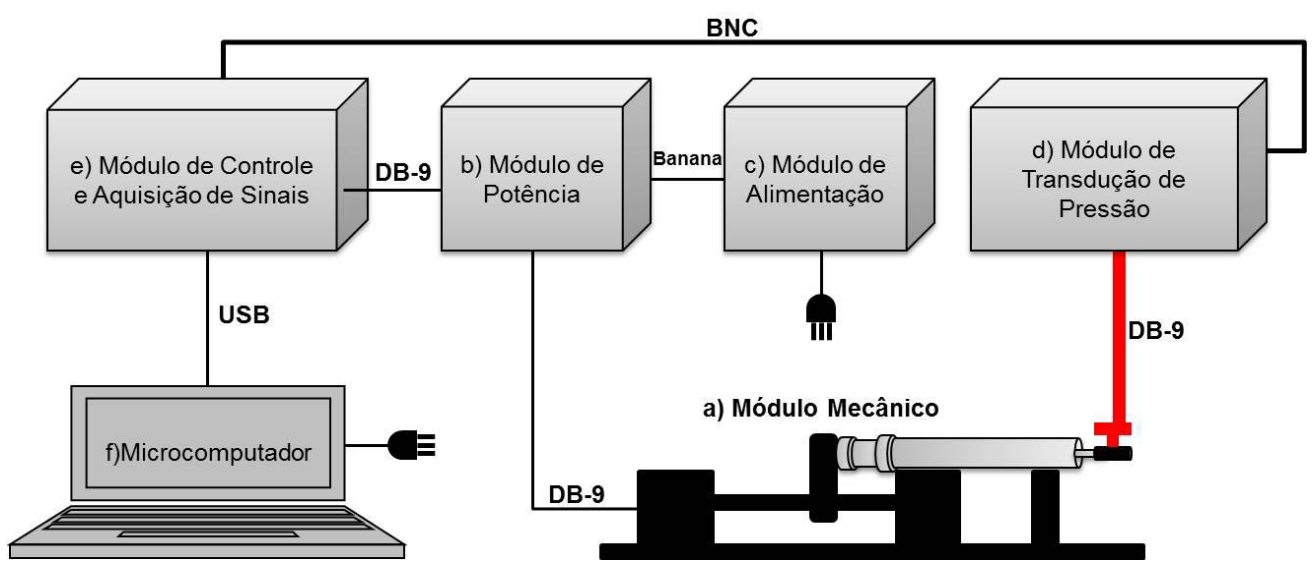

Figura 3.1 - Diagrama de blocos do IPPR.

Conforme a Figura 3.1, o IPPR pode ser dividido em cinco módulos e um microcomputador, identificados individualmente no diagrama por uma letra. Os termos DB-9, BNC, Banana e USB são designados a cada tipo de terminal utilizado para realizar a ligação entre módulos, com exceção dos módulos (f) e (c) que, além de se conectar com outros módulos, precisam de cabos para conexões na rede elétrica.

Os módulos, com exceção do microcomputador, podem ser observados na fotografia da Figura 3.2. 


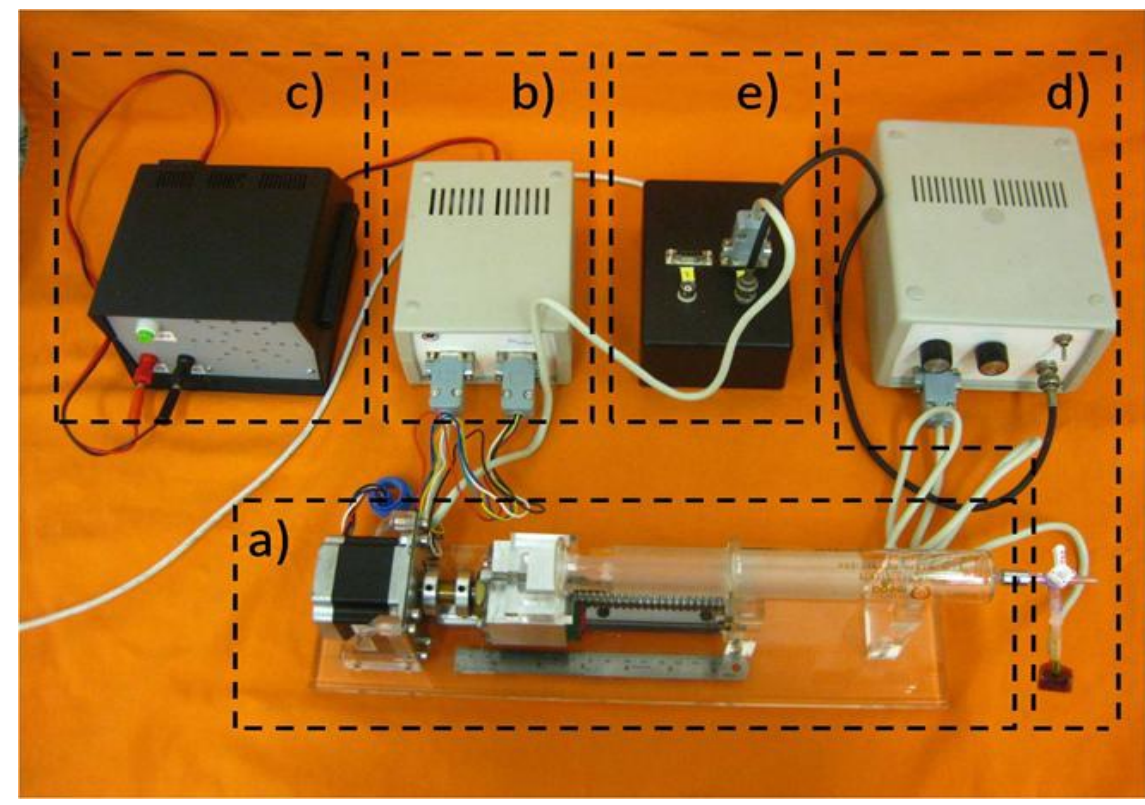

Figura 3.2 - Fotografia do insuflador pulmonar para pequenos roedores sem o microcomputador: a) Módulo mecânico; b) Módulo de potência; c) Módulo de alimentação; d) Módulo de transdução de pressão; e) Módulo de controle e aquisição de sinais.

No Capítulo 4, serão descritos com mais detalhes cada módulo do IPPR, usando programas de desenho gráfico avançado e simulações elétricas. O principal intuito da descrição detalhada apresentada no Capítulo 4 é documentar o equipamento, de maneira que uma réplica possa ser implementada por qualquer outro grupo de pesquisa.

\subsection{TESTES DE BANCADA DO IPPR}

Esta seção apresenta a metodologia de avaliação das principais funções do IPPR ao realizar a AMR pelo método quasi-estático durante a insuflação.

O processo de insuflação do IPPR pode ser caracterizado ao medir, em diferentes velocidades e volumes, o deslocamento do êmbolo da seringa. Por outro lado, a pressão manométrica medida pelo IPPR pode ser avaliada ao monitorar a tensão elétrica de saída do módulo de transdução de pressão, variando a pressão aplicada no transdutor de pressão. 
Buscou-se, na implementação do IPPR, uma boa precisão tanto no volume fornecido como na pressão medida. Essa necessária precisão se torna um desafio ainda maior, por se tratar de um insuflador para animais de pequeno porte, já que as variações de volume a serem medidas são pequenas.

Neste capítulo, foram descritas as montagens e os procedimentos utilizados para avaliar as funções fundamentais do IPPR.

Os testes de bancada realizados foram baseados no protocolo experimental apresentado sob a forma de diagramas de blocos na Figura 3.3.

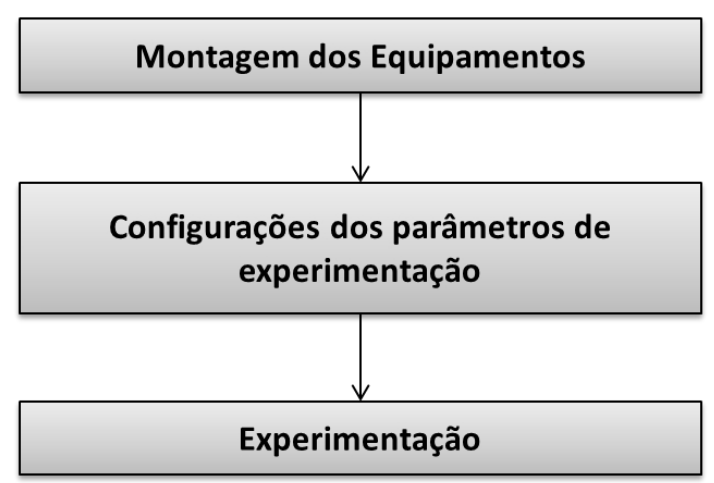

Figura 3.3 - Diagrama de blocos explicativo do protocolo experimental para testes de bancada.

O diagrama de blocos acima demonstra a sequência de etapas para avaliação de deslocamento (volume e velocidade) e pressão realizados no IPPR. Estes ensaios foram realizados no LEB da EPUSP.

\subsubsection{Avaliação de volume e velocidade do IPPR}

O objetivo desta seção foi caracterizar, através da execução de um protocolo experimental em bancada, o comportamento com que o IPPR desloca o êmbolo da seringa para insuflar, à velocidade lenta, um volume de ar controlado nos pulmões do roedor.

Para isto, precisou-se, em primeiro lugar, realizar a montagem dos equipamentos necessários para experimentação. Assim, foram realizadas as ligações dos módulos $e, b, c$ e, $f$ do IPPR, seguindo a Figura 3.4. 


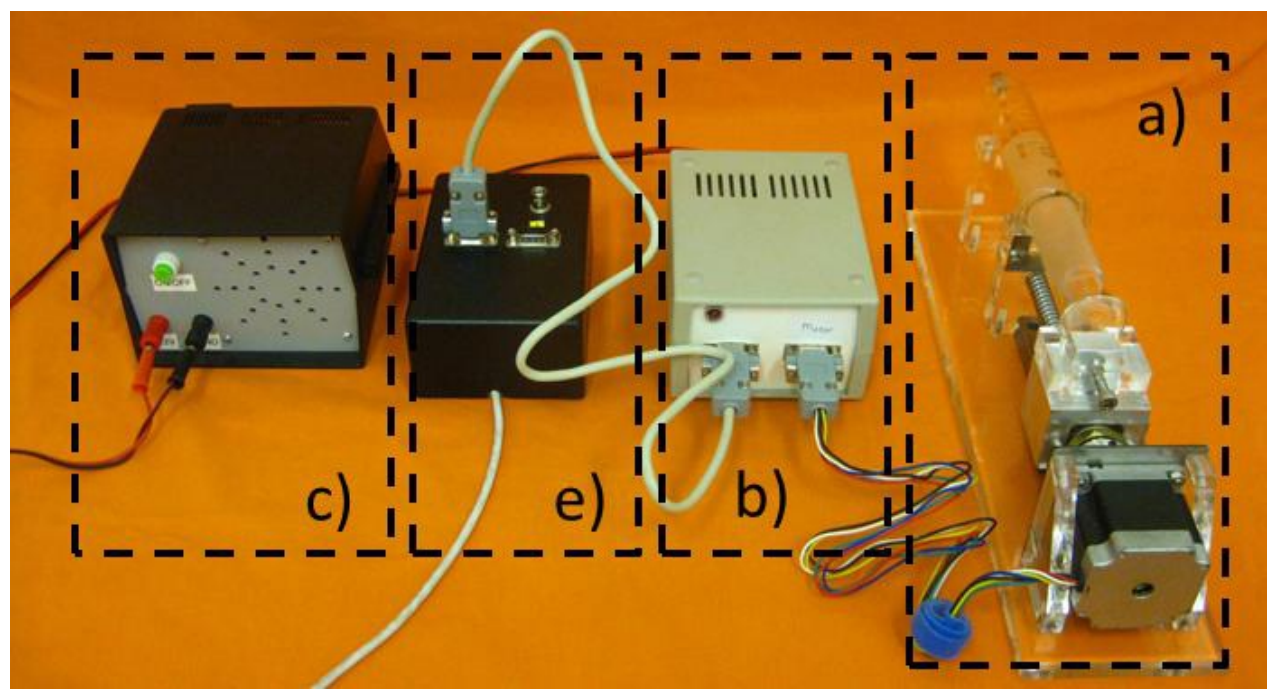

Figura 3.4 - Equipamentos usados para avaliação de volume e velocidade do IPPR, com exceção do microcomputador (f).

$\mathrm{Na}$ montagem, na Figura 3.4, podemos observar os módulos do IPPR necessários para movimentar o êmbolo da seringa, após ligação e calibração dos mesmos. Nesta configuração, a movimentação do êmbolo é controlada pelo microcomputador, mediante o envio de comandos em unidades relacionados ao motor de passos, por exemplo, ou o número de passos, ou as unidades de deslocamento em centímetros $(\mathrm{cm})$ ou o seu valor proporcional de volume $(\mathrm{mL})$, limitado pelo espaço disponível no módulo mecânico e o tipo de seringa.

Esta distância é diretamente proporcional à capacidade total de insuflação do IPPR (Cinst_IPPR), devido a geometria da seringa utilizada. Para calcular a Cinst_IPPR foi utilizada a equação de volume de um cilindro de comprimento $d$ e raio $r$, observada na equação 3.1 .

$$
V o l=\pi \cdot r^{2} \cdot d
$$

Onde $\operatorname{Vol}[\mathrm{mL}]$ é o volume insuflado, $\pi$ é uma constante geométrica e seu valor aproximado é 3,1416, $r$ [cm] é o raio do êmbolo da seringa, e $d$ [cm] é a distância percorrida pelo êmbolo da seringa ao realizar uma manobra de insuflação. As dimensões $r$ e $d$ podem ser observadas na Figura 3.5 apresentada a seguir. 


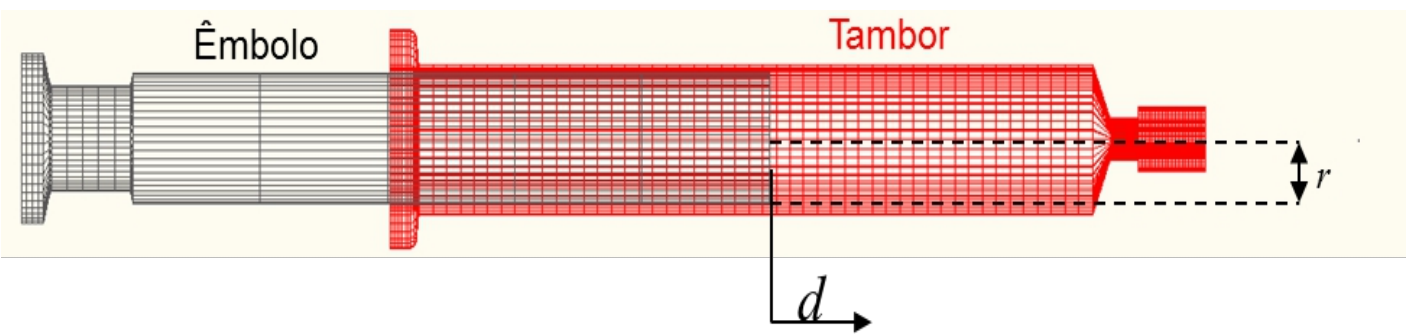

Figura 3.5 - Esquema geométrico da seringa do IPPR. Linhas da cor preta desenham a geometria do êmbolo da seringa. Linhas da cor laranja desenham a geometria do tambor da seringa.

A variável $d$ é diretamente proporcional ao volume injetado nos pulmões, devido à relação geométrica do tambor da seringa, dada pela equação $3.1 \mathrm{e}$ observada na Figura 3.5.

Como consequência, para avaliar a quantidade de ar transferido do tambor da seringa até os pulmões, é necessário medir a distância $d$ em diferentes condições, para comprovar a eficácia do IPPR ao mover o êmbolo da seringa.

Também foi utilizado um paquímetro (74030, Tamiya, EUA), de $0,005 \mathrm{~cm}$ de precisão e, um termo-higrômetro (MT-242, Minipa, China) para monitorar as condições ambientais durante os ensaios.

Esta avaliação consistiu em medir, com o paquímetro, a distância entre um ponto fixo (PF) e um ponto variável (PV) do módulo mecânico do IPPR antes e depois de uma manobra de insuflação. Desta forma, são obtidas duas medidas chamadas Amplitude 1 e Amplitude 2. A Amplitude 1 se refere à distância inicial, antes de uma manobra de insuflação, e a Amplitude 2 é a distância final depois de uma manobra de insuflação. A diferença entre estas amplitudes determina a distância $d$ proporcional ao volume insuflado. Estas medições podem ser observadas com mais detalhes na Figura 3.6. 


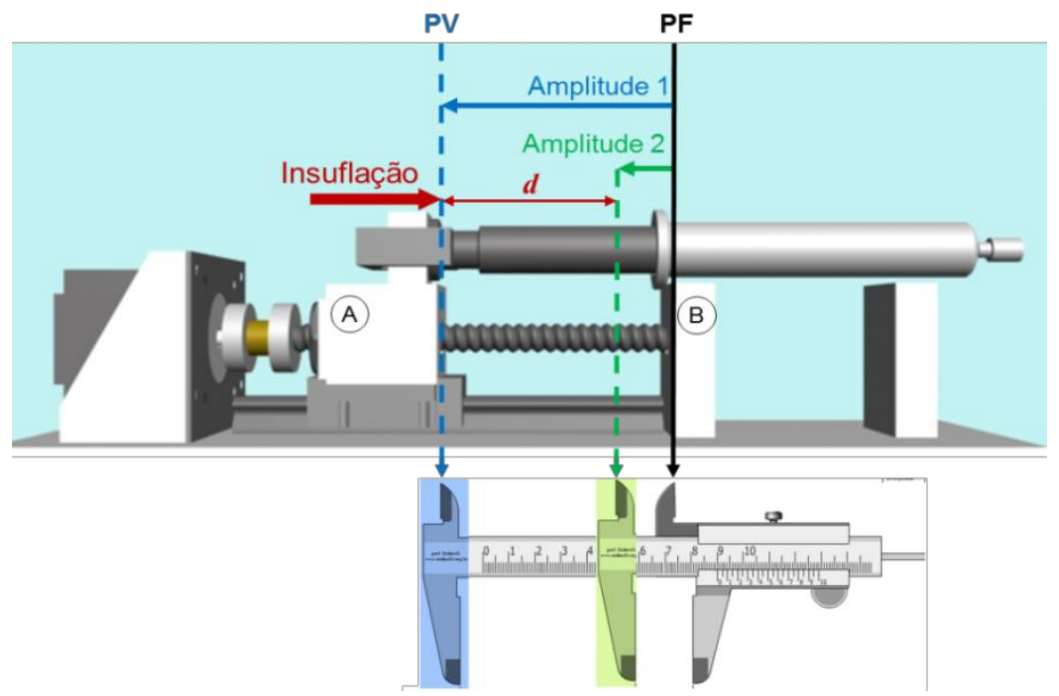

Figura 3.6 - Esquema ilustrativo da montagem realizada para avaliação de deslocamento e velocidade do IPPR.

Na parte inferior da Figura 3.6, é observada a forma em que foi utilizado o paquímetro para medir as amplitudes ao executar uma manobra com o IPPR. $\mathrm{Na}$ Figura 3.6, pode ser observada a localização física dos pontos PF e PV. As Amplitudes 1 e 2 correspondem à distância entre PF e PV ao medir, com os apoios do paquímetro, a distância que separa o carrinho de fixação do êmbolo (letra A) e o suporte de acrílico (letra B).

Para avaliar a velocidade de insuflação do IPPR, foi calculado o intervalo de tempo $(\Delta t)$, em segundos, transcorrido ao mover o êmbolo da seringa a uma distância $d$. Este intervalo de tempo foi calculado utilizando a equação 3.2.

$$
\Delta t=\frac{1}{\text { famostragem }} \cdot \# \text { amostras }
$$

onde famostragem é a frequência de amostragem do IPPR, e \#amostras é o número de amostras obtidas em uma manobra de insuflação. O \#amostras pode ser observado no arquivo final gerado pela plataforma de instrumentação virtual de controle do IPPR.

A velocidade de insuflação $(V e l)$ do IPPR foi avaliada utilizando a equação 3.3. 


$$
V e l=\frac{V o l}{\Delta t}
$$

onde $V o l$ é o volume calculado ao medir a distância $d$ e $\Delta t$ é o intervalo de tempo calculado pela equação 3.2.

Finalmente, para avaliar o volume e a velocidade do IPPR, foram realizados 20 tipos de manobras de insuflação, utilizando quatro volumes distintos $(5 \mathrm{~mL} ; 10$ $\mathrm{mL} ; 20 \mathrm{~mL} ; 40 \mathrm{~mL})$ e cada volume avaliado em cinco velocidades diferentes $(0,01$ $\mathrm{mL} / \mathrm{s} ; 0,05 \mathrm{~mL} / \mathrm{s} ; 0,1 \mathrm{~mL} / \mathrm{s} ; 0,55 \mathrm{~mL} / \mathrm{s} ; 1 \mathrm{~mL} / \mathrm{s}$ ). Cada manobra de insuflação foi repetida 12 vezes, de forma aleatória, entre cada cenário de volume e velocidade. Em cada uma das manobras, foram medidas, com o termo-higrômetro, a temperatura $\left(\operatorname{temp}\left[{ }^{\circ} \mathrm{C}\right]\right)$ e a umidade relativa $(u r[\%])$ durante os ensaios.

Para cada grandeza física medida (d, \#amostras, temp, ur), foi calculada a média aritmética $(\bar{X})$ utilizando a equação 3.4 .

$$
\bar{X}=\frac{\sum_{i=1}^{N} X_{i}}{N}
$$

onde $\sum_{i=1}^{n} X_{i}$ é a soma de todos os valores experimentais medidos e $N$ é o número de medidas.

Além da média aritmética, foi calculada a incerteza padrão da medida, através do cálculo do desvio padrão ( $s$ empregando a equação 3.5 .

$$
s=\sqrt{\frac{\sum_{i=1}^{N}\left(X_{i}-\bar{X}\right)^{2}}{N-1}}
$$

em que $X_{i}$ representa os dados, $\bar{X}$ é a média aritmética do conjunto de dados, e $N$ é o total de dados medidos.

Nos casos em que as grandezas físicas possuem incertezas combinadas, devido aos cálculos matemáticos com variáveis medidas experimentalmente, como é o caso dos índices $\mathrm{Vol}, \Delta t$ e $\mathrm{Vel}$, foi utilizada a equação 3.6 para determinar o desvio padrão da grandeza. 


$$
\Delta s^{2}=\left(\frac{\partial f}{\partial X_{1}}\right)^{2} \cdot\left(s_{X_{1}}\right)^{2}+\left(\frac{\partial f}{\partial X_{2}}\right)^{2} \cdot\left(s_{X_{2}}\right)^{2}+\ldots+\left(\frac{\partial f}{\partial X_{n}}\right)^{2} \cdot\left(s_{X_{n}}\right)^{2}
$$

onde $\Delta s$ é o desvio padrão da incerteza combinada, $f$ é função utilizada para calcular o valor de interesse $(V o l, \Delta t, V e l) . X_{1}, X_{2}, \ldots, X_{n}$ e $s_{X_{1}}, s_{X_{2}}, \ldots, s_{X_{n}}$ são respectivamente as variáveis independentes da função $f$ e os desvios padrões das variáveis independentes correspondentes.

Por último, foi calculado o erro sistemático percentual $\left(E_{S}\right)$ da insuflação a velocidades lentas do IPPR utilizando a equação 3.7.

$$
E_{S}=100 \cdot \frac{\left(\bar{X}-X_{T}\right)}{X_{T}}
$$

onde $\bar{X}$ é a média aritmética do conjunto de dados e $X_{T}$ é o valor teórico da grandeza medida (BALBINOT, BRUSAMARELLO, 2010a).

Todos os ensaios foram realizados no LEB da EPUSP.

\subsubsection{Avaliação de pressão do IPPR}

O objetivo deste protocolo experimental foi avaliar o comportamento do módulo de transdução de pressão do IPPR. O IPPR utiliza o módulo de transdução de pressão para transformar o sinal de pressão manométrica em um sinal elétrico adequado para ser salvo no microcomputador.

O módulo de transdução de pressão possui, além dos terminais de comunicação, a possibilidade de ajustar o ganho $(G)$ e o nível DC (off-set).

Para esta avaliação, se utilizou, além do módulo de transdução de pressão, um manômetro de água do tipo tubo em U e um multímetro digital (HT-2000, HIKARI, Brasil). Na Figura 3.7,pode ser observado um desenho e uma fotografiada montagem definida para avaliar, em diferentes condições controladas, o comportamento do módulo de transdução de pressão, ao medir a tensão elétrica de 
saída (Ts $[\mathrm{V}])$ com o multímetro digital, correspondente à pressão $\left(P\left[\mathrm{cmH}_{2} \mathrm{O}\right]\right)$ calibrada no manômetro de coluna de água auxiliar.

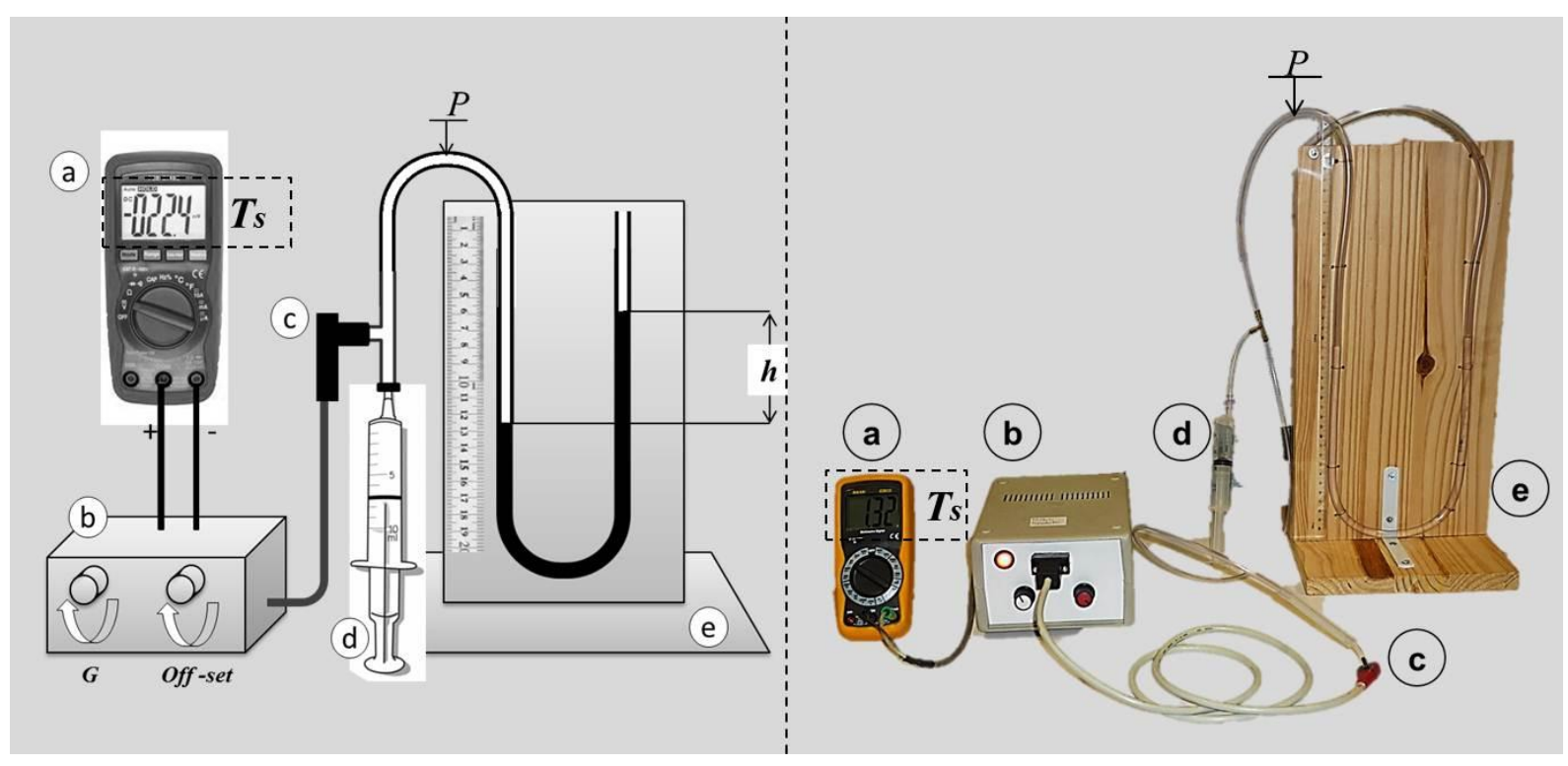

Figura 3.7 - Esquema explicativo da montagem para avaliação de pressão do IPPR. a) Multímetro digital, b) Módulo de transdução de pressão conectado ao transdutor de pressão (c), d) Seringa auxiliar, e) Manômetro de coluna de água auxiliar.

A montagem observada na Figura 3.7consiste em assegurar, com o manômetro de coluna de água (e) e a seringa auxiliar (d), uma pressão constante conhecida que possa ser medida pelo transdutor de pressão (c). Esta pressão constante é transformada pelo transdutor de pressão em um sinal elétrico, facilitando sua aquisição e seu monitoramento na saída do módulo de transdução de pressão (b) com ajuda de um multímetro digital (a). Este sinal elétrico de saída pode ser ajustado através dos botões ganho e off-set antes de cada experimentação.

O manômetro de pressão de coluna de água é um medidor mecânico de pressão estática, baseado na equação de volume da equação 3.8:

$$
P=h \cdot \rho \cdot g
$$

onde $P$ é a pressão exercida pelo peso da coluna de água com massa específica $(\rho)$ e de altura $h$ observada na Figura 3.7, por ação da força da gravidade $g$.

Neste trabalho, se utilizou a nomenclatura de pressão manométrica em centímetros de água $\left(\mathrm{cmH}_{2} \mathrm{O}\right)$ para se referir à pressão manométrica $P$. 
Considera-se como uma repetição de medida a incursão em passos progressivos de $4 \mathrm{cmH}_{2} \mathrm{O}$ de pressão ajustados com a seringa, ao ir e voltar desde o valor mínimo no manômetro de pressão até a escala máxima possível.

Foram realizadas 24 repetições com dois transdutores de pressão diferentes $(S n 1)$ e $(S n 2)$. Para cada transdutor, se realizaram aleatoriamente 12 repetições com ganho mínimo (Gmín) e 12 repetições com ganho máximo (Gmáx). Também foram monitoradas, em cada repetição, a temperatura (temp $\left[{ }^{\circ} \mathrm{C}\right]$ ) e a umidade relativa (ur [\%]) do local de ensaio, com ajuda de um termo-higrômetro (MT-242, Minipa, China).

Para o conjunto de repetições com parâmetros experimentais iguais ( $G$ e $S n)$, foram calculados a média aritmética e o desvio padrão (erro aleatório) da tensão elétrica de saída $(T S)$ com a equação 3.4 e a equação 3.5 , respectivamente.

Além dos dados anteriores, foi realizada uma regressão linear, com o intuito de avaliar a relação entre a variável independente $T s$ e a variável dependente $P$, medida pelo módulo de transdução de pressão. Esta regressão linear se realizou aplicando o critério de mínimos quadrados, ajustando os dados experimentais a uma reta da forma da equação 3.9 .

$$
T s=a \cdot P+b
$$

onde $a$ é o coeficiente angular e $b$ o coeficiente linear da reta. O parâmetro $a$ foi determinado pela equação 3.10 (BALBINOT, BRUSAMARELLO, 2010b).

$$
a=\frac{N \cdot \sum P \cdot T s-\sum P \cdot \sum T s}{N \cdot \sum P^{2}-\left(\sum P\right)^{2}}
$$

onde $N$ é o número de repetições.E $b$ pode ser estimado utilizando a equação 3.11

$$
b=\frac{\sum T s \cdot \sum P^{2}-\sum P \cdot \sum P \cdot T s}{N \cdot \sum P^{2}-\left(\sum P\right)^{2}}
$$

Também foi calculado o coeficiente de correlação $\left(R^{2}\right)$. Este índice indica a relação linear entre duas variáveis aleatórias quantitativas. $R^{2}$ é calculado ao utilizar 
a equação de Pearson (BALBINOT, BRUSAMARELLO, 2010b) apresentada na equação 3.12 .

$$
R^{2}=\left(\frac{N \cdot\left(\sum x \cdot y\right)-\sum x \cdot \sum y}{\sqrt{\left[N \cdot \sum x^{2}-\left(\sum x\right)^{2}\right] \cdot\left[N \cdot \sum y^{2}-\left(\sum y\right)^{2}\right]}}\right)^{2}
$$

onde $N$ é o número de amostras, x e y são, respectivamente, os valores de tensão elétrica medidos e os estimados pela regressão linear.

Calculou-se o máximo desvio de tensão elétrica ao se achar a porcentagem de linearidade (Lin\%) do módulo de transdução de pressão com a equação 3.13.

$$
\operatorname{Lin} \%=100 \cdot \frac{D i f_{\text {max }}}{F E_{s}}
$$

Onde Dif $_{\text {máx }}$ indica a maior diferença entre a tensão elétrica medida, e o valor médio calculado, e $F E_{s}$ indica o fundo de escala da saída.

Foi estimada a sensibilidade $(S)$ do transdutor de pressão com a equação 3.14:

$$
S=\frac{\Delta T S}{\Delta P}
$$

onde $\Delta T s$ é a razão de variação de tensão elétrica na saída do módulo de transdução de pressão e $\Delta P$ indica a razão de variação de pressão na entrada do módulo.

Por último, foi calculada a resolução de medida de pressão do IPPR (Res_Pr), em $\mathrm{cmH}_{2} \mathrm{O} /$ bit. A resolução do IPPR está relacionada com as especificações do conversor análogo digital (A/D), integrado no módulo de controle e aquisição de sinais, calculado pelo índice $R_{A D}$ da equação 3.15 e pela relação pressão de entrada $\left(F E_{E}\right)$ e tensão elétrica de saída $\left(F E_{S}\right)$ imposta pelo módulo de transdução de pressão.

$$
R_{A D}=\frac{V_{\text {faixa.entrada }}}{2^{\text {N.bits }}-1}
$$


Na equação $3.15, R_{A D}$ é a resolução do conversor (A/D), $V_{\text {faixa.entrada }}$ é o valor da amplitude da faixa nominal de entrada e N.bits é o número de bits de entrada do conversor (A/D). Assim, a resolução do IPPR de medida de pressão (Res_Pr) foi calculada usando a equação3.16:

$$
R e s_{-} P r=R_{A D} \cdot \frac{F E_{E}}{F E_{S}}
$$

Todos os ensaios foram realizados no LEB da EPUSP.

\subsection{AMR DE MODELO ANIMAL DE DOENÇA PELO MÉTODO QUASI- ESTÁTICO}

Esta seção explica em detalhes o protocolo experimental, desenvolvido para AMR, pelo método quasi-estático em roedores de pequeno porte envenenados por Paraquat. O protocolo é apresentado resumidamente sob a forma de diagrama de blocos na Figura 3.8.

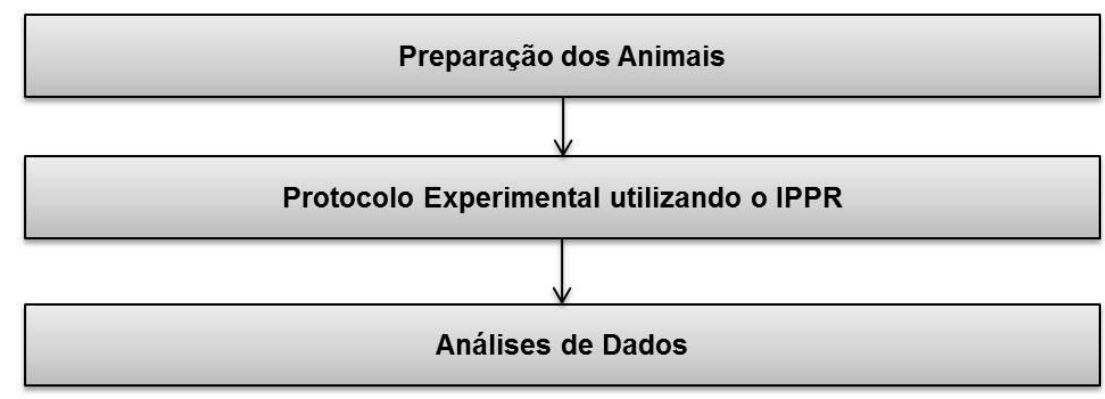

Figura 3.8 - Diagrama de blocos do protocolo experimental para AMR em roedores.

O protocolo de AMR em roedores foi desenvolvido no LIM 05 da FMUSP. A seguir,será descrito cada um dos blocos apresentados. 


\subsubsection{Preparação dos animais}

Para o experimento realizado nesta pesquisa, foram utilizados ratos machos da linhagem Wistar, não-SPF (do inglês specific pathogen free), provenientes do Biotério da FMUSP. Estes animais receberam cuidados de acordo com as normas estabelecidas no Guide for the Care and Use of Laboratory Animal (Institute of Laboratory Animal Resources National Academy of Sciences, Washington, D.C., 1996) e seguindo os Princípios Éticos na Experimentação Animal da legislação brasileira e do Colégio Brasileiro de Experimentação. Este protocolo com animais foi incluído no projeto de pesquisa número CAPPesq 0908/07, aprovado pela CAPPesq da Diretoria Clínica do Hospital das Clínicas da FMUSP.

Os animais disponíveis para experimentação foram divididos, de forma aleatória, em dois grupos de quantidades iguais, nomeados assim: grupo controle (CTR) e grupo Paraquat (PRQ).

O grupo PRQ está relacionado ao modelo animal de doença por envenenamento com Paraquat (1,1' dimetil-4,4' bipiridilo dicloro). O Paraquat é um herbicida que causa instabilidade alveolar, provocando a destruição das células produtoras de surfactante pulmonar existentes na interface ar-líquido. O herbicida Paraquat pertence ao grupo dos bipiridílicos e tem de ampla utilização na agricultura de países em vias de desenvolvimento, incluindo o Brasil, devido a sua ampla disponibilidade e a seu baixo custo. $O$ efeito colateral de tal herbicida pode comprometer a quase todos os níveis de nosso organismo, mas se destaca de forma especial nas deficiências respiratórias, sendo responsável por grande parte dos casos de falecimento por insuficiência pulmonar (ALVAREZ, B.; ROSADO, L.; BERENGGGUER, 1998).

Assim, o grupo $P R Q$ recebeu dicloreto de paraquat de forma intraperitoneal, dissolvido em solução salina ( $\mathrm{NaCl}$ 0,9\%), em uma dose de $25 \mathrm{mg} / \mathrm{kg}$. O grupo CTR recebeu somente solução salina com dose de $1 \mathrm{~mL} / \mathrm{kg}$.

Após 24 horas, os animais foram pesados e anestesiados com xilazina $2 \%$ (0,5 mL/kg ip) e $10 \%$ de ketamina ( $0,9 \mathrm{~mL} / \mathrm{kg}$ ip).

Sob efeito da anestesia, os animais foram exsanguinados pela secção dos grandes vasos abdominais, através de incisão longitudinal do abdômen. Em seguida, o tórax foi aberto com uma transecção do diafragma abdominal,obtendo-se, 
assim,a exposição total dos pulmões. Em seguida foi feita a traqueostomia por incisão no pescoço do animal, para exposição da traqueia; nela foi feito um corte pelo qual foi passada a cânula metálica (14 gauge) e fixada por amarração com fio de sutura do tipo algodão 3,0. Um exemplo de um animal já preparado para experimentação se observa na Figura 3.9.

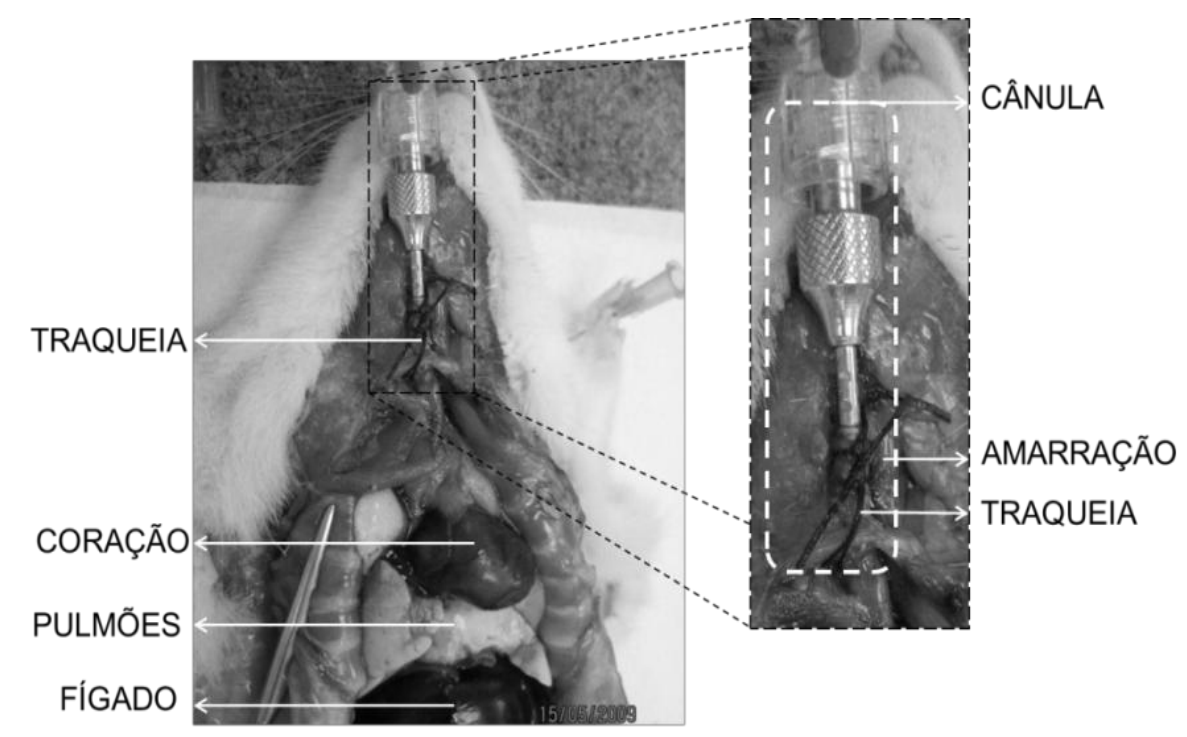

Figura 3.9 - Fotografia de um animal CTR preparado e acoplado ao IPPR.

Na Figura 3.9, do lado esquerdo, observa-se um animal do grupo CTR com os pulmões expostos e, do lado direito, observa-se, de forma ampliada, o acoplamento da cânula com as vias áreas do animal mediante amarração.

\subsubsection{Protocolo experimental utilizando o IPPR}

No protocolo experimental, são apresentados os processos relacionados à montagem,à preparação do IPPR e ao tipo de acoplamento realizado entre o equipamento e o roedor.

A montagem e a preparação do IPPR são fundamentais para a obtenção de curvas P-V condizentes com as propriedades mecânicas respiratórias do animal. Assim sendo, neste procedimento, se calibram os instrumentos de medição e controle, fazendo uso do software desenvolvido em plataforma de instrumentação 
virtual (LabVIEW 8.5, National Instruments, EUA) no microcomputador, e se configuram as condições próprias da experimentação.

De igual modo, neste processo, se deve acoplar o IPPR ao animal, de forma confiável, para assegurar a transferência de ar da seringa para o SR do animal, mantendo-se a pressão gerada pelo tecido pulmonar.

\subsubsection{Montagem e configuração do IPPR}

Este protocolo foi executado aproximadamente 1 hora antes de atingir as 24 horas necessárias para que os animais dos grupos CTR e PRQ fossem considerados prontos para experimentação, segundo o apresentado na seção 3.3.1 sobre modelo animal de doença.

A preparação do IPPR foi realizada sequencialmente, seguindo o diagrama de blocos da Figura 3.10:

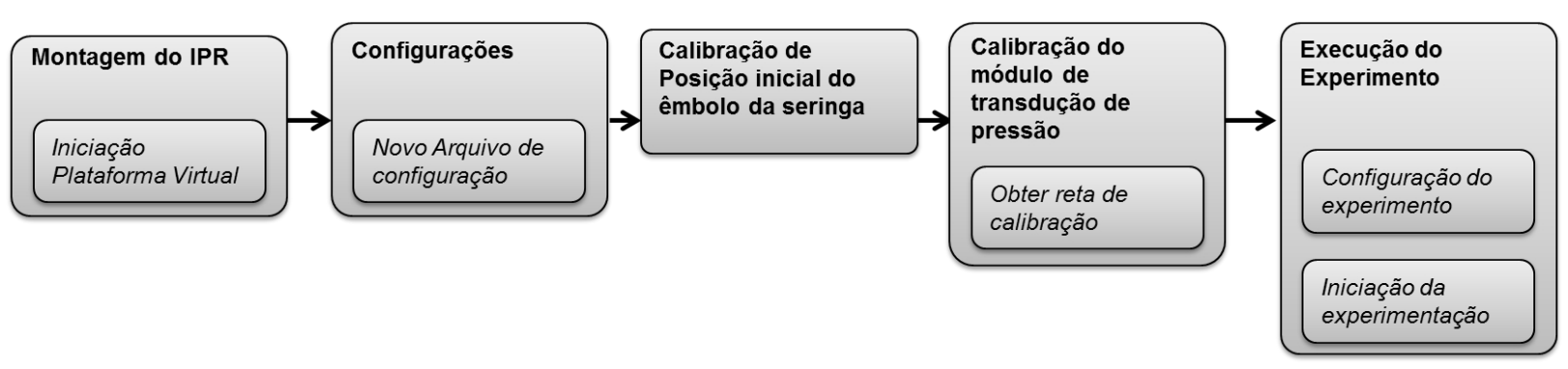

Figura 3.10 - Diagrama de blocos dos processos de preparação do IPPR

A montagem deve ser realizada em um local adequado para experimentação com animais. É indispensável fixar os cabos de conexão entre os módulos, assim como também os cabos à rede elétrica (de $127 \mathrm{~V}-60 \mathrm{~Hz}$ ), de forma segura. Os módulos devem estar sobre uma superfície estável e nivelada. Neste estudo, foi utilizada uma bancada ampla; adicionalmente, foram usadas duas bandejas de altura regulável (LabJack, Fisatom, Brasil), para deixar, na mesma altura,o módulo mecânico e abandeja com o roedor preparado para experimentação.

Após a preparação do espaço adequado e dos equipamentos necessários, foram realizadas as conexões entre os módulos e o computador, deixando por último a conexão à rede elétrica. 
Depois de energizados os módulos, aguardou-se aproximadamente trinta minutos, com a intenção de alcançar o equilíbrio térmico dos componentes eletrônicos de cada módulo. Uma visão da montagem e da preparação do IPPR, com exceção do animal para experimentação, se observa na Figura 3.11.

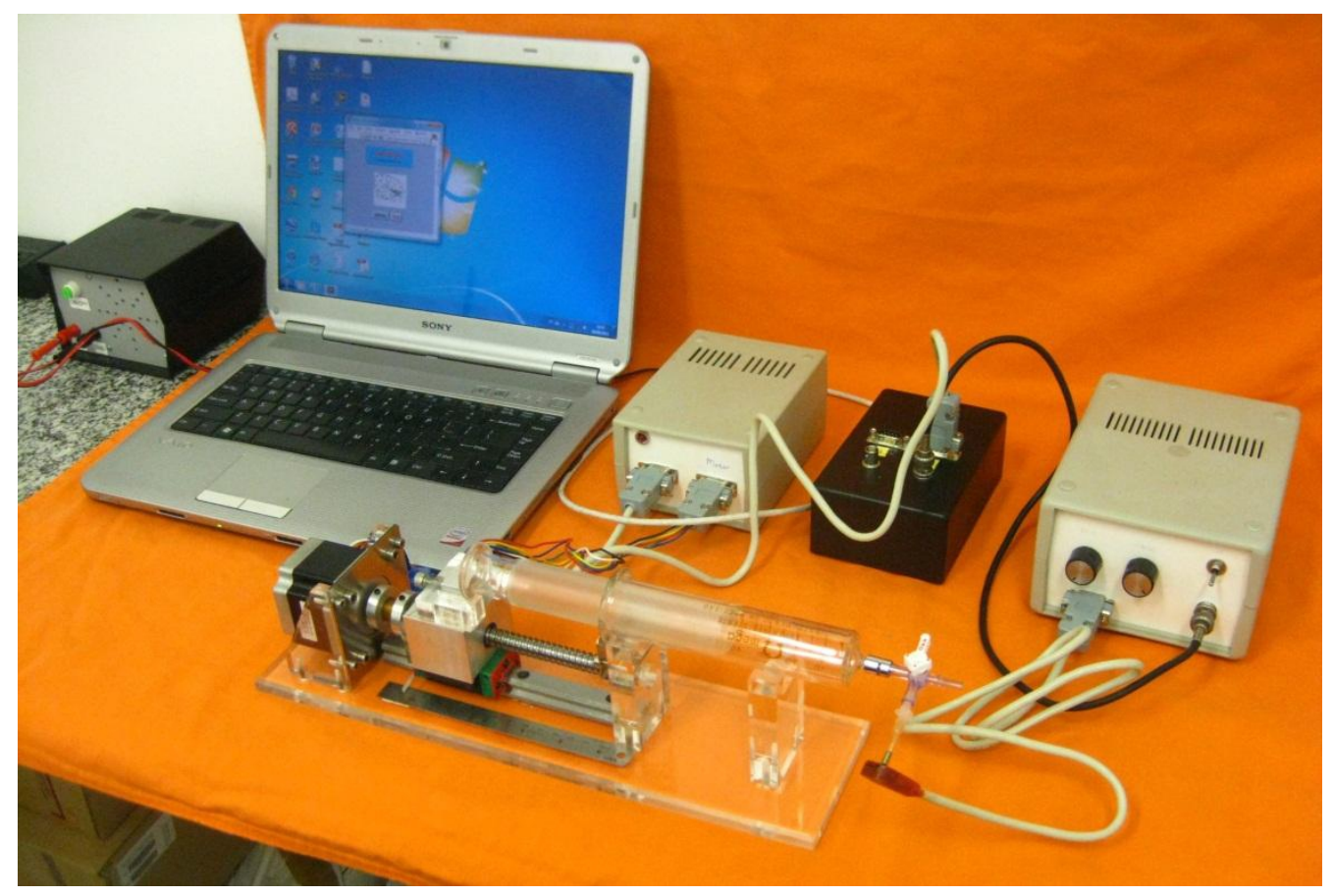

Figura 3.11 - Fotografia do IPPR em funcionamento.

Passado este intervalo de tempo, procedeu-se à iniciação no microcomputador do software de controle e aquisição de dados do IPPR e, em seguida, foi realizada a configuração do IPPR.

Esta configuração consistiu em carregar e calibrar os parâmetros de experimentação para a AMR pelo método quasi-estático no software disponível no microcomputador.

A configuração do IPPR está relacionada ao fornecimento dos parâmetros adequados de funcionamento do módulo de potência e, por conseguinte, do acionamento do módulo mecânico, especificamente do motor de passos do IPPR e do tipo de seringa utilizada. A tela do software na qual as informações são carregadas é observada na Figura 3.12. 


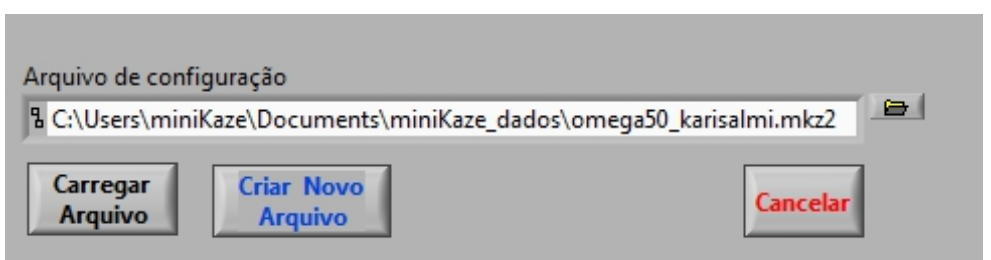

Figura 3.12 - Janela para a configuração do módulo de potência

Nesta janela, existem três possibilidades:

- $\quad$ Carregar Arquivo, esta opção carrega um arquivo predeterminado no qual se encontram os parâmetros de configuração necessários para 0 funcionamento do IPPR; este arquivo contém as informações necessárias para o funcionamento correto do módulo de potência e do módulo mecânico (motor de passos e seringa)

- $\quad$ Criar Novo Arquivo, quando selecionada esta opção, são cadastradas diversas informações em um formato padrão predefinido; depois de cadastradas as informações, os dados são salvos em local do disco rígido definido pelo usuário

- $\quad$ Cancelar sai desta tela e retorna à tela inicial de experimentação

Ao selecionar uma das duas primeiras opções anteriores, os parâmetros configurados para experimentação para o IPPR por método quasi- estático são:

- $\quad$ Nome da seringa: Omega 50

- $\quad$ Número de passos por mililitro: 80

- $\quad$ Número de passos por cm (índice $d$ ): 500

- $\quad$ Controlador do motor: Karisalmi

- $\quad$ Modo: Full

- $\quad$ Power: High

- Pasta de localização dos dados finais: d:Vocalização_do_usuário

Estes parâmetros são salvos em um arquivo tipo texto (txt); uma imagem deste arquivo se observa na Figura 3.13. 


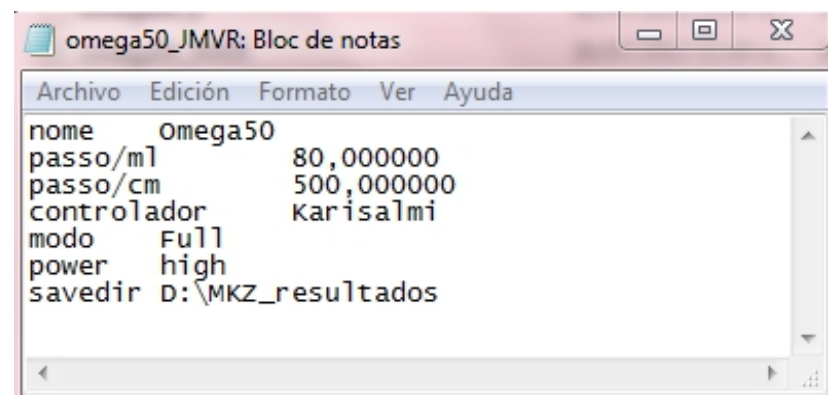

Figura 3.13 - Imagem do arquivo de configuração do IPPR

Logo que são carregadas as configurações, procede-se à calibração da posição inicial do êmbolo da seringa na posição de Cins_IPPR; na Figura 3.14, é apresentada a tela do software na qual realiza-se esta tarefa.

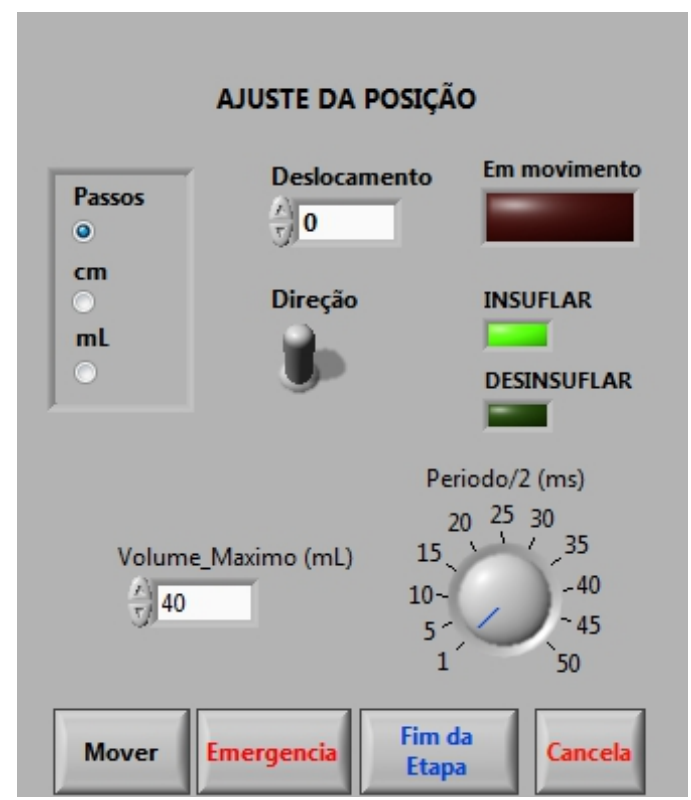

Figura 3.14 - Janela para o ajuste da posição do êmbolo da seringa

Esta janela fornece diversas opções para definir a posição inicial do êmbolo, isto propicia grande flexibilidade na operação de posicionamento do êmbolo da seringa controlada pelo computador.

As opções de atuação com o IPPR, mostradas na Figura 3.14, podem ser selecionadas para variar o sentido e a velocidade do deslocamento do êmbolo da seringa (Insuflar, Desinsuflar). Além disso, o deslocamento em si pode ser realizado fornecendo-se o número de passos a ser realizado pelo motor ou a distância em centímetros $(\mathrm{cm})$ ou o volume em mililitros $(\mathrm{mL})$.

A opção Volume_Máximo $(m L)$ é preenchida como variável de segurança para não exceder do volume de insuflação máximo permitido por IPPR. 
A opção "Emergência" cancela automaticamente qualquer manobra em execução. O botão "Mover" executa a ação programada. "Cancelar" fecha esta tela e volta para a tela da Figura 3.12. A opção "Fim da Etapa" salva automaticamente a posição final na qual foi deixado o êmbolo da seringa, e o volume máximo permitido, e continua com a configuração seguinte do IPPR.

Conforme a sequência do diagrama de blocos da Figura 3.10, continua-se com a configuração do módulo de transdução de pressão. Na Figura 3.15, são ilustradas as opções que o usuário tem para calibrar o módulo de transdução de pressão.

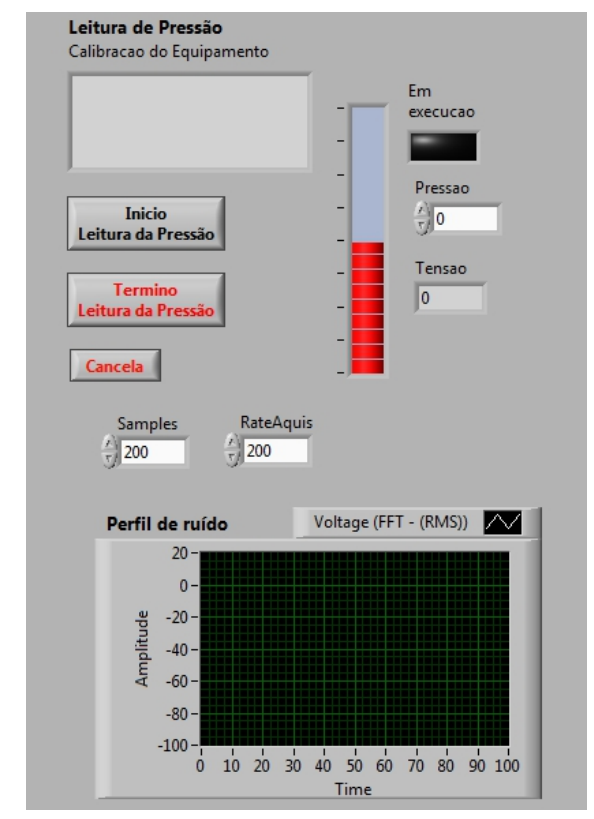

Figura 3.15 - Janela para a calibração do módulo de transdução de pressão

A calibração do módulo de transdução de pressão é executada mediante o registro de quatro pontos consecutivos de pressão, utilizando um manômetro de coluna de água auxiliar acoplado ao módulo de transdução de pressão, como pode ser observado na Figura 3.16. 


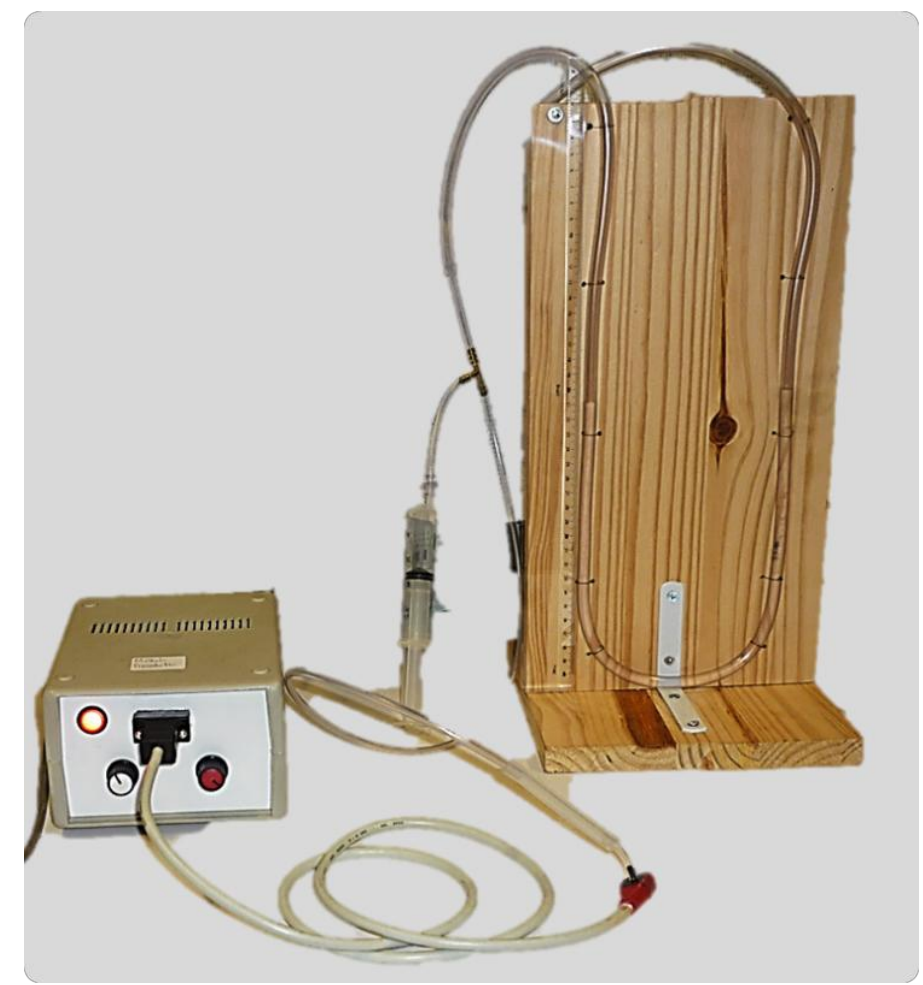

Figura 3.16 - Fotografia do módulo de transdução de pressão acoplado ao manômetro auxiliar, necessários para a calibração de pressão do IPPR.

O sistema funciona ao selecionar, na janela da Figura 3.15, a opção "Início de Leitura de Pressão". Quando é selecionada esta opção, o programa salva o sinal medido pelo transdutor de pressão ao selecionar a função "Término Leitura de Pressão". Desta forma, são salvos quatro pontos diferentes de pressão: 0, $816 \mathrm{e}$ $20 \mathrm{cmH}_{2} \mathrm{O}$, aplicados no transdutor de pressão com ajuda do manômetro de pressão.

Depois de realizadas as quatro aquisições, o sistema automaticamente realiza uma regressão linear para determinar a reta de calibração do módulo de transdução de pressão. Seguindo a equação 3.17 :

$$
P=a \cdot T e+b
$$

onde $T e$ é a tensão elétrica de entrada e $P$ é pressão. $a$ e $b$ são constantes que definem o comportamento do transdutor

Concluída a calibração do módulo de transdução de pressão, abre-se a janela de aquisição de dados, observada na Figura 3.17. 


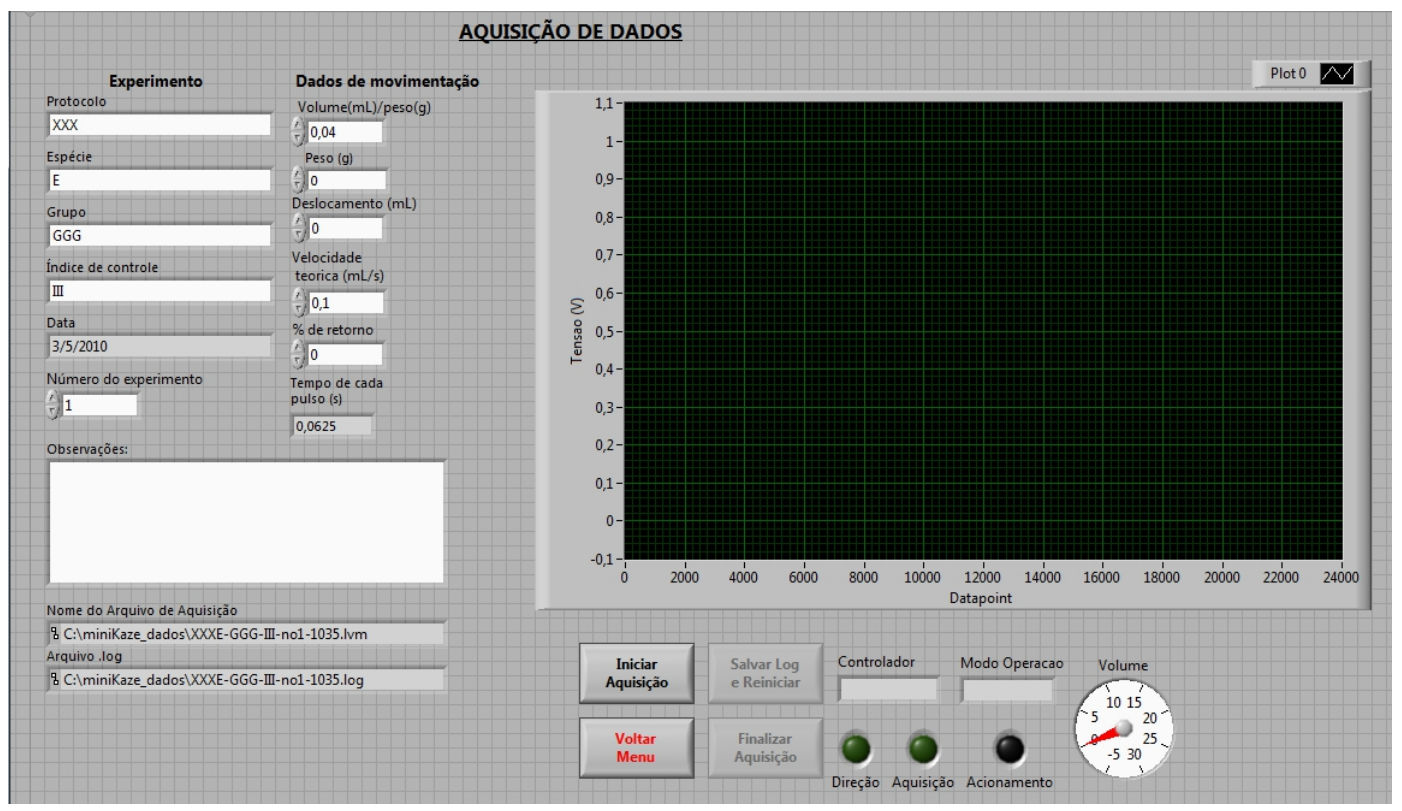

Figura 3.17 - Janela virtual para a configuração de execução do experimento com o IPPR

Nesta janela, são configurados os dados correspondentes à identificação do experimento de AMR: nome do protocolo experimental, data e número do experimento. Também é configurado o tipo de manobra de insuflação pulmonar, podendo-se modificar a velocidade, o volume e o deslocamento. Para este tipo de AMR foi configurada a insuflação a $0,1 \mathrm{~mL} / \mathrm{s}$ e $40 \mathrm{~mL}$ de ar.

Antes de começar a experimentação com animais, é preciso realizar o acoplamento entre o IPPR e o animal, este processo é apresentado a seguir.

\subsubsection{Acoplamento do IPPR e do animal}

Esta seção explica o método de conexão entre o IPPR e o animal, através de uma chave de fechamento de três vias. Esta peça rígida possibilita a transferência de ar do tambor da seringa do IPPR para as vias aéreas do SR do roedor e também proporciona a ligação do transdutor de pressão.

A chave de fechamento de três vias, e suas conexões, é apresentada na Figura 3.18. 


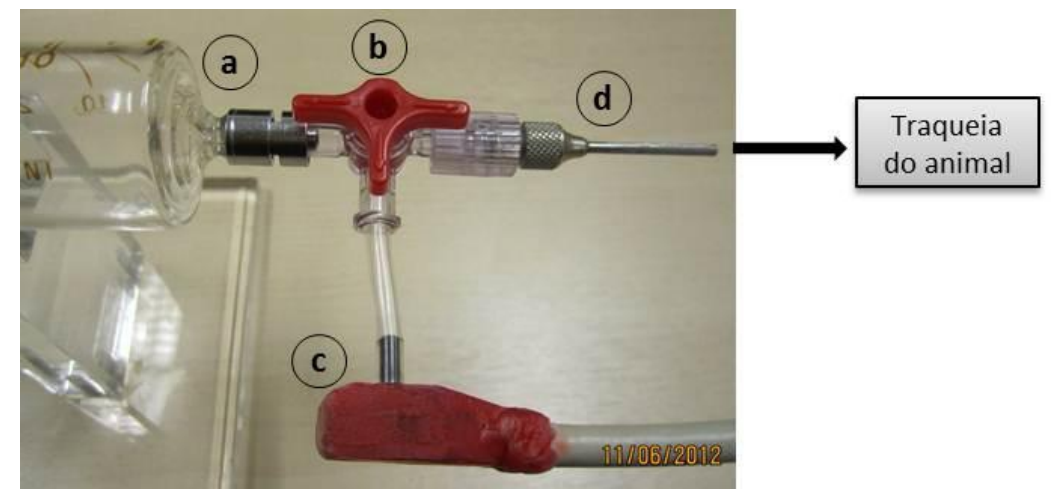

Figura 3.18 - Diagrama explicativo da chave de fechamento de três vias e suas ligações. a) Seringa, b) Chave de fechamento de três vias, c) Transdutor de pressão, d) Cânula.

A chave de fechamento de três vias se acopla com a seringa, com a cânula e com o transdutor de pressão, assegurando a passagem do incremento de volume de ar para o SR do rato e mantendo o mesmo nível de pressão entre a seringa, o SR e o transdutor de pressão, conforme Figura 3.19.

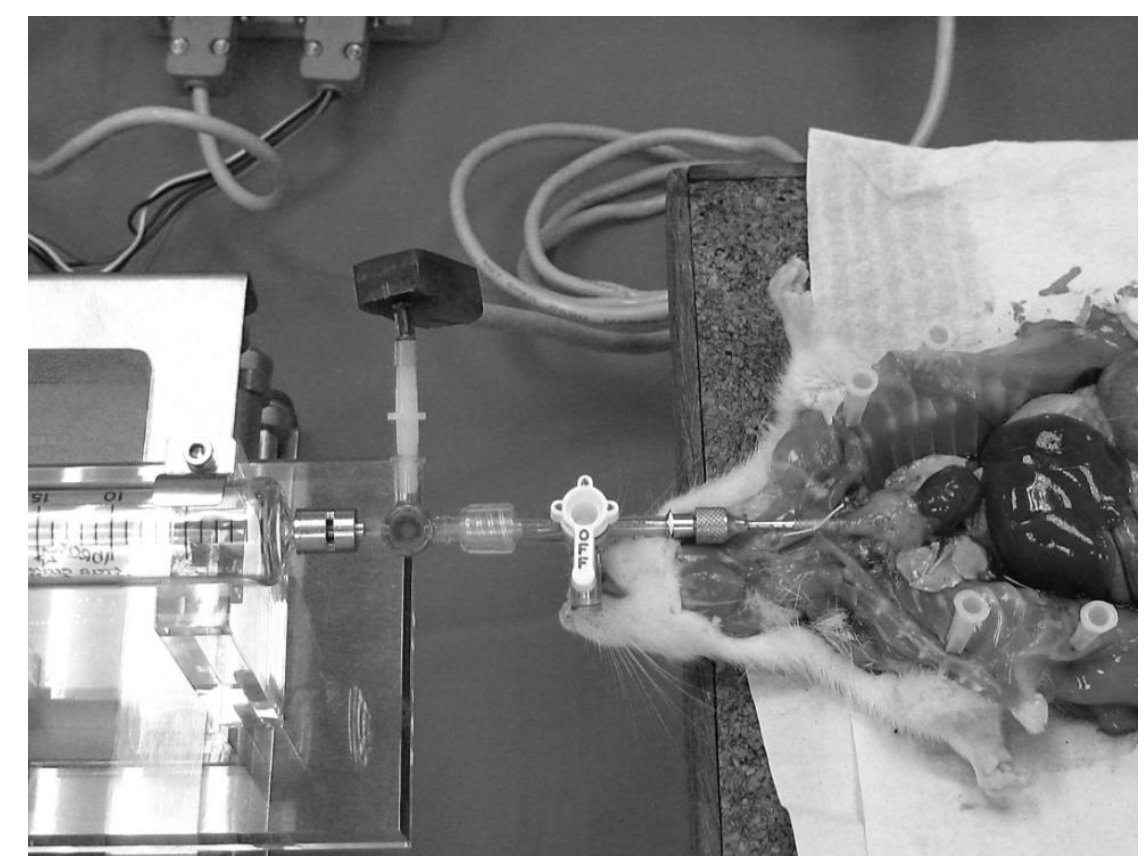

Figura 3.19 - Figura da AMR de roedor utilizando o IPPR

Assegurado o acoplamento, continuou-se com a AMR para os 20 animais, insuflando cada animal na mesma ordem em que foram identificados no protocolo de manipulação de animais. 


\subsubsection{Execução do experimento}

Após montagem, a calibração e o acoplamento do IPPR ao animal, selecionase a opção Iniciar Aquisição na tela da Figura 3.17. Desta forma, carregam-se as configurações pertinentes para experimentação, para controlar o módulo mecânico e adquirir o sinal de pressão.

Antes de iniciar de fato a experimentação, o software de controle pede ao usuário a confirmação de algumas condições fundamentais para assegurar o bom funcionamento do IPPR, como: posicionamento correto do êmbolo da seringa, índice de experimentação correta e fonte de alimentação acionada.

Ao iniciar o experimento, é possível controlar a execução do IPPR, permitindo iniciar, finalizar e cancelar a insuflação. Também pode-se observar, em tempo real, os dados adquiridos de pressão, ao se observar, na tela do microcomputador, a curva de pressão versus tempo.

Durante este intervalo de tempo, o microcomputador envia os comandos de ação para o motor de passo e realiza a aquisição da pressão pulmonar do roedor. Deve-se evitar qualquer tipo de perturbação externa à experimentação, especificamente as relacionadas aos processos adicionais do microcomputador, estes processos podem gerar variações nos valores de pressão medidos e dos pulsos de controle do motor de passos.

Uma vez terminada o processo de insuflação, pode-se, após o desacoplamento do animal, realizar o retorno do êmbolo da seringa na posição inicial de Cins_IPPR.

Terminada a experiência, os dados de pressão e volume são salvos no microcomputador em arquivos (tipo texto e tipo html), enquanto os dados das curvas P-V são salvos em formato de imagem tipo bmp,para posterior análise de dados. 


\subsubsection{Análise de dados}

Este processo é de grande importância na AMR, porque nele é realizada a análise estatística e, como consequência, são determinadas as diferenças entre a mecânica respiratória de animais normais e daqueles sob efeito de Paraquat.

Os dados das curvas P-V, obtidos com o IPPR pelo método quasi-estático, segundo explicado no Capítulo 2, podem ser ajustados a modelos matemáticos. Para isto, o IPPR facilita a manipulação dos dados, ao dispor dos resultados P-V de cada experimentação no formato $\mathrm{html}$ e no formato de texto, além de figuras em formato bmp de rápida consulta. Um exemplo de uma curva P-V adquirida pelo IPPR é apresentado na Figura 3.20.

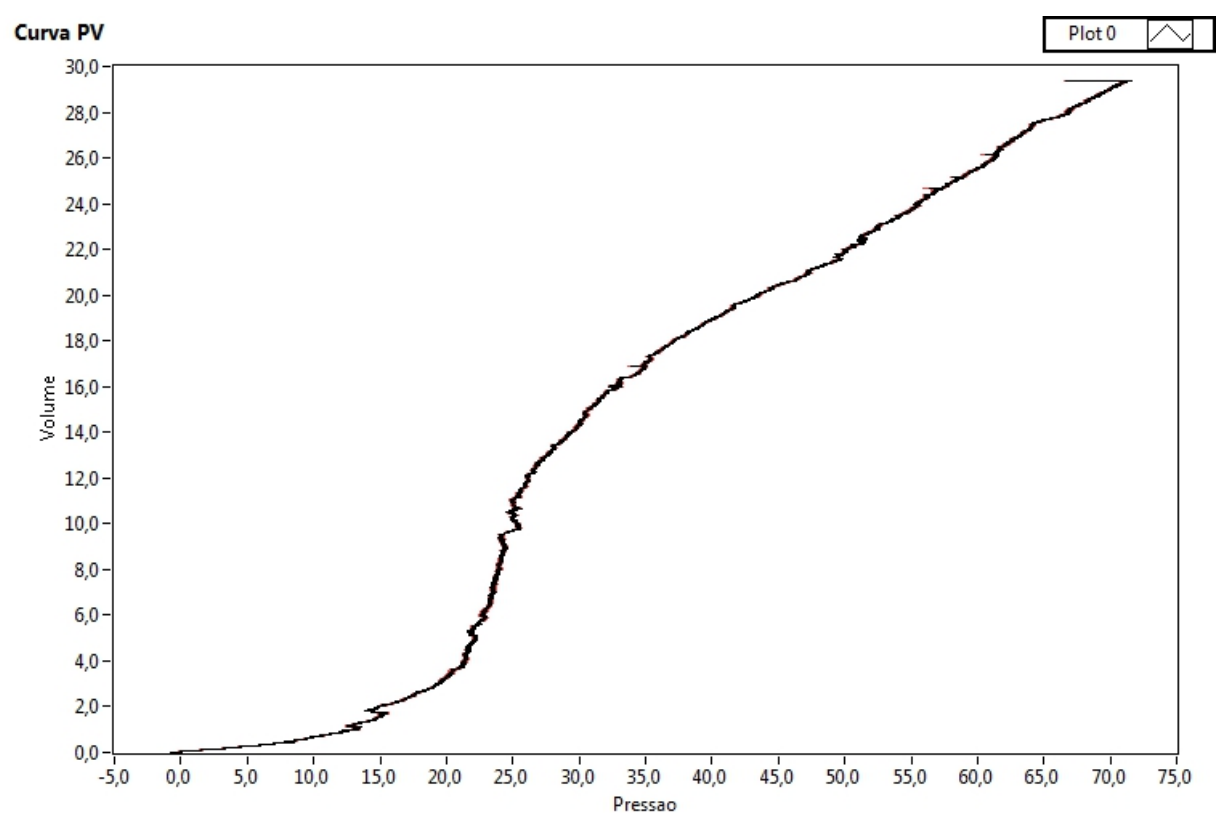

Figura 3.20 - Curva P-V de um animal do grupo CTR utilizando o IPPR.

Neste trabalho, os dados foram analisados usando uma plataforma de programação matemática (MATLAB, The Mathworks, EUA). Nesta plataforma, foram importados e analisados os dados de pressão e volume de cada experimentação. $O$ sistema implementado para a análise de dados segue a ordem exposta no diagrama de blocos da Figura 3.21. 


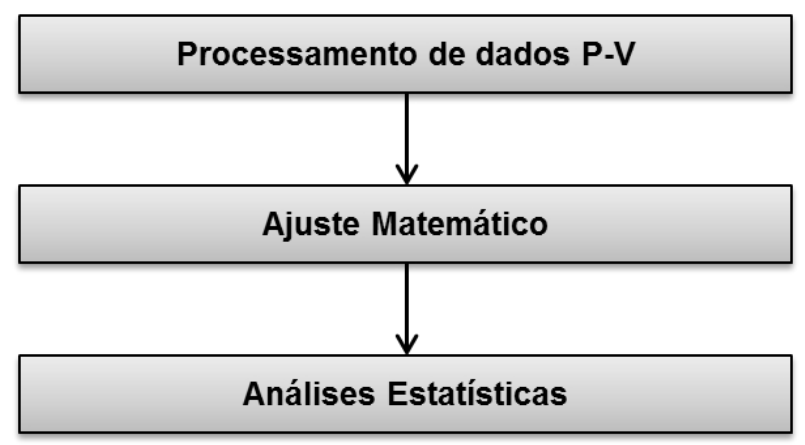

Figura 3.21 - Diagrama de blocos dos processos realizados para a análise de dados obtidos pelo IPPR.

Em primeiro lugar, são importados os dados originais de cada animal para o software, fazendo uso de programação computacional. Neste programa, também se realiza a filtragem dos dados originais, implementando um filtro digital passa-baixas de média móvel, para diminuir o erro influenciado por altas frequências.

Optou-se por adotar o critério proposto por Glaister et. al (1973) e, assim sendo, os dados $\mathrm{P}-\mathrm{V}$ foram analisados somente para valores de pressão até a CPT_aprox $\left(35 \mathrm{cmH}_{2} \mathrm{O}\right)$.

O limite inferior da pressão para ajuste foi variado entre $50 \%$ e $100 \%$ da CPT,conforme apresentado por Colebatch, $\mathrm{Ng}$ e Nikov (1979). Para isto, foram processados 10 intervalos de dados de $\mathrm{P}-\mathrm{V}$. O primeiro intervalo de dados de $\mathrm{P}-\mathrm{V}$ foi limitado para pressões entre $32,5 \mathrm{cmH}_{2} \mathrm{O}$ e $35 \mathrm{cmH}_{2} \mathrm{O}$. O segundo intervalo foi limitado entre $30 \mathrm{cmH}_{2} \mathrm{O}$ e $35 \mathrm{cmH}_{2} \mathrm{Oe}$ assim sucessivamente até o limite inferior de $10 \mathrm{cmH}_{2} \mathrm{O}$.

Para cada intervalo de dados, se fez o ajuste matemático da equação 2.11, utilizando o algoritmo interativo de otimização de Levenberg-Marquardt (LMA na sigla em inglês). Este algoritmo calcula os índices matemáticos da equação 2.11,ao minimizar a soma do erro quadrático do ajuste. Foram obtidos os valores dos índices $A, B$ e, $K$ para cada intervalo, além do coeficiente de correlação $R^{2}$ calculado pela equação 3.12 .

Foi escolhido, como sendo o intervalo de dados que seria considerado para análise, aquele que tivesse o maior número de dados experimentais e mantivesse $o$ coeficiente de correlação $R^{2}$ maior ou igual a 0,99.

Após do ajuste matemático,foi realizada a análise estatística dos índices $A, B$, $K$, e $h$. Analisaram-se os dados utilizando um pacote estatístico (XLSTAT 7.5.2, Addinsoft SARL, EUA) para um software de planilha eletrônica (Excel14.0.6, 
Microsoft, EUA). Os índices do ajuste exponencial foram submetidos a testes estatísticos de normalidade Shapiro-Wilk, Jarque-Bera e Anderson Darling, com nível de significância alfa de 0,05. Comprovada a normalidade dos índices calculados, se compararam as diferenças do grupo CTR e PRQ por teste estatístico t-student (Unpaired t-Test) com nível de significância alfa de 0,05. 


\section{RESULTADOS}

Neste capítulo, serão descritos os resultados referentes a:

a) Documentação do IPPR

b) Testes de bancada do IPPR

c) AMR de modelo animal de doença pelo método quasi-estático

\subsection{INSUFLADOR PULMONAR PARA PEQUENOS ROEDORES (IPPR)}

Nesta seção, apresenta-se a documentação dos módulos do IPPR. Esta documentação foi desenvolvida com ajuda dos softwares de desenho gráfico 3D (3D Max, Autodesk, EUA), AutoCAD (Autodesk, EUA) e software de simulação de circuitos elétricos Multisim (Multisim Education Version, National Instruments, EUA).

\subsubsection{Módulo mecânico}

O módulo mecânico é composto basicamente por um motor de passo, um fuso cilíndrico de esferas e uma guia linear com seu trilho. Além disso, possui uma base de acrílico, acoplamentos e uma seringa de vidro de $50 \mathrm{~mL}$. Estas peças estão interconectadas umas com as outras seguindo o diagrama de blocos encontrado na Figura 4.1.

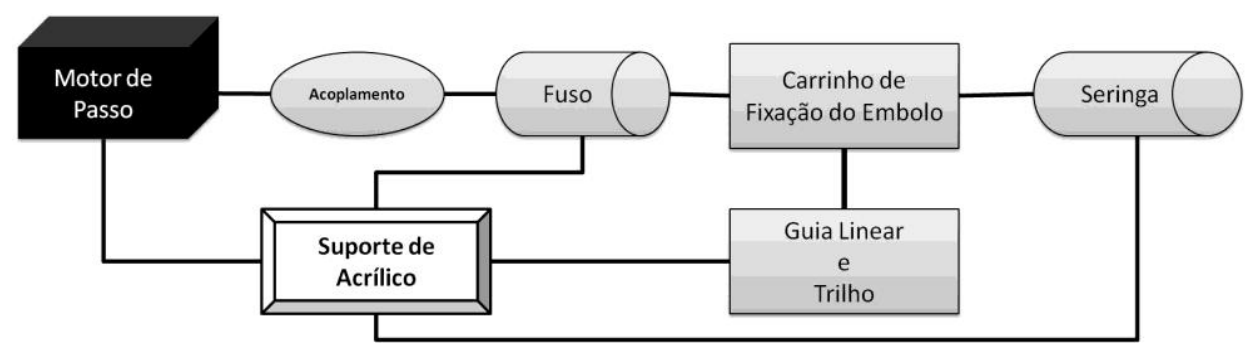

Figura 4.1 - Diagrama de blocos do módulo mecânico 
As seguintes subseções explicam, de forma detalhada, cada um dos blocos que compõem o módulo mecânico apresentado na Figura 4.2.

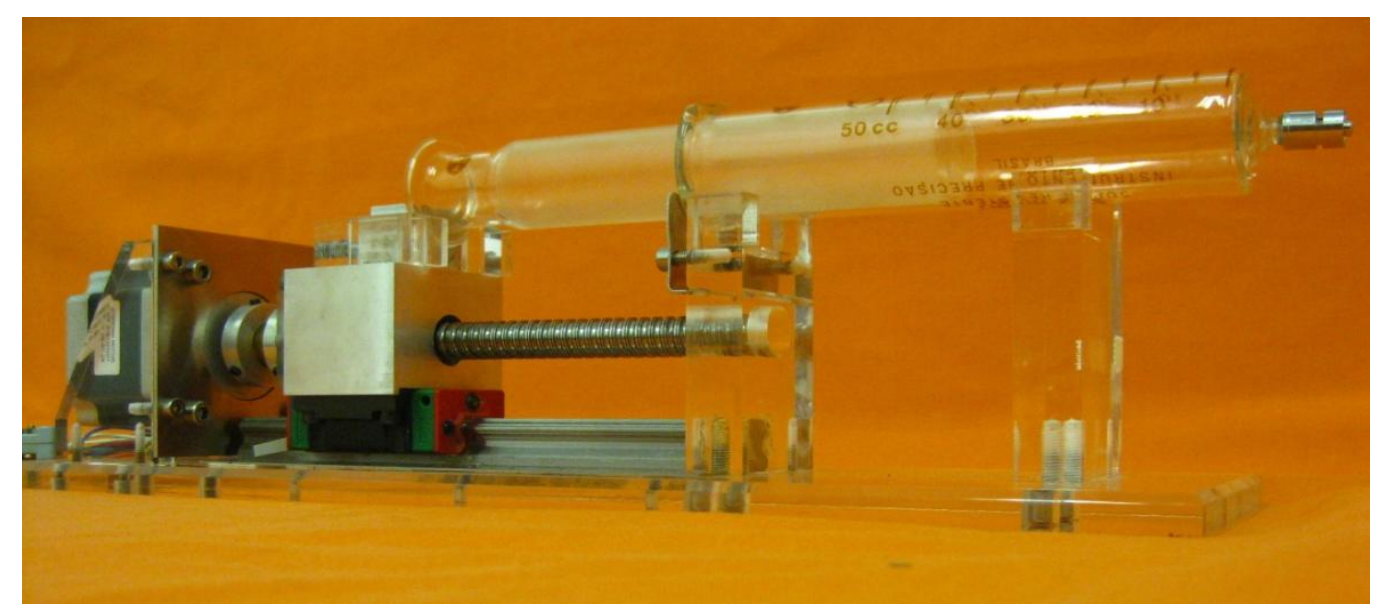

Figura 4.2 - Fotografia do módulo mecânico do insuflador pulmonar para pequenos roedores

\subsubsection{Motor de passos}

O motor de passos (57BYGH207, Circuit Specialists, EUA) utilizado neste insuflador para a pesquisa é um dispositivo eletromecânico que converte pulsos elétricos em movimentos mecânicos discretos. Suas características principais estão sumarizadas na Tabela 4.1

Tabela 4.1 - Características principais do motor de passos (57BYGH207, Circuit Specialists, EUA).

\begin{tabular}{ll}
\hline CARACTERÍSTICA & DESCRIÇÃO \\
\hline Tamanho-padrão & NEMA 23 \\
Ângulo do passo & $1,80 \% \pm 5 \%$ \\
Número de fases & 4 \\
Tensão de operação & $12 \mathrm{~V}$ \\
Indutância/fase & $60 \pm 20 \% \mathrm{mH}$ \\
Resistência/fase & $30 \pm 10 \% \Omega$ \\
Torque de manutenção & $8,0 \mathrm{~kg} \cdot \mathrm{cm}$ \\
Massa & $0,7 \mathrm{~kg} \mathrm{Max}$ \\
\hline
\end{tabular}


Este motor de passo é do tipo magnético permanente, unipolar de 6 fios, composto por dois enrolamentos por fase, um para cada sentido de corrente, e com uma derivação central entre o enrolamento de duas bobinas. A Figura 4.3 apresenta esquematicamente as ligações das bobinas do motor de passo.

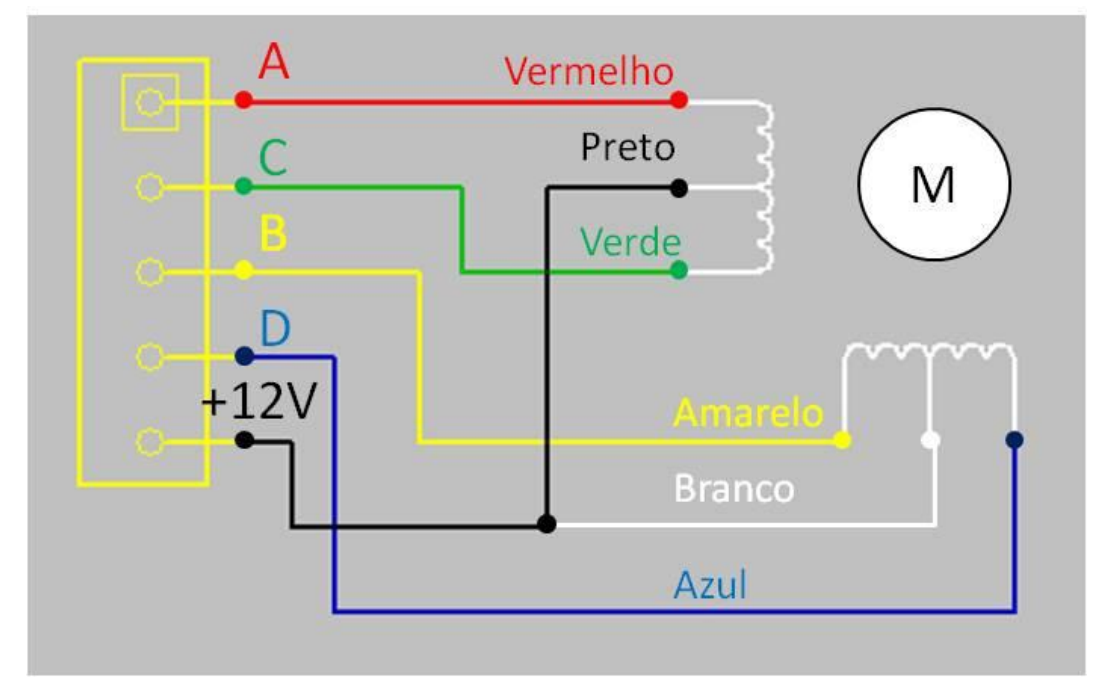

Figura 4.3 - Diagrama esquemático das ligações das bobinas.

Este motor funciona pela atração dos polos do rotor permanentemente magnetizado com os polos do estator. Assim, neste motor, a direção da corrente através das bobinas do estator determina quais serão os polos do rotor atraídos pelos polos do estator. A direção da corrente em motores unipolares depende de qual metade das bobinas é energizada.

Uma metade da bobina 1 está distribuída na parte superior e a outra está na parte inferior, como se observa Figura 4.4. A bobina 2 está entre a parte direita e a esquerda do estator.
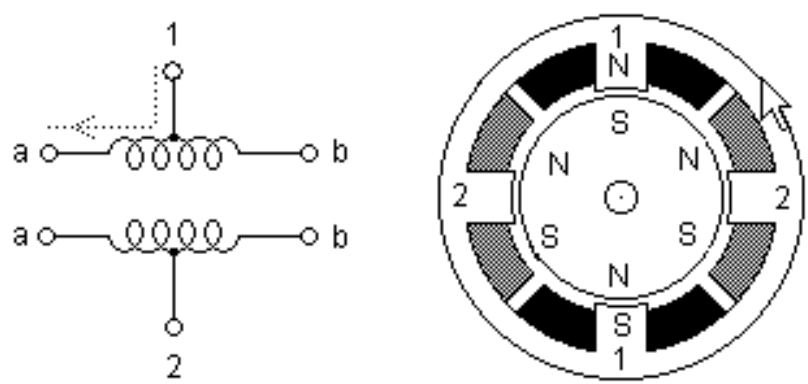

Figura 4.4 - Esquema da secção transversal de um motor de passo unipolar de 30 graus por passo (AN907, Microchip, EUA). 
No IPPR, a sequência de acionamento dos polos do estator se faz energizando duas metades das bobinas ao mesmo instante de tempo ${ }^{3}$, dando ao motor maior torque, mas também incrementando a potência utilizada pelo motor (CONDIT; JONES, 2004, p.2).

O motor se encontra fixado no módulo mecânico, conforme enfatizado na Figura 4.5.

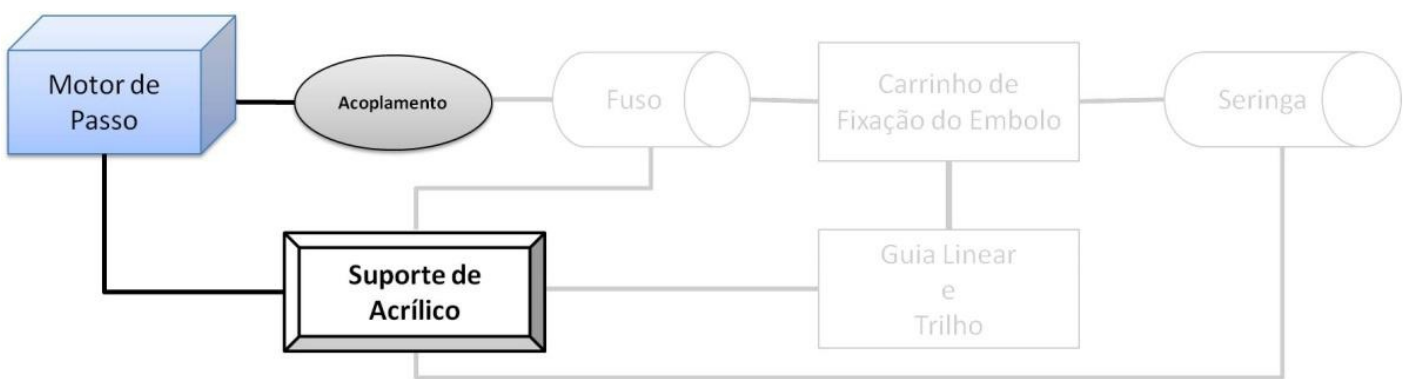

Figura 4.5 - Diagrama de blocos do módulo mecânico, com ênfase nas interações do motor de passo.

Na Figura 4.6, está representada a fixação do motor com a base de acrílico.

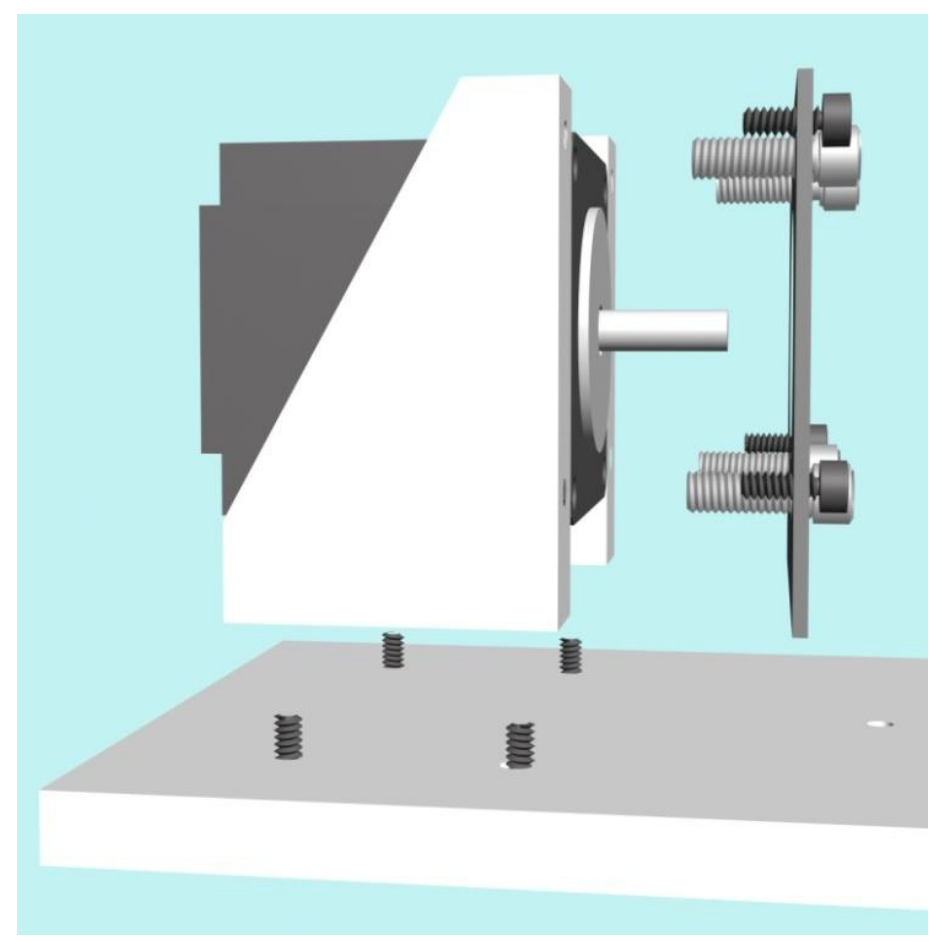

Figura 4.6 - Desenho do mecanismo de fixação do motor na base de acrílico.

\footnotetext{
${ }^{3}$ Esta sequência de acionamento será explicada com maior detalhe na seção 4.1.2.
} 
Uma fotografia do mecanismo de fixação do motor de passos na base de acrílico é apresentada na Figura 4.7.

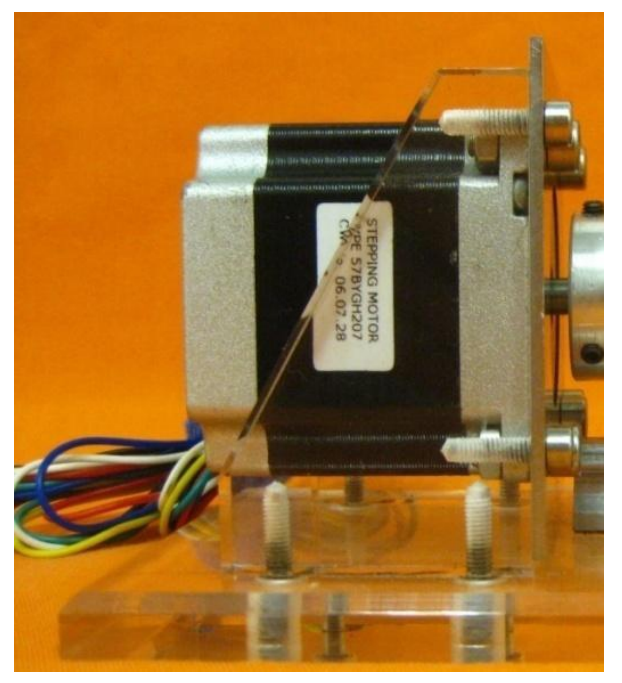

Figura 4.7 - Motor de passo fixado na base de acrílico e na placa metálica de fixação.

O motor está fixado na base de acrílico utilizando como intermediária uma placa metálica de $2 \mathrm{~mm}$ de espessura, cujas outras dimensões e características são apresentadas na Figura 4.8.

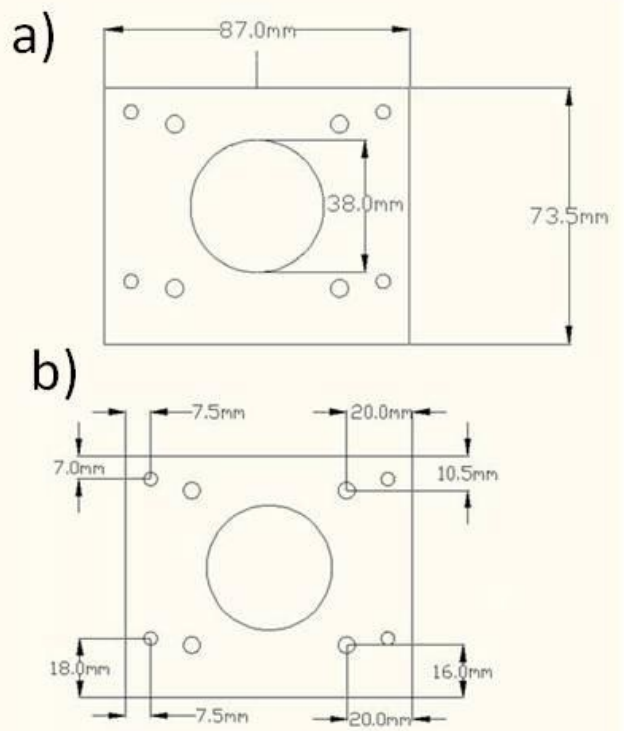

Figura 4.8 - Dimensões da placa de fixação do motor na base de acrílico. (a) Comprimento e largura. (b) Posicionamento dos orifícios correspondentes aos parafusos M5 de fixação. 
O motor é fixado na placa metálica por meio de quatro parafusos de cabeça cilíndrica com sextavado interno (Allen) de $5 \mathrm{~mm}$ de diâmetro (M5). A placa metálica, junto com o motor, se fixa na base de acrílico sobre dois suportes também de acrílico paralelos, com dois parafusos M5 na base de cada suporte. Desta forma, o motor fica sobre a base de acrílico, o que o deixa com o eixo de rotação do motor no lugar adequado para realizar a movimentação necessária.

O ajuste da posição do motor é o parâmetro inicial para calcular o posicionamento das demais peças do insuflador pulmonar para pequenos roedores.

\subsubsection{Acoplamento}

O acoplamento é a peça de união entre o motor de passos e o fuso cilíndrico de esferas, conforme pode ser observado na Figura 4.9.

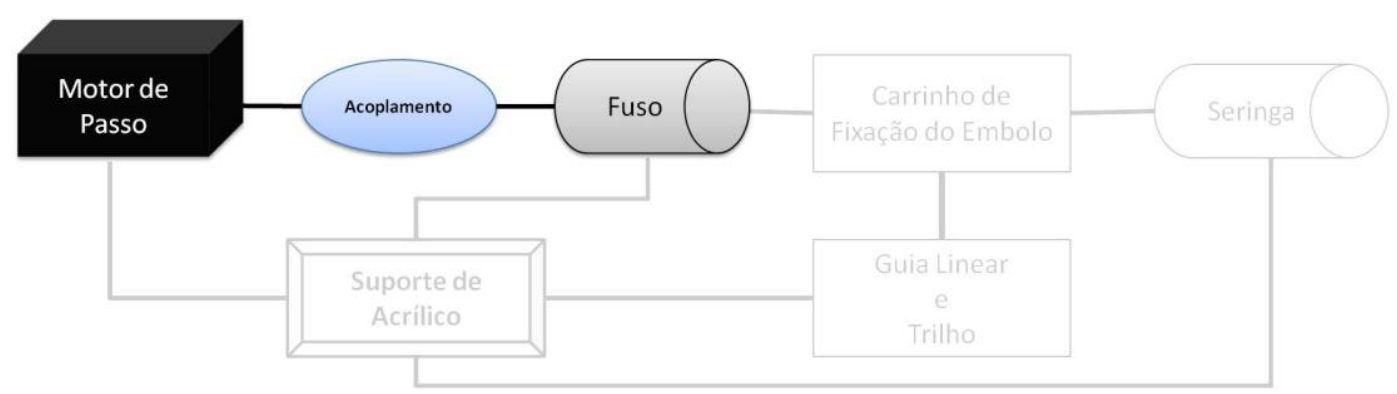

Figura 4.9 - Diagrama de blocos do módulo mecânico, com ênfase nas interações do acoplamento.

Esta peça é necessária para transmitir o movimento do motor para o fuso cilíndrico. O acoplamento é composto por um cilindro de elastômero termoplástico (Santoprene®, Exxon Mobil Corporation, EUA) no qual, em cada extremidade, encontra-se um anel metálico que serve de suporte para três parafusos de pressão que são utilizados para conectar o rotor do motor, de um lado, e o fuso cilíndrico de esferas, do outro. As dimensões do acoplamento podem ser observadas na Figura 4.10 . 
a)

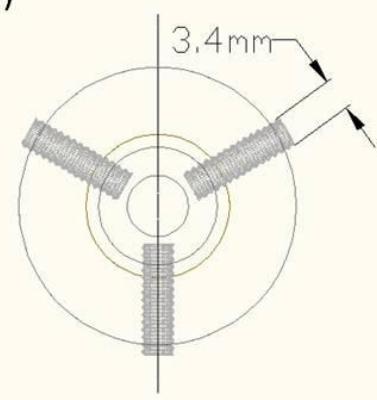

b)

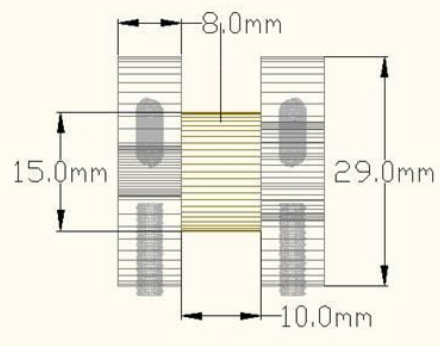

Figura 4.10 - Dimensões do acoplamento. (a) Vista frontal da peça.

(b) Vista lateral da peça.

Um desenho do acoplamento ainda não engatado no insuflador de pulmonar para pequenos animais é apresentado na Figura 4.11.

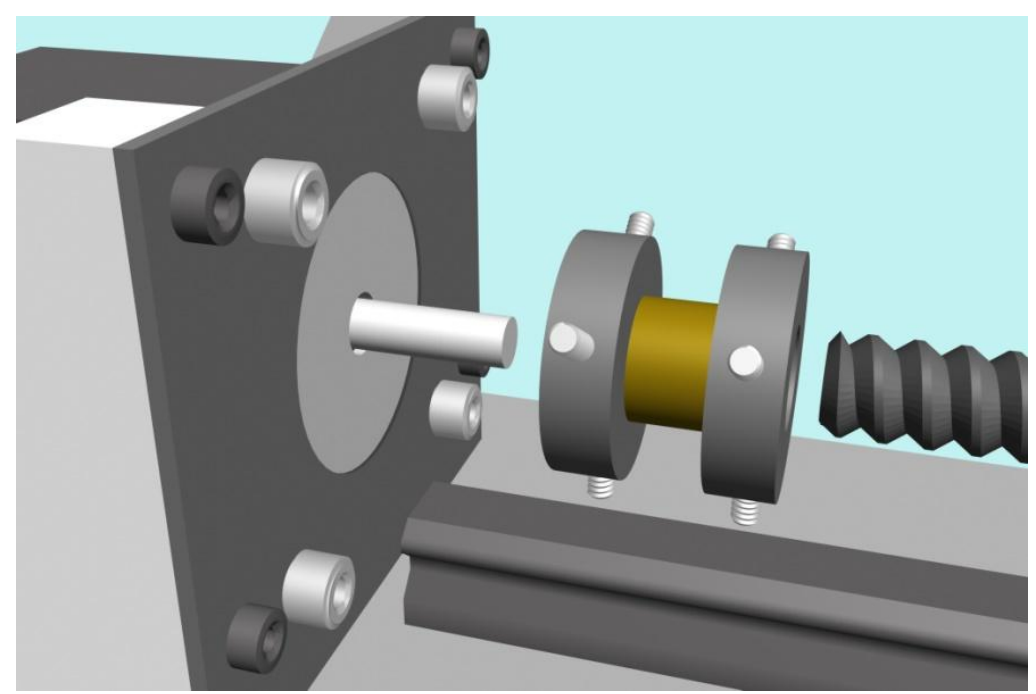

Figura 4.11 - Desenho do acoplamento ainda não colocado na posição final no insuflador mecânico

Além da fixação por parafusos de pressão, existe a pressão exercida pelo material termoplástico entre os cilindros metálicos do acoplamento, como se observa na Figura 4.12. 


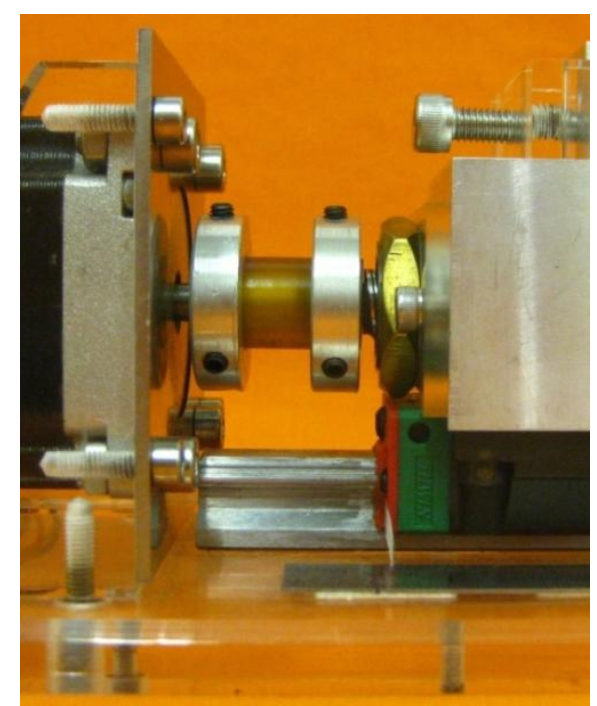

Figura 4.12 - Acoplamento no insuflador para pulmões de pequenos roedores

\subsubsection{Fuso cilíndrico de esferas}

O fuso cilíndrico de esferas é composto por um fuso cilíndrico (R12-4-300300-0,05, HIWIN Technologies Corp., Taiwan) e por uma castanha de fuso (R124B1-RSV-0.05, HIWIN Technologies Corp., Taiwan). O fuso cilíndrico está conectado no acoplamento termoplástico, de um lado, e repousa sobre um suporte de acrílico em sua outra extremidade. Além disso, o carrinho de fixação do êmbolo está conectado também ao fuso cilíndrico de esferas, através da castanha de fuso. A Figura 4.13 apresenta um diagrama de blocos que enfatiza essas conexões no módulo mecânico.

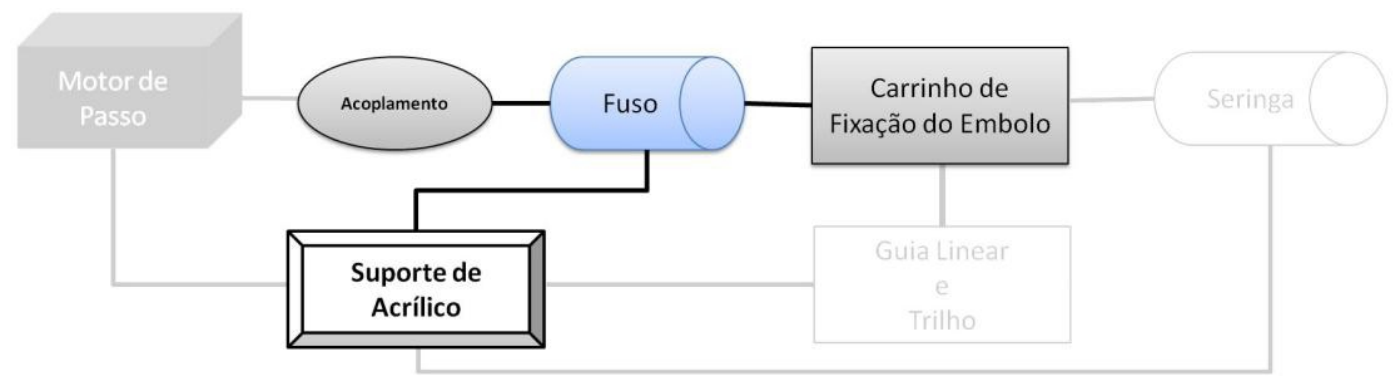

Figura 4.13 - Diagrama de blocos do módulo mecânico, com ênfase nas interações do fuso cilíndrico de esferas

A fixação entre o fuso e o acoplamento se encontra descrita na seção 4.1.1.2. 
A ligação entre o fuso e o carrinho de fixação do êmbolo se faz por intermédio da castanha de fuso, vide Figura 4.14, que está conectada ao carrinho através de uma porca de fixação e uma placa de acrílico com dois parafusos M5.
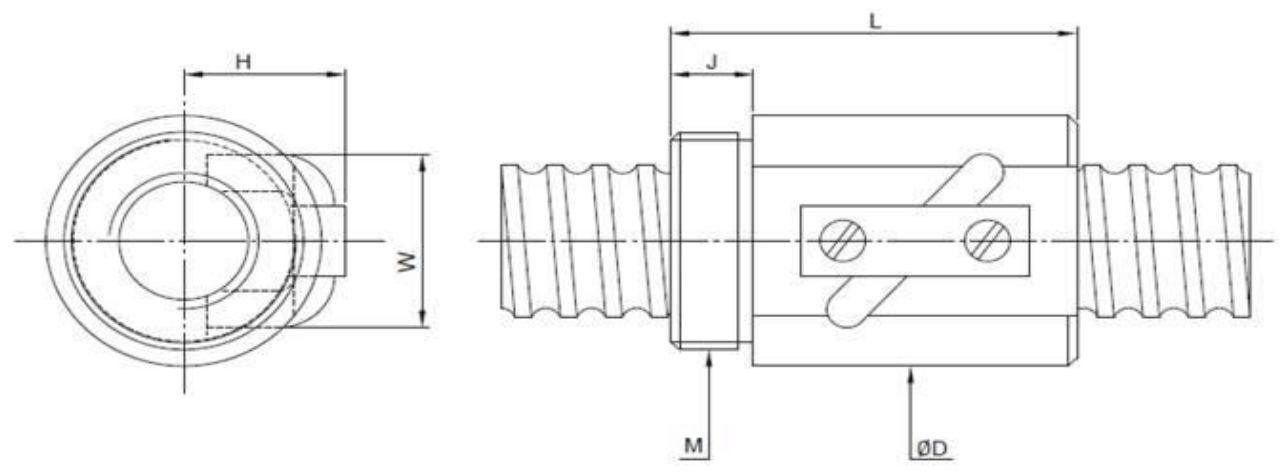

Figura 4.14 - Desenho da castanha de fuso cilíndrico de esferas (HIWIN Technologies Corp.)

A função do fuso cilíndrico de esferas é converter movimento rotatório em movimento linear, transmitindo os giros do motor à castanha pela movimentação das esferas metálicas no seu interior, com um torque de empuxo de alta precisão. Sua configuração permite $4 \mathrm{~mm}$ de movimentação linear em uma volta do parafuso, com um erro aproximado de $0,05 \mathrm{~mm}$ ao percorrer $300 \mathrm{~mm}$;suas especificações se encontram na Tabela 4.2.

Tabela 4.2- Especificações do fuso cilíndrico de esferas (todos os valores estão em milímetros)

\begin{tabular}{|c|c|c|c|c|c|c|c|}
\hline \multicolumn{3}{|c|}{ Dimensões } & \multicolumn{2}{|c|}{ Castanha } & \multirow{2}{*}{$\begin{array}{c}\text { Comprimento Linha } \\
\text { de montagem }\end{array}$} & \multirow{2}{*}{$\begin{array}{c}\begin{array}{c}\text { Largura tubo } \\
\text { de retorno }\end{array} \\
\text { W }\end{array}$} & \multirow{2}{*}{$\begin{array}{c}\text { Altura tubo } \\
\text { de retorno } \\
\text { H }\end{array}$} \\
\hline $\begin{array}{l}\text { Diâmetro } \\
\text { Nominal }\end{array}$ & $\begin{array}{l}\text { Diâmetro } \\
\text { das esferas }\end{array}$ & $\begin{array}{c}\text { Distância linear } \\
\text { alcançada por rotação }\end{array}$ & L & $\mathrm{D}$ & & & \\
\hline 12 & 2,381 & 4 & 32 & 25 & 10 & 22 & 21 \\
\hline
\end{tabular}

Como se observa na Figura 4.14, a castanha do fuso possui, no seu extremo, uma rosca de largura J;esta rosca,e também uma porca hexagonal cônica externa de $24 \mathrm{~mm}$ de diâmetro, são utilizadas para conectar o carrinho de fixação do êmbolo, como se apresenta na Figura 4.15. 


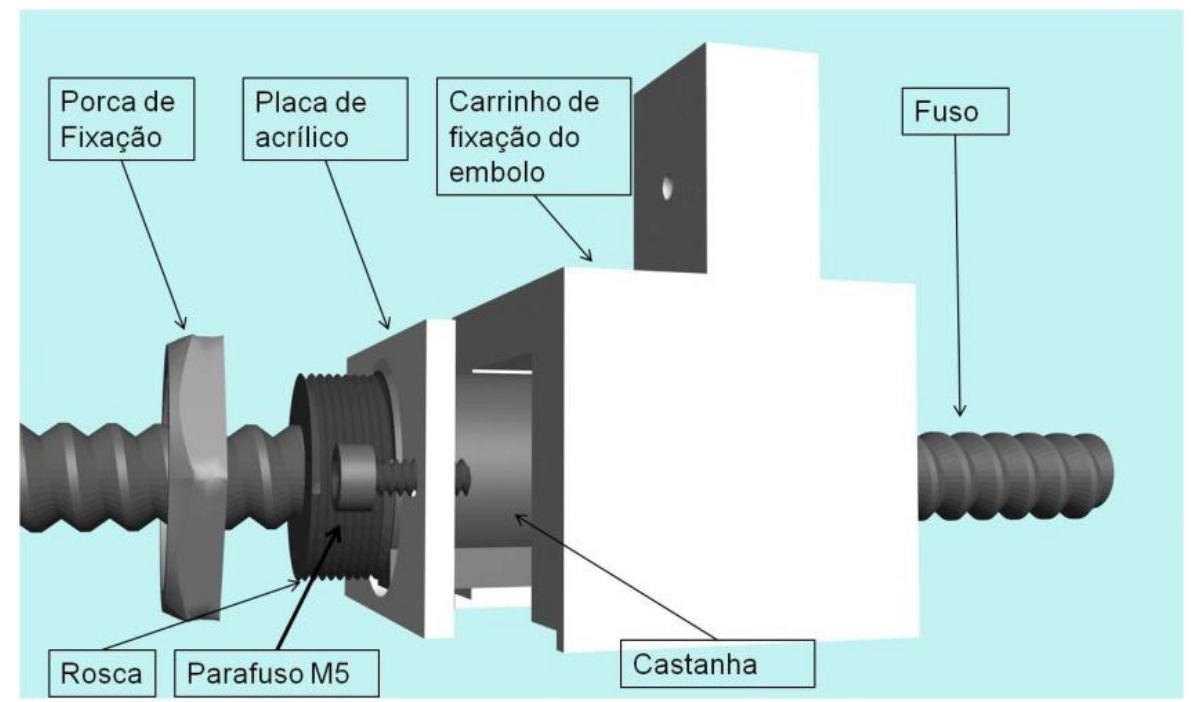

Figura 4.15 - Desenho de configuração da união entre a castanha do fuso cilíndrico e o carrinho de fixação do êmbolo.

O fuso cilíndrico de esferas integrado ao insuflador é apresentado na Figura 4.16.

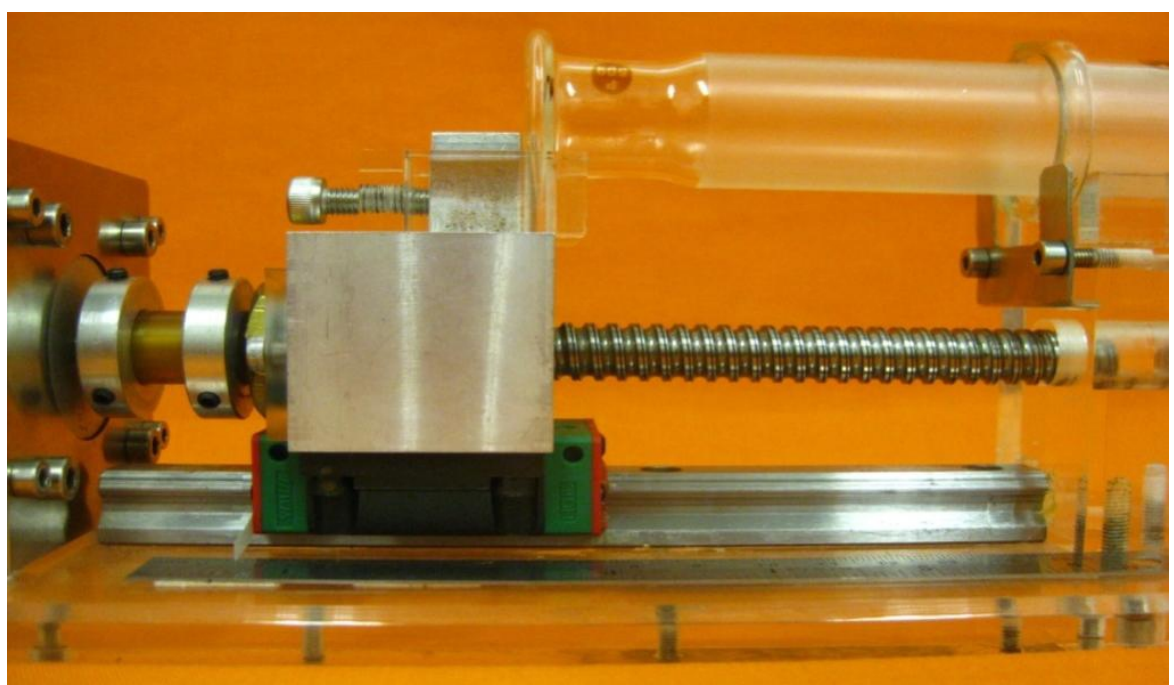

Figura 4.16 - Fuso de esferas do insuflador conectado, à esquerda, ao acoplamento e apoiado, à direita, no suporte de acrílico. Observase também o carrinho de fixação do êmbolo da seringa. 
4.1.1.4 Carrinho de fixação do êmbolo

O carrinho está encarregado de transmitir a movimentação linear ao êmbolo da seringa (Figura 4.17), de forma firme, suave e constante. Por isso, ele está conectado também ao fuso cilíndrico de esferas, à guia linear e ao trilho.

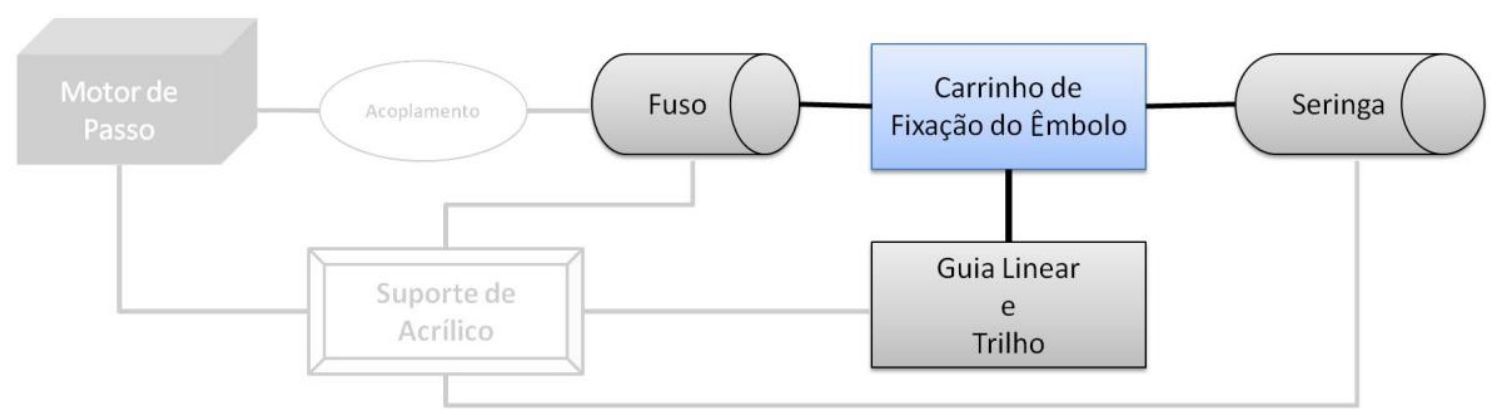

Figura 4.17 - Diagrama de blocos do módulo mecânico, com ênfase nas interações do carrinho de fixação do êmbolo.

Este dispositivo possui três tipos de acoplamentos: o primeiro encontra-se entre $o$ fuso e o carrinho, o outro entre $o$ carrinho e a guia linear e $o$ último posiciona-se entre o carrinho e o êmbolo da seringa.

O Acoplamento 1 já foi descrito no item 4.1.1.2. O Acoplamento 2 é composto por quatro parafusos M5 que fixam a guia linear ao carrinho. O Acoplamento 3 , situado entre o carrinho e a seringa, é composto por um parafuso M5 e uma peça de acrílico desenhada para fixar o extremo do êmbolo da seringa na peça superior do carrinho. Na Figura 4.18, são apresentados detalhes destes acoplamentos. 


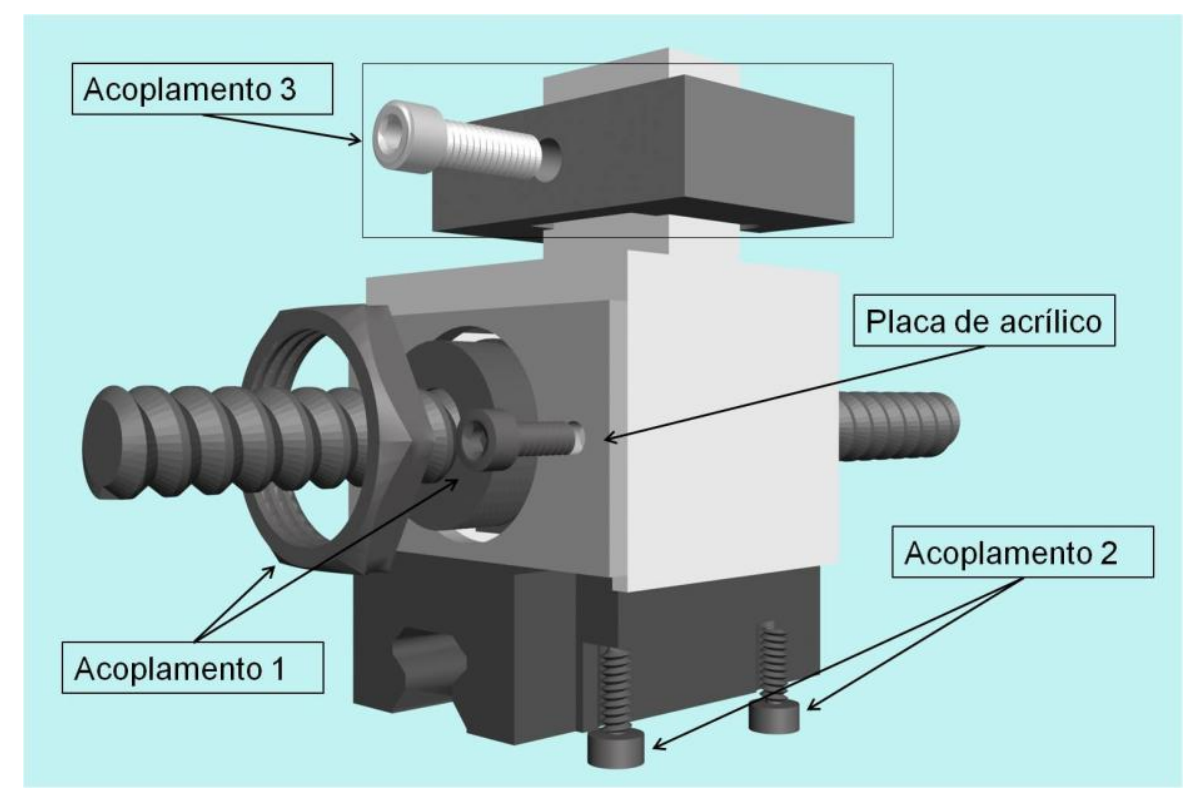

Figura 4.18 - Desenho 3D do carrinho com os acoplamentos. O Acoplamento 1 é composto pela porca da castanha do fuso de esferas e por dois parafusos M5 e a placa de acrílico. O Acoplamento 2 é composto por quatro parafusos M5.O Acoplamento 3 é composto por uma peça acrílica para fixação do extremo do êmbolo.

Como se observa na figura anterior, o Acoplamento 3 é uma peça que se conecta ao carrinho de fixação. Sua geometria é apresentada na Figura 4.19.

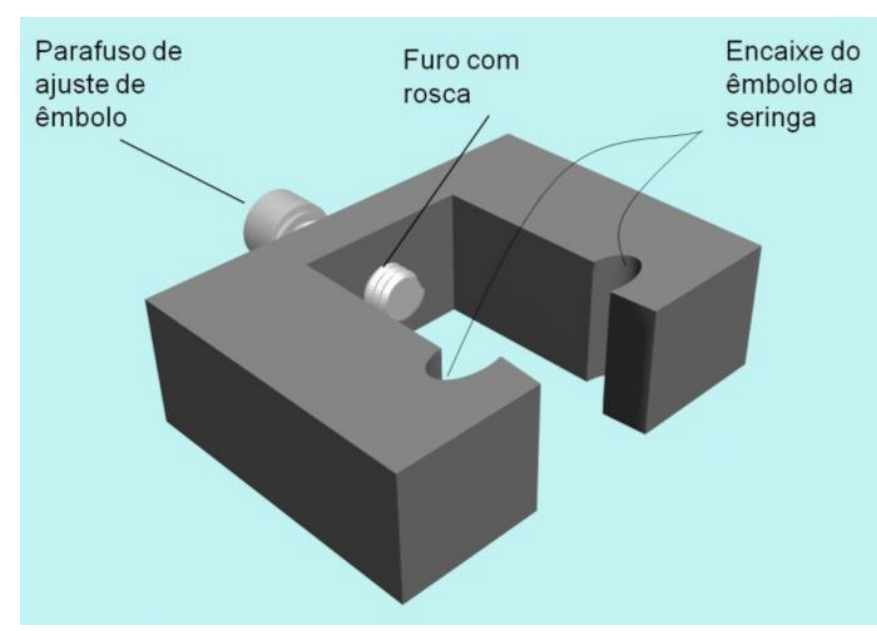

Figura 4.19 - Desenho do acoplamento entre o êmbolo da seringa e o carrinho de fixação (Acoplamento 3).

O carrinho apresenta, na sua parte superior, uma placa metálica com uma pequena concavidade na parte posterior para encaixe do parafuso do Acoplamento 3. Na Figura 4.20, são apresentadas as dimensões do Acoplamento 3. 

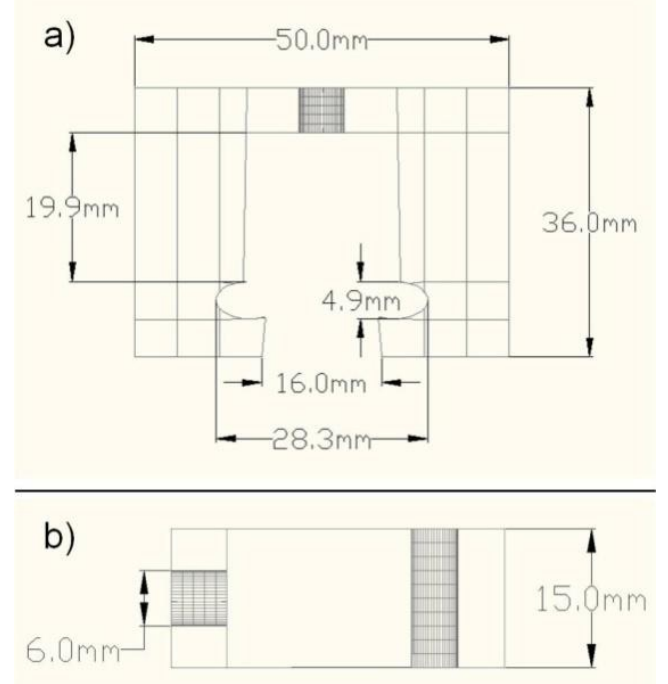

Figura 4.20 - Dimensões do Acoplamento 3. (a) Vista superior. (b) Vista lateral.

O material de fabricação do carrinho é alumínio e suas dimensões são apresentadas na Figura 4.21.
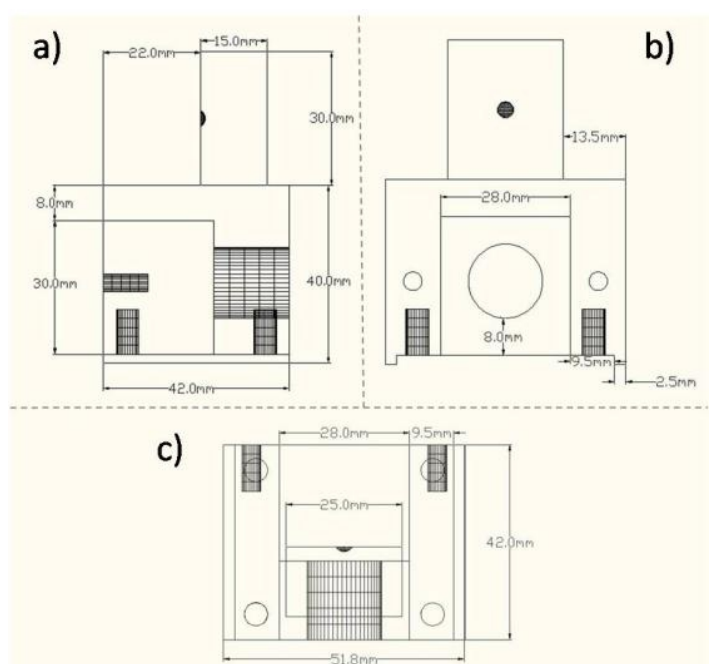

Figura 4.21 - Dimensões do carrinho de fixação do êmbolo. (a) Vista lateral direita. (b) Vista posterior. (c) Vista inferior

$\mathrm{Na}$ parte inferior do carrinho, existem quatro orifícios com rosca para os parafusos M5 de fixação com a guia linear. Na parte posterior do mesmo, existem dois orifícios com rosca para os parafusos M5 de fixação da placa de acrílico (Figura 4.18), que fixa a castanha do fuso cilíndrico de esferas ao carrinho, estes orifícios, no carrinho, são apresentados na Figura 4.22. 


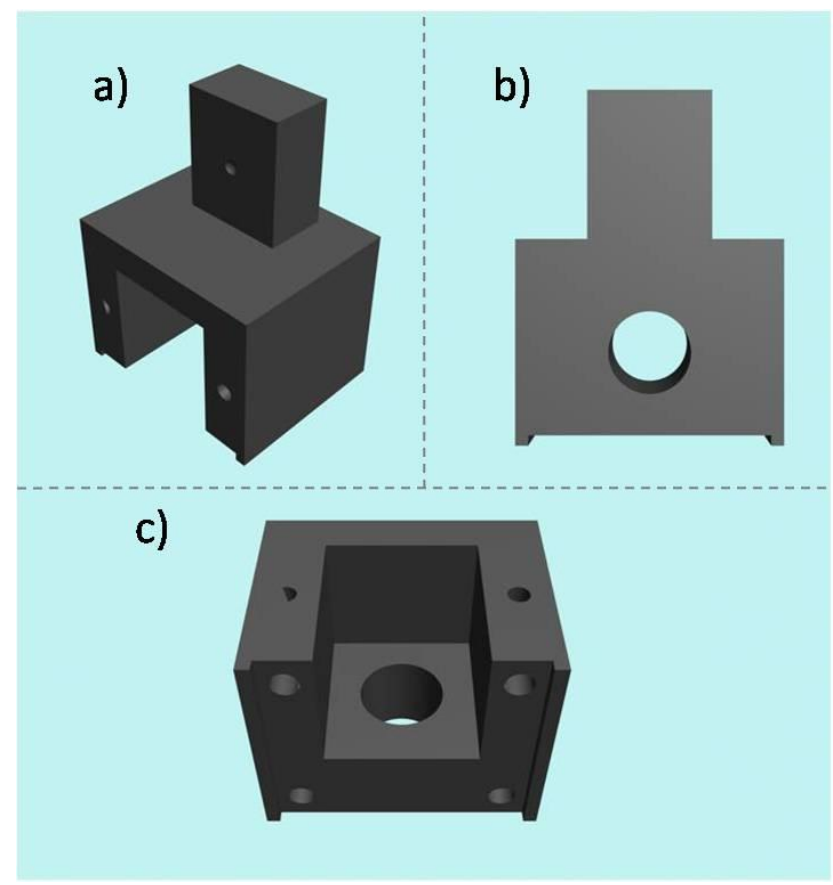

Figura 4.22 - Carrinho de fixação do êmbolo. (a) Vista em perspectiva da lateral direita e frontal. (b) Vista frontal. (c) Vista posterior/inferior

Resumidamente, o carrinho de fixação do êmbolo está fixado na guia linear, através do Acoplamento 2, e também se fixa ao fuso cilíndrico de esferas através da castanha do fuso e do Acoplamento 1. Além disso, o carrinho conecta-se ao êmbolo da seringa através do Acoplamento 3, que é fixado manualmente através de um parafuso (Figura 4.19). Dessa forma, a rotação do motor de passos movimenta linearmente o carrinho e, por consequência, o êmbolo da seringa. O carrinho de fixação do êmbolo pode ser observado na Figura 4.23.
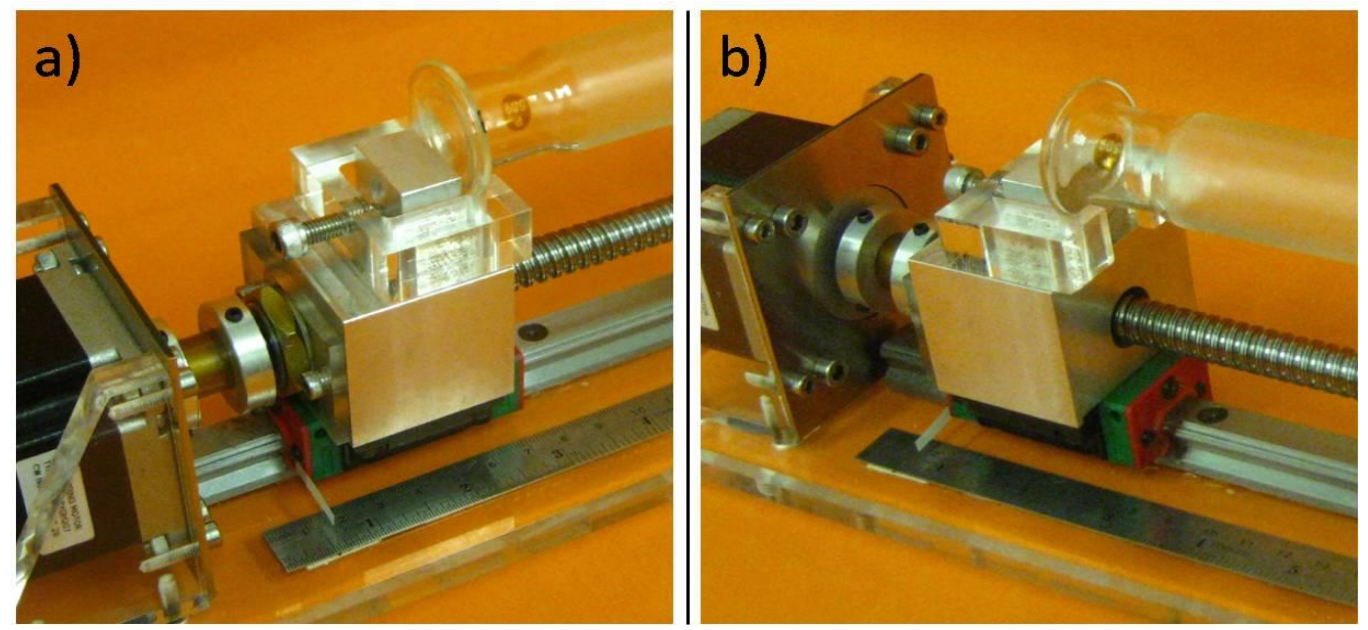

Figura 4.23 - Carrinho de fixação do êmbolo. (a) Vista lateralposterior. (b) Vista lateral-frontal 
4.1.1.5 Guia linear e trilho

A guia linear (HGW15-CC-Z0-C, HIWIN Technologies Corp., Taiwan) e o trilho (HGR15-R200-C, HIWIN Technologies Corp., Taiwan) permitem a movimentação linear utilizando esferas de deslizamento entre o trilho e a guia. Esta guia linear pode atingir altos níveis de precisão com baixo coeficiente de fricção.

$\mathrm{Na}$ Figura 4.24, são apresentadas as conexões da guia linear e do trilho no módulo mecânico.

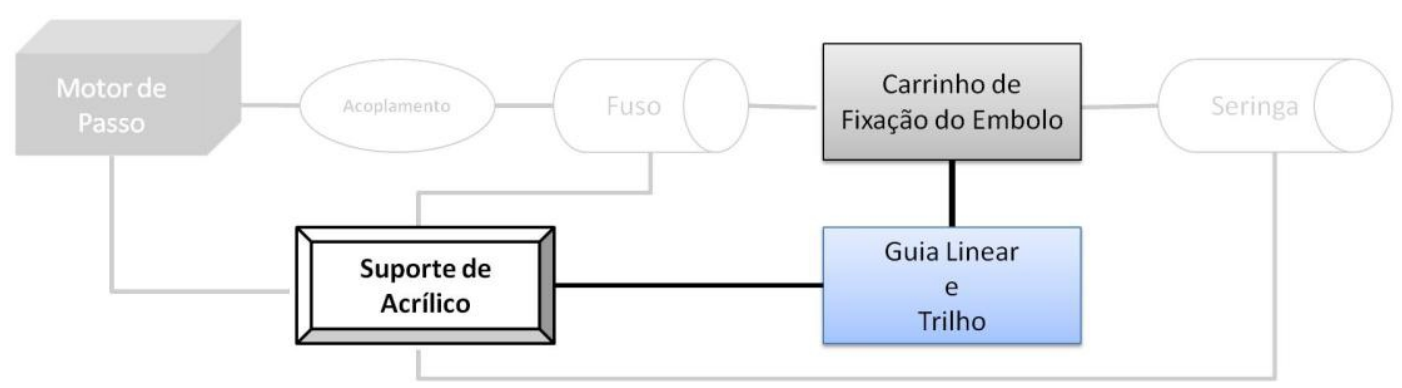

Figura 4.24 - Diagrama de blocos do módulo mecânico, com ênfase nas interações da guia linear e do trilho

O acoplamento entre a guia linear e o trilho se faz usando os canais de deslizamento, com esferas existentes na guia linear e com os canais externos do trilho, os quais se ajustam hermeticamente um ao outro pelo fato de serem peças complementares, conforme Figura 4.25.

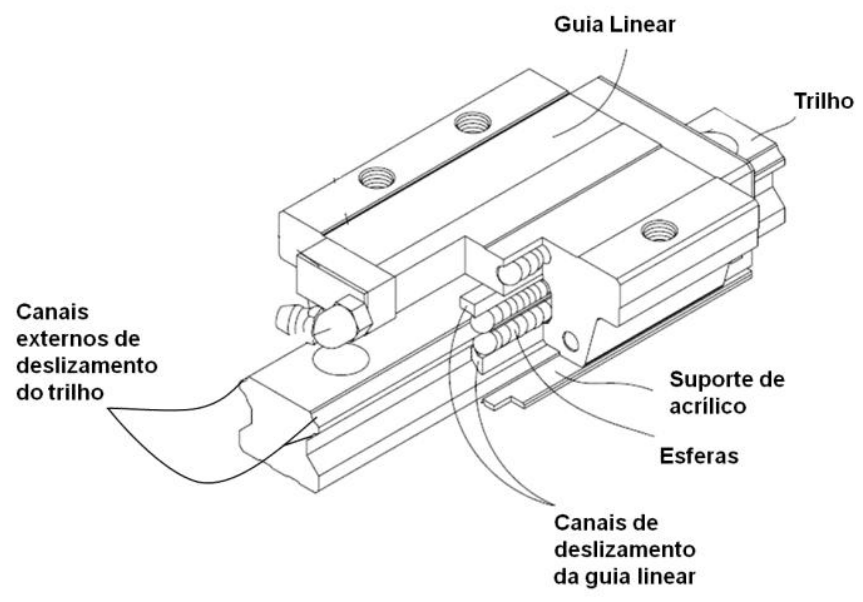

Figura 4.25 - Corte da guia linear para verificar conexão com o trilho.

Figura editada de HIWIN Technologies Corp., Taiwan. 
O acoplamento entre a guia linear e o carrinho já foi explicado na seção 4.1.1.5. O trilho é fixado no suporte de acrílico utilizando-se três parafusos M5. As dimensões dos orifícios no trilho e as dimensões gerais da guia linear são apresentadas na Figura 4.26 .

a)

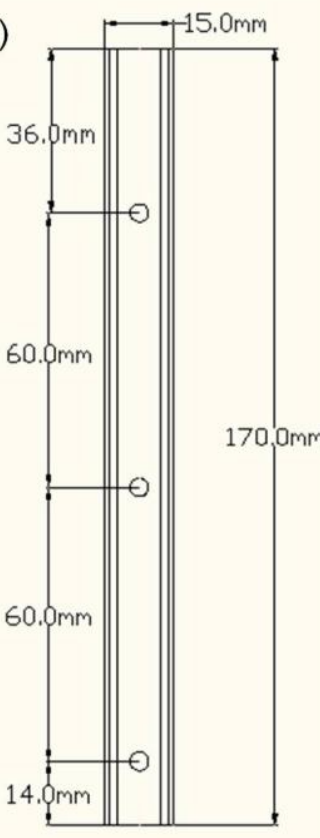

b)

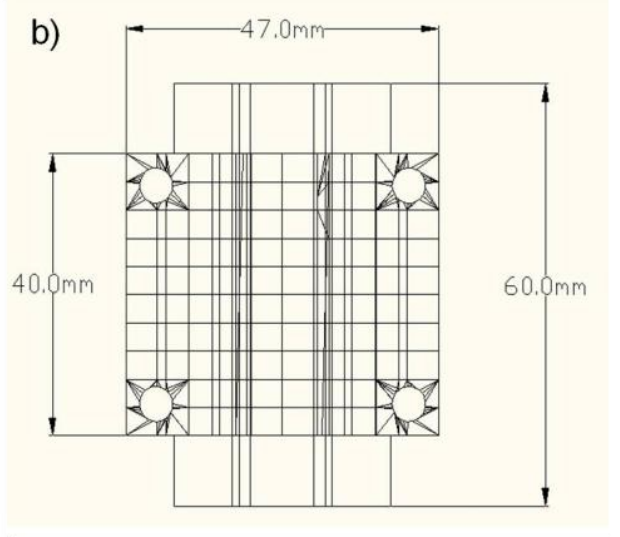

c)

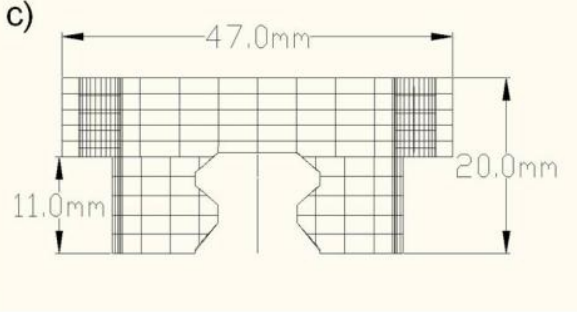

Figura 4.26 - Dimensões da guia linear e do trilho. (a) Dimensões do trilho. (b) Dimensões da guia linear - vista superior. (c) Dimensões da guia linear - vista posterior

Um desenho da guia linear e do trilho é apresentado na Figura 4.27.

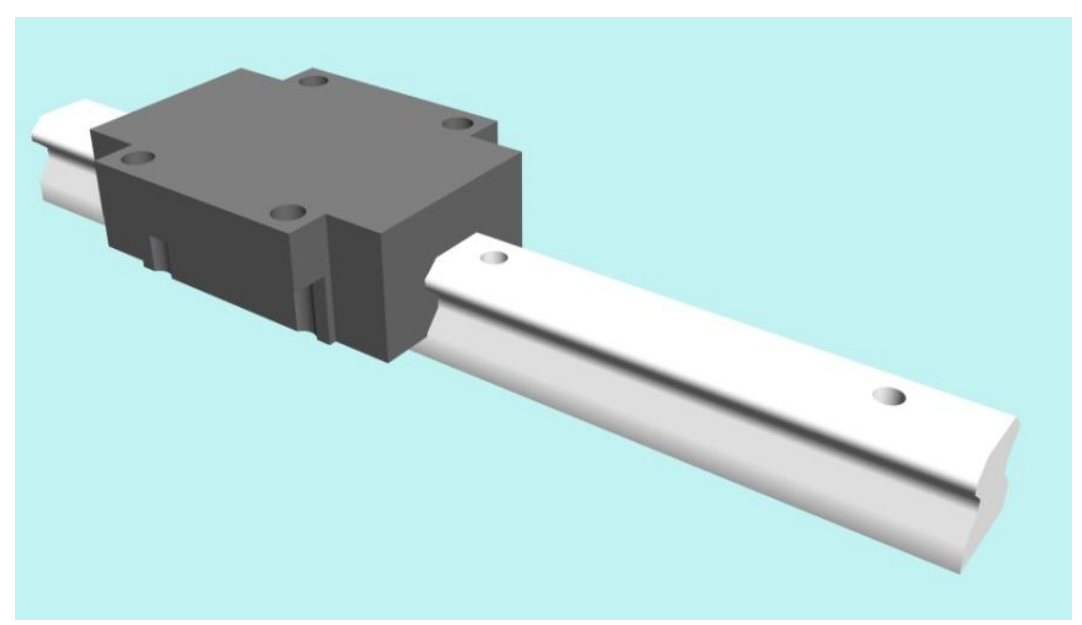

Figura 4.27 - Desenho 3D da guia linear e do trilho. 
4.1.1.6 Suporte de acrílico

O suporte de acrílico apresenta interações com quatro peças integrantes do módulo mecânico, conforme apresentado, em forma de diagrama de blocos, na Figura 4.28.

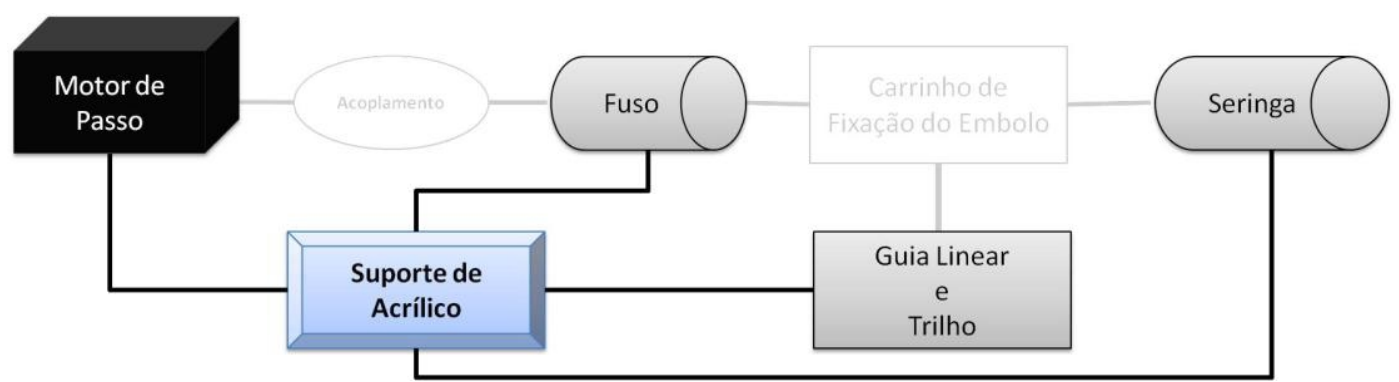

Figura 4.28 - Diagrama de blocos do módulo mecânico, com ênfase nas interações do suporte de acrílico

O suporte de acrílico é composto por cinco peças de acrílico unidas por parafusos; uma delas, de formato retangular, serve de base para todo 0 dispositivo;outras duas, de formato pentagonal, sustentam o motor e duas peças, de formato octogonal, são utilizadas para manter a seringa na posição correta, sendo que uma delas também serve de mancal para o fuso cilíndrico de esferas, conforme Figura 4.29.

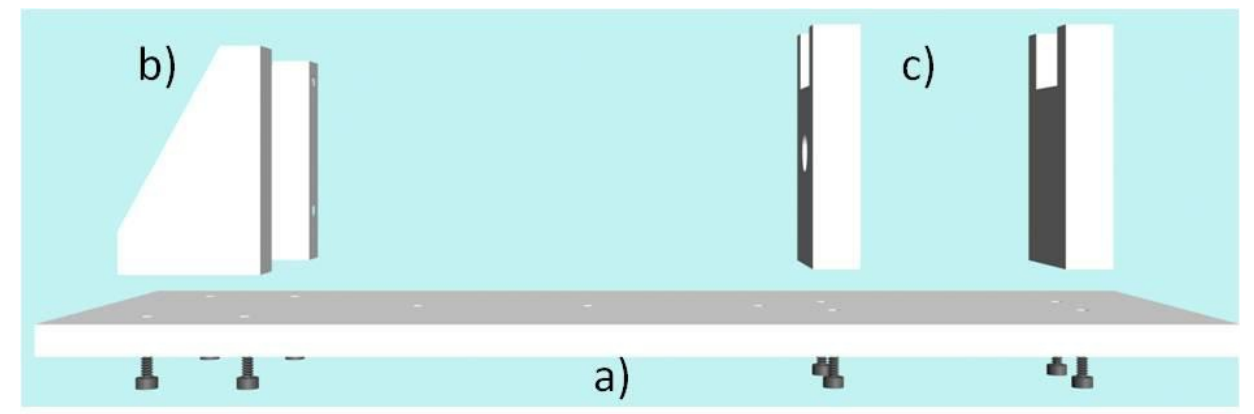

Figura 4.29 - Desenho espacial do suporte de acrílico. (a) Base do insuflador mecânico. (b) Suporte do motor. (c) Suporte de fixação da seringa a peça à esquerda também serve de mancal para o fuso cilíndrico de esferas.

$\mathrm{Na}$ base do insuflador, existem onze orifícios para passagem de parafusos M5 e para proteção das cabeças dos parafusos. Na Figura 4.30, são apresentadas as 
dimensões exatas de cada uma das furações necessárias para fixar o suporte do motor, o trilho e os suportes da seringa.

a)

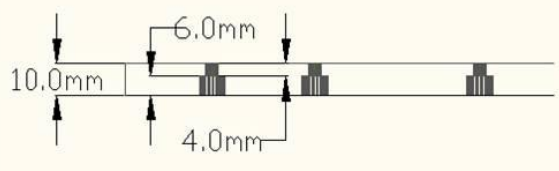

b)

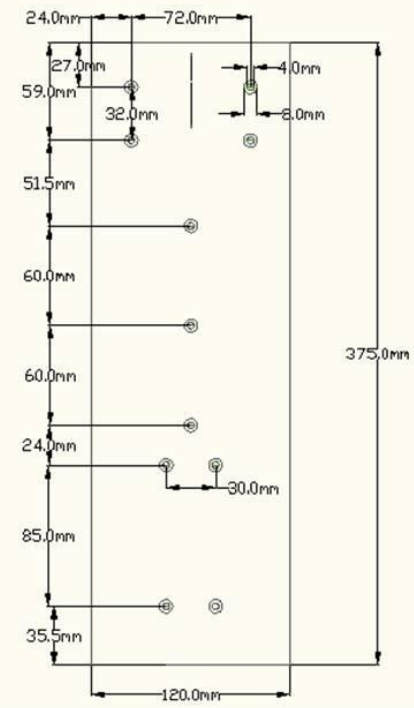

Figura 4.30 - Dimensões da base do insuflador mecânico. (a) Orifícios com rosca e espessura do acrílico. (b) Posições dos orifícios de fixação.

Na Figura 4.31, estão descritas todas as dimensões do suporte do motor. Tanto o suporte da direita como o da esquerda têm as mesmas dimensões. Os quatro orifícios de cada um dos suportes apresentam rosca para parafuso M5.

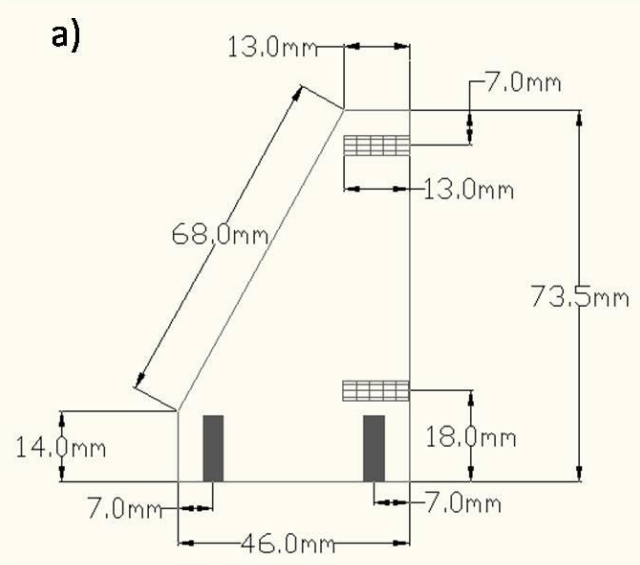

Figura 4.31 - Dimensões dos suportes do motor. (a) Dimensões gerais laterais do suporte. (b) Vista posterior do suporte b)

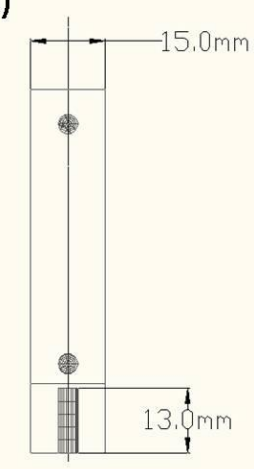

Na Figura 4.32, são apresentadas as dimensões dos suportes para a seringa, sendo que a única diferença entre os dois suportes é a presença, em um deles (o 
mais perto ao motor), de um orifício de $14 \mathrm{~mm}$ de diâmetro à altura de $32,5 \mathrm{~mm}$, onde o fuso é apoiado. O espaço existente na parte superior dos suportes foi calculado para que a seringa o ocupe livremente. Na parte inferior das peças, estão as dimensões dos quatro orifícios com rosca para parafusos M5.
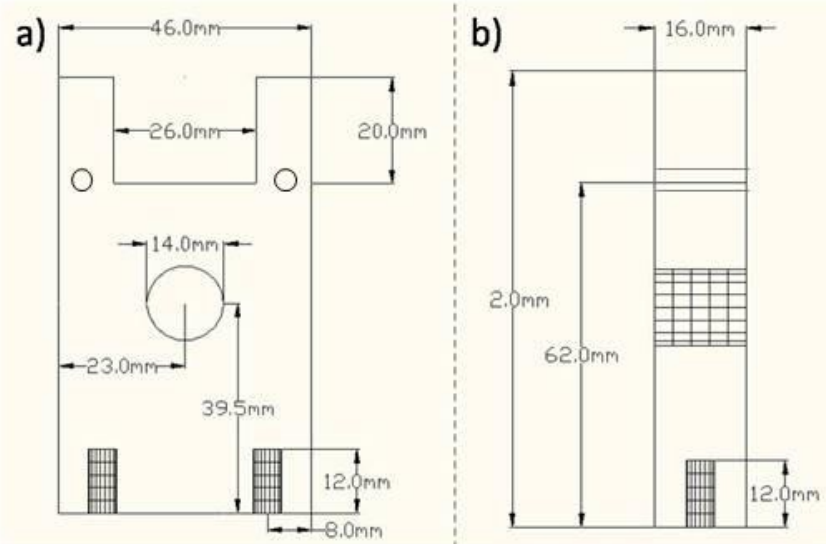

Figura 4.32 - Dimensões das duas peças de suporte para a seringa, sendo que uma das peças apresenta um orifício de $14 \mathrm{~mm}$ de diâmetro e a outra não. (a) Vista frontal. (b) Vista lateral.

A Figura 4.33 apresenta a placa metálica para fixação da seringa no suporte de acrílico. Esta peça fixa o chanfro do tubo da seringa, quando a placa metálica é pressionada contra o suporte de acrílico, através do aperto dos parafusos realizado manualmente.

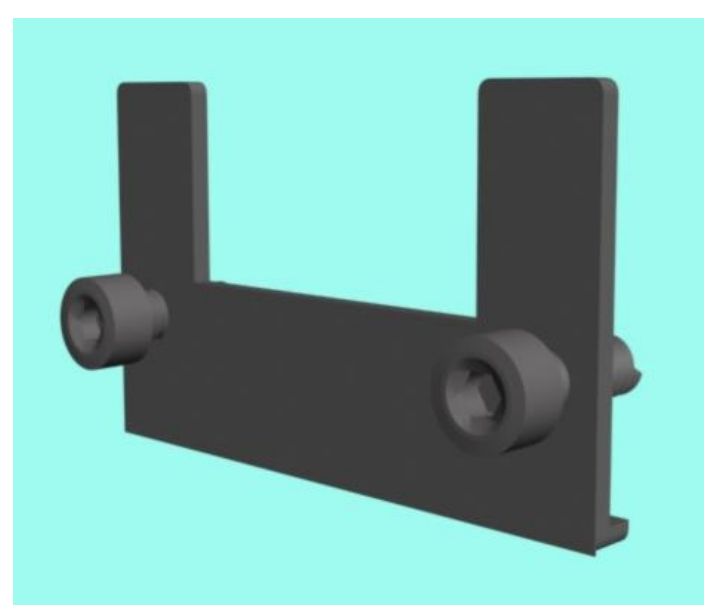

Figura 4.33 - Desenho espacial do acoplamento metálico para ajuste de seringa

As dimensões da placa metálica são apresentadas na Figura 4.34. 

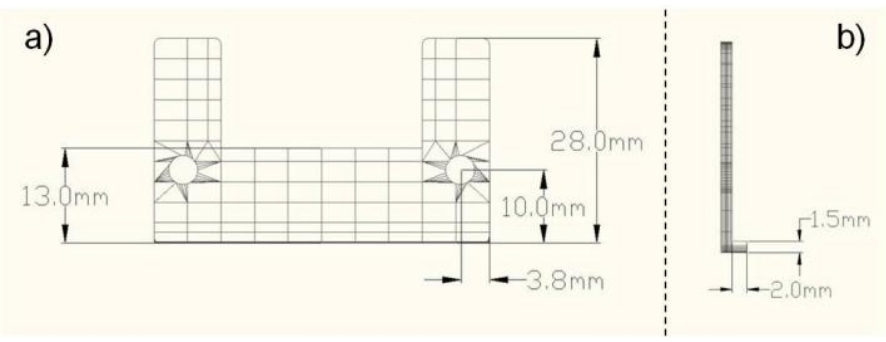

Figura 4.34 - Dimensões da placa metálica de acoplamento com a seringa. (a) Vista frontal da peça. (b) Vista lateral

Esta fixação é importante para que, durante a movimentação do motor, a seringa não saia da sua posição. Uma fotografia da fixação da seringa pela placa metálica é apresentada na Figura 4.35.

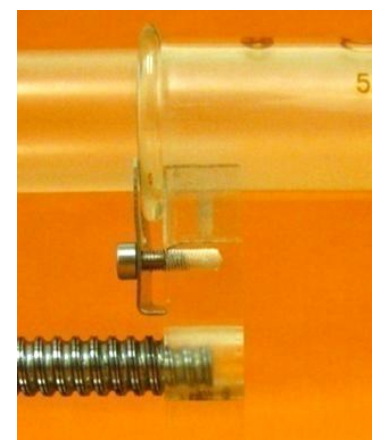

Figura 4.35 - Fotografia da peça metálica de fixação de seringa no suporte de acrílico.

As peças em acrílico são transparentes, conforme observado na Figura 4.36.

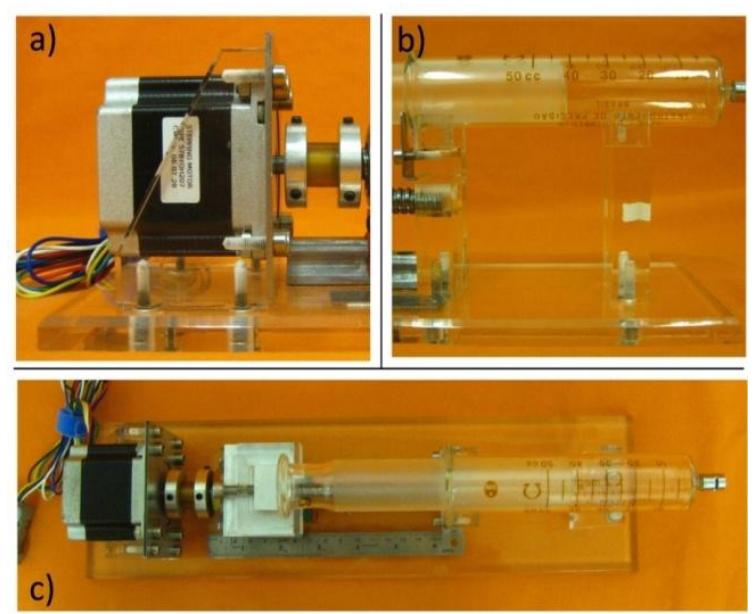

Figura 4.36 - Suportes em acrílico. (a) Suporte do motor. (b) Duas peças para suporte da seringa a peça mais à esquerda também serve de mancal para o fuso de esferas. (c) Base de acrílico do insuflador. 


\subsubsection{Seringa}

A seringa utilizada (50 cc, Omega, Brasil) é de uso comercial, mas sua comercialização está bastante reduzida, principalmente devido à concorrência com similares de material plástico de menor custo e de uso único. Nesta pesquisa, não foram utilizadas seringas plásticas devido à resistência que o êmbolo de borracha apresenta à movimentação contínua do êmbolo dessas seringas (VINSON,1999).

O êmbolo da seringa de vidro se acopla ao carrinho de fixação e o corpo da seringa é fixado, através do seu chanfro, à placa metálica no suporte de acrílico. A Figura 4.37 apresenta as conexões da seringa com o resto do módulo mecânico.

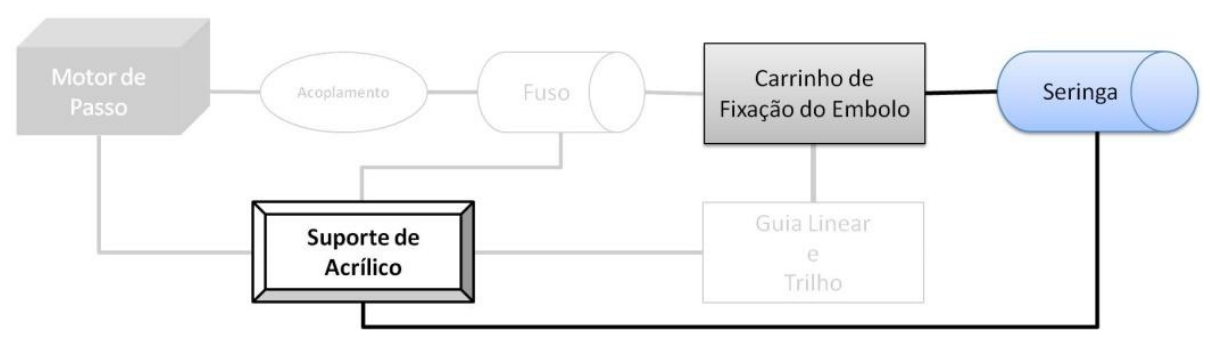

Figura 4.37 - Diagrama de blocos do módulo mecânico, com ênfase nas interações da seringa

As ligações da seringa foram explicadas detalhadamente nas seções: 3.2.4 e 3.2.6. A Figura 4.38 apresenta uma fotografia da seringa, com capacidade de $50 \mathrm{~mL}$, utilizada nesta pesquisa.

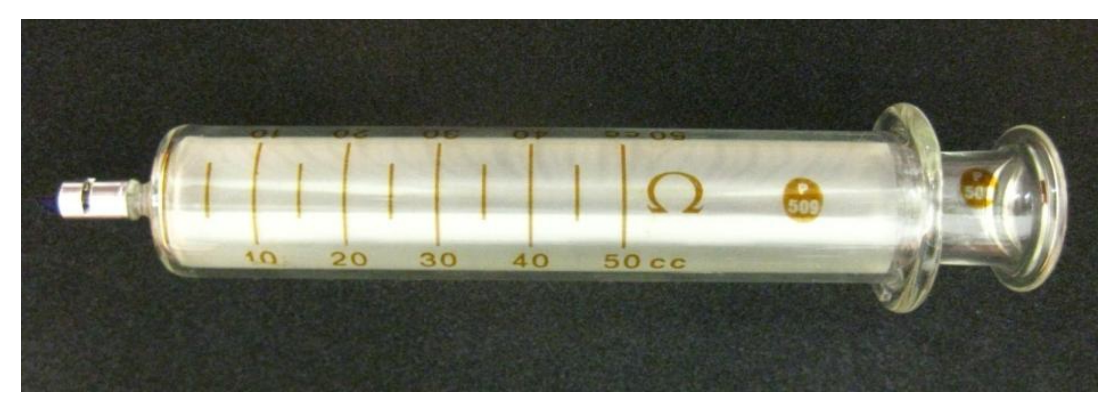

Figura 4.38 - Fotografia da seringa de $50 \mathrm{~mL}$ utilizada. 


\subsubsection{Módulo de potência}

Este módulo é responsável por transformar os sinais de comando, provenientes do módulo de controle e aquisição de sinais, em sinais com potência suficiente para energizar as bobinas do motor de passo. A Figura 4.39 enfatiza as interações do módulo de potência com os outros módulos integrantes do insuflador pulmonar para pequenos roedores.

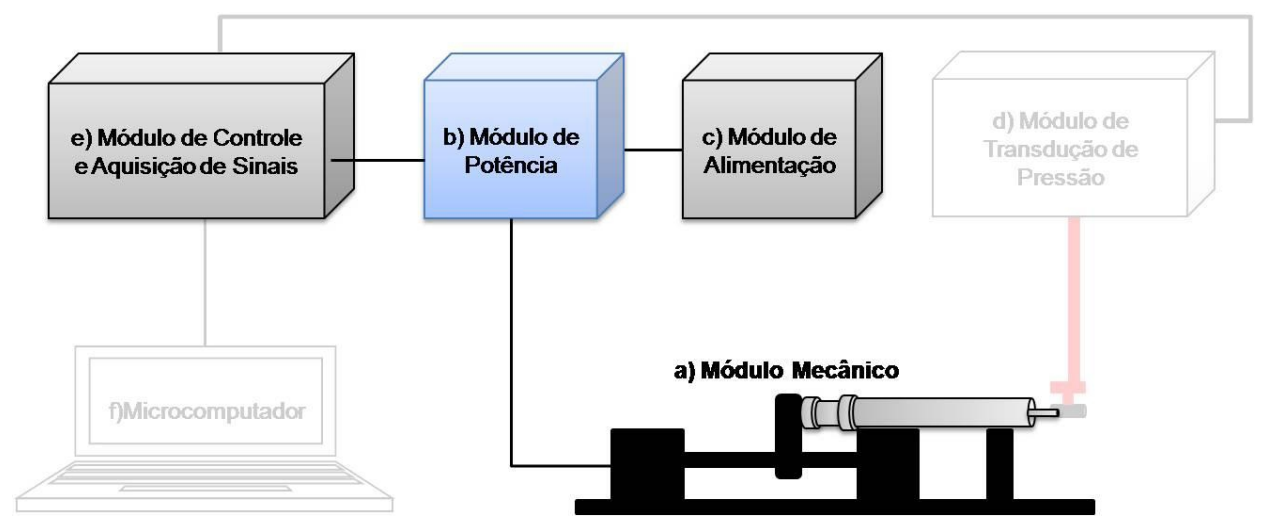

Figura 4.39 - Diagrama de blocos do insuflador de pulmões, com ênfase nas interações do módulo de potência

Neste caso, em particular, o módulo tem como circuito fundamental o proposto por Kari Salmi (1997, que é de livre uso. Este circuito pode ser utilizado para realizar as movimentações de um motor de passo unipolar de quatro fases que consuma menos de 500 mA em modo de passo completo.

O circuito implementado é apresentado na Figura 4.40. Ele é composto por três circuitos integrados e um diodo zener (15 V, 1W). O primeiro circuito integrado (Cl-1) tem quatro portas OU-exclusivo (XOR) (74LS86, On Semiconductors, EUA). O segundo circuito integrado (Cl-2) temdois flip-flops J-K (74LS112, Fairchild, EUA). O terceiro circuito integrado $(\mathrm{Cl}-3)$ tem sete transistores na configuração Darlington, cada canal suporta até $500 \mathrm{~mA}$ de corrente nominal (ULN2003APG, Toshiba, Japão), corrente necessária para garantir a energização das bobinas do motor. 


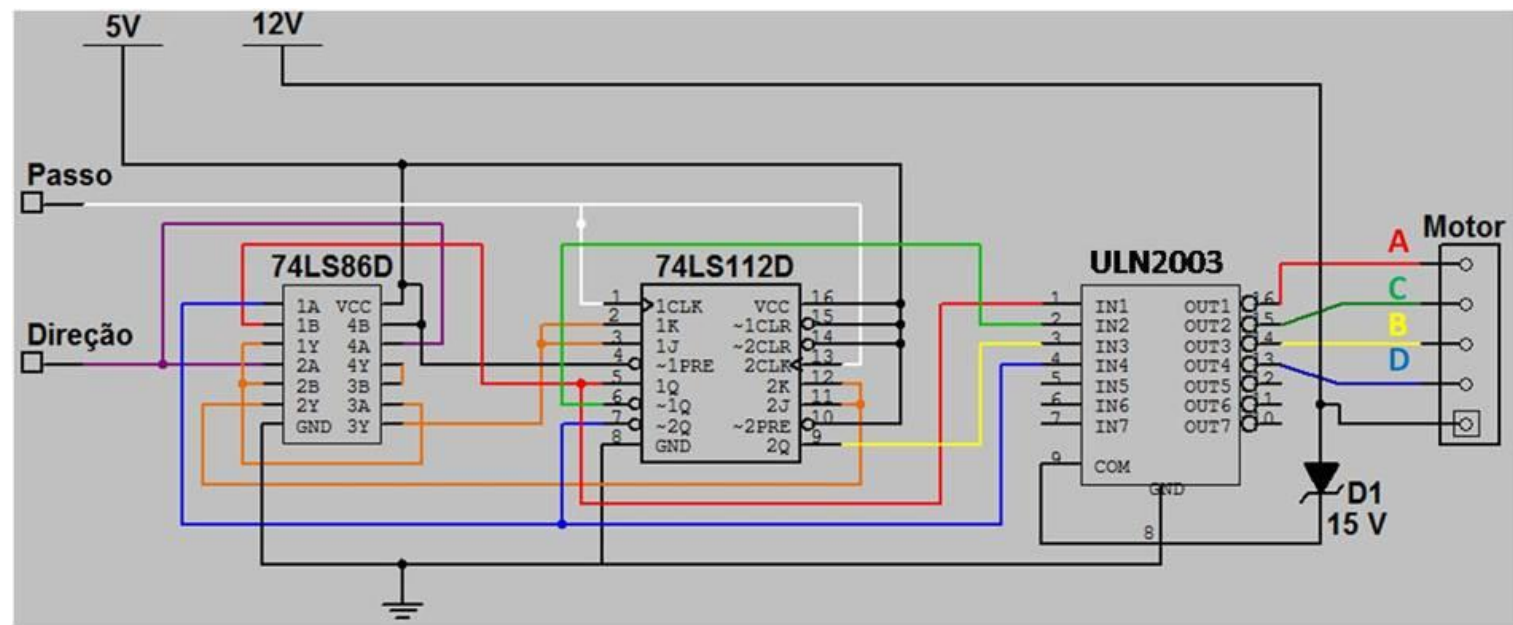

Figura 4.40 - Circuito do módulo de potência.

De maneira geral, o circuito implementado pode ser dividido em duas partes: uma responsável pela transformação do sinal de passo em sinais com padrão para excitação das bobinas do motor (parte lógica) e outra parte responsável por transformar esses sinais, com padrão para excitação das bobinas do motor, em sinais com potência suficiente para o acionamento das bobinas do motor (parte de potência).

A parte lógica é realizada pelos $\mathrm{Cl}-1$ e $\mathrm{Cl}-2$, conforme pode ser observado no diagrama lógico apresentado na Figura 4.41.

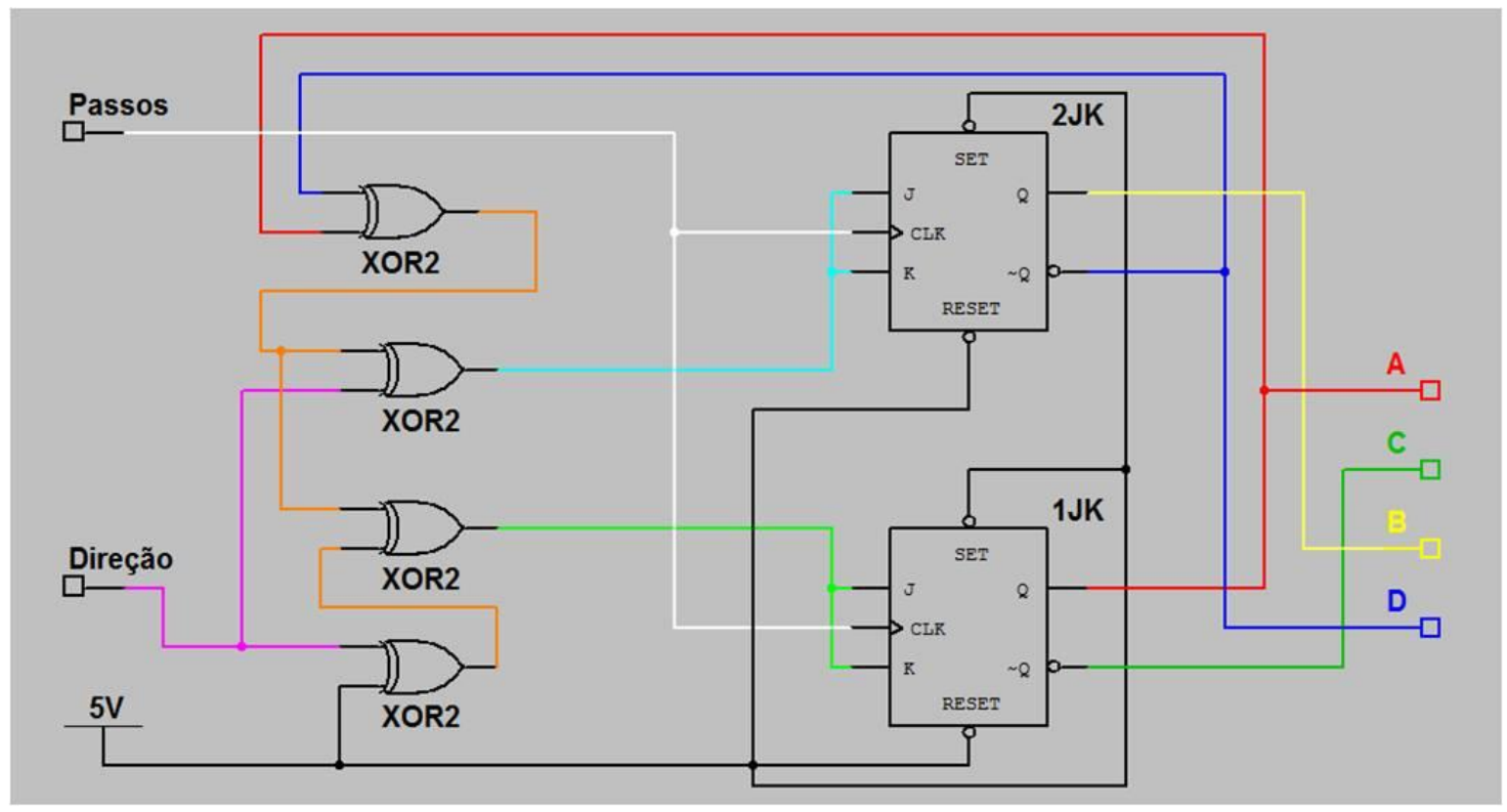

Figura 4.41 - Diagrama lógico do controle do motor de passos 
Uma simulação de 8 passos com troca de direção é apresentada na Tabela 4.3.

Tabela 4.3- Simulação de 8 passos com troca de direção no quinto passo.

\begin{tabular}{cccccc}
\hline Passo & Direção & Bobina A & Bobina B & Bobina C & Bobina D \\
\hline 1 & 0 & 1 & 0 & 0 & 1 \\
2 & 0 & 1 & 1 & 0 & 0 \\
3 & 0 & 0 & 1 & 1 & 0 \\
4 & 0 & 0 & 0 & 1 & 1 \\
& & & & & \\
5 & 1 & 0 & 0 & 1 & 1 \\
6 & 1 & 0 & 1 & 1 & 0 \\
7 & 1 & 1 & 1 & 0 & 0 \\
8 & 1 & 1 & 0 & 0 & 1 \\
\hline
\end{tabular}

A parte de potência é realizada pelo $\mathrm{Cl}-3$ que, basicamente, transforma sinais de $5 \mathrm{~V}$ em sinais de $12 \mathrm{~V}$ e protege de possível queda da tensão perto do GND, pela comutação de energização das bobinas ao utilizar diodos de proteção (CONDIT; JONES, 2004, p.8). Esta sequência lógica e o circuito foram simulados (Multisim Education Edition 11.0, National Instruments, EUA). A simulação do analisador lógico se encontra na Figura 4.42, tendo sido dividida em duas partes:a primeira com o pino de direção, em valor lógico zero desativado; e a segunda com valor lógico um ativado. Foi habilitado um switch de início de simulação e outro de final, para se observar o início da sequência de simulação. 

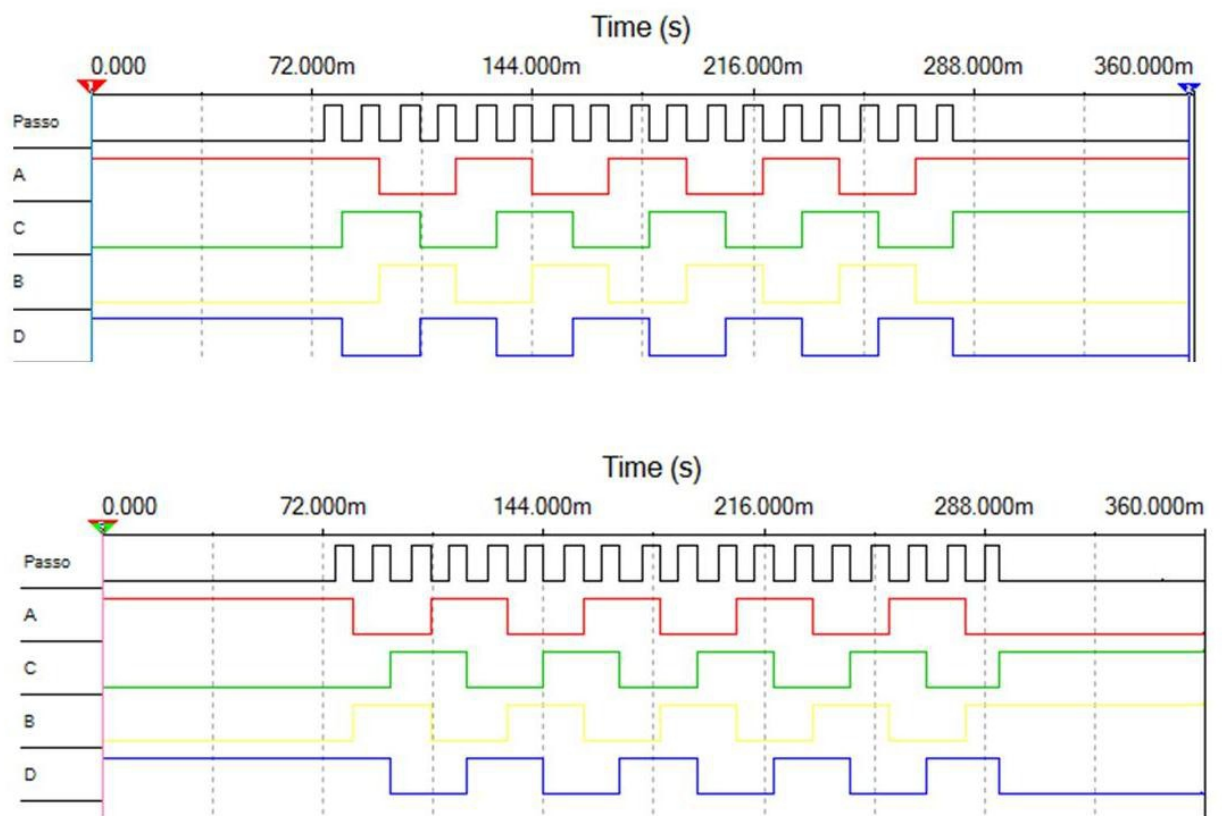

Figura 4.42 - Simulação dos estados das fases do motor em modo passo completo, com frequência de passos de $80 \mathrm{~Hz}$. (A) Estados de ativação das bobinas do motor de passo quando a direção está em estado desativado. (B) Estados de ativação das bobinas do motor de passos quando a direção está em estado ativado.

A ligação entre o módulo de potência e o motor de passos é realizada através de conectores tipo DB-9, como pode ser observado na Figura 4.43.

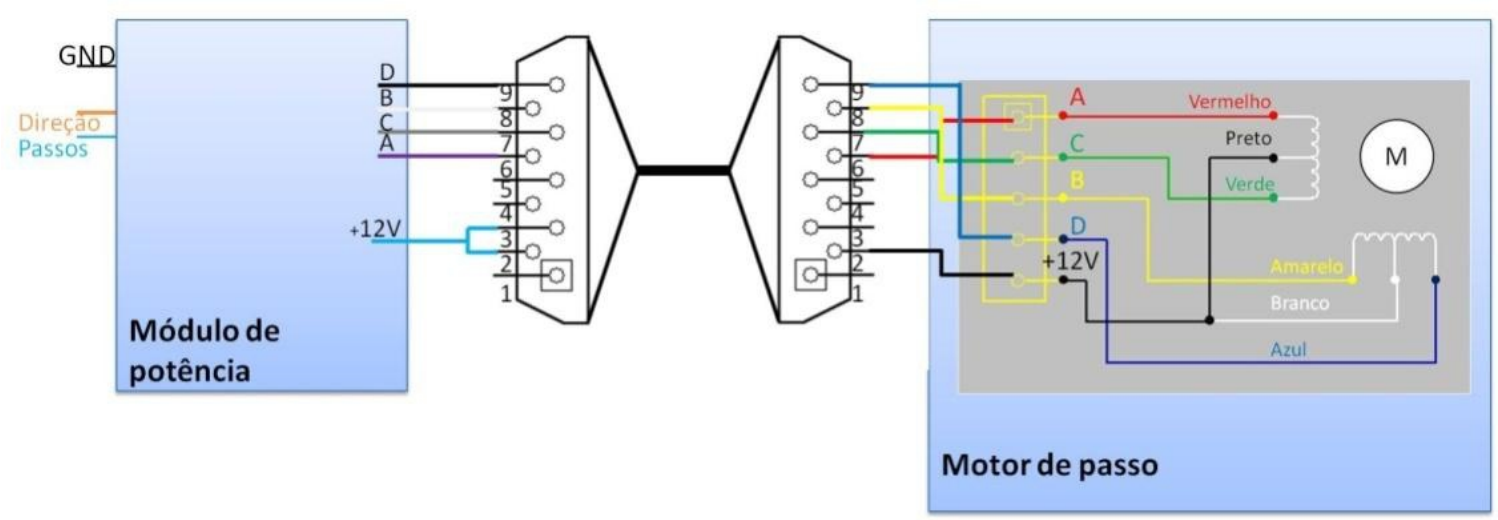

Figura 4.43 - Desenho esquemático da ligação do módulo de potência 
4.1.3 Módulo de alimentação

O módulo de alimentação interage com o resto do insuflador pulmonar para pequenos roedores, conforme apresentado na Figura 4.44.

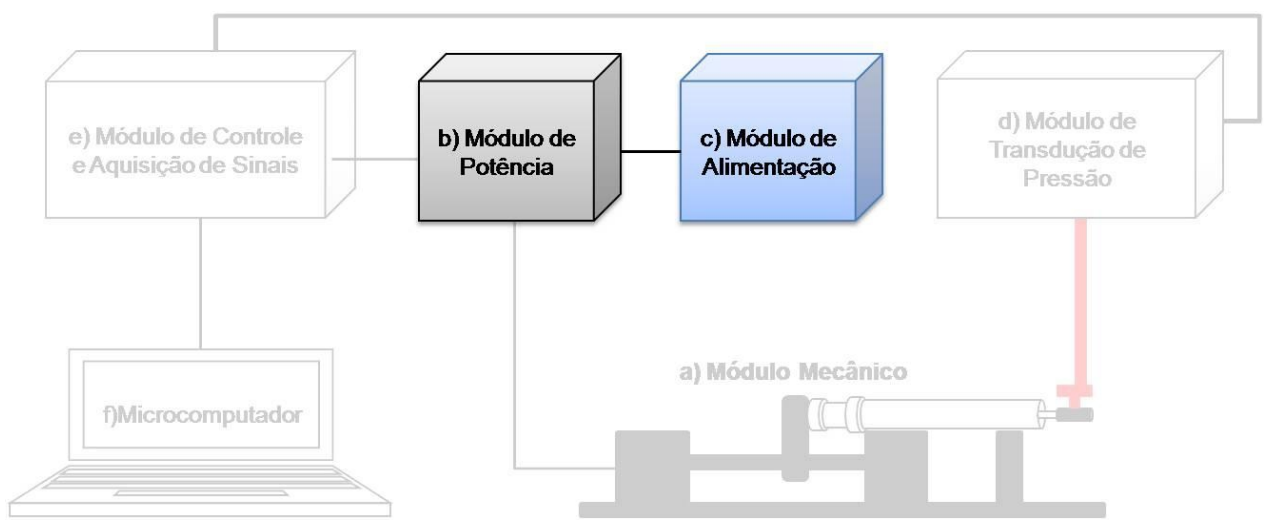

Figura 4.44 - Diagrama de blocos, com ênfase nas interações do módulo de alimentação

Este equipamento é basicamente uma fonte de alimentação em corrente contínua para o módulo de potência do motor de passo. O módulo de alimentação é conectado à tensão da rede elétrica $(127 \mathrm{~V}-60 \mathrm{~Hz})$ e produz uma tensão contínua em sua saída (12 V, $3 \mathrm{~A})$.

Para dissipar parte do calor gerado pelo módulo de potência, há um ventilador de $50 \mathrm{~mm}$ de diâmetro $(12 \mathrm{~V}, 180 \mathrm{~mA})$. Para proteção do circuito, há um fusível de $600 \mathrm{~mA}$.

O circuito elétrico deste módulo de alimentação é apresentado na Figura 4.45; trata-se basicamente de um retificador de onda completa, com ponte de diodos e um regulador de tensão.

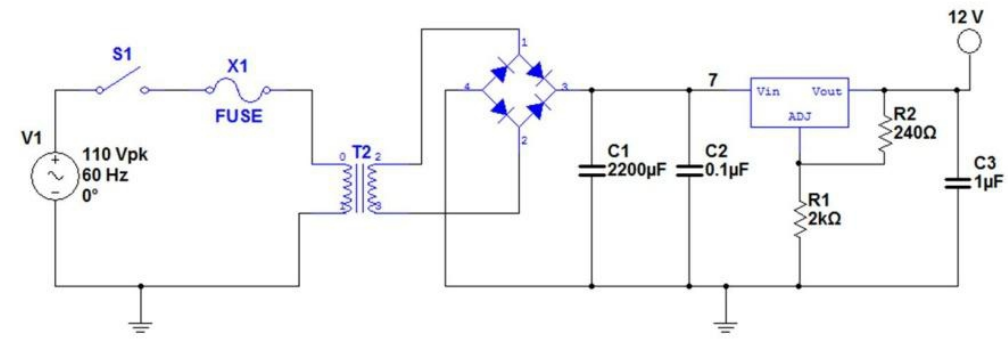

Figura 4.45 - Circuito do módulo de alimentação 
O transformador utilizado, de $3 \mathrm{~A}$, apresenta bobina primária de $127 \mathrm{~V}$ e bobina secundária de $12 \mathrm{~V}$ eficazes. Além do transformador, o módulo possui diodos em ponte, série $1 \mathrm{~N} 400 \mathrm{X}$, de $3 \mathrm{~A}$, com um filtro capacitivo de retificação de $2.200 \mu \mathrm{F}$, de $35 \mathrm{~V}$,em alumínio, e um capacitor regulador para o circuito integrado, de 0,1 $\mu \mathrm{F}$.

O regulador de tensão utilizado nesta fonte (LM350, National Semiconductors, EUA) é ajustável (1,2 V a $33 \mathrm{~V}$ ) e de $3 \mathrm{~A}$. Este circuito integrado foi calibrado para trabalhar com uma corrente de ajuste $\left(\mathrm{l}_{\mathrm{adj}}\right)$ de $100 \mu \mathrm{A}$, utilizando um resistor padrão, de $220 \Omega$, e um potenciômetro ajustável de $10 \mathrm{k} \Omega$.

A montagem elétrica e o ventilador interno estão protegidos e fixados em uma caixa plástica (100×139x150mm) (PB-215, Patola, Brasil). O terminal de alimentação externo do módulo é de tipo fêmea standard para cabo de força de127 V. A saída de $12 V$ é fornecida utilizando-se dois conectores tipo banana fêmea, sendo que o terminal positivo é o borne vermelho e o terminal de referência é o borne preto, conforme Figura 4.46.

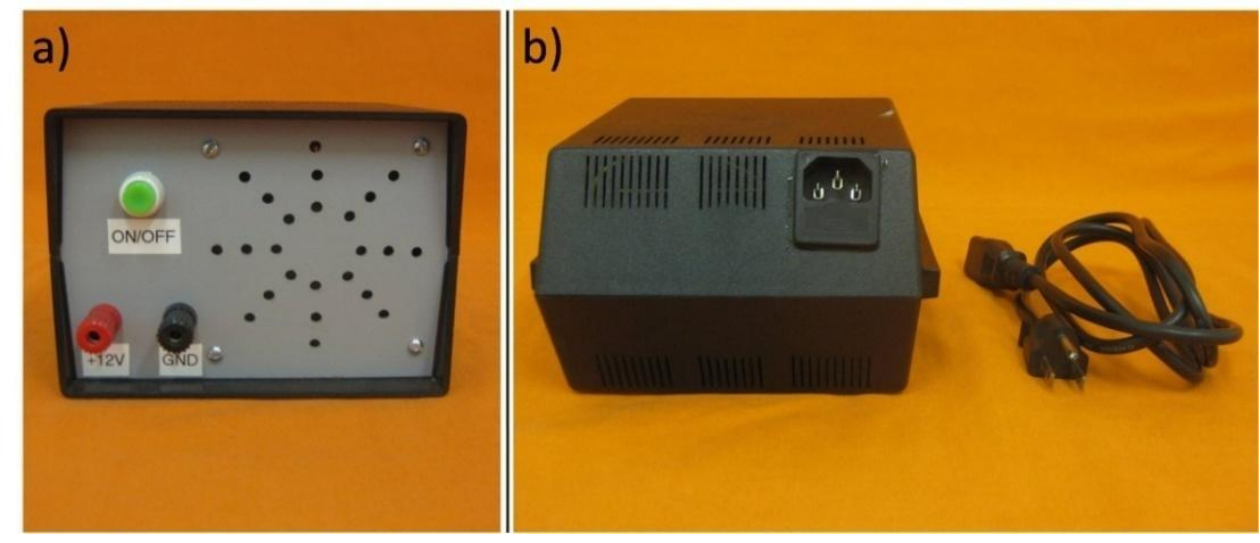

Figura 4.46 - Fotografia do módulo de alimentação

\subsubsection{Módulo de transdução de pressão}

O módulo de transdução de pressão, apresentado em destaque no diagrama da Figura 4.47, é composto por um transdutor de pressão, um circuito amplificador de sinal, um circuito de controle de nível DC (off-set) e um circuito de filtragem prédigitalização. 


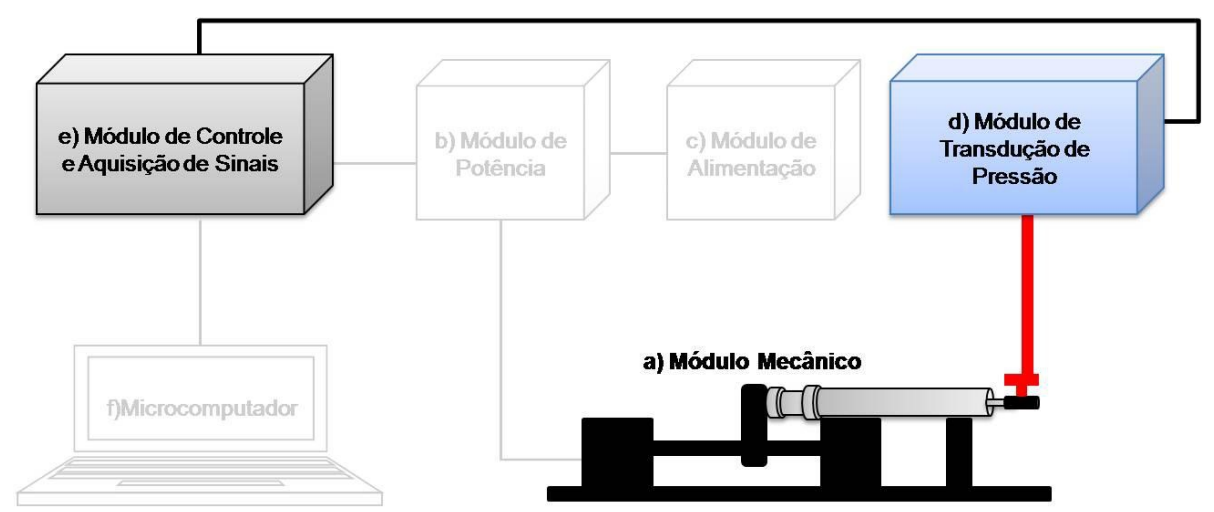

Figura 4.47 - Diagrama de blocos, com ênfase nas interações do módulo de transdução de pressão

\subsubsection{Transdutor de pressão}

O transdutor de pressão utilizado (FPM-07PG, Fujikura, Japão) é baseado em uma ponte de Wheatstone, com sensor piezelétrico em um dos braços da ponte. $O$ transdutor é encapsulado no padrão DIP-6, conforme apresentado na Figura 4.48.

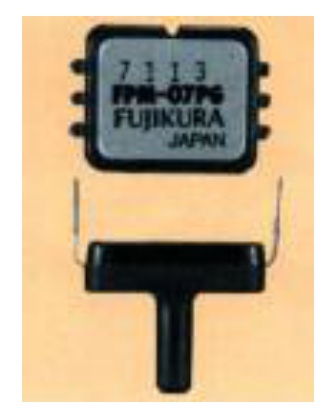

Figura 4.48 - Transdutor de pressão utilizado (Fujikura, Japão).

O esquema interno, segundo o fabricante, com a pinagem, é apresentado na Figura 4.49. 


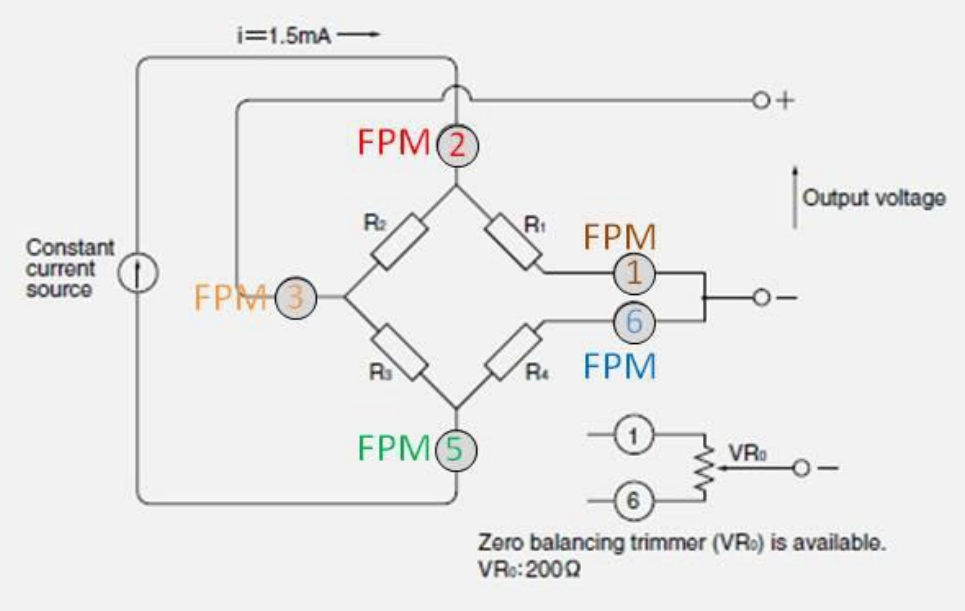

Figura 4.49 - Esquema interno do transdutor de pressão (fornecido pelo fabricante). Os números circulados indicam os pinos no circuito integrado (Fujikura, Japão).

Este transdutor é conectado à placa de amplificação e filtragem do sinal através de um cabo DB-9 padrão fêmea. Nesta placa, está contida também a fonte de corrente que alimenta o transdutor de pressão.

A Figura 4.50 indica um esquema da conexão do transdutor através de cabo com um terminal DB-9 fêmea. Na Figura 4.51, é apresentada uma fotografia da composição final.

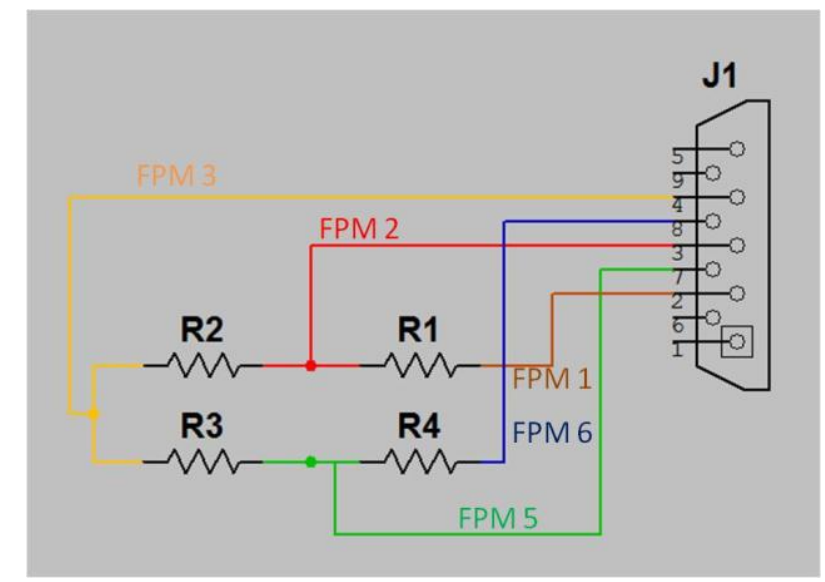

Figura 4.50 - Esquema do transdutor e ligações com o conector DB-9 fêmea

O transdutor de pressão foi protegido no seu exterior com copolímero de acrílico (Jet, Brasil), como se amostra na Figura 4.51. 


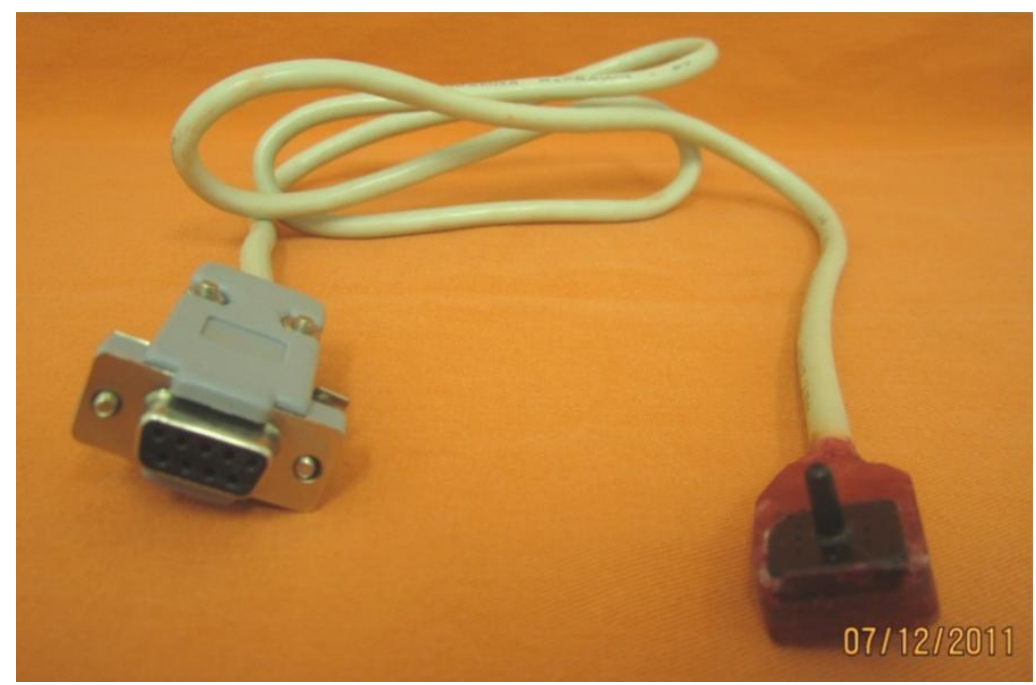

Figura 4.51 - Fotografia final do transdutor conectado ao cabo.

O transdutor de pressão está protegido por um copolímero acrílico tingido de vermelho.

4.1.4.2 Alimentação do transdutor de pressão

O transdutor de pressão (FPM-07PG, Fujikura, Japão) necessita de uma corrente constante de 1,5 mA como alimentação. Essa fonte de corrente foi construída na mesma placa que abriga o circuito de condicionamento do sinal.

A fonte de corrente contínua utiliza um diodo de referência de tensão (LM385, National Semiconductor, EUA) com Vref $=1,2 \mathrm{~V}$. Um amplificador operacional (TL072P, Texas Instruments, EUA), na configuração buffer, aplica a tensão entre a ponte e o resistor de $820 \Omega$, que define uma corrente de 1,46 mA.

A Figura 4.52 indica a conexão da fonte de corrente ao conector DB-9 do transdutor de pressão. 


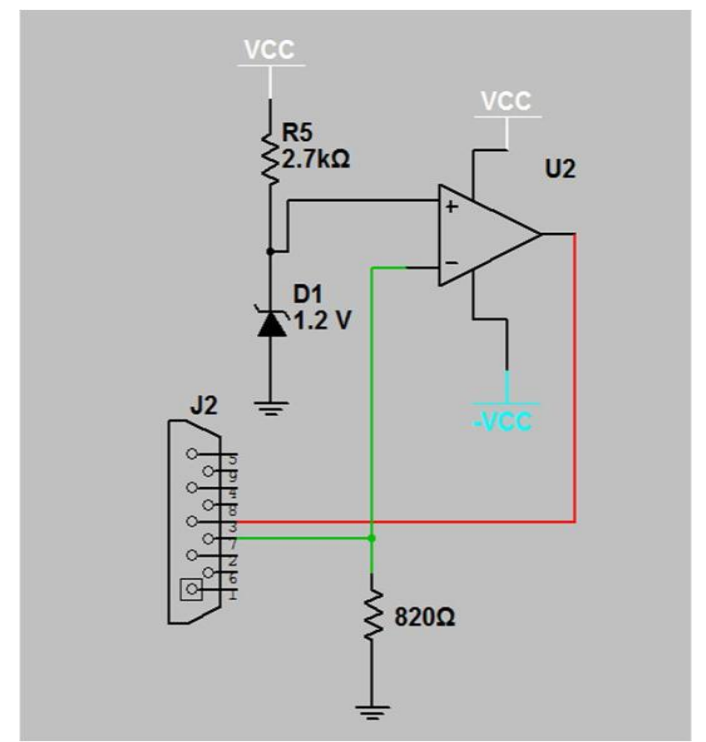

Figura 4.52 - Fonte de corrente que alimenta o transdutor de pressão.

\subsubsection{Amplificação e ajuste de nível DC do sinal analógico}

A amplificação é realizada através de um amplificador de instrumentação (AD620, Analog Devices, EUA), que tema possibilidade de controlar o ganho através de uma resistência aplicada entre os pinos 1 e $8\left(R_{g}\right)$ de seu encapsulamento padrão DIP-8. O ganho é dado pela equação 4.1:

$$
G=\frac{49400}{R_{g}}+1
$$

Por conseguinte, colocou-se um potenciômetro de $200 \Omega$ em série com um resistor de $180 \Omega$ entre esses pinos para efetuar o controle do ganho, conforme pode ser observado na Figura 4.53. 


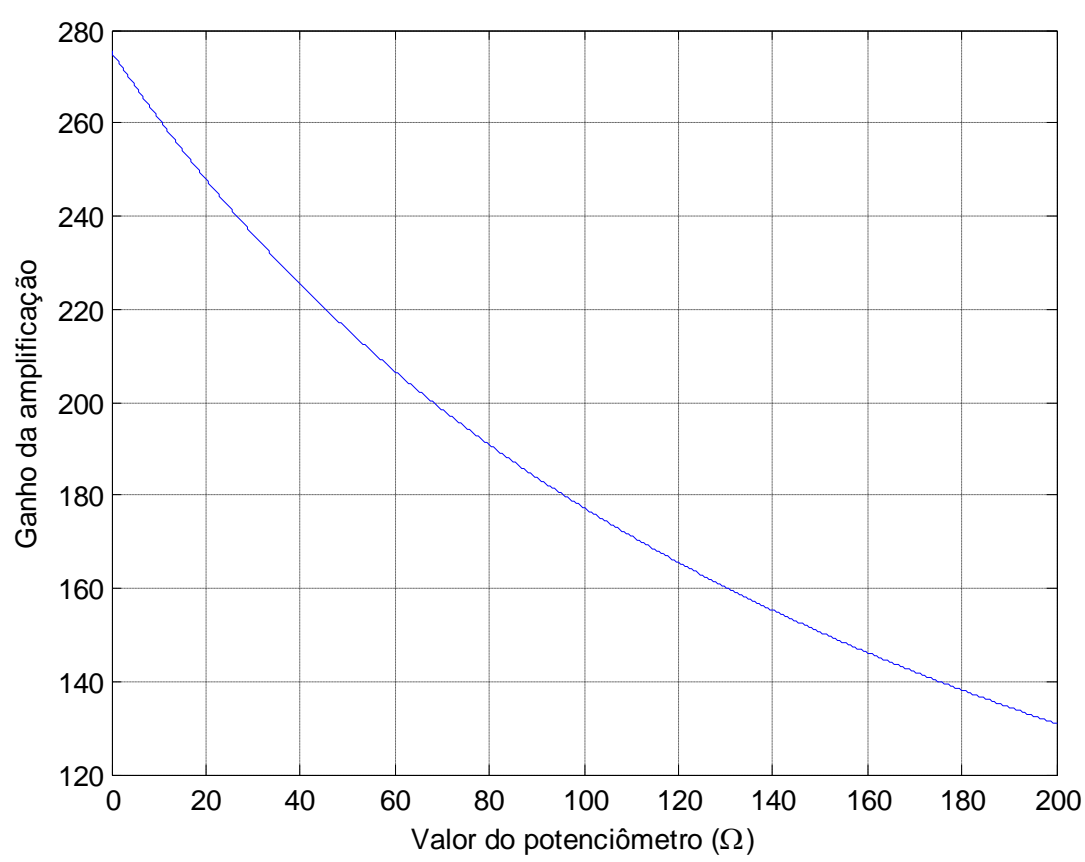

Figura 4.53 - Ganho da amplificação em função do valor do potenciômetro

Após essa amplificação, efetua-se o controle de nível DC usando um amplificador operacional (TL072P, Texas Instruments, EUA) na configuração somadora. Uma tensão contínua, proveniente de um divisor de tensão resistivo, controlado por um segundo potenciômetro, é somada ao sinal amplificado. Assim, espera-se obter um sinal de grande excursão que fique dentro dos limites do sistema de aquisição de sinais responsável pela digitalização dos dados.

A alimentação dessa placa é feita através da rede elétrica e reguladores de tensão de $+12 V$ (LM7812, National Semiconductor, EUA) e -12 V (LM7912, National Semiconductor, EUA). As tensões simétricas de +12 e $-12 V$ são necessárias para alimentação dos circuitos integrados e formação das tensões de referência.

$\mathrm{Na}$ Figura 4.54, observa-se o esquema do circuito descrito anteriormente. Vale lembrar que os fios 2 e 5 já estão sendo usados para a alimentação da corrente contínua (evidenciada na Figura 4.52). Note-se que a conexão de saída do transdutor de pressão é feita no padrão DB-9 fêmea (Figura 4.50); assim, a entrada desse subsistema deve ser feita utilizando-se um conector DB-9 macho. 


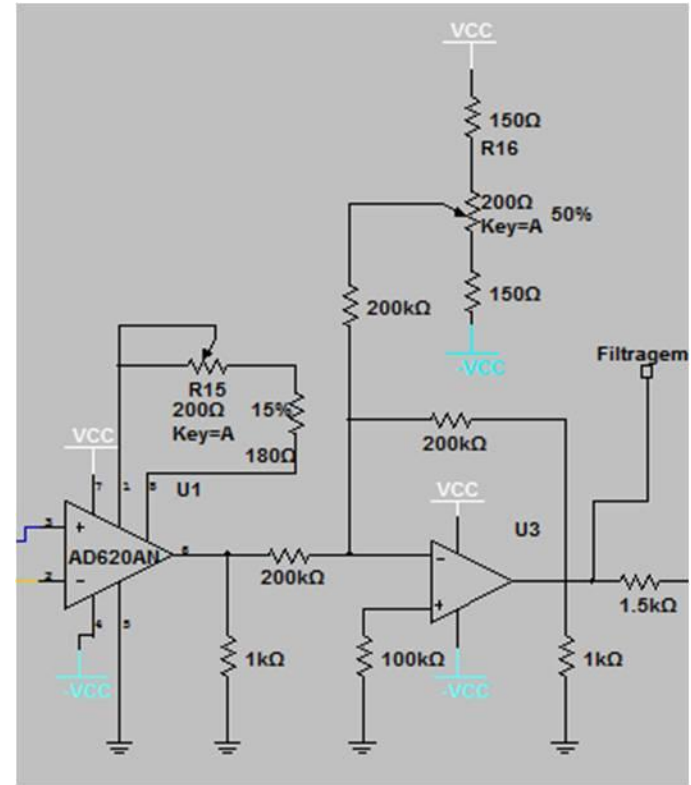

Figura 4.54 - Circuito responsável pela amplificação e pelo acréscimo de valor DC (off-set) ao sinal analógico.

\subsubsection{Filtragem pré-digitalização}

A filtragem é a última etapa do tratamento do sinal. Como em todo o processo de conversão analógico/digital de um sinal, houve a preocupação com os efeitos de aliasing e, com isso, implementou-se um filtro passa-baixas do tipo Bessel, com frequência de corte de $50 \mathrm{~Hz}$. Trata-se de uma configuração tipo Sallen-Key, com 6polos. O esquema é apresentado na Figura 4.55

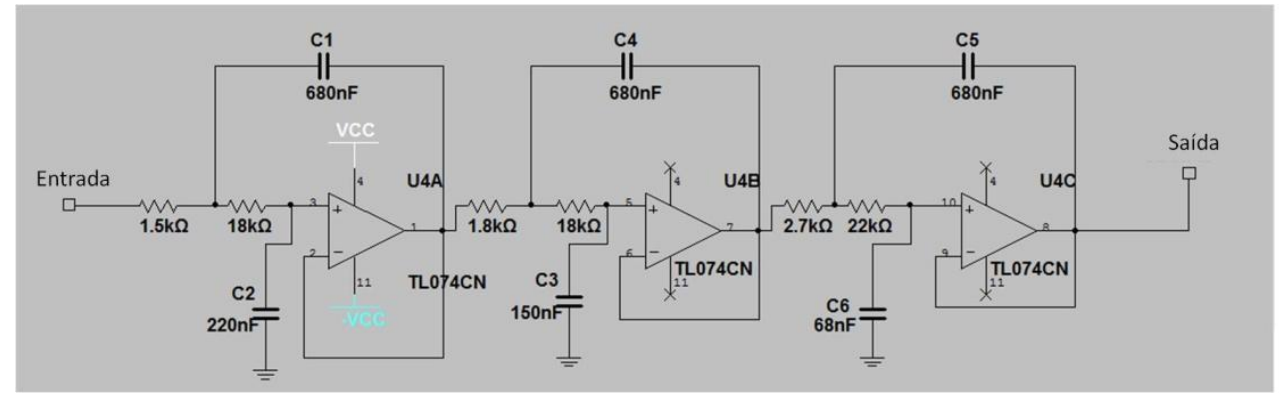

Figura 4.55 - Esquema do filtro passa-baixas com frequência de corte de $50 \mathrm{~Hz}$

A saída dessa etapa é feita através de um conector tipo BNC. 
4.1.5 Módulo de controle e aquisição de sinais

O insuflador pulmonar para pequenos animais utiliza este módulo como 0 instrumento de geração de sinais de controle do motor de passos e de captação de sinais elétricos enviados pelo módulo de transdução de pressão, conforme enfatizado na Figura 4.56.

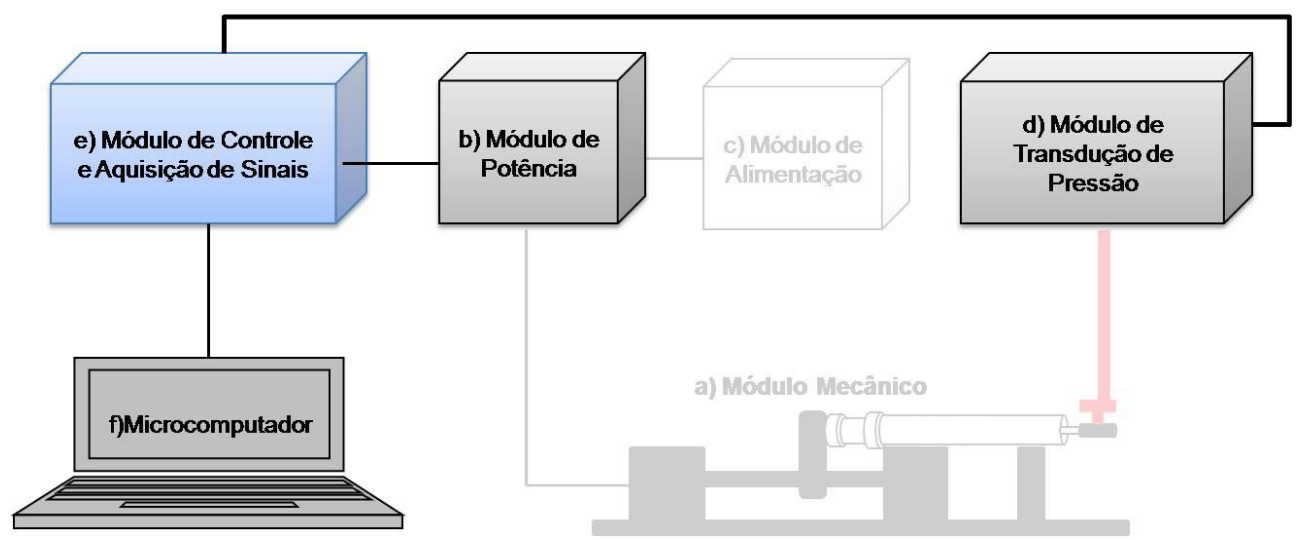

Figura 4.56 - Diagrama de blocos do insuflador, com ênfase nas interações do módulo de controle e aquisição de sinais.

Este módulo é constituído basicamente por um sistema de aquisição de dados multifunção, que contém um conversor analógico-digital (A/D), um conversor digital-analógico (D/A) e portas de entrada/saída digitais integrados (USB-6008, National Instruments, EUA). Este dispositivo é controlado por um programa em ambiente LabVIEW (8.5, National Instruments, EUA). As características do sistema de aquisição de dados multifunção utilizado são apresentadas na Tabela 4.5. 
Tabela 4.4 - Características do sistema de aquisição de dados multifunção (USB 6008, National Instruments, EUA)

\begin{tabular}{cc}
\hline Função & Sistema de aquisição de dados \\
\hline Entradas analógicas & 8 \\
Máximo intervalo de tensão elétrica de entrada & $-10 \mathrm{~V}, 10 \mathrm{~V}$ \\
Canais análogos de saída & 2 \\
Canais digitais bidirecionais Entrada/Saída & 12 \\
Contador de 32 bits & 1 \\
Resolução entrada analógica & 12 bits diferenciais \\
Taxa máxima de amostragem de entrada analógica, de um só & $10 \mathrm{KS} / \mathrm{s}$ \\
canal & $10 \mathrm{KS} / \mathrm{s}$ \\
Taxa máxima de amostragem de entrada analógica, canal múltiplo & Coletor aberto \\
\hline
\end{tabular}

O sistema de aquisição de dados multifunção se comunica com 0 microcomputador usando um cabo USB (do inglês Universal Serial Bus);além disso, se comunica com o módulo de potência através de um conector DB-9 fêmea e com o módulo de transdução de pressão por um cabo com conectores tipo BNC.

Este equipamento foi acondicionado dentro de uma caixa plástica (53x85x123mm) (PB-112, Patola, Brasil), com terminais de conexão para os cabos de comunicação entre ele e os outros módulos, como pode ser observado na Figura 4.57 .

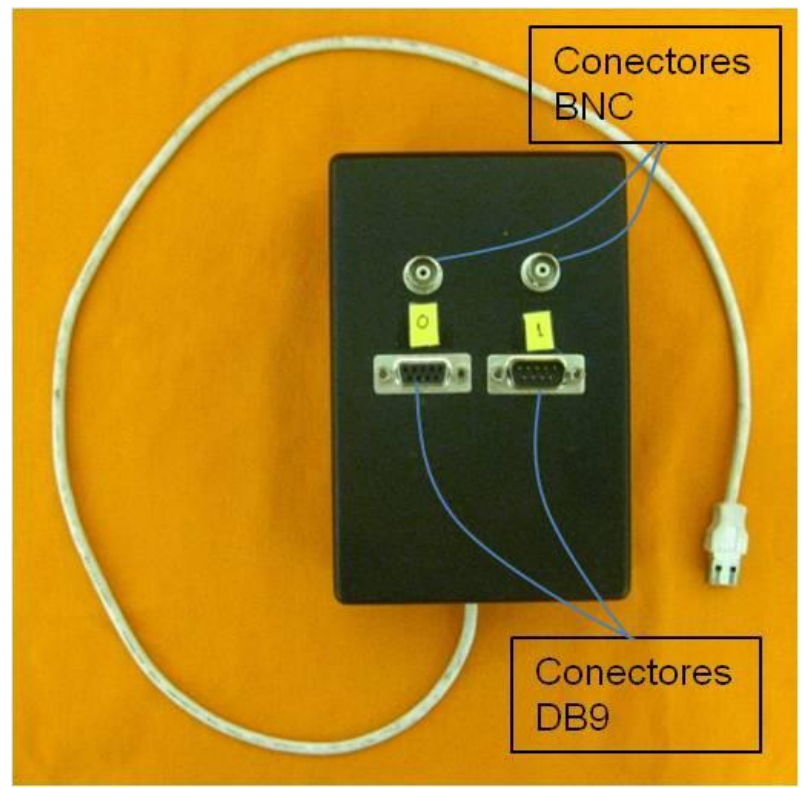

Figura 4.57 - Módulo de controle e aquisição de sinais. 
Foram utilizadas portas digitais de saída para o controle do motor de passos, correspondentes a pulsos para o motor e a seleção de sentido de giro. Além disso, a tensão elétrica de $5 \mathrm{~V}$ e a de referência de terra (GND) também são obtidas do equipamento. $\mathrm{Na}$ Tabela 4.5, são apresentadas as conexões entre as portas do sistema de aquisição de dados multifunção e o conector DB-9.

Tabela 4.5 - Conexões do sistema de aquisição de dados multifunção com módulo de potência

\begin{tabular}{llll}
\hline Equipamento & DB-9 & Função \\
Pino & Porta & Fêmea & \\
\hline 17 & P0. 0 & 6 & Passo \\
18 & P0.1 & 7 & Direção \\
19 & P0. 2 & 2 & -- \\
20 & P0. 3 & 4 & - \\
21 & P0. 4 & 8 & ------ \\
31 & $+5 V$ & 1 & Alimentação \\
32 & GND & 9 & Referência \\
\hline
\end{tabular}

A aquisição de dados de saída do módulo de transdução de pressão se faz através do canal 0 do conversor $A / D$.

$\mathrm{Na}$ Figura 4.58, são apresentadas todas as conexões das portas utilizadas do sistema de aquisição de dados multifunção e os tipos de cabos/conectores utilizados nas ligações com os módulos de transdução de pressão e módulo de potência. 


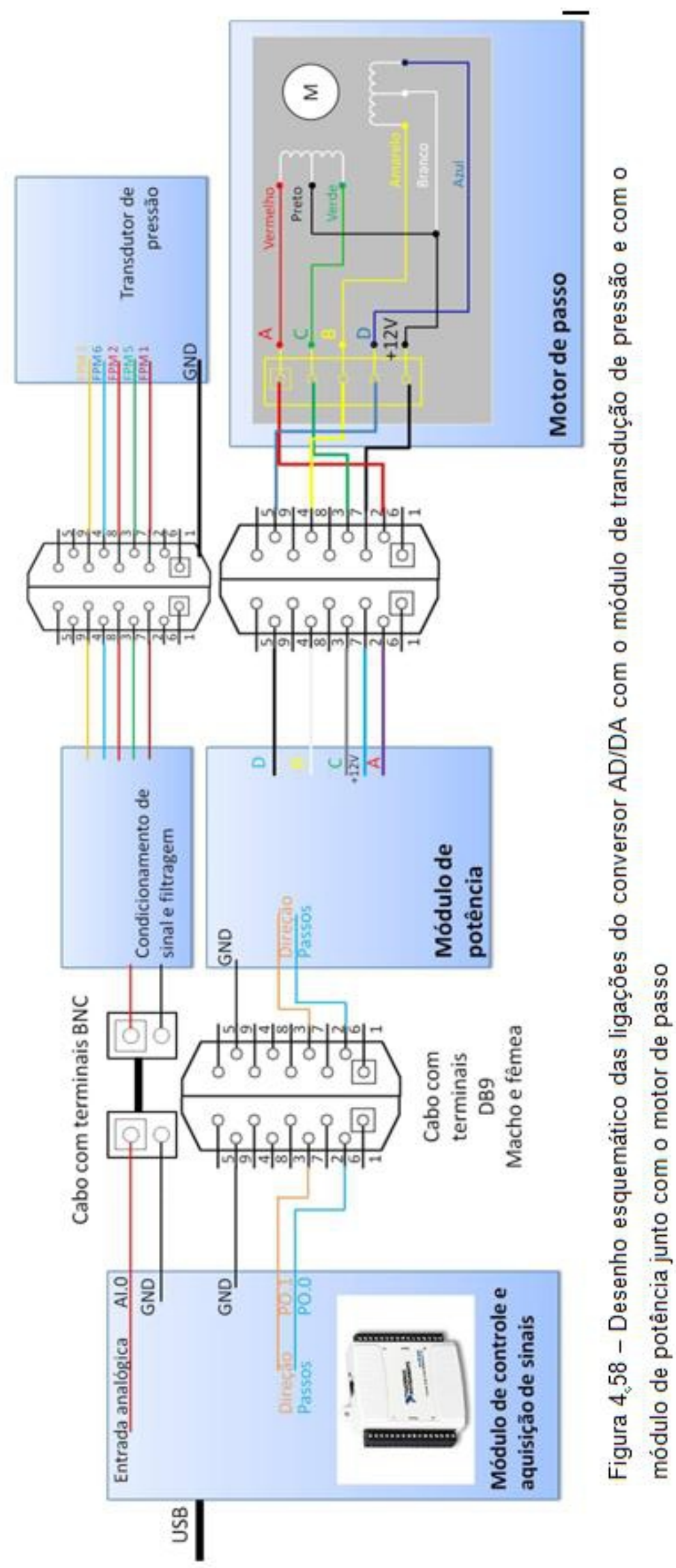




\subsubsection{Microcomputador}

O microcomputador utilizado foi um notebook com processador Intel Core 2 Duo de 2,0 GHz, com memória RAM instalada de 4GB, com sistema operacional Windows 7 Professional de 64 Bits (Microsoft, EUA). Neste equipamento, foi instalado o software de controle e aquisição de dados compatível com o módulo de controle e aquisição de sinais, conforme Figura 4.59. Este software foi desenvolvido em plataforma LabVIEW (versão 8.5, National Instruments, EUA).

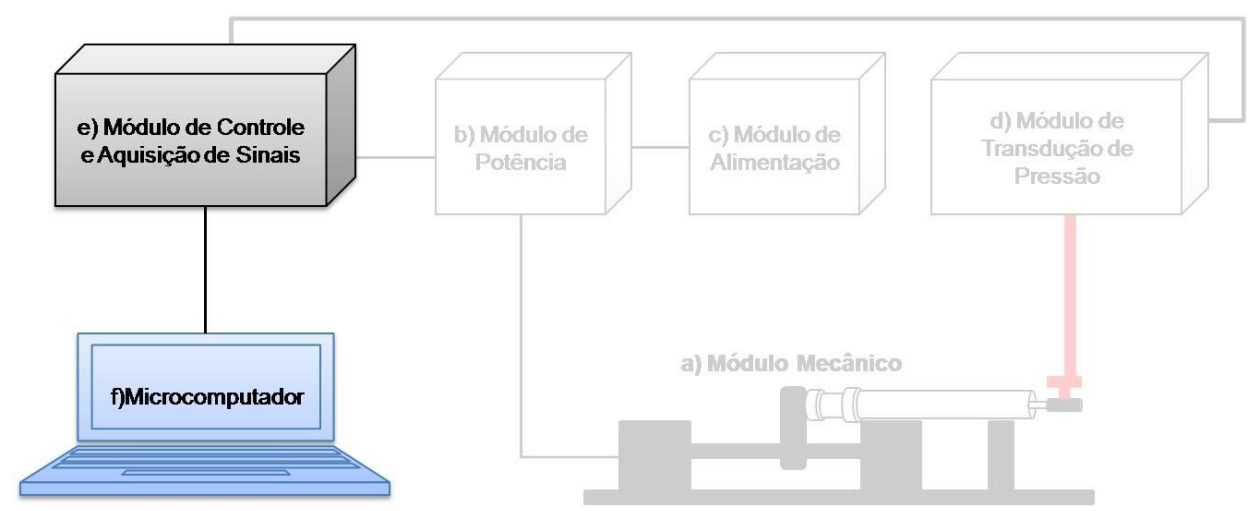

Figura 4.59 - Diagrama de blocos do insuflador,com ênfase nas interações do microcomputador.

O software implementado realiza os seguintes processos:

- $\quad$ Controle do motor de passo

- Configuração e aquisição do sinal do módulo de transdução de pressão

- Configuração dos parâmetros de experimentação da seringa

- Coleta, análise, apresentação e armazenamento dos dados da experimentação

Estas tarefas são realizadas em ordem lógica, para facilitar ao usuário a interação com o equipamento de insuflação pulmonar. O fluxograma do programa implementado é apresentado na Figura 4.60. 


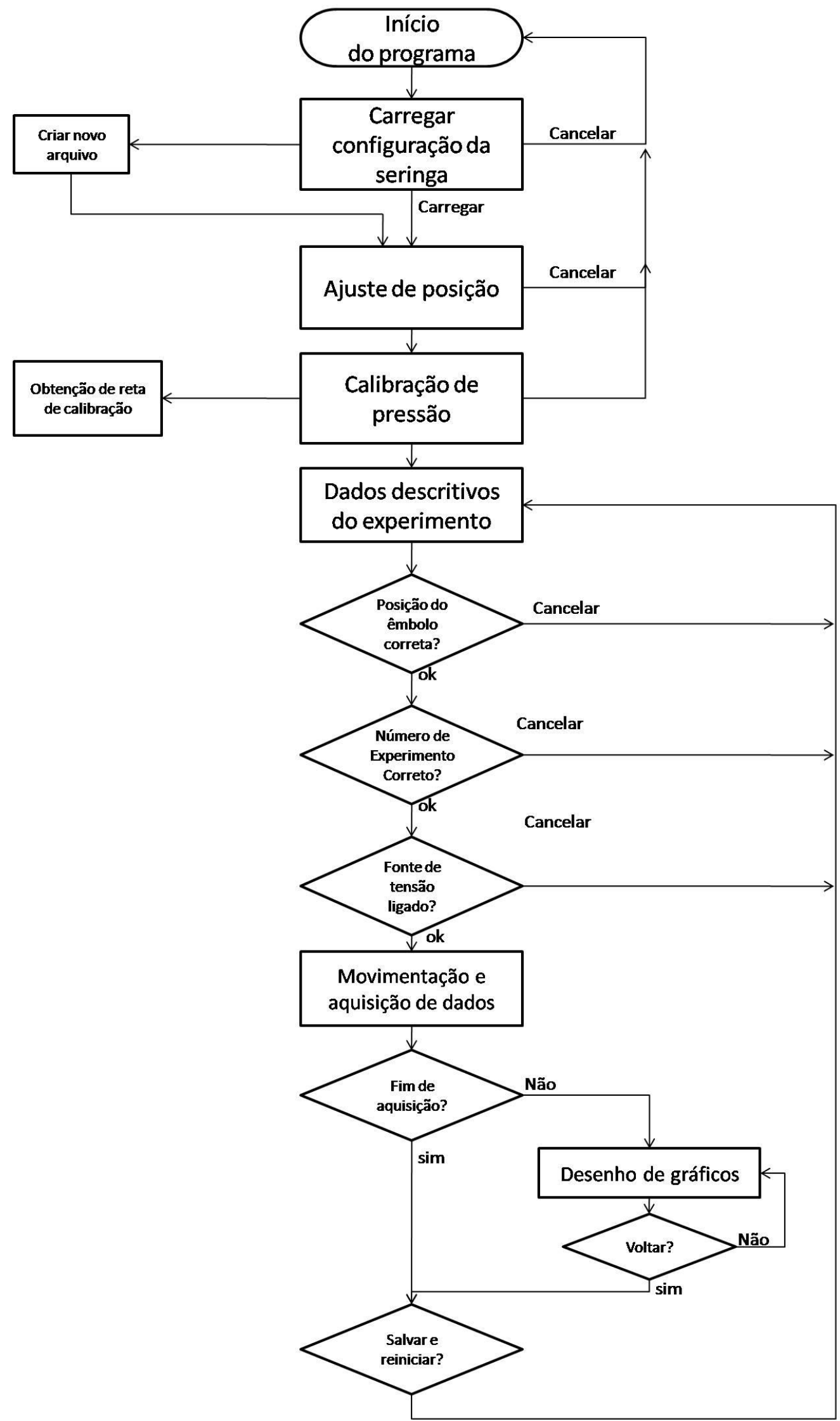

Figura 4.60 - Fluxograma do programa de controle do insuflador pulmonar para pequenos roedores. 


\subsection{TESTES DE BANCADA DO IPPR}

Nesta seção, são exibidos os resultados obtidos com os protocolos de avaliação do IPPR apresentados no Capítulo 3, seções 3.2.1 e 3.2.2.

4.2.1 Avaliação de volume e velocidade do IPPR

Conforme apresentado na seção (3.2.1), para caracterizar o comportamento de insuflação de ar do IPPR foi necessária a medida de parâmetros físicos próprios do módulo mecânico, como as distâncias $d, r$ e Cins_IPPR.

A distância $d$ medida foi de $7,000 \pm 0,005 \mathrm{~cm}$ e o raio $r$ de $1,380 \pm 0,003 \mathrm{~cm}$. Uma vez medidas as distâncias, os valores obtidos foram substituídos na equação 3.1, obtendo-se o valor médio da Cins_IPPR de $41,88 \mathrm{~mL}$, com desvio padrão de $0,23 \mathrm{~mL}$, calculado pela equação3.6.

Os resultados das manobras de insuflação são apresentados nas tabelas 4.6 a 4.10 . 

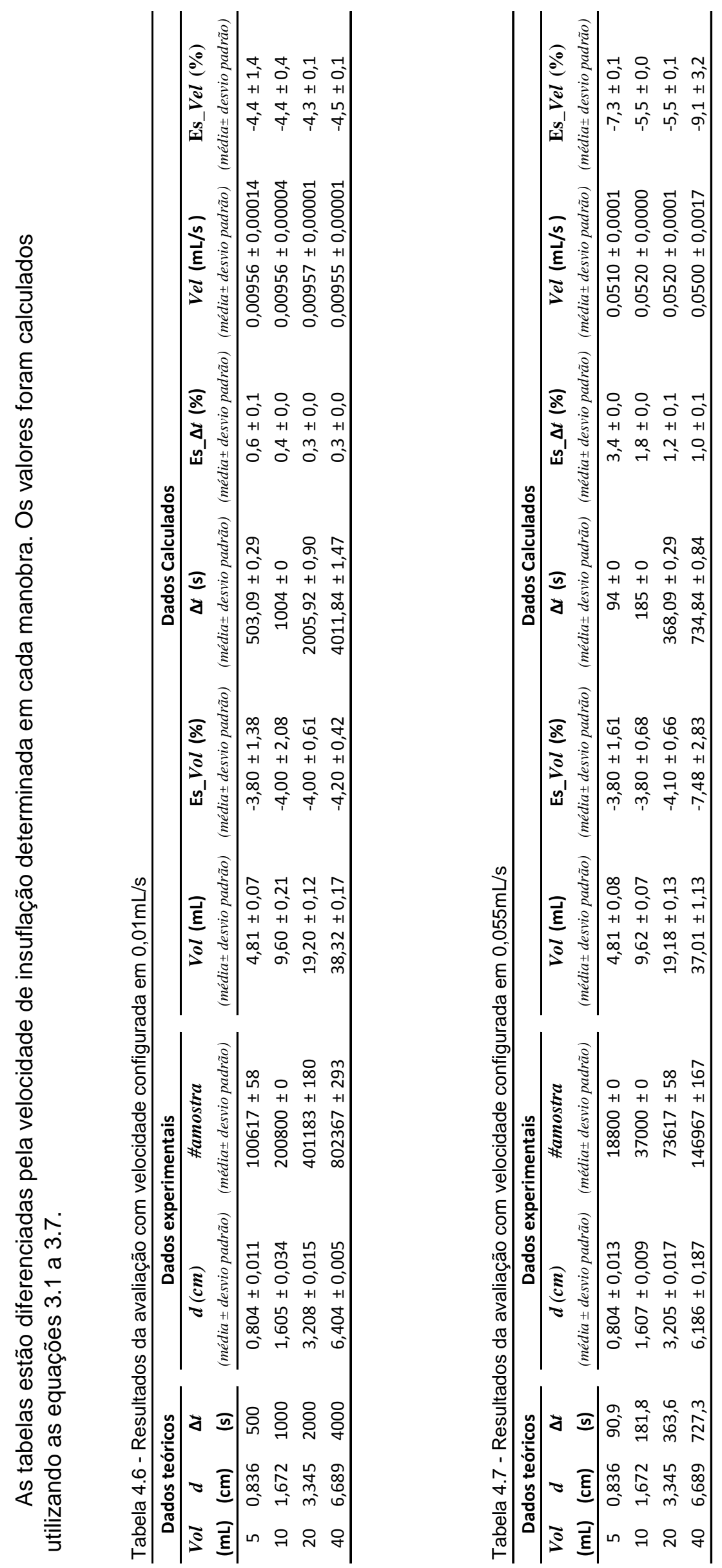

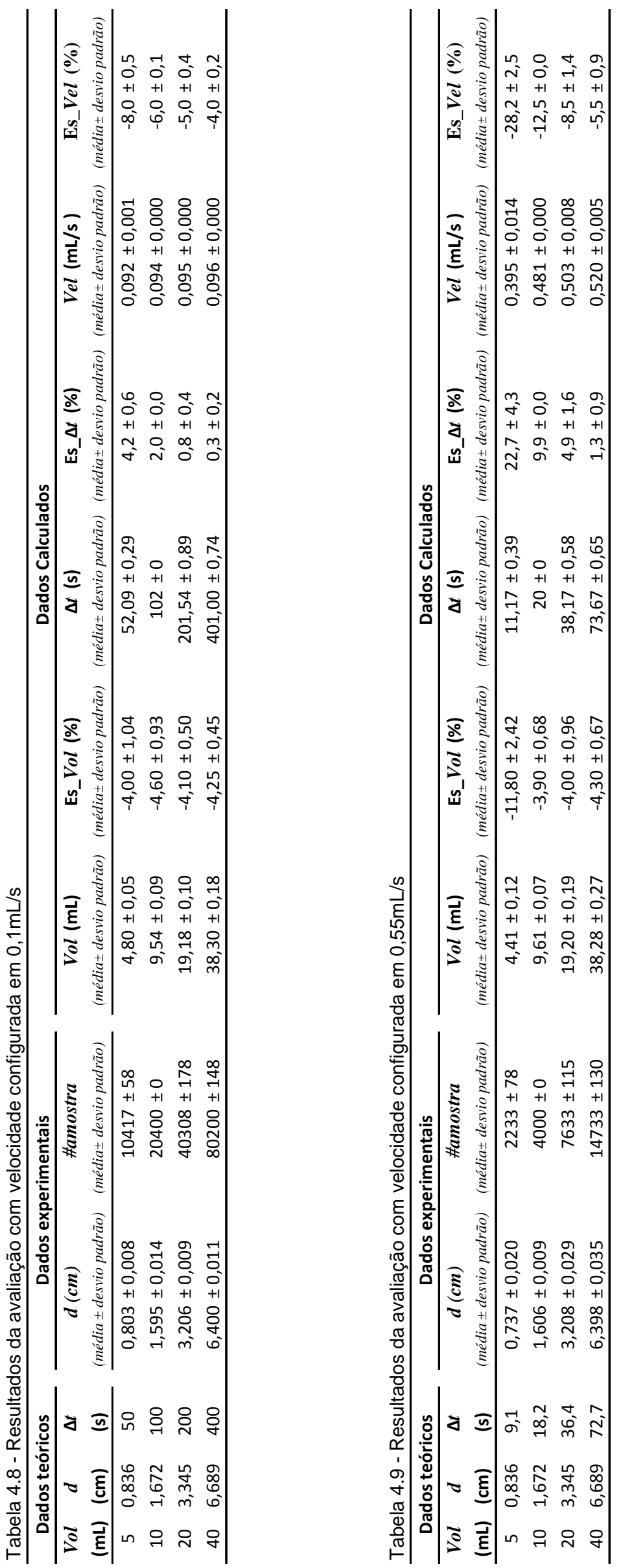


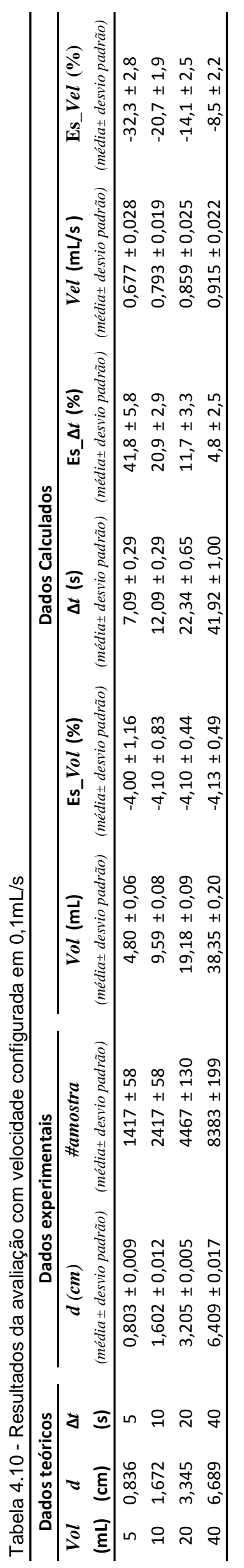


As tendências dos erros do volume insuflado, do intervalo de tempo de insuflação e da velocidade do IPPR, calculadas pelos índices de erro sistemático Es_Vol $(\%), \quad$ Es_st $(\%), \quad$ Es_Vel(\%), para as diferentes manobras, podem ser observadas, para fins de comparação entre as diferentes velocidades teóricas de insuflação, nas Figura 4.61 a 4.63.

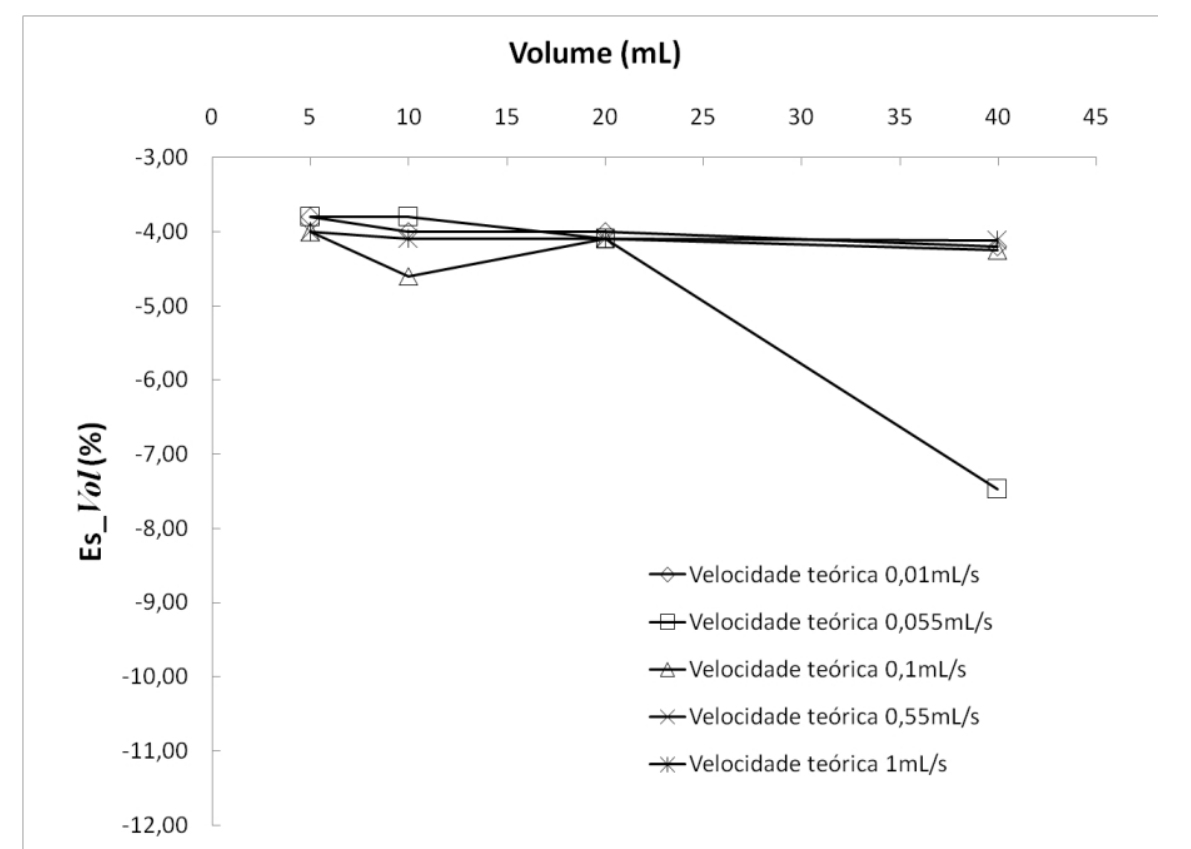

Figura 4.61 - Comportamento do erro sistemático do volume medido a diferentes volumes e velocidades programados no IPPR.

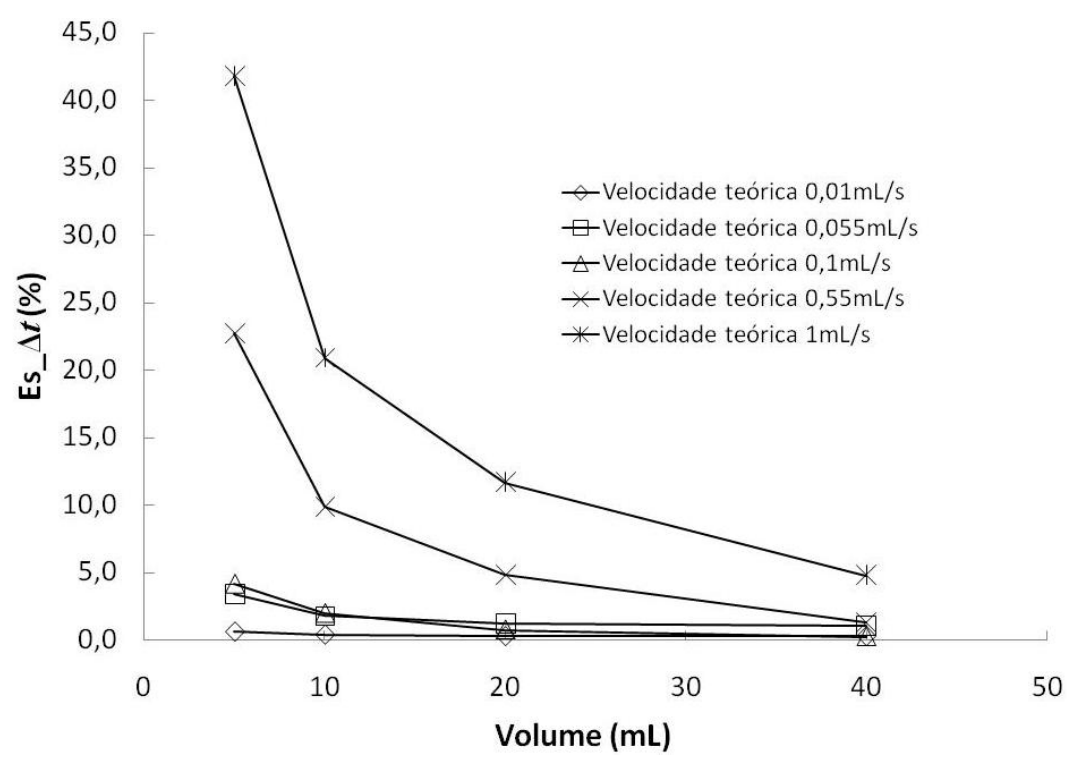

Figura 4.62 - Comportamento do erro sistemático do intervalo de tempo medido a diferentes volumes e velocidades programados no IPPR. 


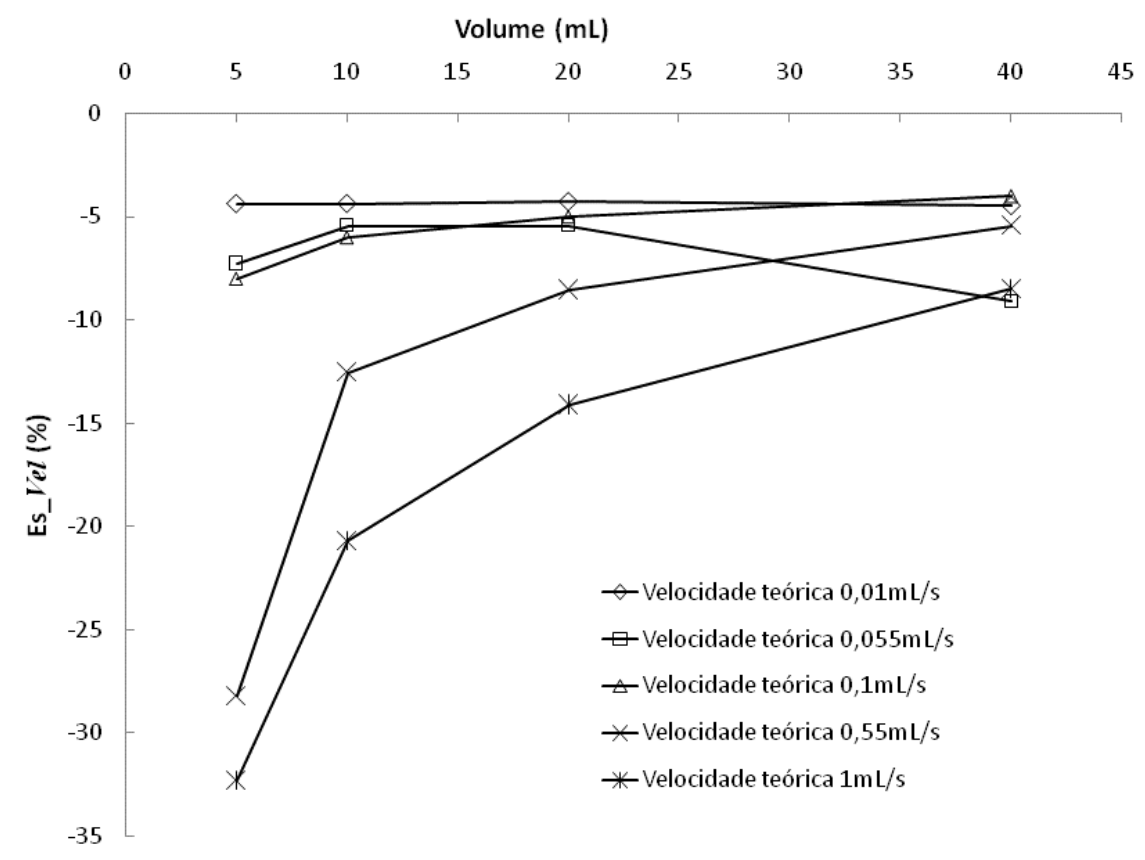

Figura 4.63 - Comportamento do erro sistemático da velocidade medida a diferentes volumes e velocidades programados no IPPR.

$\mathrm{Na}$ Tabela 4.11, são apresentados os dados referentes às condições ambientais presentes durante a realização das manobras de insuflação do IPPR no LEB, sala D2-22 da EPUSP.

Tabela 4.11 - Dados referentes às manobras de insuflação para avaliação de volume e velocidade do IPPR

\begin{tabular}{|c|c|c|}
\hline Condições ambientais & $\begin{array}{c}\text { Máxima } \\
\text { (média } \pm \\
\text { desvio- } \\
\text { padrão) }\end{array}$ & $\begin{array}{c}\text { Mínima } \\
\text { (média } \pm \text { desvio- } \\
\text { padrão) }\end{array}$ \\
\hline Temperatura ambiente $\left({ }^{\circ} \mathrm{C}\right)$ & $23,07 \pm 1,49$ & $23,32 \pm 13,42$ \\
\hline Umidade Relativa (\%ur) & $38,62 \pm 5,51$ & $35,61 \pm 5,11$ \\
\hline *Pressão atmosférica ambiente (hPa) & $931,46 \pm 3,32$ & $930,99 \pm 3,29$ \\
\hline
\end{tabular}

* Dados obtidos no site do INMETRO (www2.inmetro.gov.br), nas datas referentes à experimentação. 


\subsubsection{Avaliação de pressão do IPPR}

Foram realizados 48 ensaios, sendo 24 incursões com o transdutor $S n l$ e as outras com o transdutor $\mathrm{Sn2}$. Cada conjunto de ensaios foi dividido aleatoriamente em 12 incursões com ganho máximo (Gmáx) e 12 com ganho mínimo (Gmín). Os dados obtidos podem se observados na Tabela 4.12.

Tabela 4.12 - Dados referentes às incursões de pressão para avaliação de pressão

\begin{tabular}{|c|c|c|c|c|c|}
\hline & & \multirow{2}{*}{\multicolumn{2}{|c|}{ Sn1 }} & & \\
\hline & & & & \multicolumn{2}{|c|}{ Sn2 } \\
\hline & & Gmín & Gmáx & Gmín & Gmáx \\
\hline \multirow{2}{*}{$\begin{array}{l}\text { Faixa nominal } \\
\text { de entrada }\end{array}$} & $P \min \left(\mathrm{cmH}_{2} \mathrm{O}\right)$ & $-34,4 \pm 0,1$ & $-34,4 \pm 0,1$ & $-34,4 \pm 0,1$ & $-34,4 \pm 0,1$ \\
\hline & $\operatorname{Pmax}\left(\mathrm{cmH}_{2} \mathrm{O}\right)$ & $37,7 \pm 0,1$ & $37,6 \pm 0,1$ & $37,6 \pm 0,1$ & $37,6 \pm 0,1$ \\
\hline \multirow{2}{*}{$\begin{array}{l}\text { Faixa nominal } \\
\text { de saída }\end{array}$} & $\begin{array}{c}\text { Ts.mín (V) } \\
\text { (média } \pm \text { desvio-padrão) }\end{array}$ & $-2,07 \pm 0,02$ & $-4,75 \pm 0,06$ & $-0,83 \pm 0,01$ & $-1,86 \pm 0,05$ \\
\hline & $\begin{array}{c}\text { Ts.máx (V) } \\
\text { (média } \pm \text { desvio-padrão) }\end{array}$ & $2,24 \pm 0,03$ & $5,08 \pm 0,06$ & $0,91 \pm 0,03$ & $2,15 \pm 0,05$ \\
\hline
\end{tabular}

Para calcular os índices $S, \operatorname{Lin} \%$ e Rsn, resultantes das equações 3.13 a 3.16, foi preciso definir os índices intermédios descritos naTabela 4.13.

Tabela 4.13 - Dados referentes aos índices envolvidos na avaliação de pressão do IPPR

\begin{tabular}{|c|c|c|c|c|}
\hline & \multicolumn{2}{|c|}{ Sn1 } & \multicolumn{2}{|c|}{ Sn2 } \\
\hline & Gmín & Gmáx & Gmin & Gmáx \\
\hline $\operatorname{Dif}_{\text {máx }}(V)$ & 0,03 & 0,1 & 0,03 & 0,06 \\
\hline$\Delta T \boldsymbol{s}(\boldsymbol{V})$ (média \pm desvio-padrão) & $0,24 \pm 0,01$ & $0,55 \pm 0,01$ & $0,10 \pm 0,23$ & $0,22 \pm 0,01$ \\
\hline $\boldsymbol{\Delta P}\left(\mathbf{c m H} \mathrm{H}_{2} \mathrm{O}\right)$ (média \pm desvio-padrão) & $4,0 \pm 0,1$ & $4,0 \pm 0,1$ & $4,0 \pm 0,1$ & $4,0 \pm 0,1$ \\
\hline$V_{\text {faixa.entrada }}(V)$ & 20 & 20 & 20 & 20 \\
\hline N.bits & 12 & 12 & 12 & 12 \\
\hline $\boldsymbol{R}_{A D}($ V/bits $)$ & 0,005 & 0,005 & 0,005 & 0,005 \\
\hline $\boldsymbol{F E}_{\boldsymbol{E}}\left(\boldsymbol{c m} \boldsymbol{H}_{2} \mathrm{O}\right)$ (média \pm desvio-padrão) & $37,7 \pm 0,1$ & $37,6 \pm 0,1$ & $37,6 \pm 0,3$ & $37,6 \pm 0,3$ \\
\hline $\boldsymbol{F E} \boldsymbol{E}(\boldsymbol{V})$ (média \pm desvio-padrão) & $2,24 \pm 0,03$ & $5,08 \pm 0,06$ & $0,91 \pm 0,03$ & $2,15 \pm 0,06$ \\
\hline
\end{tabular}

$\mathrm{Na}$ Tabela 4.14, se observam os índices calculados com ajuda da Tabela 4.13 . 
Tabela 4.14 - Dados dos índices de sensibilidade, regressão linear e Res. MTP dos transdutores utilizados

\begin{tabular}{|c|c|c|c|c|c|}
\hline & & \multicolumn{2}{|c|}{ Sn1 } & \multicolumn{2}{|c|}{$\operatorname{Sn} 2$} \\
\hline & & Gmin & Gmáx & Gmín & Gmáx \\
\hline \multicolumn{2}{|c|}{$\begin{array}{c}S\left(\mathbf{V} / \mathbf{c m H}_{\mathbf{2}} \mathbf{O}\right) \\
\text { (média } \pm \text { desvio-padrão) }\end{array}$} & $0,06 \pm 0,03$ & $0,14 \pm 0,01$ & $0,02 \pm 0,06$ & $0,06 \pm 0,01$ \\
\hline \multirow{3}{*}{$\begin{array}{l}\text { Regressão } \\
\text { Linear }\end{array}$} & $\boldsymbol{A}$ & 0,06 & 0,1 & 0,02 & 0,06 \\
\hline & $B$ & 0 & 0 & 0 & 0 \\
\hline & $R^{2}$ & 1 & 1 & 1 & 1 \\
\hline \multicolumn{2}{|c|}{$\begin{array}{c}\boldsymbol{\operatorname { R e s }} \_\boldsymbol{P r}\left(\mathbf{c m H}_{2} \mathbf{O} / \mathbf{b i t}\right) \\
(\text { média } \pm \text { desvio-padrão) }\end{array}$} & $0,084 \pm 0,001$ & $0,037 \pm 0,001$ & $0,206 \pm 0,007$ & $0,088 \pm 0,002$ \\
\hline
\end{tabular}

Os resultados do cálculo da linearidade dos transdutores testados são observados na Figura 4.64.

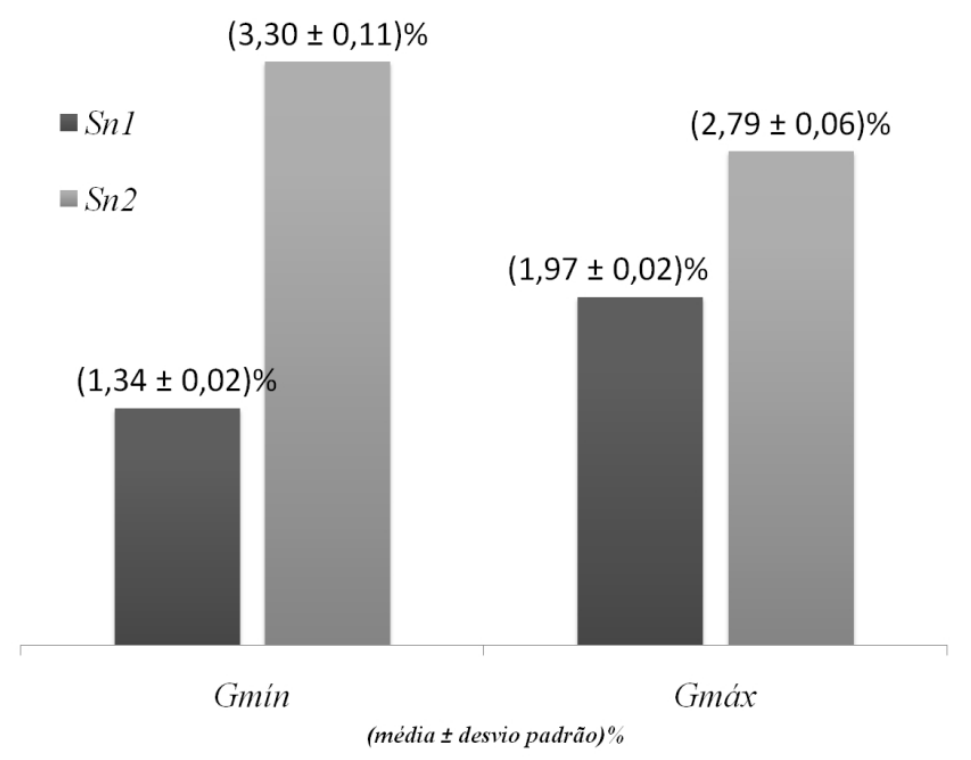

Figura 4.64 - llustração da linearidade $\operatorname{Lin}(\%)$ dos transdutores $S n 1$ e $S n 2$ ao variar $G$. Valores apresentados (média \pm desvio-padrão)\%.

As retas que representam o comportamento linear dos transdutores de pressão podem ser observadas na Figura 4.65. 


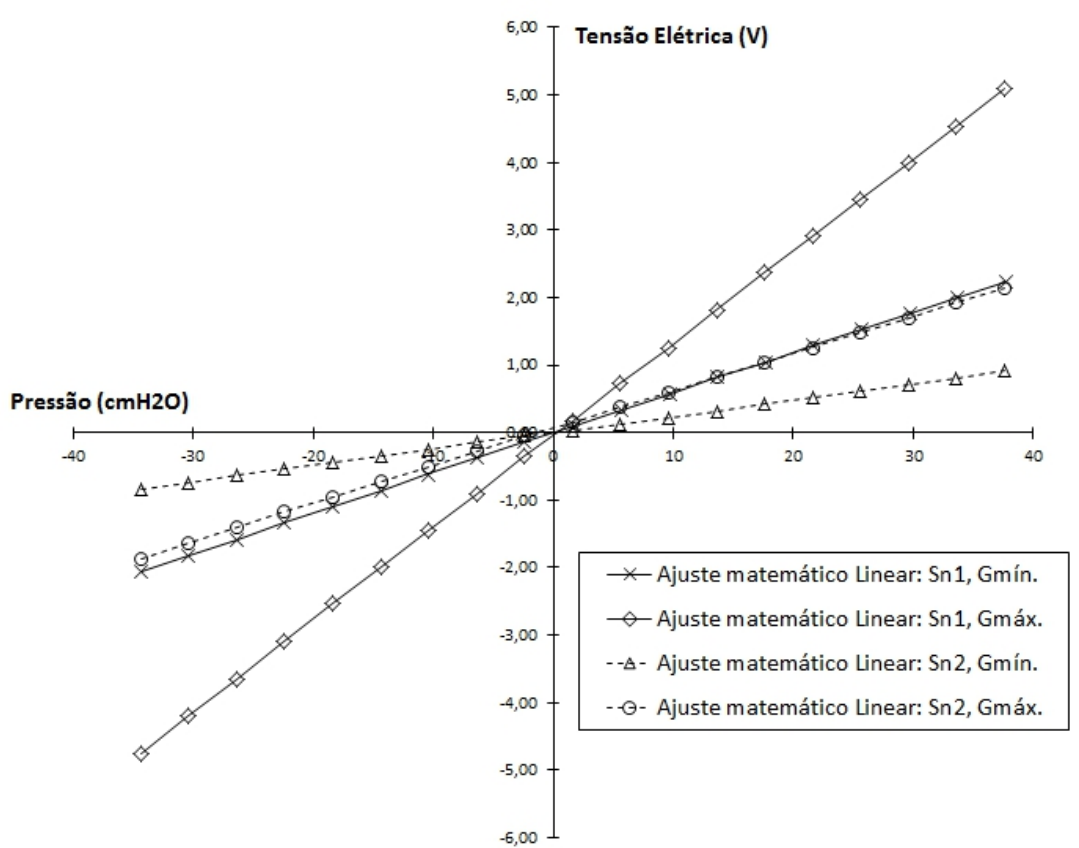

Figura 4.65 - As retas tracejadas representam o comportamento linear dos transdutores $S n 1$ e $S n 2$.

Por último, são apresentados, na Tabela 4.15, os dados referentes às condições ambientais da sala D2-22 do LEB-EPUSP, local de experimentação deste protocolo de avaliação.

Tabela 4.15 - Dados referentes às incursões de avaliação de pressão do módulo de transdução de pressão

\begin{tabular}{|c|c|c|}
\hline Condições ambientais & $\begin{array}{c}\text { Máxima } \\
\text { (média } \pm \text { desvio-padrão) }\end{array}$ & $\begin{array}{c}\text { Mínima } \\
\text { (média } \pm \text { desvio-padrão) }\end{array}$ \\
\hline Temperatura ambiente $\left({ }^{\circ} \mathrm{C}\right)$ & $22,75 \pm 0,94$ & $22,09 \pm 1,15$ \\
\hline Umidade Relativa (\%ur) & $37,55 \pm 2,66$ & $33,73 \pm 1,49$ \\
\hline *Pressão atmosférica ambiente (hPa) & $932,13 \pm 1,71$ & $932,35 \pm 1,71$ \\
\hline
\end{tabular}

\subsection{AMR DE MODELO ANIMAL DE DOENÇA PELO MÉTODO QUASI- ESTÁTICO}

$\mathrm{Na}$ Tabela 4.16, são apresentadas a massa de cada animal, além da média e do desvio-padrão dos grupos CTR e PRQ. 
Tabela 4.16 - Massa em gramas dos animais CTR e PRQ

\begin{tabular}{lccccccccccc}
\hline Animais & $\mathbf{1}$ & $\mathbf{2}$ & $\mathbf{3}$ & $\mathbf{4}$ & $\mathbf{5}$ & $\mathbf{6}$ & $\mathbf{7}$ & $\mathbf{8}$ & $\mathbf{9}$ & $\mathbf{1 0}$ & $\begin{array}{c}\text { Média } \pm \\
\text { Desvio-Padrão }\end{array}$ \\
\hline CTR & 238 & 248 & 232 & 212 & 256 & 220 & 208 & 238 & 203 & 232 & $229 \pm 18$ \\
PRQ & 240 & 210 & 206 & 244 & 220 & 248 & 262 & 198 & 266 & 242 & $234 \pm 24$ \\
\hline
\end{tabular}

Os resultados das curvas P-V obtidas para os animais CTR podem ser observados na Figura 4.66.

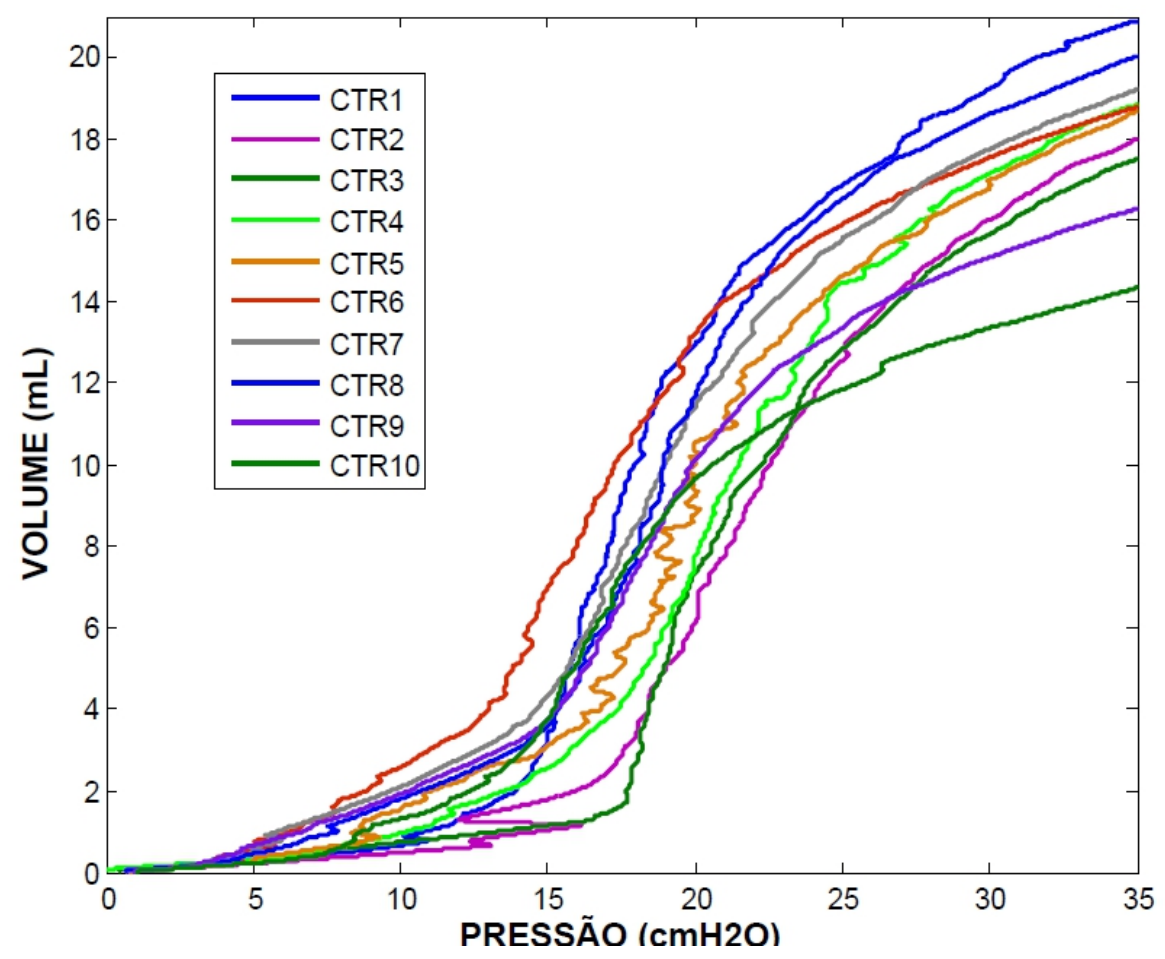

Figura 4.66 - Curvas P-V dos animais do grupo CTR.

De igual forma, na Figura 4.67 se observam os resultados das curvas P-V do grupo $P R Q$. 


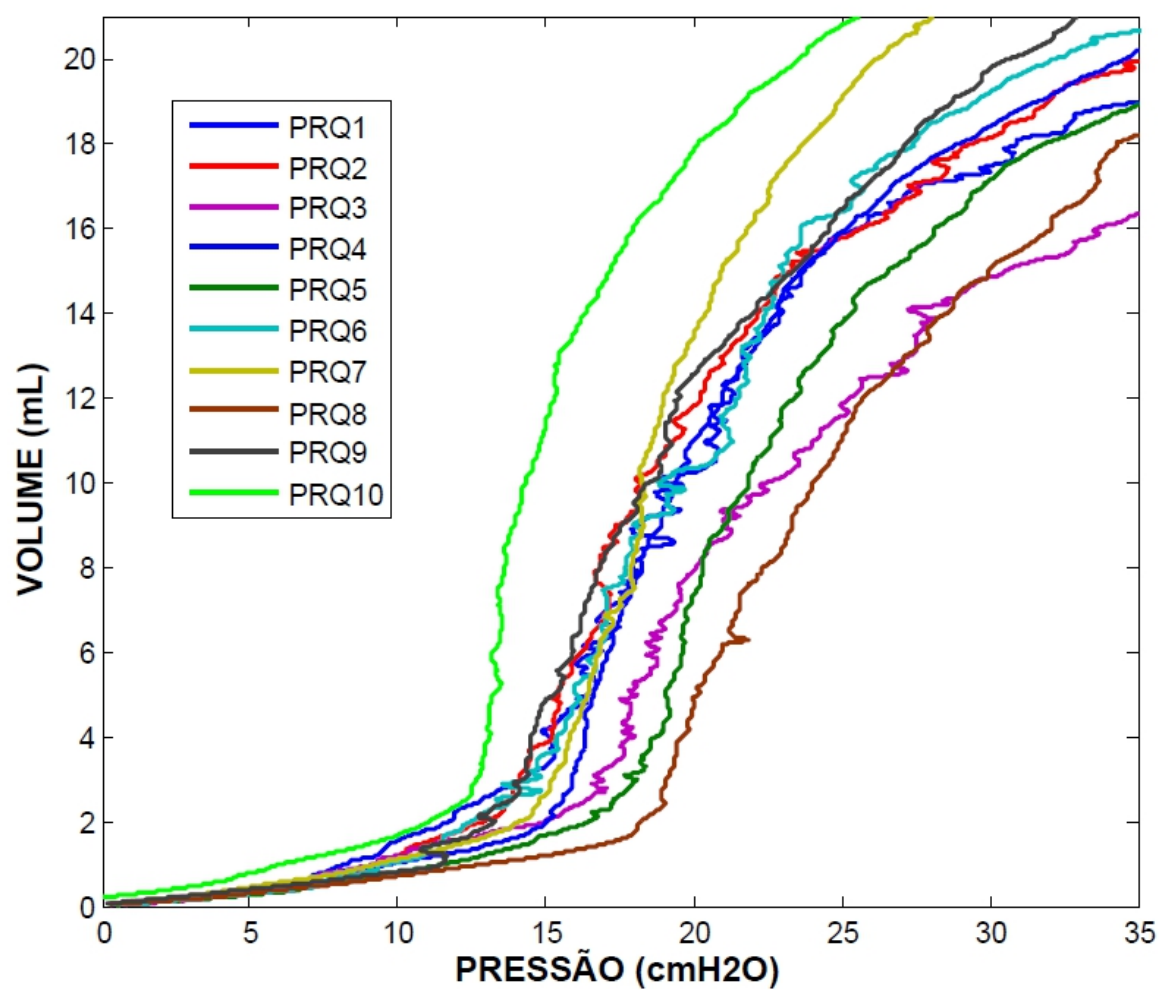

Figura 4.67 - Curvas P-V dos animais do grupo PRQ.

Os resultados dos coeficientes de correlação $R^{2}$ dos ajustes do modelo exponencial aos 10 intervalos de dados podem ser observados na Tabela 4.17. Conforme critério apresentado no Capítulo 3, o intervalo de dados escolhido para análise foi o 7 (de $17,5 \mathrm{cmH}_{2} \mathrm{O}$ a $35 \mathrm{cmH}_{2} \mathrm{O}$ ).

Tabela 4.17 - Dados do coeficiente de correlação $R^{2}$ para cada intervalo.

\begin{tabular}{|c|c|c|c|c|c|c|}
\hline & \multicolumn{2}{|c|}{ Intervalo } & \multicolumn{2}{|c|}{ CTR } & \multicolumn{2}{|c|}{ PRQ } \\
\hline & $\begin{array}{c}\text { limite } \\
\text { inferior } \\
{\left[\mathrm{cmH}_{2} \mathrm{O}\right]}\end{array}$ & $\begin{array}{c}\text { limite } \\
\text { superior } \\
{\left[\mathrm{cmH}_{2} \mathrm{O}\right]}\end{array}$ & $\begin{array}{r}R^{2} \\
\text { (Média }\end{array}$ & \pm DP) & $R^{2}$ (Média & \pm DP) \\
\hline 1 & 32,5 & 35 & 0,989 & $\pm 0,018$ & 0,968 & $\pm 0,043$ \\
\hline 2 & 30 & 35 & 0,994 & $\pm 0,029$ & 0,985 & $\pm 0,065$ \\
\hline 3 & 27,5 & 35 & 0,996 & $\pm 0,045$ & 0,989 & $\pm 0,091$ \\
\hline 4 & 25 & 35 & 0,994 & $\pm 0,084$ & 0,993 & $\pm 0,116$ \\
\hline 5 & 22,5 & 35 & 0,992 & $\pm 0,146$ & 0,994 & $\pm 0,154$ \\
\hline 6 & 20 & 35 & 0,991 & $\pm 0,250$ & 0,993 & $\pm 0,223$ \\
\hline 7 & 17,5 & 35 & 0,991 & $\pm 0,357$ & 0,992 & $\pm 0,336$ \\
\hline 8 & 15 & 35 & 0,982 & $\pm 0,541$ & 0,985 & $\pm 0,444$ \\
\hline 9 & 12,5 & 35 & 0,969 & $\pm 0,813$ & 0,977 & $\pm 0,683$ \\
\hline 10 & 10 & 35 & 0,950 & $\pm 1,117$ & 0,960 & $\pm 0,974$ \\
\hline
\end{tabular}


Os parâmetros do modelo exponencial, ajustado no intervalo de dados escolhido, são apresentados na Tabela 4.18.

Tabela 4.18-Parâmetros do ajuste exponencial para o intervalo de dados escolhido

\begin{tabular}{lrlrl}
\hline & \multicolumn{2}{c}{ CTR } & \multicolumn{2}{c}{ PRQ } \\
Índices & \multicolumn{2}{c}{ (Média \pm desvio-padrão) } & \multicolumn{2}{c}{ (Média \pm desvio-padrão) } \\
\hline $\boldsymbol{A}(\mathbf{m L})$ & 19,92 & $\pm 2,18$ & 22,62 & $\pm 2,55$ \\
$\boldsymbol{B}(\mathbf{m L})$ & 158,32 & $\pm 77,88$ & 122,56 & $\pm 66,23$ \\
$\boldsymbol{K}\left(\mathbf{c m H} \mathbf{O}^{-1}\right)$ & 0,139 & $\pm 0,023$ & 0,112 & $\pm 0,026$ \\
$\boldsymbol{h}\left(\mathbf{c m H}_{\mathbf{2}} \mathbf{O}\right)$ & 5,13 & $\pm 0,86$ & 6,51 & $\pm 1,49$ \\
\hline
\end{tabular}

Utilizando os parâmetros acima apresentados, foram traçadas as curvas P-V do modelo exponencial para os grupos CTR e $P R Q$, como se observa na Figura 4.68 .

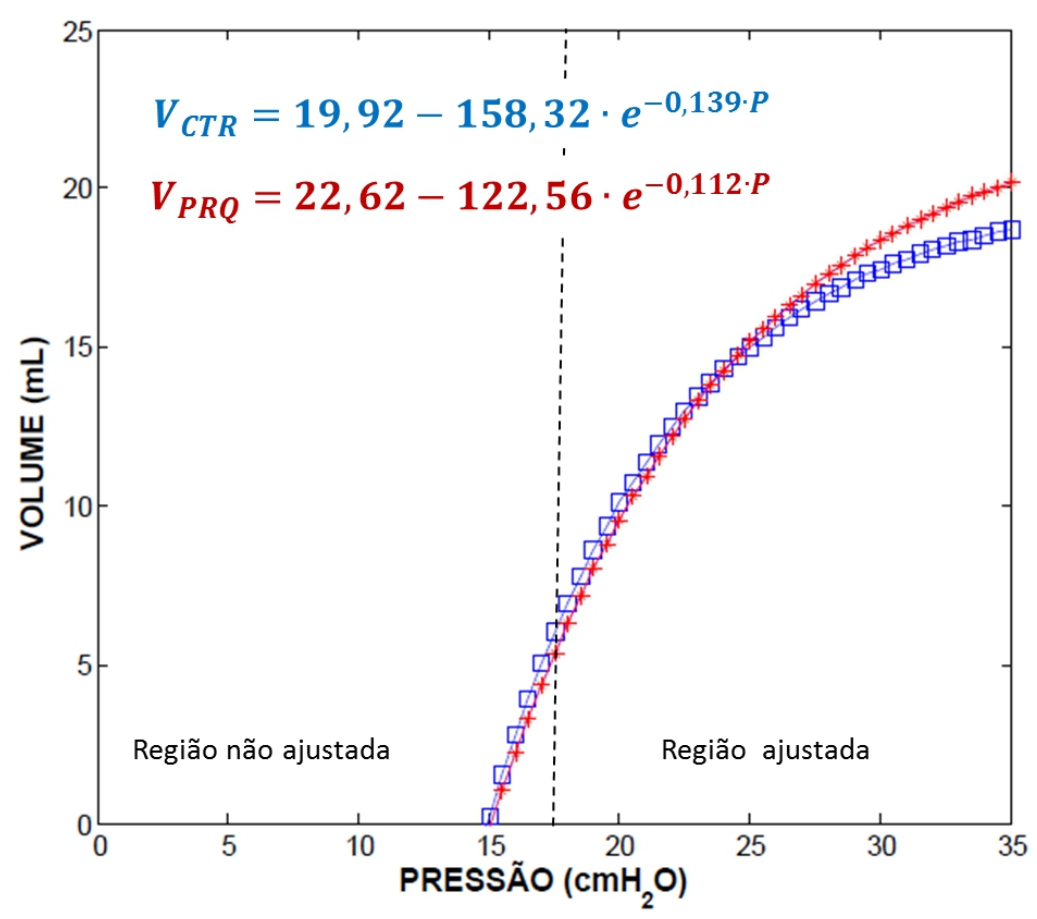

Figura 4.68 - Ajuste exponencial, CTR (quadrado) e PRQ (estrela). $V_{C T R}, V_{P R Q}$ são as equações resultantes do ajuste matemático exponencial dos grupos CTR e PRQ.

Os parâmetros do modelo exponencial $A, B, K$ e $h$ apresentam distribuição estatística normal. E os índices $A, K$ e $h$ dos grupos CTR e PRQ apresentam diferenças estatísticas significativas $(p<0.05)$. 


\section{DISCUSSÃO}

Neste capítulo, serão discutidos os resultados apresentados no Capítulo 4, referentes à: A documentação e avaliação do IPPR; E da avaliação de mecânica respiratória em roedores mediante o ajuste de curvas $\mathrm{P}-\mathrm{V}$ ao modelo matemático exponencial.

\subsection{DOCUMENTAÇÃO DO IPPR}

O IPPR é um equipamento de construção simples, mas que permite a realização de diversos experimentos em um modelo animal de doença, dando ao pesquisador flexibilidade para alterar padrões de insuflação, variando volume e velocidade de insuflação.

A implementação do IPPR surgiu de uma demanda existente dentro do grupo de pesquisa do LEB: realizar a insuflação lenta de pulmões de pequenos roedores, com o intuito de avaliar o recrutamento alveolar,pelo parâmetro conhecido por elastância negativa proposto por Alencar e colaboradores (2002). Devido a problemas de ordem operacional,os pulmões analisados deveriam partir de um estado totalmente colabado. O IPPR não foi utilizado para a avaliação de elastância negativa, mas foi empregado em outros estudos de AMR em roedores (FERREIRA et al.,2010;CIRELLI et al., 2010; RIVAS et al., 2012).

O IPPR apresenta diversas limitações, como, por exemplo, a falta de um mecanismo contra falhas de operação do usuário, a ausência de sistemas de detecção de fim de curso, a existência de trepidações durante a movimentação do carrinho de fixação do êmbolo, entre outras. Além disso, um software de controle mais elaborado poderia permitir a insuflação com outros padrões, além do incremento constante de volume realizado atualmente. Entretanto, acredita-se que, com o conhecimento adquirido na implementação desse insuflador pulmonar de pequenos roedores, seja possível projetar melhorias no sistema atual 
e,eventualmente,realizar projetos de equipamentos mais sofisticados para AMR respiratória em pequenos roedores.

Tendo em vista que um trabalho de mestrado deve apresentar duração temporal finita, melhorias no IPPR serão realizadas por outros pesquisadores no futuro.

\subsection{TESTES DE BANCADA DO IPPR}

\subsubsection{AVALIAÇÃO DE VOLUME E VELOCIDADE DO IPPR}

As avaliações de volume e velocidade (seção 4.2.1, tabelas 4.6 a 4.10 ) mostram uma tendência diferente para cada cenário testado (velocidade de insuflação e volume distintos). Os valores de Es_Vol, segundo a Figura 4.61, mostram que, para todos os volumes programados, a quantidade de ar transferido do tambor da seringa para o exterior é sempre menor, majoritariamente $-4 \%$, e isso ocorre de forma independente da velocidade de insuflação.

Provavelmente, esses erros no deslocamento do êmbolo da seringa se devem às perdas na quantidade de passos do motor e/ou à demora na realização dos passos, pois, como pode se observar na coluna \#amostras das tabelas 4.6 a 4.10 , apenas em cinco cenários de volume e velocidade $(10 \mathrm{~mL}$ a $0,01 \mathrm{~mL} / \mathrm{s}$, a 0,055 $\mathrm{mL} / \mathrm{s}$, a $0,1 \mathrm{~mL} / \mathrm{s}$ e a $0,55 \mathrm{~mL} / \mathrm{s}$; e $5 \mathrm{~mL}$ a $0,055 \mathrm{~mL} / \mathrm{s}$ ) não há variabilidade no número de amostras,variável que é relacionada com a quantidade de passos do motor.

As perdas na quantidade de passos do motor e/ou a demora na realização dos passos interferem também no intervalo de tempo de insuflação; com isso, também há um erro no intervalo de tempo de insuflação medido (Es_tt), conforme pode ser observado na Figura 4.62.A tendência dos intervalos de tempo decorrido sem uma insuflação é ser sempre maior do que o intervalo de tempo esperado, sendo que o erro aumenta com a velocidade de insuflação e diminui com o volume insuflado programado. 
A influência das perdas na quantidade de passos do motor e/ou da demora na realização dos passos também se estende para a velocidade de insuflação, já que esta depende tanto do volume insuflado como do intervalo de tempo decorrido durante a insuflação. Essa influência pode ser observada na Figura 4.63. A velocidade ( $\mathrm{Vel}$ ) programada no IPPR é bastante modificada nas velocidades maiores $(0,55 \mathrm{~mL} / \mathrm{s}$ e $1,0 \mathrm{~mL} / \mathrm{s})$, mas mantém-se estável em aproximadamente $-5 \%$ para as outras velocidades testadas.

Essas perdas na quantidade de passos do motor e/ou na demora na realização dos passos podem ocorrer devido a falhas no hardware implementado, mas a principal suspeita da causa dessas perdas recai sobre o comportamento multitarefa do sistema operacional utilizado pelo microcomputador que controla o sistema. Como o sistema operacional não permite que o programa de controle do IPPR seja executado com prioridade total, pode-se esperar que o sistema operacional causas se alguns atrasos na execução do programa de controle, já que o sistema operacional permite que outros programas interrompam o processamento do programa de controle em momentos aleatórios para cumprimento de tarefas diversas.

Uma tentativa para sanar o problema foi realizada utilizando um microcontrolador (PIC24FJ128GA010, Microchip, EUA) para realizar todo o controle e a aquisição dos dados do IPPR (CIRELLI et al., 2010), substituindo-se, assim, o software desenvolvido em plataforma de instrumentação virtual que é executado em um sistema operacional multitarefa. Entretanto, a operação do sistema microcontrolado ficou bastante complexa e optou-se, mesmo com erros da ordem de $5 \%$ a $10 \%$, em trabalhar com o software, já que a complexidade da operação poderia trazer mais erros devido à má utilização do equipamento e até mesmo pela possibilidade de inviabilizar a realização de experimentos por técnicos do laboratório.

Para minimizar os erros de volume e de velocidade, optou-se por sempre realizar os experimentos com o IPPR com baixos valores de velocidades, já que isso faz com que o sistema apresente os menores erros. Vale ressaltar que, apesar dos erros existentes, os valores reais de volume e velocidade utilizados no experimento podem ser recuperados nos arquivos de aquisição de dados e, com isso, pode-se realizar a compensação/correção na análise dos dados. 


\subsubsection{AVALIAÇÃO DE PRESSÃO DO IPPR}

Foram utilizados dois transdutores de pressão ( $S n 1$ e $S n 2)$ do mesmo modelo (FPM-07PG, Fujikura, Japão), para serem submetidos aos testes de bancada com o módulo de transdução de pressão. Os resultados obtidos nestes testes foram apresentados na seção 4.2.2, tabelas 4.12 a 4.14 e figuras 4.64 e 4.65 .

A resolução de medida de pressão do IPPR $\left(\right.$ Res_Pr) foi de $0,04 \mathrm{cmH}_{2} \mathrm{O} / \mathrm{bit}$, no melhor caso ( $\mathrm{Sn} 1$ com Gmáx), e de $0,21 \mathrm{cmH}_{2} \mathrm{O} /$ bit, no pior caso (Sn2 com Gmín), conforme pode ser observado na Tabela 4.14. Assim, tomando como referência o pior cenário, tem-se que diferenças menores que $0,21 \mathrm{cmH}_{2} \mathrm{O}$ não são perceptíveis para o IPPR. Este valor de Res_Pré consequência direta da baixa sensibilidade $(S)$ do módulo de transdução de pressão, pois o intervalo de valores de tensão elétrica de saída do módulo de transdução de pressão é bastante baixo, quando comparado com o intervalo de tensões elétrica de entrada do conversor $A / D$ utilizado. Essa deficiência pode ser sanada aumentando-se o ganho do módulo de transdução de pressão e isso deverá ser implementado em versões futuras do IPPR.

$\mathrm{Na}$ aplicação deste trabalho de mestrado, modelagem matemática de curvas $\mathrm{P}-\mathrm{V}$ em modelo animal de doença, essa baixa resolução não é crítica. Entretanto, o aumento do ganho do módulo de transdução de pressão se tornará obrigatório em estudos de avaliação de recrutamento alveolar, através da análise de elastância negativa (ALENCAR et al.,2002).

O máximo desvio da tensão elétrica de saída $(\operatorname{Lin} \%)$ foi de $3,3 \%$, no pior caso (Sn2 com Gmín), e de 1,3\%, no melhor caso (Sn1 com Gmín), conforme pode ser observado na Figura 4.64. Isso evidencia que existem diferenças entre os dois transdutores de pressão utilizados, apesar de ambos serem do mesmo modelo.

O coeficiente de correlação $R^{2}$ da regressão linear foi igual à unidade para todas as retas de calibração (Tabela 4.14), o que sugere que os transdutores estão operando de forma linear. Segundo o fabricante dos transdutores, o modelo empregado apresenta histerese de $0,2 \%$, mas este valor é calculado para uma faixa de nominal de pressão de entrada entre $-492,12$ e $492,12 \mathrm{cmH}_{2} \mathrm{O}$, faixa maior do que à empregada nesta avaliação. 
Apesar dos transdutores testados (Snle $S n 2$ ) serem do mesmo modelo(FPM07PG, Fujikura, Japão), os testes de bancada mostraram diferenças entre os transdutores, evidenciadas nos resultados apresentados em toda seção 4.2.2. Essas diferenças podem ser explicadas, já que, segundo o fabricante, existem variações na impedância da ponte de Wheatstone entre transdutores do mesmo modelo, sendo que esta impedância pode variar entre $4.000 \Omega$ e $6.000 \Omega$ (FUJIKURA LTD, 2010).

Essas diferenças entre dois transdutores de pressão do mesmo modelo reforçam a necessidade da realização de procedimentos de calibração no início de cada experimento, como o implementado no software de controle e aquisição de dados do IPPR e apresentado na Figura 3.15.

\subsection{AMR DE MODELO ANIMAL DE DOENÇA PELO MÉTODO QUASI- ESTÁTICO}

Uma forma quantitativa de análise de curvas P-V quasi-estáticas usada com frequência é a análise da complacência (SALAZAR; KNOWLES, 1964).

A complacência das curvas $\mathrm{P}-\mathrm{V}(\mathrm{dV} / \mathrm{dP})$ mostra que, no início da inspiração, a pressão aumenta de forma considerável enquanto volumes pequenos entram nos pulmões (complacência baixa), como se observa nas Figuras 4.68 e 69.À medida que se aumenta o volume, novas unidades alveolares são ativadas, facilitando a entrada de ar por recrutamento alveolar (complacência maior) (HAAS, 2000). Uma vez recrutadas as unidades alveolares, a relação P-V passa a apresentar comportamento próximo do linear. Por último, a pressão aumenta mais em relação ao volume (novamente complacência baixa), indicando o limite de insuflação pulmonar, o que sugere hiperdistensão pulmonar e complacência perto de zero (HAAS, 2000).

A análise da complacência é de grande importância, na atualidade, no melhoramento de terapias respiratórias, como a ventilação (HAAS, 2000), mas possui limitações ao comparar as forças elásticas envolvidas na respiração pulmonar de indivíduos diferentes. Algumas destas limitações são devidas a 
variações fisiológicas de parâmetros como CV, CRF e CPT, dependentes das condições do indivíduo e do tamanho dos pulmões (SALAZAR; KNOWLES, 1964).

O estudo desenvolvido visou mostrar que a análise por modelagem matemática exponencial pode complementar a análise por complacência.

As curvas P-V dos grupos CTR e PRQ, das Figuras 4.68 e 4.69, analisadas através do exame das complacências, não apresentaram diferenças significativas. Porém, Silva, Zin e Saldiva (1998) demonstraram que existem diferenças morfológicas e viscoelásticas significativas entre os pulmões de ratos normais e os de ratos com deficiências respiratórias induzidas por Paraquat.

Estas diferenças morfológicas demonstraram que, em pressões menores de $15 \mathrm{cmH}_{2} \mathrm{O}$, os animais sob o efeito de Paraquat apresentam menor superfície de troca gasosa e maior instabilidade alveolar, sugerindo maior esforço respiratório para abrir novas unidades alveolares. Estas diferenças diminuem quando os pulmões atingem pressões próximas a $25 \mathrm{cmH}_{2} \mathrm{O}$.

As análises exponenciais, realizadas na seção 4.3.5, comparam os dados pressão-volume de animais no intervalo entre $17,5 \mathrm{cmH}_{2} \mathrm{O}$ e $35 \mathrm{cmH}_{2} \mathrm{O}$. Valores menores para extremo inferior do intervalo de análise aumentam radicalmente o erro do ajuste matemático; este erro está associado à inflexão da curva $\mathrm{P}-\mathrm{V}$, por efeitos de recrutamento em valores de baixo volume pulmonar. Este intervalo para ajuste de curvas P-V, pela equação exponencial, também foi sugerido por Colebatch et al. (1979), que determinaram que o intervalo ideal de ajuste de curvas P-V em humanos por equação exponencial é entre 50 e 100\% da CPT. Neste trabalho, em particular, o valor aproximado da CPT foi adaptado da pesquisa desenvolvida por Glaister e colaboradores (1973), que mostraram que a pressão aproximada, em pulmões de animais expostos à pressão ambiente e com volume próximo à $\mathrm{CPT}$, é de $35 \mathrm{cmH}_{2} \mathrm{O}$.

Os índices $A$ e $K$ dos grupos CTR e PRQ apresentam diferenças estatísticas significativas, sugerindo que os animais do grupo $P R Q$ têm distensão do tecido pulmonar em volumes aproximados à CPT $\left(35 \mathrm{cmH}_{2} \mathrm{O}\right)$, em relação ao grupo CTR, devido à diferença no índice $A$, de forma similar aos estudos de Silva, Zin e Saldiva (1998).

De igual modo, a diferença significativa do índice $K$, ao ser um valor que reflete o comportamento de complacência pulmonar, complementa análises morfológicas anteriores, que sugerem diferenças em nível alveolar nos pulmões. 
O índice $h$,pressão de insuflação média, pouco utilizado na literatura, mas apresentado no trabalho original de Salazar e Knowles (1964), também mostra, de forma direta, os resultados reportados na literatura. Este resultado apresenta a diferença de 1,38 $\pm 0,87 \mathrm{cmH}_{2} \mathrm{O}$ de pressão entre os grupos $\mathrm{PRQ}$ e CTR. Esta diferença pode ser interpretada como sendo a quantidade de pressão adicional que os pulmões sob o efeito do Paraquat precisam exercer para insuflar a metade da CPT. Essa diferença ocorre devido à baixa complacência pulmonar. 


\section{CONCLUSÕES}

Este trabalho de mestrado apresentou o seguinte objetivo principal: avaliar a mecânica respiratória em roedores, através da análise de curvas $\mathrm{P}-\mathrm{V}$ adquiridas pelo método quasi-estático, utilizando o equipamento IPPR. Os objetivos específicos foram: documentar o IPPR; avaliar o funcionamento do IPPR para obtenção de dados experimentais, úteis para AMR em pequenos roedores; e aplicar modelos matemáticos de curvas $\mathrm{P}-\mathrm{V}$ em roedores com lesão pulmonar induzida por envenenamento com Paraquat.

A documentação detalhada do IPPR foi apresentada no Capítulo 4, contemplando um dos objetivos específicos. $O$ intuito dessa documentação não foi comparar o IPPR com outros equipamentos, mas permitir que réplicas do IPPR possam ser implementadas por outros grupos de pesquisa, para que melhorias técnicas possam ser agregadas mais facilmente.

A avaliação do funcionamento do IPPR foi realizada através de testes de bancada que permitiram verificar as deficiências e as virtudes apresentadas pelo equipamento. O IPPR ainda carece de alguns ajustes, pois apresenta erros na indicação de volume, da ordem de $5 \%$, mas esta imprecisão pode ser compensada na análise dos dados experimentais obtidos. No futuro, pretende-se sanar essa imprecisão tornando o IPPR independente de um microcomputador com sistema operacional multitarefa.

Foi aplicado o modelo matemático exponencial nas curvas PV obtidas em roedores normais e com lesão pulmonar induzida por envenenamento com Paraquat. A aplicação do modelo matemático exponencial permitiu obter informações que corroboraram trabalhos já publicados anteriormente (SILVA e SALDIVA 1998; SILVA, ZIN e SALDIVA, 1998). Além da aplicação do modelo matemático exponencial, foi realizada uma extensa pesquisa bibliográfica, apresentada no Capítulo 2, que, além de noções de anatomia e fisiologia, permitiu melhor entendimento dos diversos modelos matemáticos aplicados na AMR pelo método quasi-estático.

Assim sendo, acredita-se que os objetivos específicos propostos foram todos cumpridos e, consequentemente, o objetivo principal também foi alcançado. 
A aceitação, a apresentação e a publicação em anais de congresso de trabalhos (FERREIRA et al.,2010; CIRELLI et al., 2010; RIVAS et al., 2012) oriundos desta pesquisa de mestrado nos leva a crer, também, que as condições para obtenção do título de mestre foram cumpridas. 


\section{REFERÊNCIAS}

ALENCAR, A. M. et al. Physiology: Dynamic instabilities in the inflating lung. Nature, v. 417 , n. 6891 , p. 809-11, 2002.

ALLEN, G.; LUNDBLAD, L. K. A.; PARSONS, P. E.; BATES, J. H. T. The transient mechanical benefits of a deep inflation in the injured mouse lung. J. Appl. Physiol., v. 93, p. 1709-1715, 2002.

ALVAREZ, B.; ROSADO, L.; BERENGGGUER, J. Intoxicación aguda via intravenosa con paraquat. An. Med. Interna,v. 12,p.343-345, 1998.

BATES, J. Lung mechanics:an inverse modeling approach. New York: Cambridge University Press, 2009. 220 p.

BATES, J. H.; IRVIN, C. G. Measuring lung function in mice: the phenotyping uncertainty principle. J Appl Physiol, v. 94, n. 4, p. 1297-306, 2003.

BALBINOT, A.; BRUSAMARELLO, V. J. Conceitos de Instrumentação. In: Instrumentação e Fundamentos de Medidas. 2.ed. Rio de Janeiro: LTC, 2010a. cap. 1. p. 6-35.

. Fundamentos de Estatística, Incertezas de Medidas e sua Propagação. In: Instrumentação e Fundamentos de Medidas. 2.ed. Rio de Janeiro: LTC, 2010b. cap. 2, p. 36-95.

BLANCHARD, S. Anatomy and physiology. In: ENDERLE, J.; BLANCHARD, S.; BRONZINO, J.Introduction to biomedical engineering. 2.ed. London: Elsevier Academic Press, 2005.cap. 3, p.73-125.

CONDIT, R.; JONES, D. W. Stepping Motors Fundamentals. AN907. Arizona: 2004.Disponível

em: <http://www.microchip.com/stellent/idcplg?ldcService=SS_GET_PAGE\&nodeld=1824\&a ppnote=en012151>. Acesso em: 02.fev.2011.

COLEBATCH, H. J.; NG, C. K.; NIKOV, N. Use of an exponential function for elastic recoil. J Appl Physiol, v. 46, n. 2, p. 387-93, 1979. 
CIRELLI, M.; RIVAS, J. M. V.; FERREIRA, M. Z. J.; SILVA, T. H. G.; ALENCAR, A. M.; MORIYA, H. T. Sistema microcontrolado para estudos de curva pressão volume em pulmões de pequenos roedores. In:XXII CONGRESSO BRASILEIRO DE ENGENHARIA BIOMEDICA, 2010, Tiradentes.Anais. Tiradentes: SBEB, 2010. p. 960-963.

D'ANGELO, E.; MILIC-EMILI, J. Statics of the respiratory system. In: HAMID, Q.;SHANNON, J.; MARTIN, J.Physiologic basis of respiratory disease. Ontario: BC Decker Inc., 2005. cap. 2, p.15-25.

DO AMARAL, R. A.; TAVARES, L. S.; LUCENA, L. S.; BRANDÃO-NETO, J. The physical origin of sigmoidal respiratory pressure-volume curves: Alveolar recruitment and nonlinear elasticity. Physica A: Statistical Mechanics and its Applications, v. 390, n. 10, p. 1791-1799, 2011.

FERREIRA, M. Z. J.; SILVA, T. H. G.; SILVA, M. F. R.; ALENCAR, A. M.; HERNÁNDEZ-FIGUEROA, H. E.; MORIYA, H. T. Influência da caixa torácica na elastância pulmonar: análise de curvas pressão-volume na inspiração. In: XXII CONGRESSO BRASILEIRO DE ENGENHARIA BIOMÉDICA, 2010, Tiradentes.Anais. Tiradentes: SBEB, 2010. p. 477-480.

FUJIKURA LTD. FPM, FHM data sheet. Japan. Disponivel em: $<$ www.fujikura.co.jp>. Acesso em: 02.fev.2010.

GLAISTER, D. H.; SCHROTER, R. C.; SUDLOW, M. F.; MILIC-EMILI, J. Bulk elastic properties of excised lungs and the effect of a transpulmonary pressure gradient. Respir Physiol, v. 17, n. 3, p. 347-64, 1973.

GUYTON, A. C. Ventilação pulmonar. In: Tratado de fisiologia médica. 8.ed. Rio de Janeiro: Guanabara koogan S.A., 1992. cap. 37, p.351-362.

HAAS, C. Volume-pressure curves during mechanical ventilation. American Association for Respiratory Care Times, p. 64-67, 2000.

HEDRICH, H., J. Hystory, Strains and Models. In: KRINKE, G. J. The Laboratory Rat. London: Academic Press, 2000. cap. 1, p.3-16.

HIRAI, T.; McKEOWN, K. A.; GOMES, R. F.; BATES, J. H. Effects of lung volume on lung and chest wall mechanics in rats. J Appl Physiol, v. 86, n. 1, p. 16-21, 1999. 
HUO, B.; FU, R. Recent advances in theoretical models of respiratory mechanics. Acta Mechanica Sinica, v. 28, n. 1, p. 1-7, 2012.

MILIC-EMILI, J.; D'ANGELO, E. Statics of the lung. In: HAMID, Q.;SHANNON, J.;MARTIN, J. Physiologic basis of respiratory disease.Ontario: BC Decker Inc., 2005. cap. 3, p.27-33.

MORIYA, H. T.; PAZZETI, R.; MARTINS, M. A.; ALENCAR, A. M.. Comparações entre dois métodos de obtenção de curva pressão-volume do sistema respiratório de ratos. XXI Congresso Brasileiro de Engenharia Biomédica. Salvador. In: XXI Congresso Brasileiro de Engenharia Biomédica, 2008, Salvador. Anais. Salvador: SBEB, 2008. p.1279-1282.

MORSTATTER, C. E.; GLASER, R. M.; JURRUS, E. R.; WEISS, H. S. Compliance and stability of excised mouse lungs. Comp Biochem Physiol A Comp Physiol, v. 54, n. 2, p. 197-202, 1976.

PAIVA, M.; YERNAULT, J. C.; VAN EERDEWEGHE, P.; ENGLERT, M. A sigmoid model of the static volume-pressure curve of human lung. Respir Physiol, v. 23, n. 3, p. $317-23,1975$.

PALLADINO, J.; DAVIS, R. Biomechanics. In: ENDERLE, J.; BLANCHARD, S.; BRONZINO, J.Introduction to biomedical engineering. 2.ed. London: Elsevier Academic Press, 2005. cap. 4, p.127-210.

PEREZ, L.; DE LA PARRA, J.; POLLO, J. Distrés Respiratorio y Ventilación Mecánica: Su historia. MediCiego,v. 10, n. Supl. 2, 2004.

RIVAS, J. M. V. ; LLANO, F. S. B. ; SILVA, M. F. R. ; MORIYA, H. T.Modelaje exponencial de curvas presión-volumen en ratones bajo el efecto de paraquat. XXIII Congresso Brasileiro de Engenharia Biomédica. Ipojuca.In: XXIII Congresso Brasileiro de Engenharia Biomédica, 2012, Ipojuca.Anais. Ipojuca: SBEB 2008. p.1279-1282.

RIVERO, A.; NAVARRO, J.; MACÍA, M.; MORA, C.; RODRIGUEZ, M.; GARCIA, J. Intoxicación por paraquat: presentación de dos casos y revisión de la literatura. An Med Interna, v. 18, n. 4, p. 208-210, 2001.

SAHEBJAMI, H.; VASSALLO, C. L. Effects of starvation and refeeding on lung mechanics and morphometry. Am Rev Respir Dis, v. 119, n. 3, p. 443-51, 1979. 
SALAZAR, E.; KNOWLES, J. H. An analysis of pressure-volume characteristics of the lungs. J Appl Physiol,v. 19, p. 97-104, 1964.

SCHUESSLER, T. F.; BATES, J. H. A computer-controlled research ventilator for small animals: design and evaluation. IEEE Trans Biomed Eng, v. 42, n. 9, p. 860-6, 1995.

SCHULZ, H.; MUHLE, H. Respiration. In: KRINKE, G. J. The Laboratory Rat. London UK: Academic Press, 2000. cap. 16, p.323-344.

SILVA, M. F.; ZIN, W. A.; SALDIVA, P. H. Airspace configuration at different transpulmonary pressures in normal and paraquat-induced lung injury in rats. Am J Respir Crit Care Med, v. 158, n. 4, p. 1230-4, 1998.

SILVA, M.F.; SALDIVA, P.H. Paraquat poisoning: an experimental model of dosedependent acute lung injury due to surfactant dysfunction. Braz J Med Biol Res, vol.31, no.3, p.445-450, 1998.

TOMIOKA, S.; BATES, J. H. T.; IRVIN, C. G. Airway and tissue mechanics in a murine model of asthma: alveolar capsule vs. forced oscillations. J. Appl. Physiol., v. 93, p. 263-270, 2002.

TORTORA, G. J. O sistema respiratório. In: Corpo humano. Porto Alegre: Artes Médicas Sul, 2000. cap. 18, p.406-431.

VAN VLACK, L. H. Características exigidas nos materiais usados em engenharia. In: Princípios de ciência dos materiais. São Paulo: Addison-Wesley Publishing Company inc., 1970. cap. 1, p.1-17.

VENEGAS, J. G.; HARRIS, R. S.; SIMON, B. A. Comprehensive equation for the pulmonary pressure-volume curve. J Appl Physiol, v. 84, n. 1, p. 389-95,1998.

VINSON, L. A. Physics of Friction Applied to Medical Devices. In: TSUKRUK, V. V.; WAHL, K. J. Microstructure and Microtribology of Polymer Surfaces. Washington, DC. ACS Symposium Series, 1999. p. 474-494

VOLGYESI, G. A.; TREMBLAY, L. N.; WEBSTER, P.; ZAMEL, N.; SLUTSKY, A. S. A new ventilator for monitoring lung mechanics in small animals.J Appl Physiol, v. 89, n. 2, p. 413-21, 2000. 
WEST, J. B. Estrutura e função- como a arquitetura do pulmão serve a função pulmonar. In: Fisiologia respiratória. São Paulo: Manole Ltda., 2002a. cap. 1, p.110.

. Mecânica da Respiração - Como o pulmão é sustentado e movimentado. In: Fisiologia respiratória. São Paulo: Manole Ltda., 2002b. cap. 7, p.89-116.

Testes de função pulmonar - como se aplica a fisiologia respiratória para medir a função pulmonar. In: Fisiologia respiratória. São Paulo: Manole Ltda., 2002c. cap. 10, p.151-164.

. Ventilação - Como o gás chega aos alvéolos. In: Fisiologia respiratória. São Paulo: Manole Ltda., 2002d. cap. 2, p.11-20. 